\title{
KINDERGARTEN AND NEW ENTRANT \\ TEACHERS' BELIEFS AND PRACTICES IN \\ MATHEMATICS TEACHING AND LEARNING
}

\author{
By \\ Brenda Mary Sherley
}

\begin{abstract}
A thesis
submitted to the Victoria University of Wellington

in fulfilment of the requirements for the degree of

Doctor of Philosophy

in Mathematics Education
\end{abstract}

Victoria University of Wellington 



\begin{abstract}
A difference between the beliefs and practices about mathematics learning and teaching held by teachers in kindergartens and teachers in new entrant classrooms may lead to problems as teachers and children manage the transition from kindergarten to school.

The New Zealand education system is governed by various curriculum documents underpinned by similar philosophies to support teacher practice. These documents are based on an expectation that teachers build from children's existing knowledge and experiences. The system is based on expectations relating to knowledge that are loosely linked to the year level and age of children.

Evidence about teachers' practices and beliefs was gathered using a case study approach. Five primary schools and their neighbouring kindergartens were purposively selected for this study. Fourteen kindergarten and five new entrant teachers were observed and interviewed and completed questionnaires about their beliefs and practices in mathematics teaching and learning over a two year period. Mathematical events were analysed to document teachers' practices. Kindergarten teachers' practice most commonly mirrored their stated beliefs about how children best learned mathematics. New entrant teachers, although possessing similar stated beliefs to kindergarten teachers, did not necessarily follow these beliefs in their classroom practice.

The beliefs of kindergarten and new entrant teachers in mathematics teaching and learning were similar, but their practices differed in several dimensions.

Kindergarten teachers believed children best learned mathematics through free play and exploration of the world around them. These teachers encouraged children to follow their own interests and supported children as they developed their ideas and became active problem solvers. These beliefs arose from teachers' personal experiences combined with the primarily sociocultural focus of the early childhood curriculum, Te Whāriki.
\end{abstract}


New entrant teachers' beliefs about mathematics learning and teaching were similar to those of kindergarten teachers - children learned through having fun, solving problems, and doing things in a real-life context. However, new entrant teachers also had clear expectations of the skills five-year-olds needed to know on their entry to school. When children did not appear to possess these skills, teachers focused on remediation of the perceived deficits. In practice, new entrant teachers directed children's learning based on their beliefs about what children needed to know to be successful at school. This approach lead to structured and managed environments with little regard for children's prior-to-school knowledge and experiences.

These inconsistencies in mathematics teaching and learning between schools and kindergartens could be minimised with professional development for teachers that focused on developing the relationships between teachers in both settings. 


\section{Acknowledgements}

To the new entrant teachers, kindergarten teachers, and principals who took part in this study I wish to offer my grateful thanks. Your willingness to be involved in this research and to share your ideas and your classroom environments has been both sustaining and challenging. I finish this study with an enormous respect for the teachers in the new entrant classrooms and kindergartens for your total commitment to doing the very best for the children you taught. Thank you also to the children in your classes who, although not directly involved in this study, accepted my presence within their environment as a participant observer of their learning activities.

To Megan Clark and Joanna Higgins, my supervisors, thank you for your constant support, guidance, and encouragement to keep on keeping on, both face to face and from a distance. After having completed research extramurally in the past, face-to-face meetings with you both were stimulating and constructive. My appreciation of your work and commitment to my study is immense.

To Belinda Hill, my thanks, you are an amazing editor and I think you may have finally taught me about the apostrophe s and when to use a comma.

To my friends and family (Greg, Dorothy, Kevin, Sandi, and Murray) who read bits and pieces and provided helpful comments, thank you.

Last of all to my family, Greg, Nikki, and Mark, thank you for your belief in me, without your love, support, and positivity this would not be complete today. 



\section{Contents}

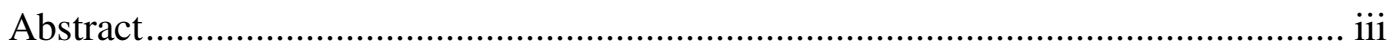

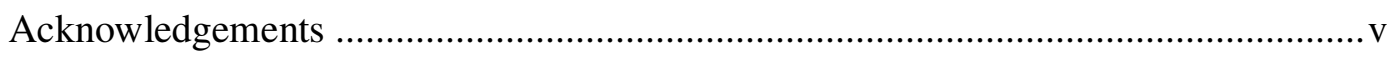

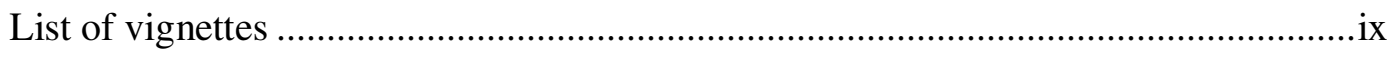

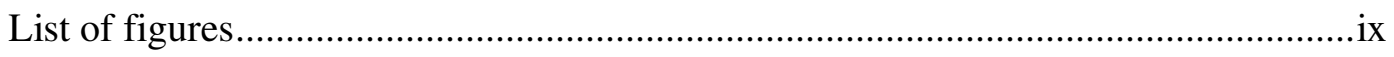

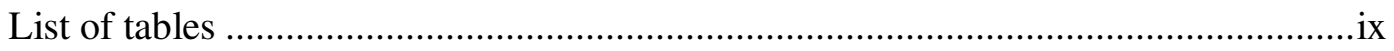

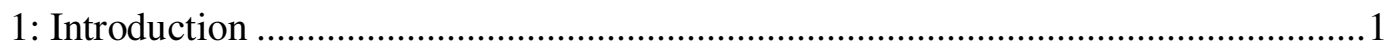

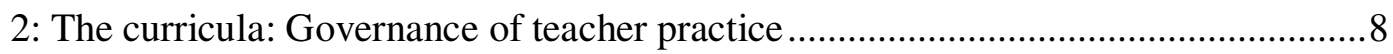

3: Mathematics teaching and learning: Theories relating to teacher beliefs and

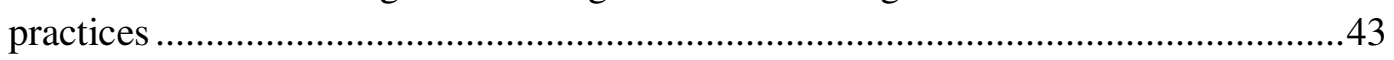

4: Transition: From early childhood centre to primary school .................................73

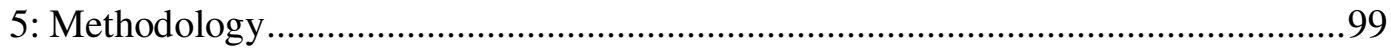

6: Findings: Kindergarten teachers' beliefs and practices in mathematics

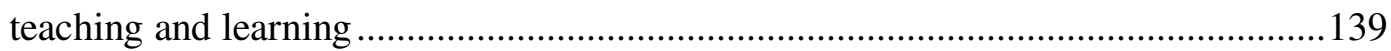

7: Findings: New entrant teachers' beliefs and practices in mathematics teaching and learning

8: Making the transition to school: Differences between kindergartens and new

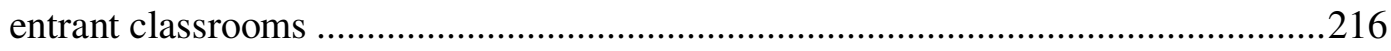

9: Discussion: Similarities and differences in teacher practices and beliefs as children make the transition from school to kindergarten

10: Conclusion: Compatibility of teacher practices and beliefs in mathematics between early childhood and new entrant school settings.

Appendix A: Information for principals and new entrant teachers regarding study

Appendix B: Consent form for teachers and principals.........................................286

Appendix C: Information letter for kindergartens participating in this study ...........287

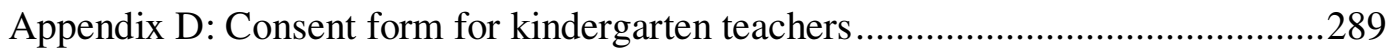

Appendix E: Semi-structured interview questions for new entrant teachers .............290

Appendix F: Questionnaires for kindergartens: modified as a result of teacher

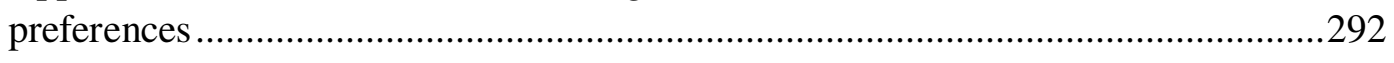

Appendix G: Semi-structured interview questions for principals ............................294

Appendix H: Interview dates with principals and comments .................................295

Appendix I: Amendments to interview questions resulting from trials .....................296

Appendix J: Observations and observation schedule .............................................299

Appendix K: Table for classification of major themes relating to teacher beliefs ....300 
Appendix L: Analysis of 'typical' events in mathematics.........................................301

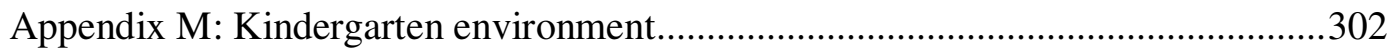

Appendix N: Comparison of kindergarten teacher beliefs, observed practices, and student activity

Appendix O: Transcript of teacher documentation of water play at Hikurangi

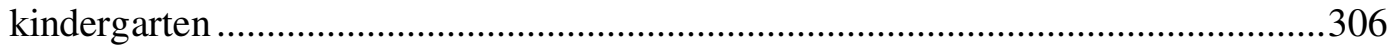

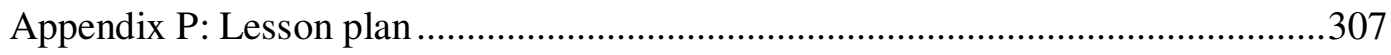

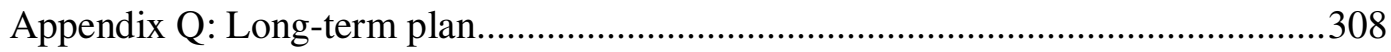

Appendix R: New entrant classroom environments .................................................309

Appendix S: Comparison of new entrant teacher beliefs about how children learn mathematics, teacher practices, and student behaviour ..................................311

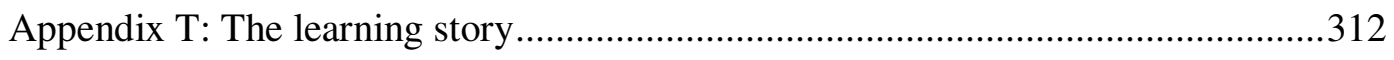

Appendix U: Kindergarten teachers' biographical data.......................313

References......................................................... 315 


\section{List of vignettes}

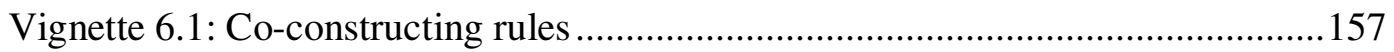

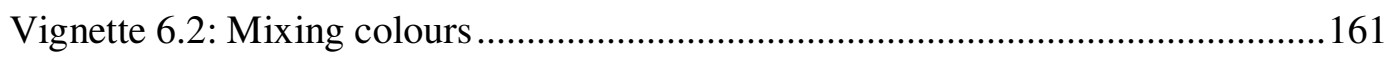

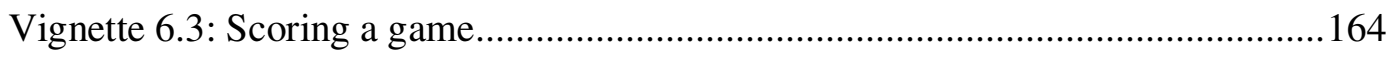

Vignette 6.4: Sorting and ordering bears ............................................................... 166

Vignette 6.5: Building an adventure playground......................................................169

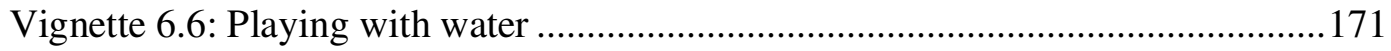

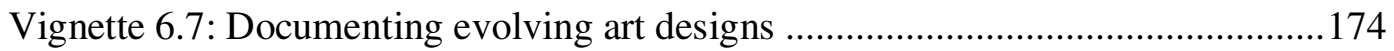

Vignette 7.1: Number identification - locating and identifying numbers ..................197

Vignette 7.2: Reproducing shapes - geometry in action .........................................199

Vignette 7.3: Counting to 20 - forwards and backwards ........................................202

Vignette 7.4: Incidental mathematics - roll call ....................................................205

Vignette 7.5: One-to-one counting - matching caterpillar legs to numbers ..............207

Vignette 7.6: Geometry - naming geometric shapes.............................................209

Vignette 7.7: Numeracy - number identification and using the 10s frame ...............212

\section{List of figures}

Figure 2.1: New Zealand Curriculum Framework ..................................................28

Figure 2.2: Key competencies: Cross-sector alignment ............................................ 34

Figure 5.1: Data overlap from multiple sources ......................................................126

\section{List of tables}

Table 2.1: Documents underlying the teaching and learning of mathematics in

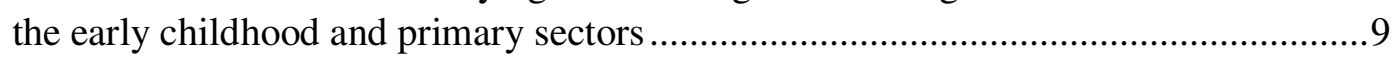

Table 2.2: Commonalities in mathematics expectations in Mathematics in the New Zealand Curriculum and Te Whāriki: He whaariki mātauranga mō ngā mokopuna o Aotearoa - Early childhood curriculum

Table 3.1: Characteristics of teacher practice within transmission and discovery

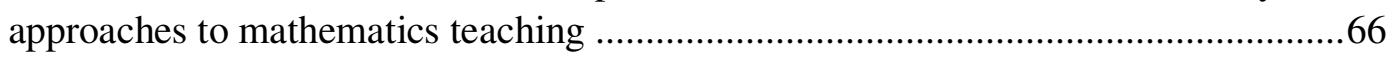

Table 5.1: Evaluative framework for analysing activity at classroom level..............107

Table 5.2: Data collection in kindergartens and new entrant classrooms in schools 
Table 5.3: Teacher beliefs about aspects of mathematics learning and actions observed.....

Table 5.4: Model of communication levels between teachers in kindergartens and in new entrant classrooms

Table 5.5: Information relating to schools, kindergartens, and teachers

Table 5.6: Ethnic composition of kindergartens and new entrant classrooms in percentage terms

Table 6.1: Summary of observed kindergarten events in each response category ....142

Table 6.2: Kindergarten teachers' beliefs and practices about the teaching of mathematics

Table 6.3: Comparison of kindergarten teacher beliefs about how children learn mathematics with observed practices and student behaviour

Table 6.4: Mathematical event structure at kindergarten

Table 7.1: New entrant teacher practices observed by response category.....

Table 7.2: New entrant teacher practices and beliefs about the teaching of mathematics

Table 7.3: Comparison of new entrant teacher beliefs about how children learn mathematics, teacher practices, and student behaviour

Table 7.4: Typical lesson structure in a new entrant classroom

Table 8.1: Kindergarten teachers' beliefs about expectations of children before school entry

Table 8.2: Teacher expectations of children on school entry

Table 8.3: Kindergarten teachers' views on the use of the curriculum .228

Table 8.4: New entrant teacher views on the New Zealand Curriculum Framework and Mathematics in the New Zealand Curriculum.

Table 8.5: Acknowledging the bicultural and multicultural nature of the kindergarten

Table 8.6: Acknowledging the bicultural and multicultural nature of new entrant classrooms 


\section{1: Introduction}

In educational theories, particularly those relating to early childhood, there has been a gradual shift from primarily developmental explanations of learning to theories with a more socioculturally based perspective on learning (Anning, Cullen, \& Fleer, 2004). These theories are evident in the curriculum documents that govern teacher practice and contribute to the development of teacher beliefs in the classroom. An exploration of teacher beliefs and practices in mathematics teaching in New Zealand seemed useful in the light of the Ministry of Education's development of national literacy and numeracy standards and the continuing investment in teacher professional development across sectors of the education system. This qualitative study was undertaken before the New Zealand Curriculum (Ministry of Education, 2007b) was phased in, so was informed by the New Zealand Curriculum Framework (NZCF) (Ministry of Education, 1993a), Mathematics in the New Zealand Curriculum (MiNZC) (Ministry of Education, 1992), and the early childhood curriculum (Te Whāriki) (Ministry of Education, 1993b, 1996). These documents have provided guidance and direction for teachers in New Zealand since the early 1990s.

My experience in professional development initially focused on primary school teachers' mathematics teaching and classroom practices, but this extended to an interest in what was happening in mathematics teaching before school entry. My previous research centred on early childhood education, so I was interested in exploring the connections between mathematics teaching and learning that occurred in the early childhood years in kindergartens and in the first year of formal schooling in new entrant classrooms.

The purpose of this research was to investigate teachers' beliefs about how children best learned mathematics in kindergarten and new entrant classrooms and to compare these beliefs with their practices in the classroom. The similarities and differences between kindergarten and new entrant teachers' beliefs and practices were evident as children transitioned from kindergarten to school. The curriculum documents guiding teacher practice were examined for commonalities that support a continuity of learning approaches as children move from kindergarten to school. 
In New Zealand, the Literacy Taskforce recommended that "By 2005, every child in New Zealand turning nine will be able to read, write and do maths for success" (Ministry of Education, 1999, p. 4). ${ }^{1}$ This government initiative has had an impact on teachers' thinking and recognises the continued importance of focusing on literacy and numeracy as crucial in a child's education (Foote, Smith, \& Ellis, 2004). This focus was reflected in reviews of early childhood centres by the Education Review Office. ${ }^{2}$ The Education Review Office (1998, p. 4) stated: the cognitive and intellectual development of children before they enter school is critical to their future educational achievement. Literacy and numeracy are essential to progress at school and the children's ability to acquire these skills is influenced by the nature of their early childhood experiences.

The preceding statement reinforces the belief that mathematics learning does not begin on school entry but is a continuation of the mathematics experiences and learning from early childhood settings, including the home environment. The curriculum documents for early childhood education (Te Whāriki) and formal schooling (the NZCF) contain guidelines intended to support the concept of a seamless education system that accounts for the needs of children within it. ${ }^{3} \mathrm{~A}$ seamless education system needs to be further explored. It is not enough to simply make school more like kindergarten or vice versa, because this may not necessarily be in the child's best interest (Peters, 2004). Protecting or insulating children from challenges at any stage in their learning may be disadvantageous to their ultimate successful transition through a variety of education levels (Clark \& Lovric, 2008).

Teachers are responsible for developing and maintaining a classroom environment that supports children as they engage with learning. Teacher beliefs about how children best learn mathematics are generally thought to impact on how teachers organise their environment for teaching, learning, and developing children's

\footnotetext{
${ }^{1}$ Success was undefined.

${ }^{2}$ The Education Review Office is the government department that reports on the quality of education in New Zealand.

${ }^{3}$ The notion of a seamless education system was introduced in New Zealand in 1999 by the then Minister of Education.
} 
mathematical knowledge (Aubrey, 1997; Aubrey, David, Godfrey \& Thompson, 2000; Barkatsas \& Malone, 2005; Cobb, Wood \& Yackel, 1990; Nisbet \& Warren, 2000; Pajares, 1992; Raths, 2001; Spodek, 1988). This study compares the degree of compatibility of kindergarten and new entrant teachers' beliefs and practices as children transition from kindergarten to new entrant classrooms, along with teachers' beliefs about how children best learn mathematics, and how these beliefs are implemented in kindergartens and classrooms. The study explores the factors that affect these beliefs and practices and details the continuities between kindergarten and new entrant classrooms to develop an understanding of the relationship between the two settings.

Kindergartens are one of the early childhood education organisations in New Zealand that provide for children before they enter compulsory schooling. They were chosen for this study due to their closer historical relationship with the staterun schools. Kindergartens in New Zealand usually cater for children up to the age of five. New entrant classrooms (known as reception classes in England and kindergarten in the United States) cater for children on school entry for up to one year, depending on school policies. The compulsory age for school entry is age six but children in New Zealand most commonly start on or around their fifth birthday.

Although the focus of this study is on kindergarten and new entrant teachers, much of the research about teacher practices and beliefs is more general. The study indicates when research is specifically about early childhood.

Internationally, the period of early childhood is most commonly recognised as the first eight years of life (Aubrey et al., 2000; Dahlberg, Moss \& Pence, 1999); this is a more comprehensive perspective than used in this study. The age of five most commonly signifies school entry in New Zealand, so in this study early childhood refers to children up to the age of five and explores the period before school entry and the transition to the new entrant class at school. 
As children make the transition from kindergarten to school, there is a commonly held (by children, parents and teachers) expectation of change (i.e., that things will be different at school) (Margetts, 1999; Perry, Dockett \& Tracey, 1998; Renwick, 1984, 1987). Teachers' beliefs and expectations of children on school entry may be incompatible with children's actual levels of knowledge, which could lead to practices that might not align with teachers' beliefs. Differing beliefs focusing around 'readiness for school' between kindergarten and new entrant teachers may lead to situations where children move from an environment where they are perceived as having positive dispositions for learning to one where they are perceived as lacking some essential skills, creating tension between the two settings. Some new entrant teachers hold a set of beliefs relating to the knowledge and skills they expect children to have mastered on school entry. When children do not appear to possess these, teachers may feel the need to fill these gaps in knowledge and skills before starting any other learning.

For the purpose of this study, transition is referred to as the process of change as children move from one educational setting (the kindergarten) to another (the new entrant classroom at primary school). Transition includes the time it takes a child to settle in the new environment. It can be a time of intense and complex demands as the child becomes socialised into the new environment. Central to this study is the exploration of the similarities and differences in teachers' practices and beliefs in mathematics teaching and learning over this transition.

The study explored the following questions in relation to mathematics teaching and learning.

- Do teachers in kindergartens and new entrant classrooms share common beliefs and perceptions about mathematics learning?

- Are there similarities and differences between teacher practice in kindergartens and new entrant classrooms that could influence the transition of children to primary school?

- What links can be made between teacher practice and beliefs about mathematics learning in kindergartens and new entrant classrooms that may ease the transition for children? 
The chapters progress from a general examination of the curriculum documents that guide teacher practice, exploring the commonalities that contribute towards the development of a seamless education system, followed by an examination of specific beliefs and practices of teachers in relation to mathematics teaching and learning. From this follows an exploration of transition practices and beliefs held by both groups of teachers before and on school entry in relation to children's competencies and knowledge of mathematics.

Chapter 2 examines the curriculum documents that guide and support teachers in mathematics teaching and learning in New Zealand. The relevant primary curriculum documents (the NZCF and MiNZC) are compared with Te Whāriki, in terms of their underlying philosophies and expectations of teachers and children in mathematics progressions along the learning continuum. Each of these documents has been used in practice for more than 10 years and was current at the time of this study. Chapter 2 also overviews the development of kindergartens in the New Zealand education sector and their possible influence on practices in new entrant classrooms.

Chapter 3 examines the beliefs and practices of teachers within a mathematical context relating particularly to the teaching and learning of mathematics. The chapter also explores teachers' personal experiences and the theories they hold about practice in the classroom, alongside the influence the curriculum may have on their practices and beliefs. The final section of the chapter details similarities and differences between kindergarten and new entrant teachers' beliefs and practices in mathematics.

Chapter 4 examines teachers' beliefs and practices about the transition of children to school. The chapter explores teachers' expectations of children's 'readiness for school', including teachers' beliefs about the mathematical knowledge they expect children to have mastered before and on school entry. A key feature of this chapter is a focus on factors that contribute to a successful transition to school from an early childhood setting in relation to mathematics learning and teaching. The chapter concludes by discussing the similarities and differences in teacher practice in mathematics, including beliefs relating to assessment, school readiness, and national policies that support transition. 
Chapter 5 outlines the methodology used in this study. In summary, this was a qualitative case study that used interviews, observations, questionnaires, and school documentation to develop a picture of the mathematics teaching and learning that occurred in selected schools and kindergartens. Teachers from five new entrant classrooms and their five neighbouring kindergartens were selected for participation in this study. The new entrant teachers in this study had had at least two years of professional development in mathematics teaching and learning. The introduction of Te Whāriki to the early childhood sector, including kindergartens, was accompanied by some professional development, although this was not as extensive as that provided with the mathematics curriculum in the primary sector. The researcher recorded and transcribed the information gathered, then returned it to participants to validate its accuracy before using it in the study. To gain an in-depth view of the mathematics teaching that was observed, the researcher gathered and analysed detailed descriptions of mathematical events using Perry and Dockett's (2002) model for identifying powerful mathematical ideas.

Chapters 6-8 discuss the findings of the study. Chapters 6 and 7 detail the information gathered relating to kindergartens and new entrant classrooms respectively, regarding teachers' beliefs and practices in mathematics teaching. These chapters use vignettes to describe in depth the mathematics teaching that was observed. The vignettes describe the event and analyse the mathematical ideas in the event, and are followed by a commentary on each observed event. Because of the volume of information gathered, the findings from each sector are reported separately. Chapter 8 reports on teachers' beliefs about children's readiness for school and how kindergarten and new entrant teachers communicate with each other. It also examines the perception each group of teachers has of its curriculum. The chapter concludes by summarising the general trends from this study, and discussing the relationship between teacher practice and beliefs in mathematics teaching and learning. 
Chapter 9 answers the research questions. The chapter also discusses the similarities and differences between kindergarten and new entrant teachers' practices and beliefs about mathematics, examines how teachers use their curriculum documents, and discusses teachers' beliefs about the transition of children to school.

The final chapter, chapter 10, examines the implications of this study for the teaching and learning of mathematics as children make the transition to school. Recommendations are made to strengthen the relationships between kindergartens and schools and build understandings relating to children's mathematical abilities and teachers' beliefs and practices. The chapter also identifies possible avenues for further research in this area and includes recommendations to enhance mathematics teaching and learning for children as they progress from kindergarten to primary school. 


\section{2: The curricula: Governance of teacher practice}

\subsection{Introduction}

How teachers interpret the basic dimensions of teaching encompasses their beliefs about teaching and learning and their interpretation of these beliefs into daily classroom practice. This classroom practice incorporates organisational and management choices teachers make in combination with their beliefs about teaching and learning. Research in educational pedagogy has confirmed the influence of teachers over student learning in every aspect of classroom practice (Anthony \& Walshaw, 2007). The decisions teachers make about their practice require them to interpret the national curriculum documents and decide how to represent them in their teaching. For this reason, the curriculum documents that support the teaching of mathematics are examined to account for their influence on teachers' practice in kindergartens ${ }^{4}$ and new entrant ${ }^{5}$ classrooms.

Within New Zealand, the current view of mathematics taught across the curricula is that mathematics teaching and learning "should provide a foundation for working, thinking and acting like mathematicians and statisticians" (Anthony \& Walshaw, 2007, p. 7). This perspective requires teachers to have not only an understanding of what children already know, but knowledge of what children need to learn and how to provide experiences that challenge and support children in their learning (Ministry of Education, 2007b). To further these aims curriculum guidelines support and promote effective teacher practice and student achievement. Carr (2006, p. 23) viewed the curriculum as a means of assisting children and their parents "to access the resources they need to direct their own lives".

This chapter explores the nature of the curriculum documents that underpin the teaching of mathematics in early childhood settings and primary schools: the early childhood curriculum, Te Whāriki (Ministry of Education, 1996), the New Zealand Curriculum Framework (NZCF) (Ministry of Education, 1993a),

4 Kindergartens in New Zealand are one of several providers of early childhood education catering for children before they start school at age five.

5 In New Zealand, new entrant (year 1) classes are the school reception class that children enter most commonly on their fifth birthday. 
and Mathematics in the New Zealand Curriculum (MiNZC) (Ministry of Education, 1992). At the time of writing, these documents provided the directions for teaching and learning in New Zealand. ${ }^{6}$ Table 2.1 illustrates the place of each document within the education system.

Table 2.1: Documents underlying the teaching and learning of mathematics in the early childhood and primary sectors

\begin{tabular}{|l|l|l|}
\hline Sector & $\begin{array}{l}\text { Underlying curriculum } \\
\text { framework }\end{array}$ & $\begin{array}{l}\text { Curriculum relating to } \\
\text { mathematics }\end{array}$ \\
\hline $\begin{array}{l}\text { Kindergarten and } \\
\text { other early } \\
\text { childhood settings }\end{array}$ & Te Whāriki $^{1}$ & $\begin{array}{l}\text { Te Whāriki }{ }^{1} \text { contains } \\
\text { guidelines to support } \\
\text { mathematical development } \\
\text { within broad directions for } \\
\text { children's learning }\end{array}$ \\
\hline $\begin{array}{l}\text { Primary school: } \\
\text { including new } \\
\text { entrant classrooms }\end{array}$ & $\begin{array}{l}\text { New Zealand Curriculum } \\
\text { Framework }\end{array}$ & $\begin{array}{l}\text { Mathematics in the } \\
\text { New Zealand } \text { Curriculum } \\
\text { follows the guidelines from } \\
\text { the New Zealand } \\
\text { Curriculum Framework }\end{array}$ \\
\hline
\end{tabular}

Sources: (1) Ministry of Education (1993b); (2) Ministry of Education (1993a); (3) Ministry of Education (1992).

Links exist between the curriculum in the early childhood sector and the curricula for the primary sector. These links are continued in the current curriculum (Ministry of Education, 2007b). Learning stories ${ }^{7}$ and the development of positive dispositions to learning are thought to link early childhood education to primary school education (Avery \& Thomson, 2003). Both Te Whāriki and the NZCF refer to the commonalities that support the transition of children to school, but Avery and Thomson suggest that the understanding of each education sector (early childhood, primary, secondary, tertiary), between the sectors, needs further development to enhance and develop these links and commonalities (see also Dickie, 1998; Wartman, 1997).

6 Te Whāriki came under the government regulatory system from 1 December 2008. The MiNZC was gazetted on 18 February 1993, making it mandatory for all state-funded schools. The NZCF has not been gazetted. The 2007 New Zealand Curriculum replaces these two documents (Ministry of Education, 2007b).

7 Learning Stories were developed by Carr (2001) as a form of narrative assessment and are discussed in chapter 4 . 
Section 2.2 provides a short historical overview of the development of kindergartens and beginning school programmes to provide a context for understanding the links between kindergartens and new entrant classes in primary school.

\subsection{Historical overview of early childhood education in New Zealand}

This brief overview of the social and historical origins of the kindergarten system and of early schooling provides background within which to position the mathematics beliefs and practices of kindergarten and new entrant teachers in New Zealand. There is no intention here to provide an in-depth historical perspective of the development of early childhood education and new entrant teaching in New Zealand. This section examines some of the general ideas relating to child development and learning and their influence on the evolution of kindergarten and beginning school programmes in New Zealand.

Education records relating to the provision of early years education in the mid 1800 s are variable but by the 1830 s some forms of infant schooling were generally seen as an integral part of missionary ventures, although many were short-lived (May, in press). The main intention was to ensure that young children developed good habits and Christian values. By the mid 1850s provincial governments were beginning to take more responsibility for education (including that of young children) and more purposeful planning was undertaken with variations between provinces.

In New Zealand, the Education Act 1877 provided for free education for children from five years of age and made it compulsory for children from seven years of age. This Act drew a clear distinction between non-state-funded pre-school, kindergarten education and state-funded education. This demarcation was one factor in the establishment and maintenance of independent early childhood education providers in New Zealand which began to show more cohesiveness in educational planning across the country. The Act defined a national curriculum for schools, centred around standards upon which children would be examined before moving to the next standard (Year level). The two years below the standards (the primers) were seen as preparatory years. Failure to reach each 
standard level meant that children were held back (May, in press), a contrast to the social promotion policies in schools today.

The first clearly documented kindergarten opened in New Zealand in Dunedin in 1889 (May, 1997). The general philosophy underlying this and other early kindergartens was philanthropic: kindergartens were seen as a means of providing routine and order for children from less-fortunate backgrounds and a way of instilling these children with good citizenship values (Middleton \& May, 1997). To support this philosophy, kindergarten programmes were formal with timetabled and structured events where children were instructed in the skills deemed necessary for participation in society. By the end of the nineteenth century and early twentieth century there was a shift in thinking regarding children's early learning. Progressive ideas relating to the importance of recognising a child's spontaneous play and developing their senses lead to a reduction in time spent preparing to meet the standards (May, 2005).

The 1904 education syllabus, described by Hogben (in Middleton \& May, 1997) as making provision for children to learn by doing, observing and reasoning, incorporated many of the new educational ideas emerging in Europe, Britain and America. Curriculum and practice were influenced by Dewey's ideas relating to children as the social centre of learning, the work of Maria Montessori and Susan Isaacs believing in the self expression of children and Froebel who recognised the unique needs and capabilities of children and first developed the idea of kindergarten ( May, in press). The New Zealand system, reminiscent of the British system, was formal and structured despite the gradual adoption of these progressive ideas relating to children's learning. Over the next 40 years, young children were separated from older children and developmental free-time activities were introduced. In general, the infant (new entrant) classrooms of this time were characterised by rote learning and seat work, with significant emphasis on the development of good habits for learning, a generally more traditional style of teaching. Following the Second World War, with the increase of the school population and resulting crowded classrooms, managing children and maintaining order were prevalent. Gradually, ideas relating to children learning through play found their way into new entrant classrooms. Bell in 1953 (in Middleton \& May, 
1997) discussed finding out about a child's prior learning and experiences before developing programmes to meet their needs, an innovative idea at the time.

Froebel's vision (Priestman, 1952) of a curriculum and programme for children that valued play and exploration and complemented the role of teachers and parents, became increasingly valued as the kindergarten and early childhood education movement grew and strengthened. These ideas continue to influence kindergarten education and had an impact on primary classes until the early 1980s.

By the beginning of the twentieth century a clear distinction had begun to emerge between schools and kindergartens. Kindergartens, although slow to move from a more formal system, became more focused on the needs of children, concepts relating to 'readiness for learning', and the ideas of Jean Piaget (Middleton \& May, 1997) were incorporated into practice. Kindergartens up to the mid twentieth century did not operate within the then Department of Education, a more formal education system. The view persisted in some quarters that attendance at kindergarten could well allay some of the deficiencies of the home environment and ensure children knew the rules when they began school (Middleton \& May, 1997). Kindergartens, outside direct Department of Education authority, had more flexibility than primary schools to change and develop their programmes as ideas relating to child development evolved, although they held to timetabled programmes into the $1960 \mathrm{~s}$. The evolution of the playcentre ${ }^{8}$ movement and the resulting ideas regarding the value of children's play, combined with the importance of recognising children's existing skills and knowledge, supported the gradual movement of kindergarten programmes towards a less formal structure with more opportunities for children to explore their ideas and interests.

The New Zealand system, at the time, while not a leader in the field, was characterised by a broad range of practices relating to the education of the whole child. Isaac's views on self expression of children, Dewey's perspectives on the social nature of learning and the emerging ideas of Piaget, and Froebel's position

\footnotetext{
${ }^{8}$ Playcentre is based on a philosophy of child-initiated play and the recognition of the importance of parents as educators of their children.
} 
on self learning contributed to New Zealand's responses to new ideas (May, in press) and contributed to the diversity of early childhood provisions.

As ideas relating to a child's readiness for learning became more accepted, new entrant classrooms became a place "to provide an environment that enhanced 'readiness"” (Middleton \& May, 1997, p. 140). This in turn supported the development of free play in junior classes with the teacher's role being to set up opportunities for play and then allowing children time to explore - the teacher as observer rather than active participant. Developmental time was an important component of junior classrooms until the early 1980s when schools were inundated with curriculum documents that emphasised the importance of achievement objectives and learning outcomes. It is thought that this increasing emphasis on covering the curriculum and observable outcomes may have contributed to the declining incidence of developmental programmes for children in their early years at school (Carr \& May, 1996; Carr, Smith, Duncan, Jones, Lee \& Marshall, 2010; Middleton \& May, 1997). Beverley Morris, a contributor to the beginning of the playcentre movement in New Zealand, confirmed this perspective of declining developmental time, "I suspect [developmental time] has been decreased in favour of more formal teaching" (personal email communication, 19/10/2006). Teachers in new entrant classrooms face a conflict between meeting achievement objectives and learning outcomes, and developing positive dispositions and strategies for learning through problem-solving activities such as those promoted in a more developmental approach (Carr \& May, 1996). May (in press) claims that the effect of reducing or abandoning developmental time in junior classes has meant teachers have more time to ensure coverage of subject areas in the curriculum leading to more directive teaching. Anecdotes from some primary teachers and advisers in New Zealand suggest some schools have been increasing discovery time (similar to developmental time) as teachers become more aware of the importance of developing children's problem-solving skills, ${ }^{9}$ although this is not yet widespread as teachers continue to face challenges in meeting the demands of the curriculum.

\footnotetext{
${ }^{9}$ Primary teacher, professional conversation at a school, Wellington, 2 June 2009; Primary teacher 2, personal conversation at a school, 19 May 2008; Senior lecturer, professional conversation,
} 
Combined with the above ideas are changing views about the role of schools and kindergartens in children's education. Kindergartens were originally seen as a place to socialise underprivileged children, then as a place to prepare children for school. However, the contemporary view is that early childhood education (including kindergartens) is a place to introduce life-long learning and to establish positive attitudes and values for learning (i.e., dispositions for learning). The perceptions of primary school teachers have been slower to change, with some new entrant teachers continuing to report that children are entering school with few skills and a lack of knowledge of key concepts that they feel should have been established through an early childhood education facility. This lack of preparedness for school in the eyes of the primary teacher (and the public) is an ongoing issue between the education a child receives at kindergarten or other early childhood centres and the education they experience at school (Blundel \& Palmer, 2009; Hopps, 2004; Timperley, McNaughton, Howie \& Robinson, 2003).

\subsection{Te Whāriki: He Whāriki Mātauranga mō ngā Mokopuna o Aotearoa - Early childhood curriculum}

\subsubsection{Principles underpinning Te Whāriki}

Te Whāriki, the early childhood curriculum, has been shaping teaching and learning in early childhood centres, including kindergartens, since 1996 (Ministry of Education, 1996). Te Whāriki was written to meet the aims and goals of educating young children in New Zealand (Carr \& May, 1996). This curriculum does not prescribe what teachers need to teach but provides outlines of broad directions for children's learning.

A key feature of Te Whāriki is its strong child-centred orientation focusing on the holistic development of the child. The term 'holistic' is defined in Te Whāriki as "tending, as in nature, to form a unity made up of other 'wholes', where the new unity is more than the sum of the parts, and in which each element affects, and is affected by, each other element' (Ministry of Education, 1996, p. 99). This study uses this definition. Te Whāriki contains a separate framework for Māori that is

Victoria University of Wellington, 15 April 2008; Numeracy lecturer, personal conversation. Victoria University of Wellington, 25 August 2007. 
linked to and sits alongside the English-medium framework (Haggerty, 2003). Te Whāriki was explicitly designed to accommodate the social and cultural context of New Zealand and incorporate best practices in early child development.

Teachers in kindergartens (and other early childhood settings) have considerable freedom to make their own decisions about how best to achieve the goals outlined in Te Whāriki. Te Whāriki does not outline specific curriculum areas to be covered, nor does it prescribe teacher practice or how to achieve the goals and principles outlined. The interpretive role of the teacher is crucial. What teachers do in mathematics is likely to be an outcome of their beliefs and knowledge about what is appropriate in mathematics learning for children (Haggerty, 2003). The belief that all children are capable of becoming proficient, successful mathematics learners underlies the principles of Te Whāriki (Anthony \& Walshaw, 2007).

Te Whāriki is written in English and Māori. The sections in Māori are written for Māori, so are not a direct translation of the English text but a parallel version. The cover of Te Whāriki shows a whāriki (a woven mat), which is indicative of the integrated nature of the underlying principles. Each page contains the woven flax motif to reinforce the interconnectedness of the parts of the document. The weaving or interconnectedness of the parts of Te Whāriki relate to how the document is used in practice, who creates the weaving, the knowledge and understandings relating to usage by children, teachers and the community (Carr \& May, 1996). The document comprises four major parallel sections in English and Māori with a separate section for Māori language centres (kōhanga reo) in Māori only. The document details the principles, strands, goals, and outcomes in English and Māori and concludes with a brief section outlining the relationships between Te Whāriki and the NZCF. Te Whāriki relates to the total of all experiences designed to foster learning regardless of the curriculum area.

Te Whāriki is unique within the New Zealand education system as it binds together in one unifying document the diverse range of early childhood settings, all of which have their own distinctive philosophies. The Māori section is not an English translation but is based on Māori pedagogy and philosophy.

Te Whāriki aims for children to grow up as confident learners and communicators, healthy in mind and body, secure in their sense of belonging and 
the knowledge that they can contribute in a meaningful way to society. Four main principles are included in the document: empowerment (whakamana), holistic development (kotahitanga), family and community (whānau tangata), and relationships (ngā hononga). The content strands are well-being (mana atua), belonging (mana whenua), contribution (mana tangata), communication (mana reo), and exploration (mana aoturoa). The skills to be developed are integrated throughout the goals of each strand and are linked together. The knowledge, skills, and attitudes outlined are linked to form a child's "working theory" (Ministry of Education, 1996, p. 16) and to develop dispositions for learning.

Although the document is divided into four sections according to the principles, its intention is that it is used as an integrated whole, and the way this is done may differ from centre to centre.

Dispositions for learning are mentioned as an outcome for early childhood education in Te Whāriki. Dispositions can be regarded as an inclination towards learning, an attitude or habit of mind evident through close observation of behaviour (Carr, 1998). Dispositions consist of situated learning strategies combined with motivation that occur across social practices, partners, and tools that lead to the development of learners who are "ready, willing and able to learn" (Carr, 2001, p. 9) These behaviour patterns, indicating positive learning dispositions, need to be frequent occurrences to be measurable and observable. The presence of positive learning dispositions is a key attribute that children should take to school with them. Carr (1998) suggests that the five key learning dispositions to be encouraged are courage, playfulness, perseverance, communication, and responsibility. Early childhood centre and school practices need to both recognise the occurrence of these dispositions and foster their continued development. The establishment of early, positive learning dispositions is a key feature in later academic success (Pascal \& Bertram, 1999). Children's early knowledge of knowing how to learn supports the establishment of positive dispositions towards learning.

Early childhood education groups in the 1990s in New Zealand were reluctant to have a national curriculum because they believed it would encourage a uniform approach' and provide opportunities for the school curriculum to move down into 
early childhood. To prevent this from happening, the early childhood community (led by Margaret Carr and Helen May) took a leading role in the writing of the national curriculum for children before school entry. Te Whāriki contains a curriculum for infants and toddlers that sets it apart from other curricula for the under fives (Haggerty, 2003). Te Whāriki resulted from the Government's commitment to developing a national curriculum for early childhood education and schools in line with an international trend to strengthen the connections between economic success and education (May, 2002).

\subsubsection{Te Whāriki: The 1993 draft}

The first draft of Te Whāriki consisted of three parts (Ministry of Education, 1993b). Part one looked at the background of the document and the context within which it was developed. Part two set out the principles and goals for all chartered early childhood education services along with exemplars of practice, demonstrating how the statements could be used for planning, evaluating, and assessing programmes. Each goal came with a set of examples showing what it looked like in practice and how it connected with the school curriculum. The final section looked at the connections between early childhood education and the school curriculum. The draft curriculum set out the appropriate experiences for children to meet the specified goals of the curriculum along with a description of developmentally appropriate activities for different age groups.

Te Whāriki recognises the integrated nature of children's learning. While mathematics learning is clearly relevant and important, it does not form a major separate focus for learning as it is integrated into many of the strands and forms a component of these. Clear descriptions were given of the kinds of activities that were appropriate, for example (Ministry of Education, 1993b, p. 93):

Communication Goal 3: Children will experience an environment in which they experience the stories and symbols of their own and other cultures

Examples for young children

Children should have the opportunity to develop early number concepts by engaging in the following activities in purposeful 
ways: exploring, comparing, and problem solving with continuous quantity ... creating and perceiving patterns, recording and timing.

The message conveyed is that mathematics development is important in early childhood and needs to be addressed as it arises, in this case under communication goals.

The title of the final part of the draft document was "Continuity between early childhood education and the school curriculum", which was indicative of the significance attached to the transition to school for children (Ministry of Education, 1993b, p. 120). Specific connections were made from the draft curriculum for early childhood to the mathematics curriculum document (MiNZC) to support the transition of children to school and the vision of a seamless curriculum. For example (Ministry of Education, 1993b, pp. 124-125):

The mathematics curriculum ... will provide opportunities for students to:

- Develop flexibility and creativity in applying mathematical ideas and techniques to unfamiliar problems arising in everyday life, and develop the ability to reflect critically on the methods they have chosen;

- Become effective participants in problem-solving teams, learning to express ideas and to listen and respond to the ideas of others;

- Develop the knowledge and skills to interpret written presentations of mathematics.

These links to the school curriculum documents were omitted in the final version of Te Whāriki against the wishes of the original writers because the Government wished to present a more integrated approach for early childhood, meaning each early childhood centre had to 'weave' its own pattern (May, 2002). The final document contained an inserted section in each of the 5 strands with descriptions of the possible knowledge, skills and attitudes a child could take to school, a major shift from the draft version which promoted greater continuity between and across sectors (May, in press). 


\subsubsection{Te Whāriki: The final document (1996)}

As a result of the consultative process, the draft curriculum was modified into its current format (May, 2002) for final publication in 1996.

The final document links the NZCF and Te Whāriki in more general terms, "Each strand of the early childhood curriculum has a number of links with the essential learning areas and essential skills of The New Zealand Curriculum Framework" (Ministry of Education, 1996, p. 93). The mathematical ideas that come under each strand of Te Whāriki are linked to the essential skills and learning areas of the NZCF. For example, under the strand well-being (mana atua), essential skills in mathematics are described as " children develop competence in mathematical concepts and enjoy using them in daily life", and the mathematics essential learning area is described as "exploring mathematical concepts encourages creativity, perseverance, and self-confidence" (Ministry of Education, 1996, p. 94).

\subsubsection{Importance of building positive dispositions to learning}

The four principles of Te Whāriki that form the framework for assessment are woven into the strands of the curriculum document. Learning stories, used as an assessment format, were introduced after the introduction of Te Whāriki as a means of recording the dispositions of a child to learn (Carr, 1998, 2006). These learning stories have been described as a form of narrative assessment that links the contribution from early childhood experiences to life-long learning (Carr, 1998; Podmore et al, 2001). Further work on learning stories, through Kei Tua o te Pae, Assessment for learning and teacher professional development relating to this (Ministry of Education, 2004b) and subsequent evaluations of this (Stuart, Aiken, Gould \& Meade, 2008) have demonstrated the shift in philosophy and assessment practices across the early childhood sector. In it early childhood teachers spoke of the changes in the way they assessed children, the professional development through Kei Tua o te Pae that supported this and their shift in teaching practice. The aim of Te Whāriki is for children to leave early childhood centres with well-established learning stories that focused on skills to do with "being a learner" (p. 3), not specific mastery of learning intentions, but learning dispositions. 
The five key domains of learning dispositions are (Carr, 2001, p. 23):

- taking an interest

- $\quad$ being involved

- $\quad$ persisting with difficulty or uncertainty

- communicating with others

- $\quad$ taking responsibility.

From discussions with the early childhood learning community, four key features of learning stories were developed (Carr, 2001; Podmore et al., 2001). The features are:

- 'describing' - describing categories of behaviour that could evolve into learning dispositions and noting the learning that is occurring

- 'documenting' - recording the learning observed through photographs and written records

- 'discussing' - sharing these important learning stories with relevant people (including the child)

- 'deciding' - focusing on the next step.

This form of assessment was ongoing, continuous, and an integral part of the teaching and learning process. Learning dispositions included evidence of children 'taking an interest' in their learning, of teachers who were closely involved in documenting the children's involvement, of children who persisted in their activity even when it was difficult, and of children who learned to take responsibility for their actions (Podmore et al., 2001). In summary, teachers were again looking for evidence that children were ready, able, and willing to learn, in other words, developing positive dispositions for life-long learning.

The lack of specific content requirements in a curriculum document appears to be a common feature of many early childhood curricula (Hedges \& Cullen, 2005), so Te Whāriki is no exception. The belief that a subject-based approach was inappropriate for early childhood education led to the deliberate omission of the specific teaching and learning of content and subject knowledge. However, embedded and interwoven with the strands of Te Whāriki (well-being, belonging, 
contribution, communication, and exploration) lies a set of clear mathematical understandings and competencies. For example, under goal 3 of the communication strand, are a list of the knowledge, skills, and attitudes that children develop and adults need to be aware of, some of them specifically related to mathematics. For example, statements such as, "familiarity with numbers and their uses by exploring and observing the use of numbers in activities that have meaning and purpose for children" and "skill in using the counting system and mathematical symbols and concepts such as numbers, length, weight, volume, shape and pattern, for meaningful and increasingly complex purposes" (Ministry of Education, 1996, p. 78).

Having no specific guidelines for content selection in Te Whāriki could be seen to absolve teachers of the responsibility to be knowledgeable about particular areas of interest for children (Hedges \& Cullen, 2005), but this is not the case. The lack of clear guidelines for content was opposed by those who believed the lack of emphasis on content knowledge was not based on clear evidence (Dahlberg et al., 1999; Farquhar, 2003; Mitchell \& Cubey, 2003). Farquhar (2003, p. 2) identified one of seven important pedagogical principles, "effective teachers use content knowledge confidently to support and extend children's learning in interactive and play-based situations”. Mitchell and Cubey (2003) likewise believed that to extend children's learning teachers must have good pedagogical and content knowledge.

If teachers in early childhood settings are unaware of the extent and depth of the knowledge and skills children possess when they arrive at a centre, then teachers may be less able to recognise and extend this knowledge. A similar situation exists in a new entrant classroom. If a teacher is unaware of the extent of mathematical knowledge possessed by a child on school entry, meeting their specific needs becomes problematic (Hedges \& Cullen, 2005; Timperley, Robinson, Howie \& McNaughton, 2003). To fully extend a child, teachers need to understand what children already know and be able to extend that learning, which in turn presupposes a depth of content knowledge in teachers. Mathematical knowledge in young children arises naturally from their own activities, both planned and unplanned. It is a teacher's responsibility to be able to recognise 
these and balance instructive activities and productive play. Essentially, teachers need to be knowledgeable enough to recognise and capitalise on the opportunities for mathematics learning that lie within the everyday experiences of children (Aubrey, 1997).

A key feature of professional development for early childhood teachers is extending subject content knowledge in mathematics so teachers can recognise and extend learning opportunities for children (Aubrey, 1997; Young-Loveridge, Carr \& Peters, 1995). Some pre-service teacher programmes consciously link Te Whāriki and the NZCF, acknowledging the overlap of curricula in an attempt to enhance teachers' subject knowledge (Haynes, 2000). Early childhood teachers, while remaining committed to the child-centred philosophy of Te Whāriki, need to have knowledge related to the essential skills of the school curriculum to enhance their ability to recognise, provide, and foster the mathematical opportunities arising for children through their play and everyday experiences. However the main focus of the early childhood curriculum continues to support a play-based, integrated learning environment that builds on children's experiences (Haggerty, 2003).

According to Hedges (2002), most unplanned learning and teaching experiences that occur within early childhood settings do not utilise teachers' subject knowledge. Hedges's study on the links between subject knowledge and beliefs and practices in early childhood education found that when teachers specifically planned learning experiences for children they used their own knowledge of that subject. During the play-based and spontaneous interactions that occur in early childhood settings, pedagogical involvement consisted of responding to children's interests. If teachers extended these further, using specific content knowledge, the quality of the interactions would be considerably stronger. She found that teachers who possessed a good subject content knowledge were more likely to be able to capitalise on incidental interactions with the children to maximise possible learning opportunities. Hedges went on to suggest that a lack of specific subject content knowledge in early childhood education and the lack of clear guidelines in Te Whāriki may limit opportunities for extended teaching and learning. 
A survey of school entry practices in new entrant classrooms, set up by the National Government in 1991 resulted in the School Entry Assessment kit (Thackeray, Syme \& Hendry, 1992; Ministry of Education, 1992b). The school entry assessment kit was a standardised measure designed to collect information on school entry practices was never fully implemented by teachers reluctant to use a measure they felt could be used for interschool comparisons. Early childhood teachers felt that such an instrument could impinge on their programmes and potentially influence their teaching. A 1997 seminar (Holmes, 1998) held at Victoria University of Wellington in conjunction with Otago University was an attempt to bridge the divide still existing between the two sectors but evidence of tensions were present. Rising expectations of new entrant teachers of children coming from early childhood further exacerbated these tensions.

Anthony and Walshaw (2007) commented on the importance of children being in an early childhood centre that provided the children with an "orientation to learning" (p. 30), that is an environment that regularly creates or capitalises on opportunities for children to problem solve and develop mathematical thinking skills. Effective teachers of mathematics are those who are able to recognise and extend opportunities arising from children's own mathematical ideas, to orient them towards mathematics (Young-Loveridge, 1989b). Lack of recognition of mathematical activities may result in missed opportunities for teachers to both extend and develop children's skills. In mathematics, teachers with more developed subject knowledge are better able to build on and extend children's existing knowledge, teachers who do not have extensive subject knowledge are less able to utilise the children's experiences and build their knowledge (Muir, 2008; Young-Loveridge et al., 1995). Within early childhood education, the conflict between providing direct instruction in mathematics skills and providing activities that support mathematics learning is addressed in the sociocultural underpinnings of Te Whāriki. By building positive dispositions to learning, teachers have a responsibility to recognise and develop learning from their own personal constructs.

Teachers have a key role in designing and shaping mathematical experiences and opportunities for children, but what they do (their practice) is likely to be a result 
of their beliefs about appropriate mathematical experiences for young children. The nature of Te Whāriki, which provides broad, general directions for teaching and learning, allows considerable latitude for teachers to make their own decisions on mathematical experiences.

\subsubsection{Te Whāriki builds on positive and interactive relationships}

Te Whāriki as a curriculum is based on the premise that in the early childhood years children's development varies considerably so the curriculum can cater for uneven progressions for learning, rapid changes, and individual and incremental differences (Carr \& May, 1996). Foote, Smith and Ellis (2004) suggested that the New Zealand Government's focus on literacy and numeracy outcomes and the necessity for the provision of evidence of successful outcomes may influence the nature of teacher practices. The pressure (real or otherwise) to implement skillsbased programmes that clearly demonstrate how teachers meet these outcomes could negatively affect the nature of teacher practice. Te Whāriki, having a more holistic outlook than school-based curricula, challenges teachers to provide a learning environment and teaching practices that do not lead to skills-based programmes, even though such programmes may be easier to describe and measure (Foote, Smith \& Ellis, 2004).

Te Whāriki is widely regarded as a progressive curriculum for early childhood (Bath, 2009) effectively incorporating both Maori and European pedagogy. The strands within it are based on a view of human development primarily derived from Bronfenbrenner's (1979) ecological model. This model, characterised by responsive and interactive learning contexts lends itself to the idea that children's learning is situated within a cultural context. This perception of children and their learning builds on positive and interactive relationships between children and teachers and the development of children's identities as learners.

\subsection{New Zealand Curriculum Framework}

Until 2008, the NZCF (Ministry of Education, 1993b) was the mandatory guiding document for teaching and learning in New Zealand schools across all the 
curricula. ${ }^{10}$ The primary function of the NZCF is to provide guidelines for learning and teaching in New Zealand. It is a framework that is intended to link the seven essential learning areas (of which mathematics is one) to each other. Each essential learning area has its own specific curriculum document.

The title of this document is in English and Māori and is illustrated with a shell motif. The Māori title, although on the cover, is less distinct than the English title. The shell motif represents the essential learning areas with a colour for each particular curriculum document. This is a 28-page document with section headings in English with a direct Māori translation, in contrast to Te Whāriki which has separate, linked Māori sections. It contains introductory sections on each essential learning area, along with the skills, attitudes, values, and assessments that are necessary at each level of the essential learning area. The term curriculum in the context of the NZCF refers to a set of national curriculum statements that define the learning principles, achievement aims, and objectives that each school is required to follow. The school curriculum details how each school is to put the national curriculum statements into practice and includes provisions for local variations. The stated purpose of the NZCF is to enable the nation to progress with New Zealanders enjoying prosperity in today's and tomorrow's competitive environments by developing individuals who can meet this challenge - the NZCF balances the needs of individuals and the needs of the society in which they live (Ministry of Education, 1993a).

The New Zealand Curriculum Framework describes elements which are fundamental to teaching and learning in New Zealand schools. It states the principles which give direction to all teaching and learning. It specifies seven essential learning areas which describe in broad terms the knowledge and understanding which all students need to acquire. The framework sets out the essential skills to be developed by all students. It indicates the place of attitudes and values in the school curriculum. It gives direction to the development of the more specific national curriculum statements which describe in more detail the required knowledge, understanding, skills and attitudes. Finally the framework 
outlines the policy for assessment at school and national levels. (Ministry of Education, 1993a, p. 4, emphasis in the original)

The NZCF provides direction for learning and assessment, defines the achievement objectives, provides for flexibility to meet each student's learning needs, and aims to ensure a coherent progression for students. It aims to encourage independent and lifelong learners and to recognise the importance of the Treaty of Waitangi, as well as reflecting the multicultural nature of New Zealand and the importance of accommodating the needs of the wider world in which we live.

The NZCF is a result of many conflicting political, social, and educational views. O'Neill (2004) described this document as providing an outcome view of the curriculum, "provided to students by the teachers through the school" (p. 26, emphasis in original). The outcomes-based framework with a focus on the mastery of basic skills, competencies, and achievement levels requires schools to report and analyse assessment data against student achievement and mastery of goals. The structure of the curriculum framework signals the seven essential learning areas. These learning areas are organised in an eight-level hierarchical structure that is not based on research and had a limited input from educationalists (O'Neill, 2004). O'Neill claimed that the result of this was the separation of teaching and learning - a focus on measurable outcomes as opposed to an educationally sound approach to teaching pedagogy. However, the NZCF is progressive in that for the first time all the essential learning areas are linked within a single document, from years 1 to 13 , supporting the then Minister of Education's vision for a seamless curriculum. The framework provides guidance for teachers in the learning progressions expected over the seven essential learning areas. Each curriculum document in the essential learning areas is directly linked to the NZCF.

The outcomes-based approach and the eight-level hierarchical structure are clearly linked to measurable outcomes for student learning. This contrasts with the underlying philosophy of Te Whāriki that builds on and extends children's own learning experiences across all curriculum areas. Figure 2.1 reproduces the diagram outlining the structure of the curriculum from the NZCF (Ministry of 
Education, 1993a, p. 5), demonstrating the relationships that lie between the essential learning areas, the principles of the curriculum, and the essential skills and attitudes that span the boundaries. Guidelines for teaching and learning for the essential learning areas are in separate curriculum documents. 
Figure 2.1: New Zealand Curriculum Framework

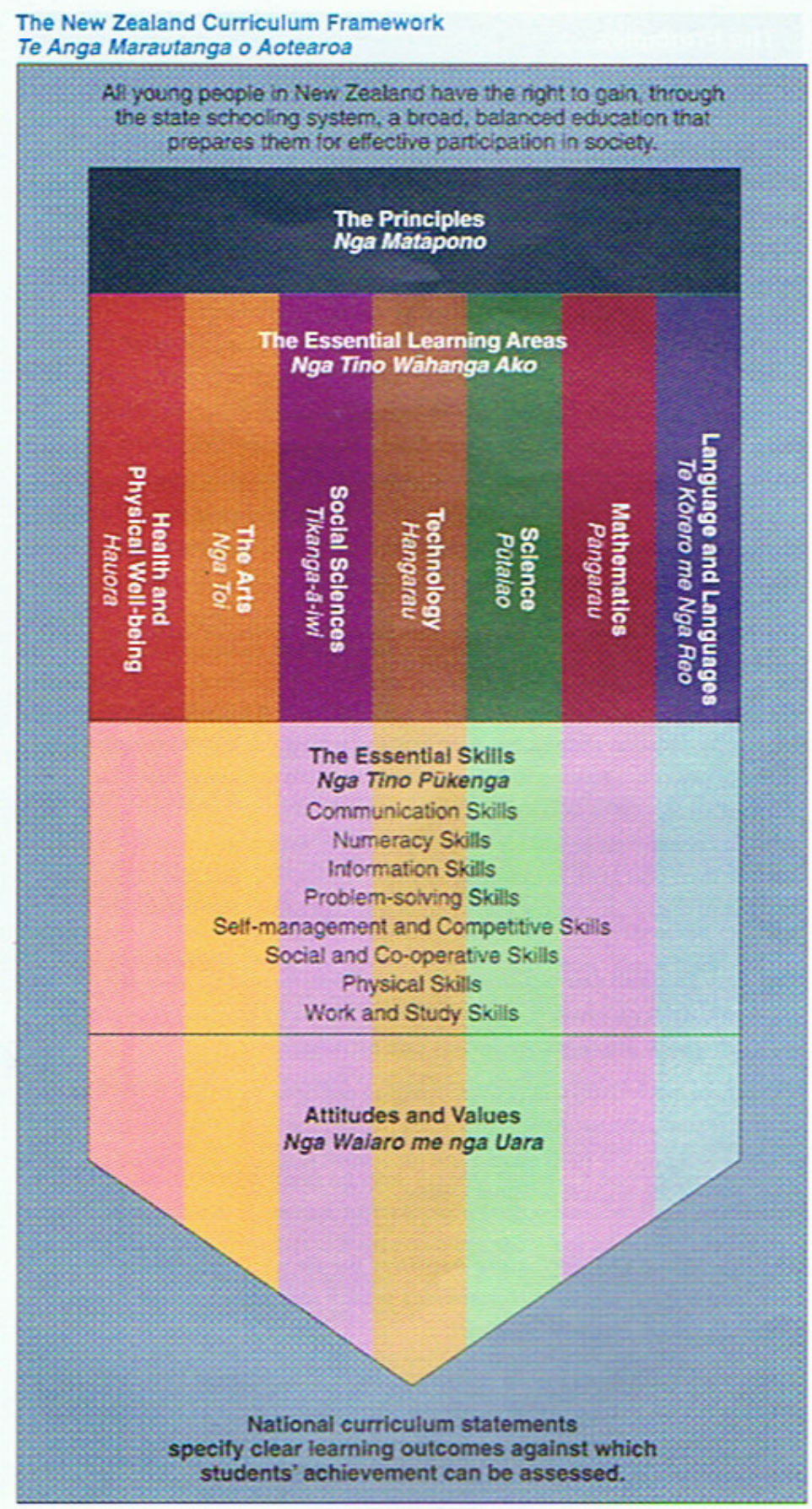

Source: Ministry of Education (1993a, p. 5).

While the New Zealand Curriculum Framework promotes the vision of a seamless curriculum, the existence of essential learning areas, the profusion of achievement 
objectives and essential skills, contribute to teachers' separation of subjects, levels and objectives in an attempt to manage the volume of information. The constraints on teaching imposed by the curriculum contribute to teachers having limited opportunities to do anything more than cover the subject areas (Carr et al, 2010).

\subsection{Mathematics in the New Zealand Curriculum and links to Te Whāriki}

The NZCF recognises the significance of the Treaty of Waitangi by stating that, "the school curriculum will recognise and value the unique position of Māori in New Zealand society. All students will have the opportunity to acquire some knowledge of Māori language and culture” (Ministry of Education, 1993a, p. 7). While this aim, of recognising and valuing the position of Māori in New Zealand, is not specifically stated in MiNZC (Ministry of Education, 1992), it does underpin it through the NZCF. ${ }^{11}$

No Māori writers were involved in the development and writing of the mathematics curriculum because a separate Māori mathematics curriculum was planned. The result of the separate curriculum was Pangarau te tauaki marautanga: He tauira. Wanganui a Tara (Pangarau) (Te Tahuhu o te Mātauranga, 1994), a translation of MiNZC. The English structure of the mathematics framework was translated into Māori rather than being based on Māori epistemology (McMurchy-Pilkington, 2004).

MiNZC outlined the general aims for mathematics education and the purpose of mathematics in society in addition to elaborating on mathematical outcomes at each level of the curriculum. The outcomes-based focus of MiNZC was based on mathematics curricula developed in England and Wales, a focus not supported by all mathematics educators in New Zealand (Neyland, 2004).

The 1990s in New Zealand was a period of educational change with the introduction of new curricula and the restructuring of schools. MiNZC was the first of seven curriculum documents introduced into schools during this time.

11 As with the NZCF, MiNZC is being phased out and replaced by the New Zealand Curriculum 2007. 
The Ministry of Education in New Zealand invited a group of mathematics educators to a meeting in 1991 to consider the development of the mathematics curriculum. The key feature of the mathematics curriculum was to define "learning aims and levels of achievement in mathematics" and "they should be similar in style to the statutory orders of the National Curriculum of England and Wales, and that they will define what students are expected to learn in schools" (Ministry of Education, 19/4/91).

The main approach to teaching mathematics was intended to be through a problem-solving approach where teachers were encouraged to present problems to their students within a realistic context. This would in turn support students to solve problems and make connections to their mathematical knowledge in ways that encouraged thinking as opposed to straight knowledge recall. The use of materials to support the development of new understandings was specified at all levels of the curriculum. Teachers were encouraged to build on what their students already knew in order to progress and extend children's learning. There was a specific reference to ensure teachers were aware of the existing knowledge of their students, "It is very important, however, that students do not have their mathematical development inhibited by, for example, repeating work which they have clearly mastered" (Ministry of Education, 1992, p. 19). Neyland (2004), the principal writer of MiNZC, claims that the mathematics curriculum was outcomes-based as a result of government direction, but his team of writers tried to mediate this by including a "mathematical processes strand". The inclusion of this strand helped to ensure the structured strands and levels were counterbalanced by the necessity of attending more to the "how" of mathematics as the mathematical processes strand underpins all the other strands. Neyland (2004, p. 154) claimed that the rate of change in curriculum development contributed to teachers spending more time doing what they perceived to be required of them (assessing against learning outcomes) and less time attending to the mathematical processes.

The ability to problem solve is a key feature of Te Whāriki, the NZCF, and MiNZC. The child as a learner is the focus. Children are encouraged to apply their concepts and skills in realistic contexts in order to develop their ability to think 
mathematically. Children build new knowledge by refining and building on their existing knowledge. Communicating, sharing, and recording their thinking allows children to make connections to other learning opportunities. These constructivist values link across early childhood and school curricula. Te Whāriki emphasises the social context that facilitates learning and the NZCF links school-based learning within the wider world outside the school. In Te Whāriki, children are recognised as competent and confident learners, developing strategies for effective learning, exploration, and thinking. The NZCF aims to give all children the opportunity to participate in a broad and balanced education that is designed to enable all children to achieve their potential and continue as lifelong learners. Both documents recognise the importance of developing positive and continuing dispositions for learning.

Commonalities exist in the underlying philosophies of the curricula for the early childhood and primary school communities. However, the objectives of the early childhood community, through Te Whāriki, present a holistic approach to education in contrast to the more outcomes-based NZCF and the mathematics curriculum. Haynes (2000) suggests that while early childhood teachers need to operate holistically, without specific subject content knowledge they are less able to extend the children's conceptual understandings. Research demonstrates that as teacher knowledge in mathematics increases so does their ability to allow student conversations to play a more important and directive role in the classroom and enhance student learning outcomes (Kuijpers, Houtveen \& Wubbels, 2010; Warren, 2009; Young-Loveridge, 1993). A focus on developing teacher capacity across both early childhood and the primary sector, not just supporting the acquisition of new mathematical skills and knowledge but creating more knowledge relating to content pedagogy and learners and the ability to make links to past, present and future learning will support better learning outcomes for children in mathematics (Hedges, 2002). The Education Review Office claimed that due to the tenuous links between Te Whāriki and the NZCF, early childhood teachers might be less able to recognise the essential skills when they are manifested in children (Education Review Office, 1998). Table 2.2 illustrates some of the links between Te Whāriki and MiNZC, which has the NZCF as its underlying framework. Increasing teacher knowledge and capacity can only help 
teachers' abilities to recognise mathematics knowledge in children and understanding the curriculum commonalities will support this.

Table 2.2: Commonalities in mathematics expectations in Mathematics in the New Zealand Curriculum and Te Whāriki: He whaariki mātauranga mō ngā mokopuna o Aotearoa - Early childhood curriculum

\begin{tabular}{|c|c|}
\hline $\begin{array}{l}\text { Mathematics in the New Zealand } \\
\text { Curriculum }{ }^{1}\end{array}$ & $\begin{array}{l}\text { Te Whāriki: He whaariki } \\
\text { mātauranga mō ngā mokopuna o } \\
\text { Aotearoa-Early childhood } \\
\text { curriculum }{ }^{2}\end{array}$ \\
\hline $\begin{array}{l}\text { Problem solving includes: } \\
\text { - devising and using problem- } \\
\text { solving strategies } \\
\text { - } \quad \text { posing questions for mathematical } \\
\text { exploration } \\
\text { - using equipment appropriately for } \\
\text { exploring mathematical ideas. }\end{array}$ & $\begin{array}{l}\text { Exploration includes: } \\
\text { - } \quad \text { initiating purposeful problem } \\
\text { solving } \\
\text { - } \quad \text { sustaining interest } \\
\text { - } \quad \text { developing reflective skills } \\
\text { - devising and solving own } \\
\text { problems using a variety of } \\
\text { materials. }\end{array}$ \\
\hline $\begin{array}{l}\text { Developing logic and reasoning } \\
\text { includes: } \\
\text { - interpreting information in context } \\
\text { - using words and symbols to } \\
\text { describe and continue patterns. }\end{array}$ & $\begin{array}{l}\text { Belonging includes: } \\
\text { - } \quad \text { having confidence and ability to } \\
\text { express their own ideas } \\
\text { - } \quad \text { having capacity to predict and } \\
\text { plan from patterns and regular } \\
\text { events } \\
\text { - enabling children to make their } \\
\text { own decisions and be self-reliant. }\end{array}$ \\
\hline $\begin{array}{l}\text { Communicating mathematical ideas } \\
\text { includes: } \\
\text { - devising and following a set of } \\
\text { instructions to carry out a } \\
\text { mathematical activity } \\
\text { - recording and talking about the } \\
\text { results of a mathematical activity. }\end{array}$ & $\begin{array}{l}\text { Contribution includes: } \\
\text { - enabling children to develop their } \\
\text { own interests and curiosity in } \\
\text { projects that require perseverance } \\
\text { and commitment } \\
\text { - developing increasingly complex } \\
\text { problem-solving skills. }\end{array}$ \\
\hline
\end{tabular}

Source: (1) Ministry of Education (1992, p. 24); (2) Ministry of Education (1996). 


\subsubsection{Required mathematics knowledge on school entry}

There are no references in MiNZC to the essential knowledge and skills in mathematics that five-year-olds should have mastered by the time they arrive at school. Teachers are expected to give children explicit opportunities to relate their new learning with the skills and experiences they already possess. Neyland (2006) stated that the writers:

did not assume that any child would arrive at school with any particular knowledge of mathematics. We assumed that children would arrive at school with a wide range of prior experiences, including having a rich experience of play and so on without any hint of formal educational knowledge. (Personal communication, 2/11/06)

This is supported in the level one progressions (MiNZC), which range from year 1 to about year 3 children (ages five to seven). The objectives are broad at each level and describe a progression of learning outcomes. On entry to school, children could be at any place on these progressions, depending on their prior knowledge and experiences, so it is clearly the responsibility of teachers to determine the existing knowledge of children in order to build from this.

This scheme explicitly recognises that each learner is an individual whose learning development and rate of progress is different from others ... It is not expected that all students of the same age will be achieving at the same level at the same time. (Ministry of Education, 1992, p. 17)

There are no specific entry requirements in the curriculum documents for children aged five when they begin formal schooling. There are clear indications that teachers need to recognise the knowledge that children already have when they begin their formal schooling and build and extend this knowledge.

\subsubsection{Links between the national curriculum guidelines and Te Whāriki}

The NZCF identifies the necessity for schools to link children's learning at school to their prior learning experiences (i.e., their experiences before school entry). It states that early primary school teaching must take into account the national curriculum guidelines for early childhood education in New Zealand (Ministry of Education, 1992, p. 3) along with requirements to respond to "each student's 
learning needs" (Ministry of Education, 1992, p. 6) to "link all learning experiences within the total school programme in a coherent and balanced way" and "build on student's previous learning experiences" (Ministry of Education, 1992, p. 7). The guidelines for early childhood education did not eventuate.

The revised curriculum, the New Zealand Curriculum (Ministry of Education, 2007b), continues to emphasise the connectedness of the curricula across the education sectors. It supports the view that the transition to school for a child is more likely to be successful when the school is able to build on the child's prior experiences and foster strong relationships with the family, teachers, and peers (p. 41). Each new stage in a child's education is connected to their prior stages, and this connectedness is emphasised at other transition points of the education system. This alignment of Te Whāriki, the New Zealand Curriculum (Ministry of Education, 2007b), and the tertiary system is illustrated in Figure 2.2.

Figure 2.2: Key competencies: Cross-sector alignment

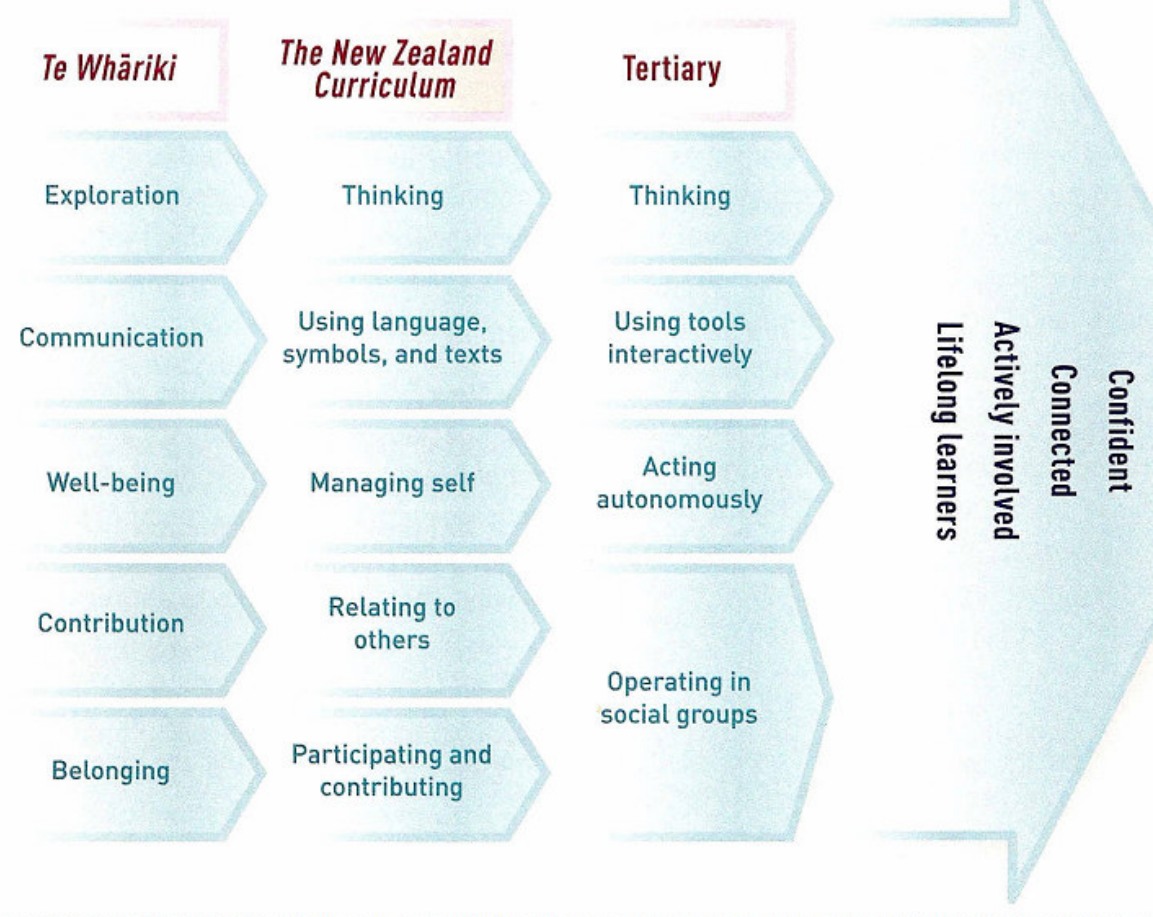

Source: Ministry of Education (2007b, p. 42). 
There are similarities and differences between Te Whāriki (the early childhood curriculum) and the NZCF. These are discussed below and are followed by an examination of the curriculum specifically related to mathematics education in New Zealand schools. These documents were developed in the late 1980s and 1990s, which heralded a period of reform in the education sector in New Zealand (Mutch, 2003).

Both documents were written within a similar time-frame but take dissimilar approaches. Mutch (2003) contended that this was due to the competing political forces of the time and their differing views on compulsory education. Historically, early childhood education has not been included in the curricula for schools in New Zealand, and it was not initially included in the vision for a seamless curriculum. While the school curriculum was influenced by government direction $^{12}$, the writers of the early childhood curriculum, primarily Margaret Carr and Helen May, had the opportunity to shape Te Whāriki according to the political and social goals articulated by the women's movement and the early childhood community (Mutch, 2003).

In Te Whāriki, the Māori title is predominant with equal size English and Māori subtitles. This sets the scene for an equal partnership in Te Whāriki between the two languages and cultures. In the NZCF, the Māori title is smaller and offside. While Māori language has a place in both documents, the NZCF has translated titles whereas Te Whāriki was written in Māori for people teaching in Māori settings (i.e., it is not a literal translation of the English), suggesting a more equal balance between both parties.

Te Whāriki is an integrated document, and the symbolism of the woven mat reinforces the holistic nature of the document. The woven nature of the mat is a reminder of the diverse nature of the early childhood field, within and between various centres, and this is further reinforced by the integration of the principles and the content strands. In contrast, the NZCF presents each essential learning area as a separate strand with its own colour, which in turn supports the discrete

\footnotetext{
${ }^{12}$ While the writers of MiNZC were directed to write a curriculum similar to the mathematics curriculum in England and Wales following a more outcomes-based approach, Neyland, the principal writer, claimed that his team were able to mediate this by including a mathematical processes strand. For more detail see section 2.5.
} 
nature of each area. The traditional subject-based structure was further linked through integration in the koru-like motif chosen. ${ }^{13}$ The MiNZC, the curriculum for one essential learning area, is supported and underpinned by the NZCF, in contrast to the more integrated nature of Te Whāriki.

Mutch (2003) closely examined the language used in the curriculum documents and framework and suggested that the language used in the NZCF and MiNZC reflected the government's policies of the time. Te Whāriki centred on the recognition of the importance of developing self-esteem and belonging, which were recognised as crucial factors for a person to take a place in society. This was a more liberal progressive view of education as opposed to the view outlined in the NZCF and mathematics curriculum.

Te Whāriki, the NZCF, and MiNZC represent different interpretations of curriculum, the latter two looking for accountability and the former recognising a more child-centred approach that is focused on the importance of the place of the child and their experiences. Te Whāriki takes a more constructivist approach whereas the NZCF and MiNZC look for the essential skills, learning areas, and competencies deemed necessary, a more outcomes-based view. The NZCF and MiNZC reinforce the separation of the learning areas and distinct curriculum documents that contributed to this separation. In primary schools this boundary is somewhat more blurred than in secondary schools, but it is still present.

Te Whāriki is not aligned with traditional subject classifications. Thus, the integrated nature of the early childhood curriculum suggests that the teachers at this level need to be more generalist in their knowledge and experience the curriculum with the aid of the children (i.e., construct it together). Assessment practices in the NZCF and MiNZC are clearly linked to achievement objectives and levels of progression; in Te Whāriki, assessment practices became more holistic through the subsequent introduction and use of learning stories.

The foreword to Te Whāriki acknowledges the diversity of the early childhood sector and the integrated nature of the resulting curriculum. It recognises the importance of these early relationships and experiences and their direct impact on children's future learning and development. The forewords to the NZCF and

${ }^{13}$ A koru pattern is a traditional Māori design based on an unfurling silver fern frond. 
MiNZC were written by the Secretary of Education, who promoted the need for the education system to meet the challenges faced by the competitive world economy by developing a highly skilled work force. Recognition of national directions for learning and assessment appear to take precedence over students' learning needs. They provide for consistency in classroom programmes for learning and assessment throughout New Zealand without detailing the supporting pedagogy. The MiNZC comes under the umbrella of the NZCF. In this way, primary teachers need to attend not only to the NZCF but to the curriculum documents that determine each essential learning area whereas teachers in the early childhood sector have the one integrated curriculum to guide their practice. There are differences between Te Whāriki and the early childhood sector on one hand and the NZCF and the primary sector on the other hand. These differences relate to different developmental contexts, expectations, and teaching styles. Learning disruptions may occur for children's learning when there is a limited continuity of learning experiences for children (Margetts, 2002). This does not suggest that experiences in early childhood education and primary school should be the same, but that links to support the continuity of learning should be strengthened (Avery \& Thomson, 2003). The limited understanding in the education sector relating to developing these links may be seen as an impediment to successful transition to school (Margetts, 1999; Wartman, 1997). A further factor is the different expectations each sector has of each other as well as differing expectations relating to children (Ledger, Smith \& Rich, 1998). A dilemma exists for teachers as to whether children should be prepared for school or whether school should be prepared for children. Many primary school teachers have a limited or lack of understanding of Te Whāriki (Horne, 1999), which has the potential to impact on plans to ensure continuity of learning experiences. Te Whāriki has a focus on developing positive dispositions whereas a school curriculum has a stronger emphasis on the development of knowledge and skills even though values and attitudes form an underlying aspect of the curriculum (Carr \& May, 1996).

Avery and Thomson (2003) found that while commonalities exist between both sectors through their respective curricula, both curricula need further 
development. They suggest that although frameworks are present to support continuity across the sectors these are not yet explicit enough. For example, in Te Whāriki, literacy and numeracy are incorporated into the exploration and communication strands, while in the primary school curriculum, literacy and numeracy are key outcomes, with an underlying focus on communication and exploration that may or may not be made explicit by teachers. In the past, the early childhood curriculum was seen as separate from the school curriculum in an attempt to prevent the reaching down of the school curriculum into early childhood education (Cullen, Foote, Jordan \& Marsich, 2002). This concern is seen to be less likely when both sectors develop stronger links, understandings, and more effective means of communicating with each other (Cullen et al., 2002).

\subsubsection{Comparing curriculum demands, scope, and purpose}

The national curriculum guidelines Te Whāriki (early childhood) and the NZCF (primary school) provide a means for a seamless education system. However, the very different styles of Te Whāriki and the NZCF may contribute to some of the problems teachers face in both settings and the discontinuities some children experience in the transition to school despite the links and commonalities between the curricula. These discontinuities relate to the different environments, assessment practices, teaching styles, and expectations of both children and teachers in mathematics learning. As previously mentioned, a problem occurs when, on the one hand, primary school teachers want children to have developed some social skills before they enter school, but also to have gained a baseline level of academic skills (May, in press). On the other hand, early childhood teachers believe their role is only to develop positive dispositions to learning (rather than specific skills) in children, which they believe conflicts with the expectations of primary school teachers (Carr et al., 2010; May, in press).

The lack of connection between teachers in primary schools and teachers in early childhood is exacerbated when they do not necessarily have an in-depth knowledge of each other's curriculum. The experience for children has instead been likened to a "metaphor of islands in an educational sea" (Hawk \& Hill, 2000, p. 2). Hawk and Hill traced the discontinuities that occurred for children as they progressed from one educational setting to another in terms of teacher training, 
buildings, pedagogy, and the variety of assessments that were carried out. Some suggestions were given to reduce the gaps between the "islands" by co-ordinating curricula, organising visits, and increasing the communication between the various stakeholders. Continuity between schools and early childhood could be improved by developing better connections not only between the curricula in both settings but between teachers as well (Margetts, 2002; Ministry of Education, 2005b).

Within the early childhood environment, teachers attempt to weave together the strands of Te Whāriki and follow the learning opportunities that arise from children's exploration of their environment. Usually, children are free to choose from a wide variety of activities supplied by teachers and are provided with opportunities for gross motor development. In contrast, in school, children have set periods in which to complete teacher-determined, -organised and -directed tasks, and the emphasis is on the acquisition of the three $\mathrm{Rs}^{14}$ along with a marked increase in 'dead' time (queuing, waiting, sitting quietly, etc.) (Renwick, 1987). Primary teachers do see advantages in children attending an early childhood centre because they feel it better prepares children for school, yet they criticise the freedom of choice given to children (Renwick, 1987). Primary teachers often believe that children in early childhood centres cannot concentrate on one thing for long (i.e., for longer than about 10 minutes), yet they believe concentration important for children so they do not shift from activity to activity unable to complete anything (Carr et al., 2010; May, in press; Peters, Hartley, Rogers, Smith \& Carr, 2009; Timperley et al., 2003; Renwick, 1987).

The use of partially shared curricula and common practices between primary and early childhood settings can create similarities between the two settings. Building on and extending from children's prior experiences by using children's learning stories from their early childhood centre as a starting point is a way of supporting children to feel 'at home' at school (Brostrom, 2005). Brostrom suggested it is not enough to create links through school visits, children need to have better developed understandings of what they have learnt in early childhood in order to better adapt to primary school, and this can be achieved through play. Links need

14 The three Rs are Reading, wRiting and aRithmetic. 
to be made by children and teachers to support the learning from one system forming the basis for the next. New entrant teachers can support more effective transitions when they develop more inclusive and flexible programmes that support continuity of programmes and expectations (Margetts, 2007).

The pressure on teachers to implement the goals of the curriculum in primary school may lessen their ability to utilise the information about children's learning that is obtained from early childhood settings (Cassidy, 2005). The implicit assumption is that children have to conform to the demands of school. Teachers do exhibit concern for the well-being of children yet this is overshadowed by the need to comply with the curriculum. All teachers interviewed by Cassidy wanted confirmation that children had the requisite social skills and could fit into the classroom (i.e., they could sit and attend to the teacher, follow instructions, hold a pencil, toilet independently, follow rules, and recognise their name). Most information about the child was gathered by the teacher observing the child rather than information passed on from early childhood. The primary teacher's focus was on getting the learning specified in the curriculum under way. Teachers concentrated on content and covering achievement objectives. To do this, children needed to possess the requisite social skills. The importance of establishing these social skills and behavioural expectations appears to over-ride more academic concerns (Burgon \& Thompson, 1997).

\subsubsection{The New Zealand Curriculum 2007 (Ministry of Education, 2007b)}

The revised version of the New Zealand Curriculum (Ministry of Education, 2007b) was released in 2007. The significant feature of this was the shift towards five broad competencies and a greater integration of primary school learning areas (May, in press). A more formal connection between the early childhood sector and the primary sector is evident in the positioning of the competencies alongside the 5 strands of the early childhood curriculum. Carr (2008) celebrates the emergence of the clear relationship between the two curriculum documents and the opportunity to link early childhood and new entrant programmes through learning journeys and pathways which are consistent with each other. The Centres of Innovation in New Zealand were beginning to explore and celebrate these links (Peters et al., 2009) and further support the continuity of learning across the 
transition from early childhood centres to school but funding for these has been subsequently cut.

While this study does not cover the educational changes with the introduction of the 2007 curriculum and the subsequent election of a National Government in 2008 , it is worth noting that national standards in reading, writing and mathematics were introduced very quickly. There is continued debate in New Zealand as to the impact these standards may have on education and teaching, including in the early years. Standards for levels and progression for schooling were used in teaching in the early twentieth century and were later discarded. Some comments on the possible implications of the reintroduction of standards may have on teaching and learning will be made in the final chapters of this study.

\subsection{Concluding comments}

Te Whāriki makes explicit links to the school curriculum. The NZCF states that teachers need to take into account the knowledge that children have when they start school and use this to build on. These requirements are indicative of the importance of fostering linkages between curricula in the interests of supporting smooth transitions between education sectors. Teachers are required to take note of children's existing knowledge and skills and to use them as a basis for their teaching and learning programmes.

Haynes (2000) reported that early childhood teachers who had knowledge of MiNZC were better able to take advantage of play activities that fostered mathematical learning than those who did not have this knowledge. These teachers believed their knowledge of Te Whāriki and MiNZC made them more confident in the provision of appropriate mathematical activities to support the development of positive mathematical dispositions among young children before school entry. In spite of this, Hawk and Hill (2000) believe many teachers in both early childhood and the primary sector lack knowledge about each other's curriculum, contributing to possible discontinuities in learning as children make the transition to primary school.

Te Whāriki portrays "a model of learning that weaves together intricate patterns of linked experience and meaning" (Ministry of Education, 1996, p. 4) rather than 
emphasising the acquisition of discrete skills. This is almost in direct contrast to MiNZC, which requires the acquisition of more discrete learning outcomes.

Te Whāriki is framed to support teachers to respond to the specific needs of the learner. Although the NZCF and MiNZC specify the need for teachers to build knowledge and strategies based on children's existing knowledge, this has become more formally focused in primary schools with an emphasis on curriculum specified outcomes and learning intentions.

The New Zealand Curriculum has signalled a closer alignment between early childhood and the primary school sectors, linking the key competencies from each (Ministry of Education, 2007b).

Connections between the curriculum documents link early childhood education to primary school. Although the school curricula are more outcomes-based than Te Whāriki is, the documents refer to teachers understanding where the child stands as a learner and the importance of developing the child from this point. This chapter outlined the nature of the curricula that govern teacher practices in New Zealand. It examined the links and commonalities between the early childhood and primary sectors through their curricula. The following chapter examines teacher beliefs and the factors that impact on these, particularly in relation to mathematics teaching and learning. How these beliefs influence the nature of teacher practice in the classroom is also discussed. Teachers' beliefs and practices about children's readiness for the transition to school are a focus of chapter 4 . 


\section{3: Mathematics teaching and learning: Theories relating to teacher beliefs and practices}

\subsection{Introduction}

A positive start to school is seen to be important to the long-term success of a child for their schooling and future life experiences (Dockett \& Perry, 2007). Children in New Zealand start school on or about their fifth birthday throughout the school year (schooling is compulsory from age six). The purpose of this chapter is to examine one aspect of starting school - the similarities and differences in the beliefs and practices of teachers of mathematics in kindergarten ${ }^{15}$ and new entrant classrooms. The previous chapter examined the curriculum documents that support teachers' practice. This chapter relates to the theories that underpin teacher practice in classroom with particular emphasis on how teachers' beliefs may affect their practices in classrooms and kindergartens.

The literature reviewed focused on the relationship between what teachers say they do (their beliefs) and what they do in the classroom (their practice).

Generally, teachers make decisions in classrooms not based on a particular theory, but based on a set of beliefs they have developed through their experiences, both formal and informal (Spodek, 1988; Stipek \& Byler, 1997). Teachers' beliefs affect how they organise for teaching, learning, and assessing as well as how they perceive children as learners (Aubrey, 1997; Aubrey et al., 2000; Barkatsas \& Malone, 2005; Beswick, Swabey \& Andrew, 2008; Cobb, Wood \& Yackel, 1990; Nisbet \& Warren, 2000; Pajares, 1992; Raths, 2001; Spodek, 1988).

It can be argued that mathematics teaching for young children may be more fully understood when the beliefs and practices of teachers are made explicit (Bell, 1990). Teaching may be seen as a practical discipline, "a consciously performed social practice that can only be understood by reference to the framework of thought in terms of which its' practitioners make sense of what they are doing" (Carr \& Kemmis, 1986, p. 113). Mathematics teaching is related to individual teachers' experiences of mathematics, how they have incorporated these into

${ }^{15}$ Kindergartens were chosen in this study from other early childhood education centres due to their closer historical relationship to primary schools in New Zealand. 
theories about how children learn and how they engage in mathematical activities aimed at maximising student achievement. What is not evident is the degree of influence of beliefs over practice and vice versa (Beswick, 2007). Classroom practices are based on some 'theory' relating to beliefs about the practice of teaching held by teachers to rationalise what they do.

Within educational settings, views on teaching mathematics are linked to beliefs about how children best learn. These beliefs range from a developmental stageby-stage view (children progress through various stages depending on their readiness for learning) to a more social constructivist view (children are competent problem solvers) (Department of Education, 2005; Kirova \& Bhargava, 2002). Views tend to be polarised between those who believe child-centred play is important and those who favour a more structured approach to early childhood education (Aubrey et al., 2000).

Beswick and her colleagues (2008) explored what they called 'attributes of powerful teaching' (p. 6) using classroom observation tools they developed, across a range of class levels. In most instances teacher practice focussed on procedural tasks as opposed to developing and extending mathematical thinking. The organisational aspects of teaching practice were prominent as teachers focussed primarily on managing learning and classroom activities. Teachers allocated limited time to have conversations with children and supporting children to make connections to prior and current learning. Classrooms in general were supportive environments but contained little evidence of attributes of powerful teaching characterised by connectedness and extending learning. These distinctions may not be clear cut in practice with teachers having the potential to hold more than one aspect of different theories to reflect their beliefs.

Teachers who hold a traditional view of mathematics learning and teaching are more likely to teach mathematics based on sets of rules and skills that are relatively independent of social constructs (i.e., a transmission model of teaching). In a predominantly traditionally based classroom, children's success is primarily based on accuracy in response to teacher questioning about prior information imparted by the teacher (Wood, 1995). Mathematics is seen as independent from social influences with the teacher positioned as the source of knowledge. 
A more constructivist perception of mathematics teaching and learning is based on the social nature of mathematics, a discipline that is actively involved in developing and expanding knowledge through social interactions and relationships (Cobb et al., 1990; Torner, 2002). Teachers holding a more constructivist perspective have the expectation that children can actively problem solve. Evidence of teachers' beliefs about mathematics teaching and learning may be evident through the observation of their classroom practice. Likewise, in practice, teachers may demonstrate a combination of beliefs from more than one theory about the teaching and learning of mathematics (Askew, 2001).

How teachers organise the environment to support the development of children's mathematical learning may be seen as indicative of the beliefs they hold about the effective learning and teaching of mathematics. Models of mathematics teaching and learning are discussed here because they contribute to the development of teacher practice in the classroom. The relationship between teachers' beliefs about mathematics learning and teaching and their classroom practice in early childhood and primary school is examined to see whether differences are evident. The categorisation of beliefs about teaching and learning is outlined as a way of exploring these beliefs in more depth.

\subsection{Beliefs and practices of teachers}

There are no consistently agreed definitions of 'beliefs' and 'practices' (Pajares, 1992).

In this study, the term 'beliefs' is used as in Beswick (2005) to refer to anything that the individual regards as being true. Beliefs can be inferred from the words and actions of an individual. The degree to which an individual supports their beliefs in different situations is presumed to be indicative of how strongly they hold those beliefs. These beliefs can be held with varying degrees of conviction (Thompson, 1992), and it is possible that individuals hold beliefs that they do not necessarily articulate or realise. In addition, these beliefs could be held on a surface level, as opposed to a deeper level, in which case they may not be incorporated into teacher practice (Raymond, 1997). An example of this would be when a teacher participates in professional development aimed at changing 
practice, and although they can discuss the influence of that professional development on their practice, they continue to teach in the way they have always taught.

The 'practice' of a teacher is held to be what they do in the classroom and how they demonstrate the art of teaching. Rivalland (2007) described this as "encompassing all observable aspects of professional practice" (p. 31). The differing beliefs teachers hold help to shape their teaching practice and style of teaching (Askew, 2001; Beswick et. al., 2009; Muir, 2008).

Beeby (1974) acknowledged the strength of teachers' beliefs and the difficulties they face in adapting these to accommodate new practices and educational theories when he wrote (p. 25):

The saddest lesson every official educational reformer has to learn is that teachers, under the pressure of instructions they have not understood or accepted, have an infinite capacity for going on doing the same things under another name, so that only the shadow of progress can be achieved by regulations and exhortation. The difficulty shows itself at its most acute when the reform that is being introduced is more than a mere change in methods of achieving old and accepted ends, and involves the introduction of new goals for teaching.

Whatever a teacher does (talking, planning, negotiating, etc.) is governed by their beliefs, thinking, and knowledge (McGee \& Penlington, 2001). The wide variety of roles within a teacher's job is characterised by immediacy and individuality, lending the roles to a constant process of interactions (Fang, 1996; Grossman, 1995). There is an assumption that teacher thinking and planning precedes teacher behaviour, but the open-ended aspects of teaching in combination with the immediate nature of the classroom and institutional constraints also impact on teacher practice in the classroom (Jaworski, 1999).

Another factor influencing practice is the curriculum. Teachers have a responsibility to teach mathematics in accordance with the curriculum. The early childhood curriculum in New Zealand, Te Whariki, is taken to be "the sum total of the experiences, activities and events, whether direct or indirect, which occur within an environment designed to foster children's learning and development" 
(Ministry of Education, 1996, p. 10). Within the early childhood context, it is everything that happens within that setting. Early childhood education in New Zealand occurs in many different settings with different philosophies. ${ }^{16}$ Kindergartens are one of the providers of early childhood education and the setting chosen for this study. ${ }^{17}$

\subsection{Theories of practice and development}

An objective for considering theories of practice and development is to be able to examine their contribution to teacher practices. How teachers perceive the readiness of children to learn assist us to understand classroom practice (Bell, 1990; McLachlan-Smith \& St George, 2000; Miller \& Smith, 2004). These theories influence how teachers arrange their environment and their practices to support children's learning.

Theories of practice are the theories teachers hold about children and their development and how to cater for these (Genishi, 1992). A teacher's perceptions and knowledge of child development influence the nature of the environment teachers provide to support children's learning. Practices that support the development of learning become part of good teaching practice and reinforce teacher beliefs about child development.

Theories of development tend to be more descriptive and do not offer specific ways to enhance children's development through appropriate strategies or learning environments. Underpinning these theories are the implicit beliefs about teaching and learning that teachers hold, resulting from their personal knowledge, experiences, and educational concepts (Bell, 1990; Beswick, 2005; Foote et al., 2004). Teachers with similar training and experiences with different implicit theories may well exhibit commonalities in their practices as a result of their participation in a common community (e.g., the school or kindergarten community with its own sets of shared beliefs).

16 Early childhood education providers include kindergartens, childcare centres, playcentres, kōhanga reo, Samoan language nests, and day-care centres.

17 For more detail about this selection, see chapter 5. 
This difficulty in separating the influence of differing theories and commonalities of practice contributes to an inter-relationship of beliefs and practices in mathematics teaching.

A New Zealand study of 12 kindergarten teachers by McLachlan-Smith and St George (2000) found that teachers primarily had very similar, predominantly constructivist, theories of practice. Whilst teachers in their study felt children's learning experiences before they started school were critical, they also believed that children did not learn until they were 'ready', a notion put forward by Jean Piaget (Cannella, 2005). Embedded in this perception was the view that children are active learners who learn through their interactions with the environment when they are ready. In addition to this, kindergarten teachers believed they should directly teach some basic skills to children where they felt a child lacked knowledge and understanding through not being 'ready'. Teachers felt it was appropriate, for example, to specifically teach literacy skills to children they perceived as having few literacy experiences at home.

In general, teachers were more concerned with their own interpretation of their practice and beliefs and had a tendency not to attribute these to any particular theory (Genishi, 1992). In some cases their beliefs about readiness to learn may in fact reduce children's opportunities to learn (Graue \& Marsh, 1996). For example, if a teacher holds the belief that many five-year-old children enter school unable to write their names and count to 10 , they will spend time focusing on filling this perceived gap in learning as opposed to building learning from children's existing knowledge and skills. It appears that teachers may hold both developmental and practice theories at the same time and apply these according to their perceptions arising from individual situations as they see fit.

Bell (1990) describes these theories of practice about how teachers operate in the classroom as operational theories that teachers develop and hold to account for their practice. Again, teachers in Bell's study held similar views to each other. There was a difference, however, between what they said they did (their beliefs) and what they actually did in the classroom (their practice). The early childhood teachers in Bell's study spent a significant proportion of their time managing children and focusing on their social development, including giving specific 
directions relating to children conforming to social norms. Teachers had specific goals for children relating to school learning, yet Bell believed that these arose from teachers' own school experiences and their interpretation of these in relation to the expectations of the primary school. These teachers in general held a noninterventionist approach to learning with the exception of the specific social behaviours they deemed significant.

In general, teachers' operational theories were consistent, that is, their accounts of their beliefs matched their practice, and Bell (1990) had several explanations for disparities when they arose. First, teachers might be reporting what they believe the questioner wants to hear. Secondly, teachers might be repeating a statement of someone else's beliefs (e.g., beliefs outlined in a curriculum document). Thirdly, it could be that teachers' genuine beliefs are over-ridden by other beliefs leading to inconsistencies.

Bell (1990) found that the formal knowledge of teachers acquired through their involvement in academic learning, if not incorporated into actual practice, can remain at a superficial level. If teacher education programmes do not support preservice teachers to engage with their beliefs, challenge their beliefs, and reflect on their practice, some teachers will continue to view teaching as a process of conforming to prescribed rules as opposed to reflecting on and developing their on-going practice.

Common sense or intuitive knowledge arising from personal experiences is seen to be a stronger influence on teacher practices than more formal sources of knowledge (Cassidy \& Lawrence, 2000). In some cases, the formal knowledge held by teachers may be inconsistent with their personal or implicit beliefs. Beliefs embedded in personal experiences may not always lead to best practice because without theory and research to back up personal theories teachers may fall back on expedience rather than relying on a theory that might require more reflection in action (Cassidy \& Lawrence, 2000). An over-reliance on these personal and implicit theories may lead to more scripted actions in the classroom, with teachers following a predetermined plan instead of following a course that results from their reflections on learning and teaching to enhance student achievement. 
A gap between the practice of teaching and beliefs about best practice may be indicative of possible educational problems (Carr \& Kemmis, 1986).

\subsection{Categorisation of beliefs}

In mathematics teaching and learning (as in literacy learning) teachers need to go beyond thinking about mathematics in terms of skill acquisition and see it more broadly as a social practice. This in turn necessitates the importance of providing a wide range of authentic and meaningful mathematical experiences. Teachers need to understand this alongside developing the pedagogical knowledge that supports this development (Foote et al., 2004).

The following three studies relate more specifically to literacy beliefs in early childhood, but have been included here as they provide general themes relating to the categorisation of beliefs that have been adapted for use in this study (Foote et al., 2004; McLachlan-Smith \& St George, 2000; Miller \& Smith, 2004). The important issue lies in the descriptions provided by teachers of literacy events and how these events were carried out in early childhood centres.

Foote et al. (2004) examined the beliefs and practices of teachers in four early childhood centres. These teachers had similar beliefs about the importance of literacy learning and the provision of meaningful and purposeful experiences within a play-based programme. In practice, these teachers delivered a formal skills-based programme, yet when the children were left alone, they created for themselves rich, authentic literacy events. Similar discrepancies between beliefs and practices were found in mathematical teaching and learning (YoungLoveridge et al., 1995) despite the more constructivist beliefs of teachers, their practice had a tendency to be more transmission oriented.

McLachlan-Smith and St George (2000) and Miller and Smith (2004) used the results of their separate work in early childhood literacy to develop categorisations to support a more in-depth examination of teachers' beliefs. These categorisations are listed below and are adapted in chapter 5 to provide general themes for semistructured interviews to explore teaching and learning practices in mathematics teaching and learning. The categorisations relate to teachers' perceptions about 
literacy learning in general, their beliefs about the curriculum, and how they believe children best develop into literate individuals. The five categories are:

- $\quad$ practitioner training and experience

- $\quad$ information about the setting

- $\quad$ knowledge about the curriculum

- $\quad$ perceptions of their role

- general beliefs about literacy learning and teaching.

The teachers in these studies described a 'theory of practice' (Genishi, 1992) with significant degrees of similarity of beliefs between each teacher despite differing levels of experience.

To change teachers' beliefs and practices, Timperley and Robinson (2001) proposed three conditions they felt were essential components of teacher professional development: exposing discrepancies in achievement data, using an external (neutral) facilitator to support the data collection and analysis, and providing teachers with alternative models of good practice. Timperley and Robinson's study was of four low decile ${ }^{18}$ schools in New Zealand. Their study found it was possible to change deficit views about the low entry-level skills of five-year-olds by presenting teachers with contradictory evidence about children's actual skills. Shifting teacher beliefs from a predominantly deficit view and addressing these discrepancies in beliefs will support the development of more positive achievement outcomes for children (Carr et al., 2000). Professional development programmes that focus on shifting teacher beliefs and expectations have resulted in improvements in children's achievement and the expectations of children held by teachers (Timperley \& Robinson, 2001).

Ethell (1998) suggested that knowledge is less influential than beliefs in deciding what and how to teach and that a strong correlation exists between beliefs and their translation into practice. The beliefs teachers have about how young children learn have a direct influence on the kinds of experiences teachers provide for children, and their knowledge of how children learn appears to be less critical.

18 The decile ranking of a school in New Zealand relates to the socioeconomic status of the area in which the school s located, with a ranking of 10 relating to the highest socioeconomic status and 1 the lowest. 
The implication is that teachers' pedagogical beliefs have the potential to influence the kinds of experiences they provide for children. There was a general lack of consistency between what teachers said they believed in and the experiences they planned for children (i.e., what they did) (Ethell, 1998; Foote et al., 2004; O'Neill, 2004; Stipek \& Byler, 1997). Research into professional development that focuses on changing teacher practice suggests some teachers have the tendency to adopt only the aspects that suit their existing practice rather than to make significant changes to their teaching practice (Muir, 2008).

However, when increased student achievement is demonstrated and/or teachers have the opportunity to implement new strategies in the context of their classroom, they are more likely to change their beliefs relating to teaching (Guskey, 1986; Muir, 2008). What teachers 'know' about appropriate literacy and numeracy does not always translate into practice (Foote et al., 2004). O'Neill supports this view and suggests that (O’Neill, 2004, p. 27):

Teachers also have power unknown to other professions, the power to close the door and do what they like regardless of change, need to consider the autonomy of teachers in this respect "structures, frameworks, regulations, assessments and evaluations" all contribute towards determining what a teacher does.

\subsection{Teacher belief systems}

Teachers develop their own personal meanings by being engaged in social practices. The role of a teacher is seen to be as both a constructor and an implementer of a curriculum in that, "The practice of teaching includes a mission and programme, guided by values and goals, forms of social interaction and communication in an institutional setting" (van Huizen et al., 2005, p. 282). Teachers are engaged in a reciprocal relationship shaped both by themselves and their participation in sociocultural practices. This view, characteristic of a Vygotskian perspective ${ }^{19}$, links individuals' functioning and development with the sociocultural practices in which they participate (van Huizen et al., 2005).

\footnotetext{
${ }^{19}$ Lev Vygotsky, a Russian psychologist, focussed on the connections between people and the sociocultural context within which they interact. His work is seen as one of the foundations of constructivism.
} 
Teachers' beliefs develop through their participation in society and are based on social values and goals. These beliefs are both shaped by and inform classroom practice and vice versa. To more fully understand the practice of teaching, consideration needs to be given to how teachers' personal beliefs about mathematics teaching and learning influence their classroom practice and how practising the art of teaching influences their beliefs.

The degree of the inter-relationship between teachers' beliefs and practices is the subject of much research (Handal \& Herrington, 2003; Nisbet \& Warren, 2000; Pajares, 1992; Raymond, 1997). Many teachers' personal theories have been built from their own experiences at school, their memories and images of what it was like for them when they learned mathematics, which in turn provide a filter for their new experiences and knowledge about the teaching of mathematics (Spodek, 1988). For example, if a teacher holds a set of beliefs relating to the necessary skills for five-year-olds on their entry to school, their perception of the child's ability is coloured by these beliefs. Should a child be lacking in any of these 'necessary' skills (in the teacher's opinion), that is what the teacher will focus on teaching as opposed to following the orientation of the curriculum, which emphasises the importance of building on children's existing knowledge and skills. These deficit assumptions about children's existing knowledge are generally associated with lower expectations for children's achievement and are more prevalent in low income areas that are often associated with a greater diversity of cultural backgrounds than those of teachers (Mitchell \& Cubey, 2003). Appropriate professional development is shown to challenge and change some of these beliefs (Mitchell \& Cubey, 2003; Young-Loveridge, 1991). Timperley and Robinson (2001) label some of these firmly held beliefs of teachers that are treated as accepted wisdom as "sayings" (p. 282), which in turn have an effect on teacher practice. In many instances, teachers' existing personal beliefs may over-ride beliefs gained from more formal sources. It can be difficult to determine the degree of influence of personal and theoretical belief systems and their impact on teacher practice and vice versa. The beliefs that teachers hold from their own early experiences in the classroom are held to be the most difficult to change and much teacher practice continues to be filtered through these beliefs 
(Atkin, 1996; Ernest, 1989; Handal \& Herrington, 2003; Raymond, 1997) in spite of professional development that may contradict these beliefs. Beliefs originating from one's experiences of mathematics are held to be more influential on classroom practice than beliefs that originate from external sources (Raymond, 1997).

The above-mentioned studies confirm the importance of incorporating teachers' experiences of mathematics as a crucial variable in determining teacher beliefs about mathematics teaching and learning.

Kennedy (1997 cited in Raths, 2001) claimed that these beliefs, developed from teachers' school experiences, play a significant role in teacher practice. Theories of practice and teaching beliefs that challenge these personal beliefs - "sayings" can frequently be dismissed as unworkable or too theoretical. Katz and Raths (1985) suggest it is difficult to change these deeply ingrained beliefs. Therefore, it is more constructive and useful to look at strengthening teacher dispositions, which in turn are more likely to lead to changes in teaching practice.

Teacher dispositions are the values, commitments, and professional ethics that influence how a teacher relates to students and the wider learning community. These dispositions are guided by attitudes about values such as beliefs about social justice and a commitment to providing a safe environment to support children's learning (Usher et al., 2003). Dispositions include looking at how teachers meet children's needs, how teachers clarify a child's needs rather than judging them, and not solely rewarding final success but valuing the successes along the way. Carr (2001) describes dispositions for learning as being ready, willing, and able to learn, which could equally well describe dispositions for teaching - being ready, willing, and able to recognise and support learners as they look for and develop opportunities to participate in learning. By using dispositions, which by their nature are more closely related to practice and more easily modelled and observed, it may be possible to change a teacher's ingrained beliefs relating to mathematics learning. If change focuses on strengthening teacher dispositions rather than on changing specific teacher beliefs, the issues around ingrained beliefs may be less critical (Raths, 2001). 
Raymond (1997) proposed a model of teaching and learning that attempted to determine the relationships between beliefs and practices that influenced teachers in the classroom. Raymond found that social teaching norms (such as perceptions related to problem solving) and their interaction with the constraints of the classroom (time, class size, regulations, etc) had the largest influence on the consistency (or lack of) between teachers' beliefs and their practices. One teacher thought that "believing in good mathematics teaching practices was a way of practicing good mathematics teaching" (Raymond, 1997, p. 569). In this way, formal (theoretical) understandings about good mathematical practices can remain on a surface level and may not necessarily be fully incorporated into practice. A further influence on classroom practice found in Raymond's (1997) study was an overall concern held by teachers for good classroom management practices, which in turn affected their classroom practice.

Likewise, Anderson et al. (2005), exploring teacher beliefs and practices in relation to problem solving, confirmed the importance of incorporating teachers' experiences of mathematics into their practice as an important variable in determining teacher beliefs. Anderson et al.'s model envisaged a cyclic path relating to the factors that influence teachers' beliefs and practices. This model allowed for the variable nature of teaching and the constant shifting of plans to accommodate student responses. However, Anderson et al. stated that any model is "merely a generalisation of a complex situation and is used to provide an illustrative guide to aid research into teachers' beliefs and practices" (p. 35). Handal and Herrington (2003) emphasised the importance of teachers' personal theories and their influence on classroom practice while Aitkin (1996) proposed a model with personal core values and beliefs as a central focus with other principles emanating from these.

From work carried out in Australia by Perry and his colleagues (Howard, Perry \& Lindsay, 1997; Perry, Howard \& Conroy, 1996; Perry et al., 1999), a further model was developed to describe teacher beliefs in mathematics. This model of Perry and his colleagues comprised two dominant perceptions of teaching - a transmission view and a child-centred view - each of which explored the nature of the beliefs that shape teacher practice. Teacher practice incorporated elements of 
each factor, relating to their confidence and knowledge of the subject matter. Teachers with lower levels of subject content knowledge tended to favour a predominantly transmission style of teaching. Lifting teachers' content knowledge positively affected their teaching style and children's achievement levels (YoungLoveridge, 1993).

A common characteristic of these models (Atkin, 1996; Anderson, White \& Sullivan, 2005; Handal \& Herrington, 2003; Perry et al., 1996; Perry et al., 1999; Raymond, 1997) is the complexity of the relationships between beliefs and practices. This makes it challenging to determine the degree of influence that beliefs have on practice and vice versa. A teacher's beliefs are held to play a significant part in how teachers organise the environment for learning (Barkatsas \& Malone, 2005).

The next section outlines approaches to teaching mathematics in the early years to develop the relationship existing between teacher beliefs and practices in mathematics teaching and learning.

\subsection{Approaches to teaching and learning of mathematics}

The commonly accepted international definition of 'early childhood' is the period of a child's life from birth to eight years (Dahlberg et al., 1999; Perry, 2000), but it is evident that a distinction exists between education before school entry and education after school entry in relation to teachers' beliefs and practices in mathematics teaching and learning. In New Zealand, this distinction occurs as children move from an early childhood setting to school (usually around age five). The years before school entry are recognised as an important period in a child's life where they begin to develop positive dispositions towards learning rather than being regarded as preparation for school (Carr, 1998, 2006; Dahlberg et al., 1999; Perry, 2000). This section explores some of the current features of beliefs and practices of teachers within early childhood settings relating to mathematics teaching and learning.

Mathematics education in early childhood is becoming increasingly highlighted in the literature as educators recognise the extent of mathematical knowledge that children possess on school entry (Lee \& Ginsberg, 2007; Young-Loveridge et al., 
1995). Programmes for early childhood education are based on beliefs about society, knowledge, the process of learning, and the relationship between theory and education (Webber, 1984). Theories about learning can be explicit or implicit. However, a shift in perspective to viewing problem solving as a critical aspect of young children's mathematical development has lead to a change in how teachers regard their role (Dahlberg et al., 1999; Department of Education, 2005). This shift is evident in the change of focus of early childhood education from a developmental, readiness perspective to the more constructivist perspective espoused in Te Whāriki.

A developmental approach takes the view that children should be left to explore mathematical ideas on their own in ways that make sense to them. In this view, the adult role is that of providing children with the necessary resources and allowing children to explore them. Alongside this is the view that children have a tendency to repeat activities with which they are familiar. In this case children who are more proficient at mathematics will continue to outperform those who are not so proficient as they gain more practice with the activities (Young-Loveridge et al., 1995). A more sociocultural approach has developed with the increasing awareness among teachers of the social and cultural aspects of children's learning. Teachers have recognised the importance of participating in and supporting the extension of children's learning. The curriculum for early childhood in New Zealand, Te Whāriki, challenged teachers in the early childhood sector to ensure they provide opportunities and support for children to develop and extend their mathematical competencies (as in all other areas).

A lack of specific mathematical content knowledge among some early childhood teachers has meant they are unable to effectively recognise mathematics events as they occur in children's play (Young-Loveridge, 1993). When children engage in mathematically related play (such as building structures, positional language development, and ordering activities) some teachers have limited knowledge of the mathematics involved and are unable to identify the developing mathematical understandings. Teachers need to be able to use appropriate mathematical language to support children as they build their existing knowledge from these understandings. The teacher's role becomes one of a facilitator of children's 
learning rather than waiting until children are ready to make the next step, as in a more developmental model of learning. As with literacy learning, teachers should understand not only the mathematical concepts but how their pedagogy contributes to this development in children. Young-Loveridge (1993) found that given appropriate professional development, the ability of teachers to support and develop children's mathematical understanding and achievement was enhanced. When teachers believe children learn mathematics through their own interactions with activities, the teacher's role is seen as more of an observer and supervisor. Equipment and activities are displayed for children to learn and play with while the teacher observes. Bell (1990) found that the teachers who described children as "learning through activity" (p. ii) had a generally non-interventionist approach to teaching and learning. Bell claimed that educational practice is only fully comprehensible in the light of how teachers make meaning, in other words, you need to understand teacher beliefs in order to begin to understand practice and these form a mutual relationship. Bell found discrepancies between what teachers in early childhood education said they believed in and what they did in practice. Teachers in Bell's study held constructivist views about how children best learned, yet in practice they held the belief that children will not learn until they are ready, so teachers should wait until children demonstrated this readiness before teachers intervene. A further factor was the contradictory belief among a few teachers that in some circumstances children should be specifically taught missing skills (as perceived by teachers) to enhance their readiness. This belief conflicted with the perception that children learn through play. Children in early childhood already have mastery over a wide variety of mathematical competencies. If these competencies are not adequately fostered, children may not realise their potential at school. Lee and Ginsburg's (2007) study of a group of early childhood teachers in America supported the belief that children need a certain degree of direct mathematical instruction in order to master basic mathematical knowledge. This perception follows current educational trends in the United States, a perception not necessarily prevalent within New Zealand. In 
addition to this, was the perception that pre-kindergarten ${ }^{20}$ teachers should ensure mathematics occurred in a fun-learning environment.

Interpretations of Piaget's work position the child as a learner and a thinker and explore the processes behind how a child reaches understanding and comes to a new set of beliefs relating to the intellectual development of a child from birth to maturity (Webber, 1984). Children take the role of initiators and, as a result of active interaction with the environment and the building of new models, they develop a new set of skills. The theory Piaget put forward was based on children making sense of the world around and relies on learning through play. Confrey's (1999) interpretation of Piaget's work described children as developing individuals and their progression was understood in relationship to their developmental pathway.

The Piagetian view is generally regarded as a developmental model of how children learn. Children pass through stages on the way to becoming abstract thinkers, generally according to their age, although this is now disputed (Yelland, 2005). Learning occurs as a result of children's interactions with materials and experiences. Curriculum models based on stage-by-stage development have evolved from Piaget's theory regarding the developmental acquisition of a set of learning skills that are a prerequisite for the next stage (Walsh, 2005). This perspective of stage-by-stage learning can lead to the perception that when a child is 'ready' they will move on to the next level. Similarly, when the child has not yet mastered all that is required for their present level, they need to remain there until they have mastery (Yelland \& Kilderry, 2005). If an early childhood curriculum follows a developmental perspective (looking always for readiness for the next step) and the content of the curriculum describes experiences suitable for children at different stages, this will impact on the kind of teaching that is delivered. Yelland and Kilderry did not question the value of Piaget's ideas but rather their dominance over early childhood curricula.

In contrast to this primarily developmental perspective of children's learning, is a more constructivist view of learning. Children are seen as actively engaging with

20 In this study, pre-kindergarten equates with a New Zealand kindergarten or early childhood centre. The term 'kindergarten' in the United States refers to the setting for children in their first year of formal schooling, which in New Zealand is the new entrant or year 1 class. 
the world around them, which leads to teachers supporting learning as it evolves. To do this effectively teachers first need to recognise the learning, and secondly they need to be able to support and extend this learning without taking over. In mathematics, this means teachers can identify the mathematics learning and understand how to extend this through the child's interests. To facilitate these understandings teachers need good levels of personal mathematical content knowledge to enable them to identify and support children's mathematical development. Direct formal instruction of numeracy skills at an early age does not necessarily help children to make a good start at school (Aubrey et al., 2000; Education Review Office, 2000).

Within the primary school system two main approaches dominate the style of teaching and learning of mathematics despite more detailed frameworks proposed by Askew, Brown, Rhodes, Wiliam and Johnson (1997), Ernest (1989), and Nisbet and Warren (2000), to name a few. A common aspect of these models of teaching and learning is the more traditional approach to teaching mathematics on one side and a constructivist, problem-solving approach on the other side.

A more traditional approach to teaching mathematics is based on the belief that children's success is based on how they are able to successfully answer questions relating to knowledge previously imparted by their teacher (Wood, 1995). A constructivist approach to mathematics teaching and learning involves both teacher and children building knowledge together by actively developing and expanding knowledge through social interactions (Cobb et al., 1990). For example, if the learning intention of a mathematics lesson is "to order whole numbers and decimals" (Ministry of Education, 2004, p. 17), a teacher with a more traditional view of teaching might give children a rule to follow with practice examples. However, a teacher with a more constructivist approach might provide children with appropriate equipment, several numbers, a problem, and ask children to work out relative number sizes co-operatively.

The model of teaching and learning proposed by Ernest (1989) incorporated aspects of teaching and learning alongside teachers' knowledge, beliefs, and attitudes towards mathematics into six categories. These categories were ranked from 1 to 6 with 1 being the most developed teaching pedagogy in Ernest's 
opinion. This model is a framework within which teachers' beliefs and practices relating to mathematics pedagogy can be positioned. Teachers may have elements of more than one level of descriptor combined in their teaching style, frequently dependent on the learning intentions of each lesson. The levels are:

- $\quad$ investigative problem solving

- conceptual understanding enriched with the problem solving model

- conceptual understanding model

- mastery of skills and facts with conceptual understanding model

- mastery of skills and facts

- day-to-day survival.

Similarly, Askew et al. (1997) classified teacher styles based on teachers' beliefs relating to how children become numerate students. They identified three dominant teaching orientations adopted by teachers based on their beliefs about mathematics teaching and learning: connectionist, transmission, and discovery. Connectionist teachers focus on encouraging students to establish connections in mathematics and emphasise the importance of teaching strategies and valuing children's methods. Teachers with a transmission orientation tend to believe in mathematics teaching as a matter of conveying sets of rules and procedures. Teachers with a discovery orientation believe students will discover methods of problem solving (Askew et. al., 1997). No teacher fits exactly within one framework; they are more likely to have a combination of orientations. However based on Askew et al. (1997), teachers that have a strong connectionist orientation were found to be more likely to have students who made greater gains in their mathematical achievement than those students whose teachers with a strong transmission or discovery orientation. Askew et al.'s analysis of teacher beliefs showed that some teachers were predisposed to fit more strongly with one orientation over others. A strong belief in connectionist teaching practices did not necessarily mean a teacher followed this in their practice; they could well practise a more transmission style in their teaching. 
In Australia, Nisbet and Warren (2000) examined the six levels of teacher practice described by Ernest (1989) and reclassified them into three broader categories of teacher practice in a similar way to Askew et al. (1997). The three categories are:

- transmission and constructivist

- $\quad$ static and mechanistic

- dynamic problem solving or connectionist.

Nisbet and Warren (2000) found that most teachers in their study fitted into the first two categories of teaching with no significant entries in the third category. The traditional view of mathematics teaching (static and mechanistic) generally focused on timed tests, with few hands-on experiences and limited relevance to social contexts. The more recent view of mathematics (transmission and constructivist) was characterised by rich hands-on experiences, with students able to explain their thinking and explore problems. A major concern in this category was the lack of open-ended problem solving with teachers continuing to favour one right answer. Although many teachers espouse a more constructivist approach to mathematics teaching, their view of mathematics learning seems to be underpinned by the belief that they still lead the learning. The classification of teacher beliefs about mathematics teaching and learning into the first two categories above with very few teachers in the third problem-driven, open-ended and connectionist view of mathematics learning was similarly reported in other studies (Askew et al., 1997; Perry et al., 1999).

There may be many mathematics classrooms where the teacher's predominant belief is that learning mathematics is about mastery over a set body of knowledge. However, perspectives are slowly changing from this traditional view to one where teachers are involved with the development of collaborative learning and active problem-solving skills (Goos et al., 1999). This more constructivist, sociocultural orientation to mathematics learning and teaching promotes a style of teaching that favours learning and develops and promotes a community of learners, a group of individuals who work together to develop mathematics learning. It may be possible to make inferences relating to teachers' beliefs from the classroom environment that reflect the enactment of these beliefs in practice 
(Goos et al., 1999), but care needs to be taken to ensure other influences (such as the curriculum, the institution, and classroom constraints) are also considered. Teachers hold similar core beliefs about how children best learn mathematics. Goos et al. (1999, p. 51) summarise these beliefs as follows.

- Students learn mathematics by making sense of it for themselves.

- Teachers should model mathematical thinking and encourage students to make and evaluate conjectures.

- Communication between students should be encouraged so they can learn from each other, sharpen their understanding, and practise using the specialist language of mathematics.

In most instances, teachers want children to be able to work problems out for themselves. Recognising the importance of allowing students to develop their knowledge and incrementally adjust their models of mathematics as they progress through school is crucial as this provides opportunities for students to make sense of their learning (Goos, Galbraith \& Renshaw, 1999; Jaworski, 1999). The dilemma arises when these core beliefs contrast with classroom practices, which is not an uncommon feature of research into beliefs and practices (Cobb, 1988; Frid, 2000; Goos et al., 1999; Jaworski, 1999).

Developing an understanding of how teachers' knowledge, beliefs, and attitudes influence their classroom practice leads to greater understanding of the teaching process (Beswick et. al., 2009; Ernest, 1989). Teachers' mental models of teaching mathematics have a direct impact on their classroom practice. Ernest found a disparity between what teachers said they believed in and what they did in practice, which is a difference between their espoused views and their enacted views. For example, a teacher's knowledge of mathematics learning theories has a bearing on their beliefs about mathematics, which in turn provides a framework for their teaching of mathematics. According to Ernest, if a teacher holds an instrumental view of mathematics learning they are more likely to follow a transmission model of teaching with strict adherence to a text or to a programme with an emphasis on mastery of skills. If a teacher holds the view that mathematics learning is a problem-solving process, they are more likely to see themselves as a facilitator of learning and support the children as active 
constructors of mathematical understandings. In this case the teacher is a participant in the child's learning as they support the development of children's emerging ideas and strategies (Wood, 1995). The teacher is viewed as primarily responsible for the shape of the curriculum in practice, which emphasises the importance of looking at the relationship between beliefs and how they are perceived and enacted (their practice).

\subsection{Contradiction between beliefs and practices}

Tension exists between the view that the goal of mathematics instruction is to transmit and the view that students construct mathematical knowledge by reorganising their mathematical cognitive structures. This tension may lead to a dilemma for teachers as what they say they do and what they do in the classroom may not be consistent. Successful instruction is more than students being able to correctly interpret the information transmitted by the teacher but also involves teachers and students able to explain how the knowledge was actively constructed (Cobb et al., 1990). The challenge with social constructivist theory is effecting a balance between teacher input and student construction, between the transmission of knowledge by teachers and the active construction of knowledge by students. Teachers may simultaneously hold constructivist and transmission views, which may further blur the distinction between beliefs and practices. According to some theorists (Frid, 2000; Nisbet \& Warren, 2000) a transmission approach lends itself to a more static way of teaching mathematics and can have a significant impact on the kinds of learning children are exposed to. Teachers might well hold strong personal beliefs about how children learn and regard themselves as competent teachers of mathematics. Frid (2000) suggests this competent practice could involve good coverage of the curriculum and the assumption that learning occurred as the result of meaningful interactions with the teacher along with children's participation in activities provided by the teacher, but this may not necessarily follow.

The central focus of a more transmission or traditional approach to teaching is that meaning is transferred from the teacher to children through the teacher's words, actions, and meanings (Cobb, 1988; Wood, 1995). From a transmission view of 
teaching, breakdowns in communication occur when children fail to encode all the relevant information embedded in the teacher's words. In this situation, instructional issues are seen as being addressed by the teacher helping children acquire mathematical knowledge.

A more constructivist approach to teaching challenges the assumption that meanings reside in words and actions independently from an interpreter (the teacher). A constructivist-oriented teacher may believe children are active meaning makers who give contextual meaning to words and actions as they interact with each other (Cobb, 1988). Although constructivist views form the basis of many current mathematics programmes and theories of teacher practice, these have yet to make a significant impact in classrooms (Ernest, 1989; Frid, 2000). A social constructivist perspective is a concept or model of how to be an effective mathematics teacher, rather than a process of using materials to develop strategies (Beswick, 2005). The role of the teacher is to facilitate cognitive structuring and restructuring of information, rather than solely to add to an existing bank of knowledge (Cobb et al., 1990).

Teachers, with a predominantly constructivist view, support children as they actively make meaning and manage continually changing language and actions to build new structures of knowledge. Such teachers may be seen to attach more importance to situations in which teachers and children communicate meaningfully and actively listen to each other's opinions and solutions as opposed to presenting children with knowledge to acquire (Cobb et al., 1990). It is theorised that in a constructivist model of teaching children are supported to build more complex and powerful structures through their interactions with mathematics problem solving (Cobb et al., 1990; Frid, 2000; Goos et al., 1999).

Teachers may believe that children best learn through problem-solving activity but this may not be realised because teachers hold the concurrent belief that children lack many essential skills on school entry, so are unable to problem solve until these deficiencies have been addressed. A lack of teacher confidence in their subject content knowledge, as previously mentioned, may be a further contributor to teachers following a more transmission style of teaching despite their avowed constructivist beliefs. 
The characteristics of the two dominant approaches to mathematics teaching and the features of the related teacher practices are summarised in Table 3.1.

The beliefs teachers have about how children learn can have a direct influence on the kinds of experiences teachers provide for children. The problem lies in determining the extent to which teachers' beliefs and knowledge influence what they teach (Ethell, 1998; Stipek \& Byler, 1997). Stipek and Byler suggest that new information teachers receive is filtered through their personal beliefs before being incorporated into teaching practice. It is assumed that individual behaviour and practice follow on from teacher beliefs (Beswick, 2005). However, it is not universally agreed that practice follows beliefs. Some argue that rather than beliefs determining the practice or behaviour, a change in beliefs is a consequence of a change in practice (Cobb et al., 1990; Nisbet \& Warren, 2000). It can be argued that the relationship between beliefs and practice is not linear but rather they develop together with beliefs shaping practice (Askew et al., 1997; Cobb et al., 1990).

Table 3.1: Characteristics of teacher practice within transmission and discovery approaches to mathematics teaching

\begin{tabular}{|l|l|l|}
\hline $\begin{array}{l}\text { Teaching } \\
\text { approach }\end{array}$ & $\begin{array}{l}\text { Characteristics of the } \\
\text { approach }\end{array}$ & $\begin{array}{l}\text { Characteristics of teacher } \\
\text { practice }\end{array}$ \\
\hline $\begin{array}{l}\text { Transmission: } \\
\text { static and } \\
\text { mechanistic }\end{array}$ & $\begin{array}{l}\text { The goal is the transference } \\
\text { of knowledge from teacher to } \\
\text { child } \\
\text { Students acquire knowledge } \\
\text { through direct instruction }\end{array}$ & $\begin{array}{l}\text { Students use desired } \\
\text { procedures without } \\
\text { conceptual knowledge } \\
\text { Mathematics is taught in a } \\
\text { static manner } \\
\text { Meaning is transferred from } \\
\text { teacher to student }\end{array}$ \\
\hline $\begin{array}{l}\text { Constructivist: } \\
\text { constructivist } \\
\text { and }\end{array}$ & $\begin{array}{l}\text { The goal is the active } \\
\text { construction of mathematical } \\
\text { knowledge } \\
\text { Communication is } \\
\text { meaningful } \\
\text { Students are actively } \\
\text { involved in learning }\end{array}$ & $\begin{array}{l}\text { Teachers have a mixed view } \\
\text { transmission models } \\
\text { Students are expected to } \\
\text { build more complex models } \\
\text { for processing mathematical } \\
\text { learning } \\
\text { Teachers and children build } \\
\text { meaning together }\end{array}$ \\
\hline
\end{tabular}




\subsection{Management of learning}

The complexity of teaching and the management of learning suggests some events need to be routinised so others may be explored in more depth. Teacher beliefs about how children best learn affect the events teachers choose to incorporate within established routines and those events chosen for in-depth exploration.

Tensions can arise between practice and beliefs because teachers have to simultaneously manage children in the classroom, undertake the process of teaching and learning, and meet the demands of the wider school environment,. Significant demands are made of teachers within their environment relating to their knowledge of a subject and their teaching pedagogy, all of which need to be balanced within the classroom situation (Aubrey, 1997).

Teachers' implicit theories about how they teach, feature in their practice and, in turn, are underpinned by the social values of the time and the current school culture (Spodek, 1988). In many cases teachers (in beginning school classes) are preoccupied with the socialisation of children into the school system, teaching children to listen to their teacher, to share, and to follow directions (Beswick, 2007; Beswick et. al., 2009; Burgon \& Thompson, 1997; Muir, 2008; Renwick, 1984). Children are taught the difference between work and play as they transition from early childhood centres to a more formal school setting (Peters, 2002; Spodek, 1988). Although all teachers do not share the same implicit theories about children's learning, many share common theories about socialisation into school, classroom management, and organisation (Spodek, 1988, p. 167). In contrast to this view of the first year at school as being about socialisation, early childhood teachers' implicit theories of teaching and learning are more concerned with providing opportunities for children to learn through play and experiences developing positive dispositions for learning. By the time children have had a year of formal schooling their teachers' implicit theories have changed from theories predominantly about socialisation to theories about how children learn.

Many of the theories held by teachers, including teachers of new entrant classrooms, that underlie classroom practice seem to be based on management 
practices and the classroom activities that support these practices (Beswick et. al., 2009; McCaslin \& Good, 1992). Teachers' decisions in their classrooms about how children learn appear to be based on teachers' personal beliefs rather than on some particular educational theory based on specific knowledge (Bell, 1990; Farquhar, 1991; Spodek, 1988). Teachers' beliefs develop from and are influenced by their early experiences, including their experiences as students of mathematics. Burgon and Thompson (1997) identified the importance teachers attached to the establishment of routines and conformance to classroom rules. Teachers had the expectation that as children moved from the new entrant classroom up through the school "they will have mastered the routines, the expectations of the mat, listening, taking turns, and caring about other people" (p. 3). This expectation creates an additional pressure on new entrant teachers to ensure children have gained these skills before moving to the next class level, and this expectation may influence the nature of teacher practices despite teachers' beliefs about teaching and learning (Burgon \& Thompson, 1997).

Spodek (1988) suggested that teachers' beliefs about children's learning change as the age of the child increases. At the early childhood level, teachers' beliefs focus on the management and socialisation of children, including recognition of the importance of play. As children move to primary school, teachers' beliefs begin to focus more on how children best learn alongside the management of classroom activities. A further factor Stipek and Byler (1997) found was that the socioeconomic status of the school influenced teachers' beliefs. Teachers of children from lower socioeconomic schools believed children need a more skillsoriented approach to mathematics whereas at schools from higher socioeconomic ranking teachers believed in a more child-centred, child-initiated approach to mathematics. This finding is consistent with that of Lee and Ginsberg (2007). Prior experiences and theories of mathematics learning and teaching act as filters for new and developing theories. In some cases these prior theories over-ride new theories of teaching and learning (Raymond, 1997). Raymond suggests that many teachers share a common belief, supported by their early memories, that teaching and learning occur within an orderly and structured environment, a climate within which "good" behaviour is encouraged ahead of learning. How this good 
behaviour is established in the classroom is a key element of managing the class or group of children in order to promote student engagement in learning (Doyle, 1983; McCaslin \& Good, 1992; Raymond, 1997).

Classrooms (more at the primary level than early childhood level) consist of children who are grouped and organised for learning experiences. A well-ordered classroom helps to ensure children are engaged in the practices of the classroom and contributes to an environment that supports the work getting done (Doyle, 1983). Raymond (1997) distinguishes between what the teacher believes, their intention to do something, and what happens in practice. In Raymond's study, teachers described their practice in terms of what they thought ought to happen. McCaslin and Good (1992) suggest that the current climate and modern curriculum intentions are undermined by teacher practices that focus on obedience and compliance while they "teach for exploration and risk taking" (p. 12). Teachers want children to be able to think and problem solve in accordance with the overall philosophies of curriculum documents, yet in practice children are asked to do this independently and quietly.

McCaslin and Good (1992) further contend that within this system children gain recognition of their efforts, not from their ability to problem solve, but through their ability to follow procedures, which in turn necessitates limited risk taking. This more narrow teacher-centred approach with a dominant focus on direct instruction has been shown to limit children's achievement (Peters, 2001). Perry (2000) describes elements he considers to be part of 'best practice' that are features of both Australian and New Zealand mathematics practices and that are supported in a New Zealand iteration of evidence about effective pedagogy in mathematics (Anthony \& Walshaw, 2007). The elements of best practice described by Perry are (p. 23):

- observe children's existing knowledge, skills, and understandings regularly

- build on this existing knowledge to provide opportunities to challenge the children's thinking

- facilitate success for individual children by linking their learning experiences to their context 
- focus on children's areas of potential, thus aiming for the children to feel satisfied

- ensure children have access to teachers who know what to expect in terms of children's mathematical development and who are adept at facilitating the children's use of increasingly sophisticated strategies

- allocate time every day for the learning and teaching of mathematics and numeracy integrated within the overall educational programme.

By focusing on the elements of best practice in mathematics teaching and learning and developing positive dispositions for mathematics teaching it may be possible to shift teacher beliefs into line with more contemporary views on mathematics teaching and learning.

\subsection{Teachers' subject knowledge in mathematics}

While teachers' levels of mathematical subject knowledge are not a specific feature of this study, it is worth noting evidence that suggests that a lack of content specific mathematical knowledge is an influence on the kind of mathematical tasks teachers provide for children (Frid, Goos \& Sparow, 2009; Warren, 2009). Increasing teachers' levels of subject knowledge has resulted in teachers of mathematics who have the confidence to make connections to learning and to allow student conversations to have a more direct impact on classroom practice (Kuijpers et. al. 2010; Warren, 2009). An increased focus on content knowledge in mathematics when combined with teacher professional development has been shown to lead to more purposeful teaching and learning in mathematics (Frid et. al., 2009). These findings support earlier work in teacher professional development such as that completed by Shulman (1987) and Young-Loveridge (1993). Increasing both content and pedagogical knowledge in mathematics has a positive effect on students' mathematics and their ability to make connections to other areas and ideas in mathematics (Muir, 2008; Schorr, 2000).

\subsection{Teachers' expectations of children}

Teacher beliefs about what children are able to do, as opposed to how they believe children best learn impact on learning in school (Peters, 2010). When teachers 
hold low expectations relating to children's knowledge and skills on entry to school, this may impact on the success of the transition to school. Variations in teachers' beliefs and practices between the early childhood sector and the primary school, and differences between the pedagogical approaches of the early childhood curriculum and that of the school may impact on how children fit into the new environment (Peters, 2010; Woodhead \& Brooker, 2008).

When teachers claim that children on school entry have very little knowledge or know nothing, they are overlooking aspects of what children do bring to school, their existing knowledge and skill sets. This view of children may position children early on in their school career as 'poor learners' (Chapman, Tunmer \& Prochnow, 2004). Teacher beliefs about students learning result from a combination of various factors (for example, the nature of the early childhood education or lack of it, previous contact with family, socio economic status). Dockett and Perry (2007) claim that teachers holding low expectations of children will maintain these despite evidence that children may be operating at higher levels. Similar findings relating to low teacher expectations of children (particularly second language learners) were found in England (Thompson \& Hall, 2008) and New Zealand (Tamarua, 2008; Young-Loveridge et. al., 1995 ).

\subsection{Summary}

Teacher beliefs and practices are interwoven in such a way that it is difficult to separate the influence of each on classroom programmes. How teachers operate in the classroom (their practice) is strongly influenced by the beliefs they hold. Many factors influence the development of teachers' beliefs about mathematics teaching and learning, including their educational experiences as well as the nature of the classroom environment. Discrepancies between beliefs and practices can arise. For example, a teacher may believe it is important to develop problem-solving skills in young children but because they feel under pressure to ensure children have the 'required' knowledge before they move on to the next class level may not implement their belief into their practice. Teachers' beliefs and their influence on practice may be difficult to separate, but it appears that in some cases teachers' beliefs about the knowledge they think children should have on their entry to 
school over-ride their beliefs about how to develop effective programmes to support children's learning in mathematics.

The following chapter builds on teachers' practice and beliefs in mathematics, specifically in relation to the transition of children from early childhood education to primary school. Teachers' perceptions of school readiness and their expectations of children in mathematics on school entry are discussed. 


\section{4: Transition: From early childhood centre to primary school}

\subsection{Introduction}

Transition from early childhood education centres to school involves change from one situation to another and the success or failure of this has the potential to impact on children's achievement (Dockett \& Perry, 2007). This chapter examines the literature related to the transition of children from an early childhood setting to a new entrant class in school, focusing on similarities and differences between the two environments.

Three main issues need to be addressed as children make the transition to primary school (Dunlop \& Fabian, 2007): differences in educational expectations, the lack of meaningful communications, and different environmental constraints. The beliefs that kindergarten and new entrant teachers hold about mathematics learning and teaching and about how to ready children for school are reviewed in this chapter to establish how the three issues listed above might affect a smooth transition to school.

Each section of this chapter highlights a different aspect of the transition to school. Section 4.2 explores general aspects of the transition, including the socialisation of children to school. Section 4.3 examines the management of transitions. Section 4.4 discusses the expectations of early childhood and new entrant teachers surrounding the transition to school and the expectations they hold about children with a particular focus on mathematics learning. It also discusses environmental differences and the apparent lack of communication between the two settings. Section 4.5 discusses the experiences of children and their mathematical knowledge. Section 4.6 discusses assessment practices. The final section, section 4.7 , looks at how some of these discrepancies have been addressed.

Many of the studies discussed in this chapter are specific to early childhood education generally, but when kindergartens are the main focus it is indicated. Within an educational setting the term 'transition' is understood to be the process of moving from one stage of education to another (Fabian, 2007). In this study, the transition phase begins before school entry in an early childhood setting 
(kindergarten) and is not generally regarded as complete until the child is fully integrated into the primary school classroom. In most cases, transition involves a change of status and of educational culture, from being one of the oldest children at an early childhood centre to being the youngest child in a school, from a usually less restrictive environment to one generally more regulated by curriculum, school timetables, and the teacher. The process of transition can cause challenges for all participants with the potential to impact negatively on long-term learning (Fabian \& Dunlop, 2002).

Effective transitions build on children's experiences and their family and social systems and require meaningful communications between all involved parties, including the primary school. Children do not make the transition in isolation; it is a complex process of adapting and adjusting to differing demands involving all participants (Carr et. al., 2010; Dockett \& Perry, 2001; Fabian, 2007; Ledger et al., 1998; Peters et. al., 2009; Wagemaker, 1998).

The management of this transition is important not just for success at school but for other areas of life (Dockett \& Perry, 1999). Dockett and Perry (2005) emphasise that children need to develop a sense of belonging, because it is a key feature in making a successful transition to school.

\subsection{Transition: Starting school}

Starting school is an important event in a child's life. When this start is positive and successful for children it is more likely to result in better social and academic outcomes for children (Dockett \& Perry, 2007). The transition to school may be better supported when children's experiences before they enter school are connected to their experiences after starting school (Pianta, 2004).

From work surrounding the transition of children to school, Dockett and Perry (2001) developed a set of 10 guidelines aimed at supporting effective and smooth transitions. These guidelines are based on the premise that the transition to school is not solely about the child; transition is a process that involves the school, the early childhood centre, the community, the family, and the child. The guidelines resulted from a series of observations and interviews with groups of teachers, parents, and children and incorporated key issues raised by the respondents. 
Primary teachers were found to focus on the importance of children being able to adjust socially to the school environment (Dockett \& Perry, 2001). A further issue of significance to teachers was the perceived ability of the child to operate as part of a group within the classroom and to follow directions from the teacher. Primary school teachers did not consider the academic knowledge that children had when they started school as important as the social factors. This does not necessarily mean the knowledge children possess on school entry was not valued, but teachers in general felt that if children were able to settle more easily in school, then they could be taught more effectively.

Dockett and Perry's (2001) guidelines contained recommendations for supporting transition in the most effective ways for a child according to their specific needs as opposed to recommending the acquisition of a predetermined set of skills that some believe ensure a child's readiness for school. A crucial aspect of this transition is the continuity Dockett and Perry $(2001,2007)$ believed should be present between the early childhood and school settings, a continuity of some practices, routines, and beliefs established through closer communication and mutual respect that may contribute towards developing a sense of belonging. Continuity of curriculum provides recognition that learning has taken place in the early childhood setting and will continue in the new entrant classroom (Carr et. al., 2010). This connectedness with children's existing knowledge will help give children confidence when they make the transition to school (Brooker, 2008; Carr et. al. 2010; Peters et. al., 2009; Timperley et. al., 2001).

Starting school has been seen in the past as a time when real learning begins, leaving behind the apparently less-structured environment of early childhood and moving into the generally more formal school environment, a perception supported by the following advice given by a parent to his child on school entry: "Now you are going to a real school, and you need not expect to enjoy yourself anymore!" (Priestman, 1952, p. 5).

Early childhood teachers play an important role in determining how children are prepared for the transition to primary school. In a similar way, the new entrant teacher faces a challenge in considering how to best meet the needs of children entering school (Wagemaker, 1998). The process of transition to school begins 
before school entry (Dockett \& Perry, 2007; Peters, 1998b). Peters (1998b) emphasised the view that, "Children need to learn to make sense of school" (p. 107). This transition has been described as a situation where children "become aware of the demands of the school situation so that their own learning will become appropriate to the constraints of the situation in the classroom" (Jackson, 1987, p. 81). Within the classroom teachers most commonly control the structure of the day, the organisation, the timing, and the cultural environment of the class (Peters, 2004). With one teacher, limited teacher aide support and around 25 fiveyear-old children, it is inevitable that children are required to work within boundaries, rules, regulations and set tasks (Carr et. al., 2010). Children have to learn to function within this different milieu.

A child's entry to school has been described as "not the beginning of development or of education in its broadest sense; but it is the beginning of society's formal attempt to instruct all children, in groups" (Clay, 1991, p. 19). The New Zealand system is one of a few in which children begin school on or about their fifth birthday. In most other countries children start at pre-determined points in the school year. The New Zealand system with variable starting dates for children, dependent on their age, ensures the new entrant teacher has a continual supply of individual children joining the class throughout the school year and increasing numbers in the class. In practice, this means the new entrant teacher not only has children joining the class throughout the school year, but has to deal with fluctuating class sizes as children move on to the next level when the number of children reaches a predetermined maximum level.

Using the Clark and Lovric (2008) model of transition, the expectation of starting school at age five has the advantage of providing a clear rite of passage to school for children. Change is seen as a sign of progression, of growing up, and children want their experiences at school to be different from their experiences before school (Perry \& Dockett, 2005). While some continuity of experience will aid the process of transition, the act of adjusting to some discontinuity is seen as an important part of the growth and development of the child and later success at school (Niesel \& Griebel, 2007). Differences, when handled sensitively, will help children develop a sense of identity within the new environment (Rogoff, 1990). 
In New Zealand, many instructional programmes, were developed more than 20 years ago when the school population was more homogeneous (Wagemaker, 1998). Now with an increasingly diverse school population in New Zealand, children are coming to school with a wider range of social, cultural, and language experiences. Teachers have to be able to recognise and capitalise on this diversity to enhance the positive experiences of children on school entry and maximise their learning opportunities. Understanding this diversity forms part of a teacher's job, and their background knowledge of children helps to support more effective transitions to school (Blaiklock, Kiro, Belgrave, Low, Davenport \& Hassell, 2002). A lack of knowledge of this diversity amongst children, their prior knowledge and learning skills could lead to a lack of challenge for children on school entry (Gallagher, 2005; Peters, 2010).

\subsubsection{Socialisation: Fitting into school}

The social aspect of the new entrant classroom is considered important to teachers and children because children are expected to fit into the school system. Renwick (1987) found that many primary teachers held the view that it was important when children settled into school that the children behaved in a way that was acceptable to the teacher. A further finding was the belief held by children and their parents that school was the place where children began to work and learn whereas in an early childhood setting children could play.

A New Zealand survey of teachers' beliefs about the transition of children to school found that although teachers espoused a collaborative approach to transition, teachers from the two different settings (kindergarten and new entrant level) held different expectations of each other (Timperley, McNaughton, Howie \& Robinson, 2003). Both groups of teachers in the Timperley et al. study felt that the arrangements they had in place for the transition of children were less than satisfactory. An important finding from their study was that teachers within the primary setting did not have enough knowledge of the children's achievements in the early childhood sector, so did not attempt to develop children by utilising their existing knowledge. This finding is similar to Aubrey's (1997) finding that none of the teachers in her study made particular use of information relating to 
children's early childhood experiences and knowledge when they planned for children's learning at school.

On arrival at school, many new entrant teachers expect children to fit into the classroom environment and settle quickly into the established routines of the classroom (McCaslin \& Good, 1992; Renwick, 1987; Timperley et al., 2003). Children are expected to arrive at school with skills that enable them to socialise with other children, conform to classroom norms, and follow direct instructions from their teacher (McCaslin \& Good, 1992). "Work is seen as something [the children] must do, while play is seen as something [the children] can do" (Spodek, 1988, p. 163). This view is consistent with the idea that when children begin school, it is the children who need to conform to the school expectations and not vice versa. The underlying message conveyed to children is to do what the teacher tells them to (Biber, 1988). McCaslin and Good (1992) describe this as “compliant cognition". In New Zealand, some management practices in the classroom focusing on conformity and order contrast directly with the intention of the curriculum to produce self-motivated and active learners (Ministry of Education, 1992).

Primary teachers do not appear to specifically request information on children's achievements from early childhood centres when they start school for the first time (Peters, 1998a; Timperley et al., 2003). This finding is indicative of teachers who are more concerned about a child's ability to socialise rather than their academic ability and is typified by comments such as "we can teach them to write their name, but it's more important to have kids who can function in the classroom" (Dockett \& Perry, 2001, p. 5). Teachers wanted to establish where children were regarding their academic knowledge at school entry so they could plan appropriately for learning but little of this information originated from the early childhood centres (Dockett \& Perry, 2001). Teachers' concerns about socialisation and conformity appear to take priority over academic considerations, leading to less attention directed towards children's knowledge and understandings when they begin school.

Using children's early childhood portfolios that include learning stories, can serve as a useful way of connecting experiences from early childhood centres to school. 
The portfolios introduce teachers to the knowledge and experiences of children and their interests. This serves as a way of connecting learning in one environment to another and helps support a child's sense of belonging to the new environment (Carr et. al., 2010, Hartley et. al., 2009, Jones, 2006, Peters, 2009). It is not surprising that new entrant teachers have a tendency to focus on order and routine when schools in New Zealand have a policy of continual entry to school throughout the year (Cullen, 1998). Socialisation and orientation to work become an important focus for teachers as they manage a constant stream of new children into their classrooms. Many new entrant teachers believe children do not have sufficient social skills when they come to school, their language is poor, and they cannot concentrate, so the management of these factors dominates teachers' time (Ledger et al., 1998). Peters' (2004) study relating to the transition of children to school suggests that when teachers believe that children have very few skills when they come from an early childhood centre to school, their classroom programmes focus on what the child is unable to do, which is a deficit approach to teaching and learning. When children are regarded as individuals on school entry, as opposed to one of a cohort of five-year-olds, there may be increased opportunities for the provision of rich mathematical activities able to provide an appropriate level of engagement for all children (Clarke, Clarke \& Cheeseman, 2006). Instruction that is aimed at a specific level for a particular age group of children may limit opportunities for children to extend their mathematical thinking and problemsolving skills (Aubrey, 1997; Clarke et al., 2006).

\subsection{Managing transitions: A seamless transition}

This section explores the similarities and differences between early childhood teachers and primary school teachers in terms of their beliefs about children as they transition to school. Also discussed are the teacher's beliefs about a child before they enter school compared with the teacher's beliefs about the same child in the new entrant classroom, and how these beliefs are communicated between both parties. Differences in assessment practices are outlined in relation to how learning and teaching are portrayed, and the communication that exists between the two settings is assessed. Different expectations relating to classroom 
management are examined in relation to the nature of the learning that is expected.

As children move from early childhood to primary school, they have to adjust from one learning environment to another, and adapt to a generally more direct, instructional, teacher-centred environment, and pedagogical style that may be in contrast to their early childhood experiences. Cassidy (2005) investigated developing a means of improving the communication between the teachers in the two settings as a way to support a smooth transition for children.

Cassidy examined the importance of developing consistent assessment and reporting procedures across all sectors of education provision for under fives in one local Scottish authority. Initially, the research started with early childhood teachers but Cassidy recognised the importance of having input from primary 1 teachers. ${ }^{21}$ She took into account primary 1 teachers' beliefs about what they considered important information about the children they received. A consistent finding was that teachers, depending on their beliefs, emphasised different priorities: for some it was organisation, some looked at children fitting into school while others focused on the learning needs of children and their individual characteristics.

As previously discussed, children's experiences of transitioning from an early childhood setting to a primary school may have a significant impact on their ability to settle quickly into a new environment and on later academic achievement (Einarsdottir, 2007; Margetts, 2002, 2007). The Ministry of Education in New Zealand emphasises the need for collaborative teamwork between all participants (early childhood teachers, primary teachers, parents, families or whānau, and communities) to facilitate a smooth transition to school (Mallard, 2002). The Ministry recommended that transition to school from early childhood centres needs to be as smooth as possible to help reduce possible barriers to learning faced by a child. Such a transition is commonly known as a seamless transition. A seamless transition keeps the focus predominantly on learning and development with the child at the centre. Mallard (2002) emphasised the importance of maintaining strong links between the early childhood

21 Primary 1 teachers are the equivalent of the new entrant teacher or reception class teacher. 
curriculum (Te Whāriki) and the New Zealand Curriculum Framework (NZCF) in which the learner is regarded as the focus of teaching and learning (respectively Ministry of Education, 1993a; Ministry of Education, 1996). As Margetts (2007) suggests, the connections between the child, their experiences, and the connections between home, early childhood, and school ultimately determine the success of the transition. The expectation may be of a seamless transition, but it is not about having everything the same. It is about working together, communicating effectively, and recognising the learning needs of each child as they enter school in order to develop positive experiences.

The 200210 year Strategic Plan (Ministry of Education, 2002b) contained specific recommendations for the early childhood and school sectors aimed at increasing the levels of collaboration and how to best manage transitions to school. Actions to support this involved "teachers from both sectors regularly meeting to discuss curriculum linkages, children's learning needs (including special education needs) and how best to manage transition from ECE to school" (Ministry of Education, 2002b, p.17). These goals are further reinforced in Ka Hikitia-Managing for success: The Maori Education Strategy 2008-2012 (Ministry of Education, 2008) and the recommendations to develop a 'transition toolkit' and provide professional development and support teachers are clearly set out.

Similarly, discontinuities at the point of transition are not uncommon between other education settings (Averill, 2001). In a study of the development of year 9 mathematics schemes in New Zealand, Averill found that some secondary school teachers took little or no notice of children's knowledge and learning from year 8 when planning what to teach at year 9 . This is in direct contrast to the aims of the NZCF, which states, "learning progresses coherently throughout schooling" and “At all levels of schooling, programmes will be built on students' previous learning experiences" (Ministry of Education, 1993a, p. 7). When teachers make little or no attempt to establish the prior knowledge of children in their class, basing their expectations on "sayings", ${ }^{22}$ whether they be in year 9 or a new

22 Timperley and Robinson (2001) refer to 'sayings' as firmly held beliefs that are treated as accepted wisdom. 
entrant aged five, learning disruptions for the children are possible (Aubrey et al., 2000; Margetts, 2002).

Similar practices to those found by Averill (2001) are seen in teachers regarding transition from year 6 to year 7. Some teachers appear to undervalue the previous educational establishment and dismiss the information received about the children as being irrelevant or inaccurate. A primary school principal (personal communication, 22/6/06). was concerned about the transition for children at his school from year 6 to year 7 (intermediate $\operatorname{school}^{23}$ ):

We sent kids with full diagnostic interview data from 2005, all the kids at year 7 (at the local intermediate) were re-interviewed in 2006, don't they trust us? What is the value then in us doing this at the end of the year, we may as well not bother.

By increasing the level of meaningful dialogue and communication levels between educational settings, it is possible that opportunities for miscommunication and discontinuities may be reduced.

\subsection{Discontinuities across environments}

Children can experience discontinuities between the two environments in several ways. Teachers in new entrant and early childhood settings may have different beliefs and expectations about how children learn and how children should behave. Assessment measures in each setting differ, as do perspectives of the environment and instructional roles. A lack of significant communication between early childhood teachers and new entrant teachers may further contribute to the discontinuity. Transition may become more difficult when low levels of interaction between the two environments exist in conjunction with variations in beliefs and learning cultures.

Early childhood settings may provide a different developmental context for children, carrying different expectations and relationships. For example, children in kindergartens are given opportunities to practice self-reflection and selfregulatory skills within a generally more open environment. Their teachers have

${ }^{23}$ Intermediate schools in New Zealand consist of year 6 and year 7 children only. Some primary schools in New Zealand also cater for year 6 and 7 children and are called full primary schools. 
the opportunity to make greater use of informal prompts and feedback that support and enhance learning (Cullen, 1998). In contrast to this, the more formal environment of the new entrant classroom may lead teachers to make significantly more use of whole-class direction and feedback. Children are more likely to be directed into activities heavily weighted towards literacy and numeracy and have less freedom to move around the classroom. The curriculum documents relating to primary school teaching and learning may contribute towards differences in educational practices. An increased focus on learning intentions and achievement objectives in the curriculum provide a measure of progress for teachers and the beginning of a learning continuum. A new entrant teacher may be teaching up to 25 children with limited extra adult support (such as a teacher aide), and the management of this situation may contribute to the development of a more structured learning programme compared with early childhood programmes. Discontinuities between events in one environment and the next can be minimised when common elements in both situations facilitate the child relating to the new environment (Brostrom, 2005). Transition from an early childhood setting to school is not solely a process of shifting from one environment to another but a dynamic, interactive process involving all parties. By creating similarities between both environments (e.g., recognising the importance of a shared overall curriculum and having common ways of organising time, space, and materials), Brostrom suggests that the transition to school could be more positive for children over the transition period. Margetts (1999) reinforced the critical importance of ensuring some continuity between the early childhood and school setting in order to support a smooth transition for children. She advocated a continuity of programmes (including curricula) and experiences between the two settings and the need for teachers in both environments to understand each other's role to develop a greater degree of inter-relationship and communication. The focus of smooth transitions should not only be on socialisation to school, but ensuring children experience a degree of similarity between the curricula and the environment and have teachers who can build on the child's existing knowledge (Brostrom, 2005). These findings relate closely to the guidelines developed by Dockett and Perry (2001) that support a more effective transition to school. 
Both Margetts (1999) and Brostrom (2005) advocate the importance of having a degree of similarity between the two educational environments to reduce the disparities between the two settings. However, Clark and Lovric (2008) suggest an alternative view focusing on the importance of taking learning to the next step, rather than focusing on continuity of common elements. This again reinforces the value of teachers having a sound knowledge of the individual learning needs of each child and features of both educational settings. Children's perception of moving up to school or 'going to big school' carries an expectation that something different will be happening at school. New learning will be happening at school and the expectation of this by children suggests they expect some discontinuity and uncertainties and these play a positive role in clearly differentiating the two environments (Peters, 2000).

\subsubsection{Differing expectations of child behaviour}

Differing expectations from teachers about how children should behave in the classroom creates a further area of discontinuity. Primary teachers expect children to be independent on school entry, look after their physical needs, and sit on the mat (Peters, 2002). The value attached to these social skills was similarly found by Perry et al. (2000). Kindergarten teachers believe part of their role is to prepare children for life.

Primary and early childhood teachers share similar beliefs about education and how children best learn, yet Dunlop (2003) found major discrepancies between these beliefs. The structures and expectations of new entrant class teachers were quite different from the expectations early childhood teachers had of children. These differences may affect the ability of a child to make a smooth transition to school. The early childhood teacher expected children to develop positive dispositions for learning through their interaction with the environment. The primary teacher expected children to be able to sit, concentrate, and work as part of a group. Being part of the group was considered more important than being an individual potentially taking the teacher's attention away from the group's needs. Dunlop's (2003) major recommendation was that starting from similar beliefs about how children learn, teachers from both settings should communicate more effectively with each other to develop an increased continuity of practice between 
the two environments. Although new entrant teachers said they felt it was more important for children to be socially ready for school, in practice they had strong expectations about the academic knowledge and skills children should possess on school entry (Peters, 2002), particularly literacy and numeracy skills. Early childhood teachers believed their role was to develop positive dispositions for learning, but they believed schools and new entrant teachers judged their success on the academic skills children had when they came to school (Robinson et al., 2000).

\subsubsection{Teachers: Communicating past each other}

Communication is assumed to be a critical feature in the successful transition of children from early childhood to a school setting (McNaughton, 1998).

McNaughton discusses the importance of both environments having similar goals and a shared body of knowledge, yet found a lack of purposeful communication between both environments and, more significantly, a lack of respect for the importance of children's experiences before they entered school. The lack of attention paid to communication may explain how early childhood teachers and primary teachers regard each other. By not attaching importance to communicating about children from the early childhood setting, primary teachers devalue the importance of early childhood education. A lack of meaningful communication can create a barrier for children as they move to school. Although there is evidence to suggest that some communication occurs between early childhood centres and primary schools, in many cases teachers are either "talking past each other" 24 or not listening, possibly because of their contrasting beliefs about what children need.

Effective transitions depend on open and meaningful communications between all participants in the process (Dockett \& Perry, 2001; Niesel \& Griebel, 2007). The focus in communication between kindergartens and schools is children and their social competencies and attitudes and how these are built on by parents, schools, and early childhood centres. Children may find it difficult to make links from one environment to the next when their new entrant teachers have different

24 An expression Metge and Kinloch (1978) use to describe an event where communication occurs but listening does not. 
expectations of them compared to kindergarten teachers and when the styles of teaching and learning are different particularly where teachers hold low expectations (Peter, 2010). Children are more likely to have positive experiences of going to school when teachers have the time to get to know children, and recognise and build on their prior experiences, see what children are able to do rather than what they are unable to do, (Farquhar, 2003; Peters et. al. 2009; Peters, 2010).

A recognition of the need for relevant and purposeful communication between primary schools and early childhood centres is central to the ease of transition (Hopps, 2004). Hopps suggests that although good communication is well recognised as important for the successful transition of children to school, evidence suggests that it does not necessarily occur. Hopps's study exposed the low regard primary teachers had for early childhood teachers as well as their differing beliefs and expectations about the children. In addition to this, teachers in both settings held different views about school readiness and behavioural expectations of the children, which in turn impacted on the ease of the children's transition to school.

Opportunities for liaison between the environments was considered important and of major benefit, but was constrained by limited time and opportunities (Cassidy, 2005). Primary teachers acknowledged that written information was sometimes received from early childhood centres about children but in general it was regarded as less valuable than the verbal transfer of information. No primary teacher in Cassidy's 2005 study used written information about children from an early childhood setting to plan for learning, although in some cases if there was a problem with a child, teachers might refer back to the written report. Primary teachers were found to prefer to make up their own minds about children (Kagan, 1994; Peters, 1998a). In general teachers recognised the value of parental knowledge about their children as they transitioned to school yet only a small number of teachers used this information to plan for children's needs. Teachers felt that a lack of common infrastructure between primary schools and early childhood settings in conjunction with limited opportunities to engage with each other contributed to the low levels of communication experienced (Smith, 1998). 


\subsection{Mathematical development: Children's knowledge}

Children's successful early childhood experiences have a significant and lasting impact on their later school performance in mathematics. The Competent Children at 10 study (Ministry of Education, 2006) found that children's later performance could not generally be predicted from competency measures taken when children are nearly five years old. The exceptions to this were children's mathematics and reading scores. This longitudinal study shows that children's progress in mathematics and reading at school can be directly related to their knowledge and experiences from early childhood.

A more recent New Zealand study on competent children (Hodgen, 2007, p. 74) found that:

about 60 percent of the children doing well (or badly - they were in the top or bottom 25 percent of the sample) for the first time we measured their numeracy, logical problem solving, or cognitive composite scores were doing equally well (or badly) at age 16. Performance in the literacy tests was slightly less consistent, particularly when comparing age-5 and age-16 scores.

These children were assessed before they entered school and their status at that time was the same when reassessed again at age 16. This suggests that if, on entry to school, a child is in a top or bottom group for mathematics they will still be in that group at age 16. The children's teachers appeared to have little impact on the children's relative levels of performance, so by implication they may not be focusing on children's specific learning needs. Early childhood teachers have a crucial part to play in developing and enhancing children's mathematical experiences before they enter school in order to set children up for the best possible start to their school career. If these experiences and learning dispositions are not then recognised and built on when a child starts school, there may be longterm implications for their progress in mathematics. However, this longitudinal study did not include information from all early childhood settings (e.g., kōhanga reo and some Pacific early childhood centres) so conclusions cannot be drawn as to the long-term effects for children from these environments (Anning et al., 2004). 
The Education Review Office's (1998, p. 4) report on the use of Te Whāriki states:

the cognitive and intellectual development of children before they enter school is critical to their future educational achievement. Literacy and numeracy are essential to progress at school and the children's ability to acquire these skills is influenced by the nature of their early childhood experiences.

Participation in quality early childhood education is consistently associated with gains in mathematics and literacy as well as general school readiness in both New Zealand and overseas studies (Mitchell et al., 2008). Consistent with Hodgen's (2007) study, these gains are maintained over time.

Early childhood teachers have a pivotal role in supporting and ensuring the smooth transition of a child to school and laying the foundations for future success in mathematics (Peters, 1998b). Although there is some resistance from the early childhood community to using the early childhood setting as a preparation for school, this community does have a key role in preparing children for ongoing learning and intellectual development and the development of positive dispositions to learning. The importance of participating in early childhood education is emphasised in studies that describe how children with good learning strategies continue using these strategies at school (Cullen, 1999), and how children who are ahead in mathematics at age five maintain this advantage (Hodgen, 2007; Wylie \& Thompson, 1988; Young-Loveridge, 1989b). Young-Loveridge and her colleagues in their study relating to the mathematical skills of 4-year-olds, found low levels of mathematical skills in children at some early childhood centres (Young-Loveridge et al., 1995). When teachers at these centres were supported with teacher development that focused on developing a greater awareness of mathematical opportunities, children made significant gains in their mathematical abilities. This study found, looking at the enhancement of mathematics of 4-year-olds in New Zealand, that 80 percent of children could rote count to 10, 42 percent of children could accurately count a group of five objects, and 55 percent of children could join a group of two objects and a group of three objects to make five. Although the study did not involve large numbers of 
children, it demonstrated that children about to start school might have higher levels of mathematical competency than previously expected by some primary teachers. Similar findings relating to children's number sense and abilities on school entry were found in England (Aubrey, 1997). While Aubrey's study was also small, half of the children could read five to nine numbers on school entry and only a fifth were unable to read any numbers, meaning children are having experiences in reading numbers before they enter school.

These studies show the levels of mathematical competencies already present in some children on their entry to school. It becomes the classroom teacher's responsibility to identify and build on these skills to continue the child's mathematical progressions. These skills are developed through children's participation in social life, their home, their environment, and their early childhood education and should continue to be developed at school.

Children's informal learning provides the basis for more formal learning generally associated with the beginning of school. Within early childhood education there is a belief that "maths is everywhere" (Carr et al., 1994, p. 262). Carr et al. suggested that teachers would become more aware of the mathematical opportunities present in each centre, if there was an increased focus on the framework for early mathematics learning based on work by Baroody and Ginsberg (1990). This framework provides an overview of the nature of mathematics that occurs over time. Level one of this framework relates to the informal and natural aspects of mathematics that occur as children observe and participate with their immediate environment, separating and rejoining quantities (e.g., in dough and water play). Level two emerges as children begin to use their existing skills to solve problems within their environment with an orientation to mathematics. The children have many opportunities for these interactions, such as conversations about how many children can be in one area at a time or counting up containers of water they fill. Children use numbers appropriately in discussing their age, scoring their own games, and developing timetables. Level three is a more formal approach to mathematics teaching associated with the study of mathematics at school. The framework provides educators with a tool to reflect on and position mathematics for early childhood education (Carr et al., 1994) as well 
as increasing the level of awareness of mathematical opportunities that are present in everyday occurrences.

Dunphy (2006) developed a similar framework also based on a sociocultural view of learning. The first stage of Dunphy's framework relates to the pleasure and interest that children showed in exploring numbers. The next stage looks at children's understandings of the purpose of numbers followed by their ability to think quantitatively and build relationships about numbers. The final stage relates to children's awareness and understanding of written numbers.

Both of these socioculturally based frameworks (Carr et al., 1994; Dunphy, 2006) position the child at the centre as they build their understandings of numbers by participating in meaningful activities supported by purposeful interactions with teachers and significant others. A more in-depth understanding of the elements of these frameworks for mathematics learning could help teachers to more accurately support children's needs in relation to their mathematical learning.

In New Zealand, mathematics in the first year of school is primarily based on a number framework that has lead to challenging teacher beliefs about what 5-yearolds are capable of (Bobis, 2002). The intended outcomes of this framework in Australia and New Zealand maybe at risk of not being achieved when teachers continue to rely on more traditional, established methods of mathematics teaching. This is despite teacher professional development being focused on improving student performance in mathematics by enhancing the professional capability of teachers (Perry \& Dockett, 2005). Perry and Dockett suggest teachers with more fixed beliefs about the teaching and learning of mathematics may be unlikely to change these beliefs as a result of current research or curriculum requirements. This seeming reluctance to change beliefs about mathematics teaching may lead to negative impacts on student learning.

\subsection{Mathematics: Assessment practices}

A major purpose of assessment in mathematics is to improve learning and teaching and to provide feedback for children and teachers about mathematical development. Assessment provides a point from which teachers can determine the next teaching and learning step (Perry, 2000). 
Contrasting methods of assessment exist between primary schools and early childhood settings, which may contribute to children having problems adjusting to school. Early childhood settings follow a form of assessment primarily based on close observations and recordings of what the child can do and this forms the basis of their planning, teaching, and learning (Carr, 2001). In primary schools, teachers tend to be more focused, evaluating teacher-determined pieces of completed work (Aubrey et al., 2000, Carr et. al., 2010).

In early childhood centres in New Zealand, assessments predominately take the form of learning stories unfolding over time to reflect a progression or developing journey with no fixed end result in accordance with the goals and principles of Te Whāriki (Carr, 2002). ${ }^{25}$ Learning stories, a form of narrative assessment, were developed as a result of changing perceptions about assessment in early childhood education and are commonly used in kindergartens as well as in other early childhood centres in New Zealand (Carr, 2002). Learning stories are used to record and monitor children's learning. The goal of the assessment, either individual or collective, evolves as the work unfolds and children and teachers build on and extend learning. Children are encouraged to view themselves as competent and capable learners in a community of learners (Mitchell, 2002). In early childhood centres, children work with their teachers to develop learning stories as a part of a total commitment to developing a holistic picture of the child and including incorporating active community participation. Teachers use the local community of an early childhood centre as a resource to develop and extend the principles of Te Whāriki (empowerment or whakamana, holistic development or kotahitanga, family and community or whanau tangata, and relationships or nga hononga). ${ }^{26}$ Children have the opportunity to reflect on and review their own learning through their learning stories. Assessment, in the form of learning stories documenting a learning pathway, arises out of children's diversity, dialogue, and activities, both independently and as part of a group, reflecting the goals and aims of Te Whāriki.

25 These goals and principles are outlined in chapter 2.

26 See section 2.3 . 
Teachers in early childhood centres had, in general, regarded themselves as "child centred', but with the advent of Te Whāriki and the detailed documentation developed through learning stories, teachers are reporting a changing perspective. The process of documenting a learning story for a child or group of children enables teachers to see and reflect on events more from a child's perspective. Attempting to view events from a child's perspective has lead to a deeper understanding for teachers, and has involved teachers working collaboratively with children to develop a significant learning community (Mitchell, 2002). The close observation and documentation of children's learning pathways helps teachers as they work towards supporting and extending learning for children.

Perry et al. (2007) have used learning stories to link children's mathematical ideas with a numeracy matrix. The matrix allows teachers to identify and analyse mathematical events and link these to the requisite learning outcomes through the structure of a learning story. The assessment practices evidenced through the learning outcomes in the matrix may support teachers to become more focused on the nature of the mathematical events and experiences that arise within the early childhood settings.

In primary schools, assessment is generally more formal with achievement data being collected using a variety of methods. In many instances teachers plan experiences for children that directly relate to the curriculum progressions, which in turn may lead to an overestimation or underestimation of children's abilities and needs (Aubrey et. al., 2000). Teachers teach directly what they feel children need to know; especially in relation to early number concepts in spite of some teachers believing it is important for children to discover number concepts for themselves. This direct teaching of number skills, based on curriculum placement, is a common feature of beginning school teaching, and the assessment of these skills was based on children attempting to repeat taught knowledge. Children's existing knowledge in mathematics is not used in assessment in many cases because of the over-riding influence of the curriculum (Aubrey et. al., 2000). Within primary schools in New Zealand, the focus of assessment is most commonly around the evaluation of a piece of work, according to predetermined criteria. Assessment by the teacher is guided by the achievement objectives 
outlined in the curriculum documents. For example, mathematics achievement outcomes and learning objectives may be singled out from the curriculum and reproduced in a list format for teachers to follow in their planning. Teachers may then concentrate primarily on pre-specified learning outcomes as opposed to following learning as it progresses. In early childhood, the assessment focuses on learning that evolves over time whereas in a primary school assessment generally indicates 'completed' learning, the difference between a learning goal and a performance goal.

The introduction of the diagnostic interview, a key feature of the Numeracy Project in New Zealand, changed assessment in mathematics from a focus on mastery to a focus on determining what the child can do. The diagnostic interview uses teacher-based interviews with individual children to determine children's existing knowledge and strategies in relation to the number framework. The teacher gains a picture of what each child can do from the diagnostic interview information and where the next learning step for that child is. This is not the only assessment tool used for mathematics in New Zealand. Other tools include informal teacher-devised assessments, basic facts tests, and progressive achievement tests. $^{27}$

Information about children's existing knowledge and skills on their entry to school should be regarded as a starting point for teaching and learning in school to reduce the disparities between the two environments and provide opportunities for children to build new knowledge from what they already know. New entrant teachers can accurately assess where the children are in terms of their mathematical content knowledge within days of the children starting school, yet the same teachers spend the rest of the year teaching 80 percent of the children what they already knew along with providing many opportunities to practice existing skills (Young-Loveridge, 1989b). This suggests primary teachers may not always use the information they have gathered effectively. It may also suggest that, although new entrant teachers gather assessment data on students effectively,

27 Progressive achievement tests are norm-referenced, standardised tests used to measure children's abilities in core curriculum areas against national and school standards. 
these assessments are over-ridden by teachers' existing beliefs about five-yearolds' mathematical competencies on school entry.

The social promotion policy in New Zealand schools contributes to the notion that at particular stages and ages children will have mastery of particular skills, strategies, and knowledge. Young-Loveridge (1991) found evidence to demonstrate that children have relatively stable numeracy skills at age five with a considerable range of achievement levels, yet some teachers in her study commented that they were familiar with only the very early levels of the curriculum because children moved on so quickly to the next class level. These teachers had little awareness of the range of abilities that children might possess, and, in fact, they assumed a readiness for children to move on after a short period in the new entrant classroom, adjusting to the ways of the school. In YoungLoveridge's (1991) study many teachers had predetermined beliefs about the mathematics skills of five-year-olds when they started school and what they needed to master in order to move successfully through the school.

Some teachers of five-year-olds believe that certain concepts in mathematics like problem solving are too difficult to learn at this early stage as they believe children lack the necessary knowledge and skills (Aubrey, 1997). Aubrey reports that many teachers in reception classes in England have a tendency to then overemphasise pencil and paper exercises in mathematics alongside developing rules and procedures. Aubrey claims that teachers with this focus do not adequately match children's existing strategies and skills to classroom programmes. These teachers, by continuing to hold these beliefs about the mathematics necessary for five-year-olds, teach a mathematics programme with a focus on knowledge transmission.

\subsection{Addressing discontinuities}

There are initiatives to reduce the discontinuity between pre-school and primary schools (Ministry of Education, 2007a; Tringham, 2006). These studies report on local initiatives in New Zealand that are aimed at increasing the level of communication and information existing between the two settings, one by building 'collegial and collaborative relationships' (Tringham, 2006, p. 11) and 
the other by creating photo books for children to familiarise them with school before they enter school. One early childhood teacher commented that "any project that gets a teacher from a contributing school to come into an early childhood centre is fantastic" (Ministry of Education, 2007a, p. 14). The Centres of Innovation projects in New Zealand funded by the Ministry of Education have supported some early childhood centres to set up their own research projects into areas of interest. One such project at Mangere Bridge Kindergarten (2008) for example aims to develop stronger links between kindergartens and primary schools.

The term 'school readiness' is used to describe a variety of understandings about what children need to know to be successful after their entry to school. In the past, the focus was predominantly on whether the child was ready to start school (Wasik, Bond \& Hindman, 2002). If the child was not determined to be ready for school, the problem was seen to lie within the child, but this perspective is changing (Wasik et al., 2002). This deficit view (of the child lacking school skills) has shifted to a focus on whether the school and the children are ready for each other. The school, and therefore the teachers, need to understand the prior experiences of the children to then make a positive impact on their learning (Wasik et al., 2002). Wasik et al. suggest that teacher beliefs about school readiness may make an impact on the programmes teachers provide. Their views shift the focus away from goals of socialisation and conformity to school to building a curriculum that incorporates the diversity of children's prior experiences and background in order to accommodate each child's specific learning needs. When schools persist with the notion that a child has to be ready for school, rather than the school ready for the child, and socialisation and conformity continue to be valued, children may be more likely to experience difficulties when they make the transition to school.

Early childhood teachers attach a high degree of importance to the child's social skills followed by their emotional maturity as strong indicators of school readiness (Cuskelly \& Detering, 2003). Sixty percent of the teachers in Cuskelly and Detering's study attached some importance to the child's academic competence, yet no teachers thought the environment the child was going to was 
important. The transition to school is a process that involves the child, their home, the school, and the early childhood setting, it should not be viewed in terms of the child making the transition and fitting into school in isolation.

Centres of Innovation studies in New Zealand for example Peters et. al., (2009), have come up with recommendations to help support a child's transition to school involving the use of artefacts (learning stories, portfolios), creating mutual projects between schools and early childhood centres and actively supporting and promoting learning continuity. The 2007b New Zealand Curriculum (Ministry of Education, 2007b) provided a means of fostering this continuity but this is dependent on both groups of teachers' abilities to make these connections.

In general, schooling differs from children's prior experiences at home or an early childhood centre in that schooling is more likely to have a focus on more structured procedures and problems specific to the school environment and the nature of the curriculum. A dissonance between the more prescribed school environment and the home or early childhood environment could have a profound effect on young children when they make the transition to school (Lave, 1990). In a school environment children are more often given focused problems to solve that are related predominantly to a single curriculum area. In the relatively lessstructured early childhood or home environment, problems arise out of real-life concerns. These problems do not fit neatly into one curriculum area, necessitating more than one approach or method to solve (Lambert, 2000). In the early childhood environment, this leads to problems being more open to multiple interpretations in contrast to the more 'guided discovery' approach common to school (Lambert, 2000).

\subsection{Summary}

The literature suggests teachers in primary schools believe children need to fit into the school system. This perception contrasts directly with that of early childhood teachers that children shape and direct their own environments through their interests and engagement with learning.

Primary teachers, concerned with the management of learning, use assessment methods to determine the gaps in a child's learning and then teach the next set of 
skills to further learning along a predetermined pathway. In early childhood centres, children control the direction of their learning according to their current interests, and teachers note these directions and progressions through learning stories based on discussions and observations. The child is perceived as an independent learner capable of managing themselves, yet on school entry, the teacher assumes control of the direction and progression of the learning in accordance with the curriculum and their beliefs about teaching and learning. It is widely agreed that children's transition to school can be more effectively supported when there are meaningful communications between all involved (Corsaro et al., 2002; Hopps, 2004; Carr et. al., 2010; Wasik et al., 2002). Children move into school more easily when they are familiar with the school environment, and their teachers know about the children's prior experiences and learning. Programmes that support effective transition need to be flexible, be inclusive, and recognise the needs of all involved. If teacher practices are to be better aligned between the early childhood and primary school settings, teachers may need to develop a more in-depth understanding about the existing knowledge of children and begin to act on this knowledge. Teachers in both settings need to work towards developing more open communication with each other making children's needs and requirements the focus of such communication.

Differences in assessment practice and a perceived lack of value attached to early childhood learning stories by primary school teachers may lead to teachers underestimating the existing knowledge held by children when they come to school. The underestimation of children's abilities combined with beliefs about the socialisation of children to school continue to influence teacher practices in the classroom and the success or otherwise of a child's transition to school. Part of creating effective transitions is to ensure the curriculum documents that underpin teacher practice contribute towards ensuring a continuity of teacher pedagogy and practice. Chapter 2 examined these documents to explore how commonalities in curricula exist with the aim of facilitating a smooth transition to school for children. Chapter 3 examined the development of teacher beliefs and the theories that underpin these. This chapter brought together teachers' beliefs and practices and the use of the curriculum to explore some of the ideas around 
the transition of children to school and their perceived readiness to learn with a focus on mathematics teaching and learning. In any discussion relating to the transition of children from an early childhood centre to a new entrant classroom, all the factors involved need to be recognised. Multiple factors influence the transition process (Carr et. al., 2010). The following chapters discuss the methodology of this study and the findings that emerged. 


\section{5: Methodology}

\subsection{Introduction}

This study aimed to investigate the beliefs and practices of kindergarten and new entrant teachers in New Zealand in order to develop a more in-depth understanding of the teaching and learning of mathematics. Of particular interest were the similarities and differences between teachers in the two educational settings as they work with children in mathematics.

Section 5.2 outlines the rationale and theoretical framework used for this case study. This section discusses the sociocultural approach that Cobb and Yackel (1996) and Tobin (2006) espouse. The use of a sociocultural approach within the evaluative case study lends itself to the collection of data from a wide variety of sources to gain detail about complex social situations.

Section 5.3 explores how the participation of the teachers, kindergartens, and schools was established through purposive sampling with due consideration to ethical guidelines. This section outlines the different methods of data collection and how the data were interpreted and analysed to maintain teachers' voices and illustrate their perspectives on teaching and learning. The section also explains the selection of the chosen mathematical events and how these were analysed and interpreted to highlight the mathematics teaching and learning that occurred. The words of the teachers have been used to illustrate aspects of this study, but the interpretation of their words and actions is mine. This section also discusses the potential for presenting a biased viewpoint and the measures that were taken to counter this possibility.

Section 5.4 examines how the data were analysed and collated using a model based on the work of Goos et al. (1999) to support the relationship between beliefs and practices in the classroom. A model of levels of interaction between kindergartens and new entrant classrooms is proposed and later used as a tool to analyse the observed interaction levels.

The final section, section 5.5, sets the scene for this study by profiling the school and kindergarten settings in this study. 


\subsection{Rationale and theoretical framework}

\subsubsection{Rationale for taking a sociocultural perspective}

This research is designed to explore the similarities and differences between teachers' beliefs and practices in kindergarten and new entrant classrooms in mathematics. A sociocultural perspective is used to examine the characteristics of teachers' beliefs and practices over the period when children make the transition from kindergarten to a new entrant classroom.

A sociocultural framework, as developed by Cobb and Yackel (1996) and expanded on by Tobin (2006), was chosen because of the potential to use collective forms of qualitative inquiry to build an understanding of the complexity of the relationship between teachers' beliefs and practices across the two settings, kindergartens and new entrant classrooms. This framework provides an opportunity for an in-depth exploration of these relationships and the identification of discontinuities.

My aim in conducting this research was to explore the discontinuities that might arise for children as they make the transition from kindergarten to primary school, particularly in relation to the teaching and learning of mathematics. Several studies explore children's mathematical knowledge around school entry and children making the transition to school (Aubrey, 1997; Aubrey et al., 2000; Baroody \& Ginsberg, 1990; Clarke et al., 2006; Dockett \& Perry, 2001, 2007; Dunphy, 2006; Perry et al., 2007; Peters, 2003, 2004; Pianta, 2004; Tringham, 2006; Young-Loveridge, 1998; Young-Loveridge et al., 1995). This study aims to provide insights specifically in relation to mathematics teaching and learning by focusing on teacher beliefs and practices in the two settings.

The focus of classroom research aims to provide a better understanding of the process of teaching and learning. Because this is an interpretive sociocultural study, a description of what happens in the classroom alongside teachers' explanations of their beliefs was used to examine the patterns of events and associated connections. Teachers' practice was observed, and comparisons between beliefs, practice, and curriculum documents were undertaken using three approaches - observations, questionnaires, and interviews. Similarly, teachers' 
beliefs about mathematics learning were compared with the curriculum documents that are the official guidelines of their practice and their observed practice in the classroom and kindergarten environments. Observations of mathematics practices in kindergarten and new entrant classrooms are described, including how teachers plan and assess to support children's learning. Mathematical events are described in vignettes and analysed in accordance with Perry and Dockett's $(2002,2005)$ categorisations as a way of building a picture of current classroom and kindergarten mathematics practices.

The following questions were posed for this research.

- Do teachers in kindergartens and teachers in new entrant classrooms share common beliefs and perceptions about mathematics learning?

- Are there similarities and differences between teacher practice in kindergartens and in new entrant classrooms that could influence the transition of a child to primary school?

- What links can be made between teacher practice and beliefs about mathematics learning in kindergartens and in new entrant classrooms that may ease the transition to school for children?

\subsubsection{Curriculum documents}

The New Zealand Curriculum Framework (NZCF) (Ministry of Education, 1993a), Mathematics in the New Zealand Curriculum (MiNZC) (Ministry of Education, 1992), and the early childhood curriculum (Te Whāriki) (Ministry of Education, 1996) were in operation for at least 10 years, but have been superseded by the New Zealand Curriculum (Ministry of Education, 2007b). This study relates to the first three documents. The Ministry of Education in New Zealand provided professional development for teachers on the introduction of each document.

\subsubsection{A case study approach}

A case study approach enables the interpretation of the beliefs and practices of kindergarten and new entrant teachers to form the basis of the analysis (Cohen, Manion \& Morrison, 2000). The strength of a case study approach lies in 
observations within a real-life context. Such observations are generally rich narratives that describe and analyse events systematically. Most case studies seek to understand a particular perspective or highlight particular events. Generally, case studies are defined in relation to the groups involved and portray an actual context and series of events.

There are several types of case studies, but they are most commonly identified in relation to their outcomes (Cohen et al., 2000; Denscombe, 2007; Merriam, 2002a; Stake, 2006). Stake (2006) would describe my study, which involves more than one setting, as a collective evaluative study because a more in-depth perspective may be gained using multiple settings. Merriam (2002a) further categorises four domains within which case studies are situated: ethnographic, historical, psychological, and sociological. This study fits most closely with what Merriam (2002a) and Stake (2006) describe as an evaluative, ethnographic case study in which an attempt is made to explain teacher beliefs and practices in relation to mathematics teaching. I used an evaluative case study approach in this study because it enabled, as a part of qualitative research, "a means of investigating complex social units consisting of multiple variables of potential importance in understanding the phenomenon" (Merriam, 2001, p. 41, 2002a). An important concern is that the case study does not stand in isolation, but is situated within a real-life context, so the researcher can search for the interrelationships and connections that lie between teacher beliefs and practices as they teach mathematics (Tobin \& Kincheloe, 2006). Teachers, children, and school communities do not exist in isolation; they interact through socially constructed cultural norms (Tobin \& Kincheloe, 2006) and understanding of the diversity of perspectives is developed through what Tobin and Kincheloe describe as "bricolage". Denzin and Lincoln (2008a, p. 5) refer to the researcher as the 'bricoleur' or a maker of quilts, because the researcher is putting together a large number of pieces of information to build a picture and tell a story. A teacher's perspective of the educational setting develops the cultural and social context in which they live and work. In this way, people from different backgrounds may relate to education through different lenses. When teachers come from similar backgrounds, Tobin and Kincheloe (2006, p. 9) say they share a "common 
culture". When students fall outside this common culture, they may be perceived as more likely to be lacking in some way, leading to an increased potential for educational difficulties.

In this study the observations and work with teachers in several settings, with the view of establishing in-depth knowledge and closely analysing information, gave the potential to establish generalisations to similar situations (Cohen et al., 2000). The difficulty in generalising from case study research due to the unique nature of each case is perceived as a weakness of this approach. Other perceived weaknesses of the approach are the possibility of presenting biased information and the difficulty in cross-checking, which may lead to doubtful reliability (Denscombe, 2007; Tobin \& Kincheloe, 2006). However, the opportunity to allow the data and the information gathered to speak for themselves counter-balances these concerns. The in-depth nature of a case study gives a unique perspective on a situation that may be lost in larger scale research projects such as surveys. Case study research is about real-life situations, so lends itself to catering for uncontrolled and unexpected outcomes through the bricolage of information gathered. Berry (2006) examines how bricolage can be used as way to research the complexity of human relationships and activities because it is about using many pieces of information and a variety of tools to attempt to build a more complete picture. Bricolage provides a broad lens through which to view many elements and structures within a study.

Steinberg (2006) believes an ethnographic approach lends itself well to bricolage and a sociocultural perspective because the analysis of events as they evolve within a natural setting and the social processes that are enacted all help to ensure that full and detailed descriptions and scripting of events occur. Ethnography is a description of peoples and/or cultures (Denscombe, 2001; Denzin \& Lincoln, 2008a). The purpose of ethnographic research is to contribute to building an understanding of why people do the things that they do; that is, to make more explicit the actions and beliefs of individuals through observations of human activities and the setting within which these activities occur (Angrosino, 2008; Aubrey et al., 2000). 
The teachers in this study were participants in the research because they played a part in gathering the data and confirming the data's accuracy. The researcher needs to spend time in the setting in order to describe the ordinary everyday events that occur. The resulting research becomes more than a description when combined with interviews and documentation; it is a construction of the totality of events (Denscombe, 2003). The large amount of detail gathered is part of the bricolage. As the participant observer in this situation, I was concerned with finding out how the members of the two groups (kindergarten teachers and new entrant teachers) understood mathematics teaching and learning and the meanings they had about this. Denscombe (2001, p. 212) stated that "the analysis of qualitative data calls for a reflexive account by the researcher concerning the researcher's self and its impact on the research".

Case study research allows opportunities for insight and understanding of the issues from the perspectives of those being studied, along with an interpretation of these issues by the researcher. This approach gave me the opportunity to use a wide range of ethnographic practices to collect information from the kindergartens and new entrant classrooms involved in this study. I used a combination of observations, semi-structured interviews, questionnaires, school and Ministry of Education documentation, and personal communications to obtain an understanding of teacher beliefs and practices in mathematics teaching over the transition from kindergartens to new entrant classrooms. The interpretive sociocultural approach taken in my study is based on the assumption that reality is based on social constructs with an agreed interpretation of the experiences that may be subject to change through social interactions (Merriam, 2001).

The use of case studies is well documented and widespread in social research as a way to build a picture of a complex situation (Denscombe, 2001, 2007; Denzin \& Lincoln, 2008b). The nature of the relationships between people and events can be explored using a variety of methods to gain information about a complex social situation to help researchers begin to understand why things happen in a particular fashion (Stake, 1995, 2006). A case study approach, as undertaken in my study, is a way to focus on the interconnected processes and relationships within social 
settings (Denscombe, 2001, 2003, 2007), in this case kindergartens and new entrant classrooms.

Gerring (2007) claimed that case study research is best defined as an in-depth examination of a single case (or a small number of cases) with the aim of being able to make generalisations across a larger number of cases with similar features. In some cases, the data gathered speak for themselves, but in most cases the researcher seeks to understand aspects of human behaviour and social perceptions in order to explore more general aspects of the study.

A primary feature of case study research is the investigation of complex and interrelated social situations. Each situation investigated in this study is unique to that particular setting. However, it was possible to find commonalities within each group, and the emergence of these commonalities can be taken as a possible indication that similar features exist across other new entrant classrooms and kindergartens in relation to teacher beliefs and practices in mathematics education (Carr \& Kemmis, 1986; Gerring, 2007; Ragin \& Becker, 1992).

Much case study research directly interprets events, with the observer interpreting what happened from their point of view. Smith (1999) is highly critical of case studies where a researcher claims to be an impartial observer of events. She claims that to accurately report events, the observer needs to empathise with the complex nature of what is being observed. The observer needs to understand and be aware of their own beliefs and values before reporting on another's. In most cases, it is not possible to be a completely impartial observer. Therefore, in this study, observations, semi-structured interviews, questionnaires, and school documentation were used to build as complete a picture as possible and led to the development of close relationships between the observer and the observed. My role was that of a participant observer where my identity as a researcher was explicit. This raises the question of the impact on what happened as a result of my presence, but time spent in the classrooms and kindergartens prior to data collection may counter some of this possible bias. 
Recognising the rights of those being studied or observed is a more recent development within the case study approach (Smith, 1999). The information gathered belongs to the group under study, and that group has the right to a final say on authenticity and the right to decline to take part at any stage of the process. The ability of the participants in this research to comment on the written up interviews helped to avoid bias that might have arisen from my interpretation of each teacher's comments. This opportunity for participants to give feedback was a major way of establishing the validity of the data gathered and helped to counter researcher bias (Aubrey, 1997).

This study is based on the sociocultural framework described by Cobb and Yackel (1996). Working within this framework involves investigating how teachers and students work together to create learning spaces within a sociocultural environment (Jaworski, 1993). Within this context, the role of the teacher becomes one of ensuring children have the opportunity to develop mathematical knowledge as they engage in social actions to solve specific problems. Jaworski (1993) believed that knowing is an action that a learner participates in by comparing new experiences with existing knowledge and adapting or reinforcing this knowledge to develop further. Shared meaning arises through social interactions and negotiation within the context of a community of learners, an idea supported by other researchers (Cobb et al., 1990; Forman, 2003; Lave \& Wenger, 1991; Tobin, 2006).

Within a sociocultural framework classroom discourse centres on the negotiation of shared meanings between teachers and children. This form of instructional and shared conversation is contrasted with a more traditional method, recitation (Lave \& Wenger, 1991). Lave and Wenger (1991) characterise this traditional method as one in which the teacher is the source of knowledge, and students are able to internalise and recite the facts through repeated practice, leading to individual skill mastery. By contrast, in what Lave and Wenger label as "reform classrooms", teachers and children develop multiple sources of learning approaches and solutions based on co-operation and collaboration within a community of learners. Within sociocultural theory, learning is related to social activity and discourse through involvement in a community of learners. 
Cobb and Yackel (1996) describe an evaluative framework within which to position classroom activity from both teachers and children. This framework allows for the emergence of unexpected events within a study. This approach is particularly useful within the context of case study as it allows for flexibility and unexpected information can be incorporated into the overall emergent picture. The sociocultural theory becomes a way of accounting for teachers' practices as they occur in the social context of the classroom. Although Cobb and Yackel's primary focus was on students' learning, they believe their framework could support the analysis of teacher behaviour in the classroom. They do not claim the framework can capture the events in a classroom but rather it can be used to examine practices in the context of a classroom, similar to the bricolage described by Tobin and Kincheloe (2006).

The framework shown in Table 5.1 describes the categories Cobb and Yackel (1996) used to support the analysis of classroom activities. I use this framework to analyse and interpret the data gathered. It provides a foundation through which to position the case study into a broader perspective outside the classroom community and allows for an in-depth look at teachers' classroom activities.

Table 5.1: Evaluative framework for analysing activity at classroom level

\begin{tabular}{|l|l|}
\hline Social perspective & Psychological perspective \\
\hline Classroom social norms & $\begin{array}{l}\text { Beliefs about own role, others' roles } \\
\text { and the general nature of mathematical } \\
\text { activity }\end{array}$ \\
\hline Sociomathematical norms & Mathematical beliefs and values \\
\hline Classroom mathematical practices & $\begin{array}{l}\text { Mathematical conceptions and } \\
\text { activities }\end{array}$ \\
\hline
\end{tabular}

Source: Adapted from Cobb and Yackel (1996, p. 177).

This research had no predetermined outcomes. A case study approach with a sociocultural lens was used to view the information gathered. This in-depth study allows opportunities to investigate the linkages between occurrences and settings (Denscombe, 2007). As a result of the interviews, observations, and extensive field notes that were gathered, common themes and similarities arose from the data. These common themes were used to build understandings about the teaching 
and learning of mathematics in the two settings. However, the reporting and analysis of the mathematical events, and teachers' beliefs and practices, although confirmed by teachers in this study, are primarily based on my interpretation of events.

\subsection{Ethical considerations and data collection}

The primary focus of the ethics of social research focuses on ensuring all participants are protected from the possibility of harm resulting from the research (Denscombe, 2007; Denzin \& Lincoln, 2008b). Within an education setting, the prevention of potential harm to teachers and students is of paramount importance. With this in mind, this section examines and discusses the underlying principles of this study.

In all approaches to the schools and kindergartens, ethical considerations were observed. The informed consent of teachers is a fundamental principle, so that teachers can make the decision to participate freely (Denscombe, 2007; Denzin \& Lincoln, 2008b; Stake, 1995). The teachers and principals at the selected primary schools were individually approached and invited to participate (the information letter and consent form are in Appendices A and B). I went to the schools to personally deliver the letters. I confirmed with teachers and principals that they understood they were under no obligation to participate and assured them that the information gathered would remain confidential and anonymous. I followed a similar process at the kindergartens (the information letter and consent form are in Appendices C and D).

In this study, individual consent was obtained after discussions with the teachers involved. Causes of unease among teachers (such as my use of a dictaphone) were freely discussed and accommodated. Teachers were fully informed about their right to withdraw from the study at any time without obligation. This was an important consideration given the extended period (up to 18 months) in which I would be involved in their working environments.

The ethical guidelines of the New Zealand Association for Research in Education were followed in this study, and ethical permission was gained from the Victoria University of Wellington Human Ethics Committee (No. 147/2005). 
Permission to carry out research in kindergartens was obtained from the regional Free Kindergarten Association.

Ensuring anonymity, a key issue in this research, was difficult due to the relationships between the schools and kindergartens. Every effort has been made to ensure specific contributions cannot be linked to a particular teacher or educational setting. In addition to this, individual interviews and observations were held to further protect the anonymity of participants. In the kindergartens, teachers completed a questionnaire. The questionnaire responses, once transcribed, were given back to individual kindergarten teachers to confirm their accuracy. The use of a pseudonym for each teacher also makes it more difficult to identify a particular individual's responses.

In New Zealand, an increasing number of researchers are in both early childhood and school settings, so particular care needs to be taken not to disrupt the environment. There needs to be recognition of the importance of fully communicating with the participants, so everybody is clear about the aims and objectives of the research and the value it may have (Hedges, 2001).

\subsubsection{Characteristics of the interviewer}

The characteristics of the interviewer inevitably have an effect on the interviewee and the interview (Denscombe, 2003). Every effort was made to reduce this effect with the interviewer attempting to maintain a passive and neutral stance while supporting the interviewee to be open and frank about their views.

My experience within the education sector has been a factor that allowed me to fit into different educational settings. I am a primary trained teacher with more than 25 years' experience. I was educated not only in New Zealand but in four other significantly different educational settings, in both public and private school systems. While most of my teaching experience has been in the primary school system, including new entrant teaching, I have taught in Samoa and undertaken research in pre-schools (Sherley, 2003), leading to a masters degree. I work as a lecturer in mathematics education at Victoria University of Wellington. This diverse experience at different levels of the education system, combined with my 
experience researching in another cultural setting, has helped me to develop an awareness of my own position in respect to others' positions.

Being an experienced teacher, as well as a researcher and lecturer, means I am comfortable and familiar in both the research setting and the education environment. The variety of my educational experiences, rather than my being educated and having teacher professional development within one cultural setting, has helped me to develop an open approach to observing teaching and learning in different settings.

\subsubsection{Selection of schools and kindergartens}

The school and kindergarten year in New Zealand runs from late January or early February to mid-December over four terms each of about 10 weeks. I decided not to collect data in the first four weeks of the kindergarten and school year to allow teachers and children to settle into their routines and establish their programmes.

The schools involved in this study had participated in teacher professional development in mathematics. Teachers in kindergartens and primary schools involved in this study had undergone professional development in relation to the curricula, and the schools had been involved in Numeracy Project ${ }^{28}$ professional development programmes for at least two years before their participation in this research.

I selected the schools for the research study, because I already had a relationship of trust with the teachers and principals who worked in them. Purposive sampling is an established way of selecting a sample that is particularly useful in qualitative research studies such as this one (Denscombe, 2007; Merriam, 2002b; Stake, 2006).

The research involved my interviewing new entrant teachers and observing in their classrooms. In a previous study, the relationship of trust took a considerable period to develop (Sherley, 2003), so I felt this timing issue could be overcome in some cases by using schools where such trust was already established.

${ }^{28}$ The Numeracy Development Project in New Zealand is a professional development project in mathematics designed to increase student achievement through teacher development programmes. 
The schools selected had participated in the Numeracy Development Project and were from a range of decile ratings. The decile rating of a school is based on a government assessment of each school in terms of the nature of the school community, particularly the predominant socioeconomic make-up of that community.

Within a purposive sample, extra attention is directed to the question of how representative the sample is. The sample of five schools in this study comprises about 20 percent of the schools in the particular region. In addition, the schools in this region have, in general, either a very high decile rating (10), corresponding to a high socioeconomic status community, or a very low decile rating (1).

The kindergartens were selected with regard to their proximity to the study schools, a further purposive sample. Each school in the study was observed along with their neighbouring kindergarten to explore the relationship they had with each other. A relationship of trust and mutual respect had to be developed in these kindergartens before observations and interviews commenced. Kindergartens were selected from the wide variety of early childhood settings in New Zealand, because they have had a closer historic relationship to primary schools (e.g., similar nature and length of teacher training) than the other early childhood settings (Middleton \& May, 1997).

Three of the five new entrant teachers introduced me to the teachers at their closest kindergarten, which helped me to build a relationship with those teachers. I visited each kindergarten for two hours before undertaking observations in order to familiarise myself with the environment and the participants.

Teachers had the opportunity to ask questions about the study, and informal discussions relating to the study indicated that no teachers appeared concerned about being observed and having their practice recorded and examined. Kindergarten teachers preferred not to be interviewed individually because of the difficulty of finding suitable times, so they asked if they could fill in questionnaires and speak informally to me as opportunities arose during the day. 
Teachers were given a pseudonym to protect their identity. Schools and kindergartens were given the same name and differentiated with a school or kindergarten label. Kindergarten and school teachers are differentiated in a similar fashion. For example, one school was called Aorangi School, the teacher was named Angela from Aorangi, and the associated kindergarten was labelled Aorangi Kindergarten as an indication of its proximity.

\subsubsection{Data collection}

The data collection consisted of observations of teachers in practice, interviews with primary teachers (Appendix E), and questionnaires for kindergarten teachers (Appendix F). School principals were interviewed separately (Appendices G and H). Kindergarten head teachers were given the same questionnaires as their staff were given. Several teachers were uncomfortable with my using a dictaphone in interviews, so I transcribed all the interviews verbatim.

In the primary school, new entrant teachers were interviewed at a time that was convenient for them. Teachers were interviewed in their classroom release time, during a lunch break, or after school. These interviews were transcribed as they occurred and were written up formally after the interview, then given to the teachers to confirm or clarify as necessary. Clarification of responses was also sought during the interview. The questionnaires for kindergarten teachers followed a similar format to the semi-formal interviews for new entrant teachers, but related primarily to kindergartens.

The evidence collected consisted of planning documents, learning stories, and long-term plans where teachers were happy to share these. No long-term plans were collected from kindergartens as kindergarten teachers in the study said longterm planning was not typically a component of their practice. Although kindergarten teachers might have had broad themes for the term, in general their plans were written up after the learning because teachers tended to follow and build on the interests of the children. I collected examples of learning stories from kindergartens. I did not collect daily plans in new entrant classrooms because these were working documents that teachers referred to and annotated as "work in progress". 
Table 5.2 summarises the observation hours and evidence collected from each location. The six types of data collection were coded as:

1. planning documents

2. learning stories

3. long-term plans

4. interview documentation

5. questionnaires

6. observations.

Table 5.2: Data collection in kindergartens and new entrant classrooms in schools

\begin{tabular}{|c|c|c|c|c|c|c|c|}
\hline \multirow[t]{2}{*}{ School or kindergarten } & \multirow{2}{*}{$\begin{array}{l}\text { Hours of } \\
\text { observation }\end{array}$} & \multicolumn{6}{|c|}{ Types of evidence collected } \\
\hline & & 1 & 2 & 3 & 4 & 5 & 6 \\
\hline Aorangi School & $\begin{array}{l}2 \text { sessions } \\
71 / 2 \text { hours }\end{array}$ & $\mathrm{X}$ & & $\mathrm{x}$ & $\mathrm{x}$ & & $\mathrm{X}$ \\
\hline Aorangi Kindergarten & $\begin{array}{l}2 \text { sessions } \\
7 \text { hours }\end{array}$ & & $\mathrm{x}$ & & & $\mathrm{X}$ & $\mathrm{X}$ \\
\hline Cascade School & $\begin{array}{l}2 \text { sessions } \\
7 \text { hours }\end{array}$ & $\mathrm{X}$ & & $\mathrm{x}$ & $\mathrm{x}$ & & $\mathrm{X}$ \\
\hline Cascade Kindergarten & $\begin{array}{l}2 \text { sessions } \\
61 / 2 \text { hours }\end{array}$ & & $\mathrm{X}$ & & & $\mathrm{X}$ & $\mathrm{X}$ \\
\hline Dundass School & $\begin{array}{l}3 \text { sessions } \\
8 \text { hours }\end{array}$ & $\mathrm{X}$ & & $\mathrm{x}$ & $\mathrm{x}$ & & $\mathrm{X}$ \\
\hline Dundass Kindergarten & $\begin{array}{l}2 \text { sessions } \\
7 \text { hours }\end{array}$ & & $\mathrm{X}$ & & & $\mathrm{X}$ & $\mathrm{X}$ \\
\hline Hikurangi School & $\begin{array}{l}3 \text { sessions } \\
8 \text { hours }\end{array}$ & $\mathrm{X}$ & & $\mathrm{x}$ & $\mathrm{x}$ & & $\mathrm{x}$ \\
\hline Hikurangi Kindergarten & $\begin{array}{l}2 \text { sessions } \\
8 \text { hours }\end{array}$ & & $\mathrm{X}$ & & & $\mathrm{X}$ & $\mathrm{X}$ \\
\hline Tongariro School & $\begin{array}{l}2 \text { sessions } \\
5 \text { hours }\end{array}$ & $\mathrm{X}$ & & $\mathrm{x}$ & $\mathrm{x}$ & & $\mathrm{X}$ \\
\hline Tongariro Kindergarten & $\begin{array}{l}2 \text { sessions } \\
6 \text { hours }\end{array}$ & & $\mathrm{X}$ & & & $\mathrm{X}$ & $\mathrm{X}$ \\
\hline
\end{tabular}


The primary school principals at the study schools were interviewed between March and August 2006. Questions were adapted from the interview questions for teachers.

Kindergarten head teachers were not interviewed separately from their teachers because they wanted to answer a questionnaire related to their practice.

Kindergarten head teachers were more involved in day-to-day teaching and learning than the school principals, who were more involved in school administration. In all instances, kindergarten head teachers and kindergarten teachers had similar beliefs, so the data gathered from these participants have been combined.

Time spent observing at the schools and the kindergartens was frequently variable because of the nature of the environment. Schools and kindergartens have unexpected events (e.g., staff absences and unscheduled visitors) that change daily programmes. The observations had to fit within the schedule of these environments and changed when required. The observations covered two days in each school, with an extra morning session in both Dundass and Hikurangi Schools. The other three teachers were unable to schedule a third morning observation session because of timetabling pressures. Tongariro School had two observations but for a slightly shorter time because a full school assembly took one afternoon out. Observations at each kindergarten covered two full morning sessions.

\subsubsection{Questionnaires and semi-structured interview trial}

The interview questions (other than the demographic questions) were piloted in a primary school and a kindergarten with teachers who were not associated with the study schools and kindergartens but were in the same geographic location. I did not include the demographic questions in the trial because they were straightforward.

The responses were analysed to critique the questions and ensure the desired information was being gathered. Some questions were too open, for example, the responses to question 4 (see Appendix I) about external factors influencing practice and beliefs showed that teachers predominantly thought about features 
such as time, equipment, and materials, but my expectation had been that teachers would give responses about the curriculum documents, long-term plans, and colleagues' expectations.

In question 2 (see Appendix I), relating to the exploration of teachers' beliefs and how teachers thought children best learned mathematics, it was evident that I needed to prepare follow-up questions to elicit more information. This was also the case in question 6 (see Appendix I). In these areas, I needed to ensure I probed further to gain all the information I sought. Responses from the pilot study (see Appendix I) were used to help determine what follow up questions could be needed in the informal interviews to expand further on teacher responses and were added to the semi-formal interview questions (Appendix E).

The pilot study suggested two similar sets of questions were necessary, depending on the setting of the interview (i.e., a questionnaire for the kindergarten teachers and questions for the semi-formal interview of new entrant teachers). Although the gist of the questions was the same, they needed to be tailored to the specific setting (e.g., referring to kindergartens specifically in the questionnaires).

All the kindergarten teachers returned completed questionnaires. Although the more formal nature of the questionnaire did not give me the same opportunities to expand on and develop teacher's ideas, opportunities arose during the kindergarten observation session for conversations about teacher's beliefs. I recorded these conversations in writing with the teacher's consent.

Kindergarten teachers completed their questionnaires in the week after the observation. Once I had written up the questionnaires, I returned them to each teacher to confirm their accuracy. No changes were required. In the reporting of these questionnaires, teachers' original words are used wherever possible.

In the new entrant classrooms, I interviewed teachers as soon as possible after the classroom observations. I observed teachers on at least two separate occasions and held a second interview of a more informal nature to clarify and extend some of the original interview comments. These interviews occurred during morning break, lunch break, or the transcript verification process. 


\subsubsection{Semi-structured interview questions}

Semi-structured interviews were used to support the development of questions about mathematics teaching and teachers' beliefs and practices. An interview is an active process, not a neutral exchange of questions and answers (Fontana \& Frey, 2008). The semi-structured nature of these interviews, combined with my personal and professional relationships with the teachers, meant I became a partner in the study rather than an impartial observer (Fontana \& Frey, 2008). The semicollaborative and ongoing partnership between the teachers and me was an important feature of the study. Engaging with teachers in their settings supported the development of a trust relationship where teachers felt confident not only to share and discuss their beliefs about mathematics teaching and learning, but also to expose their practice to observation and analysis. The questions, based on work by Aubrey (1997), Miller and Smith (2004), and McLachlan-Smith and St George (2000), were adapted to fit the needs of this study. The above studies related to literacy learning in particular, so I modified the general themes for mathematics learning. I designed the questions to enable themes to be extracted from the semistructured interviews and questionnaires.

The questions were grouped under several headings for ease of discussion. The questions related to:

- teachers' training, qualifications, and experience

- $\quad$ information about the learning setting

- $\quad$ knowledge of the curriculum

- perceptions of teachers' role

- parental involvement

- teachers' general beliefs about mathematics learning and teaching.

The questions aimed to elicit information from the teachers about their beliefs about what mathematics young children should learn and how children best learn mathematics. Of particular interest were the teachers' beliefs about the knowledge and procedures they thought best catered for the children's learning, how the teachers planned to meet these objectives, and the challenges teachers faced in meeting children's needs. 
The semi-structured interviews progressed through three stages. In the first stage, I discussed the purpose of the interview and asked introductory questions about the teacher's qualifications, experience, and mathematical knowledge. In the second stage, on the same day as the first stage, I explained the topics to be covered in the interview. In the final stage, each topic was examined in more depth as it arose, and I followed up issues that developed from the teacher's responses. Flexibility was essential to encourage the interviewee to expand on their views. The questionnaires for the kindergarten teachers were based along similar lines.

Follow-up from the interviews and questionnaires happened in all cases in a more informal fashion, over morning tea, over lunch, or during the transcript consultation process. (These follow-ups were written up in a similar fashion as the original interviews and questionnaires for later analysis.)

The semi-structured interviews gave me opportunities to probe deeply into teachers' responses. This necessitated my paying close attention to the interviewees in order to prompt further responses and reflections as the interview progressed.

\subsubsection{Observation schedule and recording}

The observation schedule was based on previous work done on recording schedules and supplemented by my own work with pre-school observations in Samoa (Denscombe, 2003; Sherley, 2003; Stake, 1995). Events were recorded at five-minute intervals with as much detail as possible in order to build a more complete picture of occurrences. An example of headings from the field and observation notes are in Appendix $\mathbf{J}$.

Participant observation was used as the main method of data collection complemented by interviews, school documentation, principal interviews, and questionnaires. Participant observation relies on the nature of the relationship established between observer and observed and requires a certain degree of involvement and understanding of the setting under study (Angrosino, 2008). Within this observation the researcher must take two roles: the role of a passive member of the group, so the patterns of behaviour are less disrupted and the role 
of an active observer in order to gather as many details as possible about the context of the observation (Aubrey et al., 2000).

Each session was recorded by hand using field notes and annotating specific events or incidental comments made by the teachers. Notes were transcribed immediately after the observation session to aid a more complete recall of each session. Cohen et al. (2000) suggest that the written records taken during observations, when written up immediately following a session and before another session, can provide full and detailed evidence of activities present. Alongside the full description of occurrences, a section of the schedule was allocated for the noting of any incidental events, comments, and environmental aspects of the school or kindergarten. The kindergarten observations related to all the teachers present in the kindergarten. The combination of a full recording of events that occurred and comprehensive field notes lends itself to a narrative style of case study.

\subsubsection{Categories of teacher interaction}

Common beliefs about teaching and learning mathematics are implicit in the kinds of interactions teachers have (Goos et al., 1999). Using a sociocultural perspective and systematically recording the evolution of events within a social situation gave me an opportunity to identify and explore common patterns of interactions that occurred across the kindergartens and new entrant classrooms (Denscombe, 2007). These commonalities were used to categorise the various interactions that occurred in these situations.

The following five categories emerged as common themes in the data gathered from observations and were decided after the collection of all observational data.

Teacher questioning: This category included the occasions when the teacher asked open-ended questions to support and extend children's thinking. Closed questions asked by the teacher were not recorded under this category.

Teacher organising: This category included the occasions when the teacher was organising the class and ensuring the children knew what to do, where to go, and what to get. The teachers were managing the children into an activity, such as getting the children to come and listen to a story, getting out equipment, talking 
with parents, and constructing opportunities to learn, in addition to organising the environment. Organisational activities that ensure the smooth running of the kindergarten and school were included in this category.

Teacher directing: This category included the occasions when the teacher was directing the learning of the children, giving instructions, or questioning the children along a specific teacher-predetermined pathway (generally, using closed questions).

Teacher supporting learning: This category included the occasions when the children were initiating or sustaining learning with the teacher supporting their choices and building on their learning.

Teachers talking about mathematics with children: This category included the occasions when the teacher was specifically supporting the development of mathematical concepts, number, space, measurement etc. The child usually initiated the mathematical event, and the teacher supported and extended the learning. Directed mathematical lessons where the teacher was directing the learning were not included in this category.

\subsubsection{Retaining the naturalness of the setting: Observer positioning in classrooms and kindergartens}

The primary consideration in my positioning as observer was to ensure as little disruption as possible to each setting. The position needed to be unobtrusive, but an effective vantage point. Familiarity with the site and time on the site contributed to the increasing acceptance of the observer.

At Hikurangi and Dundass Schools I sat out of the direct line of sight of the teacher. At Hikurangi School, I sat behind the teacher, and at Dundass School I sat slightly behind the teacher. The children and teacher appeared to ignore my presence in both schools.

Donna at Dundass School frequently commented to me about her opinion about what was happening and what was going to happen next. This seemed to be a common feature of Donna's practice. The teacher-aide in the classroom also received many side comments along the way. Angela at Aorangi School took little notice of me in her class. I was positioned at the back of the room out of her direct 
line of sight but with a good view of unfolding events. In the classroom of Tanya at Tongariro School, I sat to the side of the class and the children and teacher appeared to take little notice of my presence. At Cascade School, I sat near the back, again out of the teacher's direct line of sight, and it appeared that the children carried on as usual, paying no obvious attention to me.

All the teachers at some stage during each observation session commented on what happened in the classroom and their opinions about children starting school. These informal comments formed part of the data set I transcribed and analysed. In each kindergarten, I had a central observation point but moved round the kindergarten, always coming back to the central point before the next five-minute period. This gave me a good overview of what each teacher was doing in that particular period. The teachers were constantly on the move and appeared to take little notice of where I was situated, although on occasion a teacher would sit down with me and comment on what was occurring. This provided an opportunity for informal questioning. Teachers were told that their responses were recorded. I later transcribed these responses as part of the data set and analysed them accordingly. All transcriptions were confirmed as accurate by the relevant individual.

\subsubsection{Analysis of observational data}

The results of the observations for each kindergarten and new entrant classroom are reported individually (in chapters 6 and 7) under each of the five categories listed in section 5.3.7.

The total numbers of observations for each category were aggregated for kindergartens and new entrant classrooms separately to obtain one figure under each category. In both kindergartens and new entrant classrooms there were some discrepancies in the total number of observations accounted for by variations in observational times and environmental constraints (unexpected interruptions or events in the school day). By aggregating the data, these discrepancies are minimised. 


\subsection{Analysis of interview and questionnaire data}

In social research no clear distinction is drawn between "qualitative' and "quantitative" research (Denscombe, 2001, p. 173). These categories are not mutually exclusive, assumptions associated with both approaches tend to overlap and most distinctions arise in relation to the type and use of data gathered. Qualitative data tends to be associated with words as the unit of analysis and be more descriptive. Quantitative research tends to be associated with less personal involvement and numbers as the unit of analysis. Qualitative research is more concerned with patterns of behaviour and the interpretation of gathered information.

I analysed field notes to find common themes in the kinds of interactions the teachers engaged in. Table 5.3 illustrates the categories used to collate teacher's individual patterns of interactions (and is loosely based on the work of Goos et al. (1999)). The table allows for teacher beliefs about mathematics and how children best learn mathematics to be compared with observations of teacher practice in mathematics. These are reported in chapter 8.

Table 5.3: Teacher beliefs about aspects of mathematics learning and actions observed

\begin{tabular}{|l|l|}
\hline Beliefs relating to & Teacher actions observed \\
\hline Mathematics & Teacher-lead interactions \\
\hline Acquisition of mathematics & $\begin{array}{l}\text { Observations of structure of } \\
\text { mathematics lesson }\end{array}$ \\
\hline Readiness for learning & $\begin{array}{l}\text { Teacher knowledge of children's } \\
\text { existing knowledge }\end{array}$ \\
\hline $\begin{array}{l}\text { Necessary knowledge in mathematics } \\
\text { for school entry }\end{array}$ & $\begin{array}{l}\text { Teacher perceptions of children's prior } \\
\text { knowledge from early childhood }\end{array}$ \\
\hline
\end{tabular}

\subsubsection{Data unitisation}

The data gathered from interviews and questionnaires were compared with data gathered from observations in each setting, which enabled me to compare the 
beliefs of the practitioners and how they used the curriculum in practice and the kinds of experiences the children received.

I interviewed school principals for further information and corroboration of data. The data gathered from the interviews and questionnaires were compared with the information recorded in the observations to support the construction of an understanding of teacher beliefs and practices about mathematics education. The systematic comparison of this information, using Table 5.3, lead to the categorisation of discrete events, or incidences that lead to the unitising of the data gathered. Similar events and occurrences were grouped to form categories of information, which were in turn used to make explicit the dominant ideas emerging from this study (Aubrey, 1997).

To increase the credibility of the information gathered, I invested time in each setting to build a better understanding of the culture of the setting and trust with the participants. Prolonged exposure to the settings had the further advantage of allowing me to tease out the more important issues from the less important, using multiple sources of information, methods, and documentation.

During the field observations, I took comprehensive notes of mathematical interactions. From these notes, I wrote vignettes to illustrate the nature of the mathematics that occurred in the settings. Some of vignettes, chosen to illustrate specific mathematical events in this study, were analysed in detail to illustrate mathematisation in accordance with Perry and Dockett's (2002) categorisations (listed below).

The analysis of events provides rich data about the nature of the interactions occurring in mathematics. Perry and Dockett (2002) introduced seven categories relating to mathematical thinking that children have access to: mathematisation, connections, argumentation, number sense and mental computation, algebraic reasoning, spatial and geometrical thinking, and data and probability sense. The four latter categories are familiar, but the first three categories need clarification in a mathematical context. 
Mathematisation: the process of generating mathematical problems, concepts and ideas from real world situations and using mathematics to attempt a solution to the problems so derived.

Connections: mathematics learning is related to learning in other areas; learning in one area of mathematics can be relevant to learning in another area of mathematics; and the relevance of mathematics to the contexts in which the child is experiencing it.

Argumentation: the process that allows children to justify their own mathematical thinking and to understand other people. (Perry \& Dockett, 2005, p. 32)

I added a further two categories relating to expanding children's number knowledge and assessing and recording to contribute towards a broader description of the mathematical event: expanding children's number knowledge, and assessing and recording.

Not all categories were used to analyse each vignette. In each vignette, an example of the event used for the categorisation is identified in the comment section with colour coding used to illustrate the connection between an example of a mathematical event and the mathematical ideas evident in it. The Dockett and Perry (2005) framework is used with the addition of two categories I have added, expanding on mathematical knowledge, and assessing and recording. In each setting there were a number of possible choices for the vignettes to use in this study. The kindergarten vignettes were chosen to illustrate the full range of mathematical activities that were seen to occur. Again in the schools the vignettes were chosen to cover the gamut of mathematical activities, for example, shape, number, or algebra.

\subsubsection{Possible model of communication between the two settings}

The data collected from interviews and observations suggested that varying levels of communication existed between these settings. I developed Table 5.4 as a result of the interviews and observations to describe the classification of communication between the two settings. The table shows the nature of the communications that were observed between the new entrant classrooms and the kindergartens based 
on the comments teachers made. A table such as this could be used to strengthen and develop the level of communication between teachers at kindergartens and their neighbouring schools.

Visible signs of communication included:

- $\quad$ school visits (how often and when was the kindergarten involved?)

- combined meetings with the kindergarten and new entrant teachers to explore common issues or concerns

- both settings sharing newsletters and communications with parents

- teachers communicating by telephone

- teachers having regular visits and meetings to discuss various issues and concerns relevant to all parties

- teachers sharing information about where each institution was going and their combined and separate purposes and aims.

Depending on the nature of the communications between the two settings, the schools and kindergartens were classified into three levels of communication with level 3 being the most interactive level and level 1 the least interactive. The level of interaction between each pair of settings was determined from the comments teachers made about each setting and how they defined their relationships with each other in these settings. For example, when the new entrant teacher and the teachers at the corresponding kindergarten spoke about communicating with each other, working together for the benefit of the children, and knowing about children's existing knowledge and school, they were deemed to be a pair with high communication levels. This contrasts with a school and kindergarten pair who, from their comments about each other, appeared to operate completely separately and independently from each other.

Table 5.4: Model of communication levels between teachers in kindergartens and in new entrant classrooms

\begin{tabular}{|l|l|}
\hline Level & Description of communication \\
\hline Level 3 & $\begin{array}{l}\text { A common enterprise } \\
\text { Working in collaboration }\end{array}$ \\
\hline
\end{tabular}




\begin{tabular}{|l|l|}
\hline & $\begin{array}{l}\text { Unified purpose } \\
\text { Two-way interactive communication } \\
\text { Curriculum flow } \\
\text { Common interest }\end{array}$ \\
\hline Level 2 & $\begin{array}{l}\text { A separate enterprise with some degree of collaboration } \\
\text { Perception that kindergarten is there to prepare children for school } \\
\text { Predominantly one way communication } \\
\text { Hierarchical progressions for learning } \\
\text { School is more important than kindergarten } \\
\text { Separate unrelated curricula }\end{array}$ \\
\hline Level 1 & $\begin{array}{l}\text { Segregated enterprises } \\
\text { Separate purposes } \\
\text { Separate aims } \\
\text { Curricula not linked } \\
\text { Limited communication }\end{array}$ \\
\hline
\end{tabular}

Table 5.4 is also used in chapter 8 to describe the levels of communication perceived between the schools and kindergartens in this study.

\subsubsection{Interview analysis}

I analysed and categorised the interviews by major themes related to teacher beliefs about mathematics education. The major themes emerging were the 'units' used for analysis. Denscombe (2001) refers to this process as "unitizing" the data. I used the template in Appendix K (adapted from McLachlan-Smith and St George (2000)), to classify the major themes that arose from the observations and interviews.

The multi-method approach - a combination of interviews, questionnaires, observations, and document collection - used to gather a variety of complementary information enabled me to build a comprehensive picture of the study environments. The variety of data related to the same topic led to a more detailed understanding than if I had used only one source of data. It is a strong indication of the reliability of the evidence (Denscombe, 2001, p. 85). 
Events recorded at five-minute intervals throughout the observation were combined with notes about any important contextual factors or comments to supplement the observations. Figure 5.1 illustrates the overlap of data gathered from multiple sources. As Denzin and Lincoln (2008b) suggest, real objectiveness cannot be captured. However, the combination of more than one method adds depth to the investigation and the subsequent interpretation of the information.

Figure 5.1: Data overlap from multiple sources

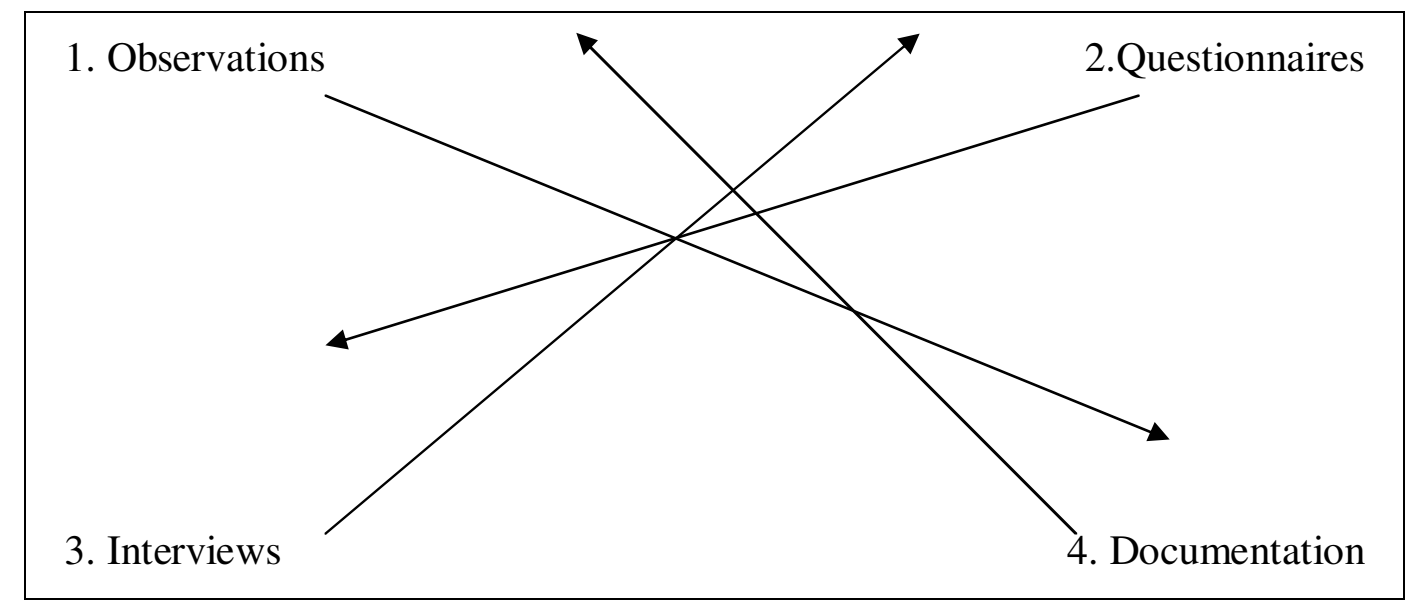

Source: Based on Denscombe (2003, p. 133).

Qualitative data is concerned with meaning and how people understand events along with patterns of human behaviour. A major feature of qualitative research that distinguishes it from quantitative research is how the data are collected and analysed. The data used in this study were a result of the way they were collected, interpreted, and then used by the researcher (Denscombe, 2003). My identity as a teacher, researcher, and facilitator along with my values and beliefs all played a role in the way the data were gathered and interpreted. As much as possible I have separated my personal experiences from the information gathered, but my identification within the educational community will have had an influence on the nature of the information gained. To partially overcome this bias, I have used the teachers' words to describe and reflect on their practice wherever possible.

From the observations, field notes, and interviews and questionnaires, a sense of the typical lesson structure emerged. This structure supported a means of analysis of typical lesson progressions within both the kindergartens and new entrant classrooms. The unitisation and categorisations exemplified by Denscombe 
(2001) and Aubrey (1997) were utilised to form a table (in Appendix L) to allow general themes to emerge. These themes are discussed in chapters 6 and 7 .

Within each mathematical event, along with the mathematisation of the vignettes, I analysed the lesson progressions to try to determine the common features of a mathematical learning activity. This task structure analysis is reported in chapters 6 and 7.

\subsection{Setting the scene: Profiles}

A new entrant classroom caters for children (usually five-year-olds) in their first year of formal schooling while kindergartens cater for children usually aged three to five. Differences in the two settings form part of my investigation into teacher practices and beliefs in mathematics teaching and learning. Each situation is briefly described in this section along with common features particular to kindergartens and new entrant classrooms.

Part of the issue surrounding kindergartens and new entrant classrooms is that they are different environments and these differences may contribute to the discrepancies between them. Kindergartens cater for children before they go to school. In this study, the focus is on teachers' beliefs and practices in mathematics. These children were generally experienced in the kindergarten environment, were comfortable with the routines, and were familiar with their teachers. In the new entrant classroom, the children were new to the environment and were part of the youngest group in the school. Teachers in new entrant classrooms have the task of familiarising children to the school environment, including establishing school routines. Although the focus in this study is on teachers' practices and beliefs in mathematics teaching and learning, the teachers were dealing with two distinct groups of children, one group at the end of their time in a kindergarten and another at the beginning of a new period at school.

\subsubsection{Kindergarten profiles}

The following kindergarten profiles provide background details to this study but do not disclose identifying details. Kindergartens have been given the same name as the nearby school to show their proximity to each other (Aorangi, Cascade, Dundass, Hikurangi, and Tongariro). 
Kindergartens were noticeably more similar to each other in terms of their physical and environmental attributes than were the new entrant classes. In particular, all the kindergartens had a smooth indoor-outdoor flow with children able to move freely around the whole space. Teachers regarded the entire kindergarten, both indoor and outdoor, as their teaching space, unlike the new entrant teachers who appeared to regard their teaching space as only within the classroom.

The kindergartens had children from many ethnicities, although Aorangi and Dundass had more Pākehā ${ }^{29}$ children than the other kindergartens. Aorangi and Dundass were the only kindergartens with only Pākehā teachers; the other kindergartens had Māori, Samoan, and Pākehā teachers. The rosters of parent helpers were from a range of cultures in all the kindergartens. More detailed information about each teacher is outlined in Appendix U.

Typically, within the kindergarten environment a group of children had two or three teachers. The number of teachers employed in the kindergarten determines the number of children that are allowed to be present, most commonly 25 to 45 children. Teachers organise a variety of activities and set out equipment, and spend most of their time interacting, observing, assessing, and supervising the children. The children, the teacher, or both determine the orientation or direction of an activity. In most instances, mathematics events result from the activities of the children, so are usually not planned.

Kindergartens in this study were inviting places to be a part of with teachers and children continually involved in a variety of activities. Teachers interacted freely with different groups of children and were concerned that children were given the freedom to develop and express their ideas with some support.

The development of positive learning dispositions was emphasised and seen in wall displays that communicated this to parents. Wall displays were in more than one language and clearly linked the children's learning to the goals and aims of the curriculum. Alongside the displays in each kindergarten were areas designed

29 Pākehā is a commonly used Māori word to describe individuals of predominantly European descent in New Zealand. 
to keep parents informed about the learning that was developing in the kindergarten.

Management routines were evident in the way children entered the kindergarten and moved around in the space, hanging up their bags and placing shared items in designated areas. Areas were designated for common equipment and activities and children had freedom of choice around these areas.

\section{Aorangi Kindergarten}

Aorangi Kindergarten was a decile 10 kindergarten with two teachers, both with more than 10 years teaching experience.

The kindergarten had a large irregularly shaped indoor area that flowed naturally to the outside, parts of which were covered for sun protection.

The inside-outside areas were informally set up so that particular spaces could be designated for specific activities, such as a puzzle space, a woodworking area, or a home corner. However, no barriers existed between the spaces, so children could move freely between activities.

All equipment was accessible to the children as they needed it.

A large mat area formed an integral part of daily whole-group activities and served as an important meeting place for the children and teachers.

Displays around the walls were in English, Māori, and Samoan and featured a combination of children's work, teacher write-ups of learning stories, information for parents, and commercial posters featuring various aspects of learning. Similar displays featured in the other four kindergartens.

\section{Cascade Kindergarten}

Cascade Kindergarten was a decile 1 kindergarten with three teachers. Two of the teachers, including the head teacher, had been at the kindergarten for more than 15 years, and the third teacher had 2 years teaching experience.

Children had freedom of access to the indoor-outdoor areas.

Teachers provided the children with toast as they arrived at the kindergarten, which served as a time to catch up or chat and set the tone for the morning. 
Teachers saw the provision of food as children entered the kindergarten as a social time.

Equipment and resources were set out so children had free access to whatever they want, with particular areas clearly intended for specific activities.

A designated mat area was used for group activities at the end of the morning.

\section{Dundass Kindergarten}

Dundass Kindergarten was decile 10 kindergarten with three teachers, the head teacher had 12 years teaching experience while the other two teachers had 1 and 5 years teaching experience respectively.

The kindergarten had a good indoor-outdoor flow and the children constantly moved between different spaces and had many opportunities to interact with a variety of activities.

A large covered outdoor area enabled children to use the area even during the wettest, coldest weather.

A large mat on one side of the kindergarten provided further opportunities for free play, movement, dance, and large-block constructions and served as a communal meeting area for teachers and children.

\section{Hikurangi Kindergarten}

Hikurangi Kindergarten was a decile 1 kindergarten with three teachers, all of whom had at least ten years teaching experience.

The kindergarten consisted of a large, irregular open space with varied alcoves in which children could explore. The indoor-outdoor flow in the kindergarten was well managed and well used by both teachers and children.

The physical attributes (including a mat area) were very similar to those in the other kindergartens.

This was the only kindergarten that restricted the children's activity choices in any way apart from during the communal mat times common to all kindergartens. For half an hour each morning the children were gathered in the areas with literacyand mathematics-type activities, because the teachers said they wanted to ensure 
all the children experienced these activities. The teachers had observed some children avoiding these activities in favour of more physical choices.

\section{Tongariro Kindergarten}

Tongariro Kindergarten was a decile 2 kindergarten with three teachers. The head teacher was an experienced teacher with more than 20 years teaching and the other two teachers both had 3 years experience at this kindergarten.

As in the other kindergartens, this kindergarten had a large open-plan area with many opportunities for intimate work spaces. There was a large, open, mat area where the children gathered for certain occasions and a combination of shaded and open outside areas. The children were not restricted in the areas they could use, which helped encourage the indoor-outdoor flow of children and teachers.

\subsubsection{New entrant classroom and teacher profiles}

The following classroom and teacher profiles provide background details to this study but do not disclose identifying details. The schools of the new entrant classrooms are Aorangi, Cascade, Dundass, Hikurangi, and Tongariro Schools and their teachers are, respectively, Angela, Caroline, Donna, Hiria, and Tanya. Each classroom was a single room with one teacher. Four of the five classrooms were connected by an internal door to the next room. This door was closed while I was there.

The teachers were all of Pākehā descent.

Each classroom had a mat area that was used for whole-class and group activities as determined by the teacher.

All teachers had some teacher-aide time allocated to them to support children's learning. Only one teacher used this teacher-aide time to support mathematics learning.

Each teacher had a daily plan and followed events from their weekly timetable. The following briefly describes the environment of each classroom. At mathematics time in the new entrant classroom the teacher primarily worked with small groups of children while other children worked on independent or 
practice activities for mathematics. The teacher usually worked alone in the classroom, although sometimes had the support of a teacher-aide who might take responsibility for supervising a group working on a practice or an independent activity. In contrast to the situation in kindergartens, the teacher usually determined the direction of the mathematics learning. Teachers had long-term plans for mathematics and daily mathematics plans for lessons.

The schools in this study are characterised by their structure and routine. The classrooms were self-contained units with the teacher in charge of the classroom and the learning that occurs within. On first impression, these classrooms were all inviting, warm, and busy places. The teachers cared about the children in their class and were concerned about ensuring children got the best possible start to their schooling.

A common feature was the variety of displays around the classroom walls, all in English, drawing children's attention to aspects of their learning. No displays informed parents about the curriculum or learning progressions that children were participating in. Routines were established and classrooms had clearly defined systems for moving around the room and organising materials and activities.

\section{Angela at Aorangi School}

Aorangi School was a decile 10 school with a large percentage of New Zealand children of Pākehā descent (90 percent).

The new entrant teacher, Angela, was an experienced teacher with more than 20 years' service. Her highest level of mathematics was University Entrance, Year 12. Her classroom was a warm ${ }^{30}$ and inviting place where children knew the routines.

Mathematics lessons usually occurred before the morning tea break (10.30 am) for about 50 minutes. There were 24 children, mainly Pākehā, in the class. Four children had English as their second language. Other ethnic groups represented were Māori, Samoan, Asian, and South African. No classroom displays acknowledge any language other than English.

30 Dockett and Perry (1999, p. 12) use the adjective 'warm' to describe the feeling of some classroom environments. 
The classroom was one of several set around a communal area that teachers in the block used as an extra space for children working independently. Children needed a teacher's permission to leave their room and move to the central space.

\section{Caroline at Cascade School}

Cascade School was a decile 1 school with a multicultural pupil composition.

The new entrant teacher, Caroline, had 23 children in her class. The children were predominantly of Māori or Pacific Island descent with one Pākehā child. Caroline had more than six years' experience teaching new entrant children and her highest level of mathematics was year 13.

Caroline had a range of mathematics displays in English in her room along with a display of Māori artefacts. The classroom was self-contained ${ }^{31}$ and opened on to a large deck. The deck was not used as part of the teaching space. Children, during teaching hours, were restricted to the classroom space.

Children were expected to line up outside the classroom when the first school bell went and wait until the teacher invited them in to sit on the mat. This formal mat time signalled the start of the day for the children and was a feature of entry to the classroom after each break time.

\section{Donna at Dundass School}

Dundass School was a decile 10 school with a predominantly Pākehā pupil composition.

The new entrant teacher, Donna, had no children in her class with English as a second language.

Donna was an experienced new entrant teacher with more than 10 years' teaching at this level and University Entrance mathematics, year 12.

The classroom environment was inviting and children appeared to be always occupied. Donna had established routines to socialise the children into school. Classroom displays were all in English.

31 Not attached to other classrooms or linked with a common area to other classrooms. 
Although this was a separate classroom space, it was part of a large open-plan area with high partitions that divided the area into self-contained teaching units with some communal open space. Donna did not use the communal space and kept the children within her appointed space.

\section{Hiria at Hikurangi School}

Hikurangi School was a decile 1 school with a large proportion of pupils from Pacific Island countries (80\%).

The new entrant teacher, Hiria, had six years' experience in the new entrant classroom at the school and had developed an inviting classroom environment. She emphasised establishing good routines for the children when they started school. She had achieved year 13 level mathematics.

Hiria had 15 children in her class of Samoan descent.

Classroom displays were all in English with no reference to any other language. The displays were bright and colourful.

This was a self-contained classroom space, considerably larger than the others in this study, with more area for the children to move around in. Children worked in areas as directed by their teacher. Although there were numerous areas in this room for the children to work in, they were restricted in their movements around the room.

\section{Tanya at Tongariro School}

Tongariro School was a decile 2 school with a multicultural pupil composition. The new entrant teacher, Tanya, had less teaching experience than the other teachers in this study (two years) and had completed first year mathematics at university.

Tanya's class was a mixture of children from Pākehā, Māori, Samoan, and Asian descent. Four children had English as a second language.

Tanya's classroom was a 'warm' (Dockett \& Perry, 1999) place with a variety of displays, all in English. 
The classroom was connected to the other rooms in the block by a rear corridor and the front door opened directly on to a courtyard. Children stayed within their classroom during teaching times unless specifically directed by their teacher.

\subsubsection{Summary tables}

Table 5.5 summarises the information about the schools and kindergartens, including the number of teachers and their self-described ethnic background. Table 5.6 contains information about the ethnic composition of the new entrant classrooms and kindergartens in this study at the time of the first observations. Some variations in this occurred over the time of the study.

This information was collected and later related to the amount of attention teachers paid to the ethnic composition of their classroom and kindergarten. 
Table 5.5: Information relating to schools, kindergartens, and teachers

\begin{tabular}{|c|c|c|c|c|}
\hline $\begin{array}{l}\text { School or } \\
\text { kindergarten }\end{array}$ & Decile & $\begin{array}{c}\text { Prior } \\
\text { relationship } \\
\text { with } \\
\text { researcher }\end{array}$ & $\begin{array}{c}\text { Number of } \\
\text { teachers } \\
\text { interviewed }\end{array}$ & $\begin{array}{c}\text { Stated } \\
\text { ethnicity of } \\
\text { teachers }\end{array}$ \\
\hline Aorangi School & 10 & Yes & 1 & European \\
\hline $\begin{array}{l}\text { Aorangi } \\
\text { Kindergarten }\end{array}$ & 10 & No & 2 & European \\
\hline Cascade School & 1 & Yes & 1 & European \\
\hline $\begin{array}{l}\text { Cascade } \\
\text { Kindergarten }\end{array}$ & 1 & No & 3 & $\begin{array}{l}\text { Māori, } \\
\text { European }\end{array}$ \\
\hline Dundass School & 10 & Yes & 1 & European \\
\hline $\begin{array}{l}\text { Dundass } \\
\text { Kindergarten }\end{array}$ & 10 & No & 3 & European \\
\hline Hikurangi School & 1 & Yes & 1 & European \\
\hline $\begin{array}{l}\text { Hikurangi } \\
\text { Kindergarten }\end{array}$ & 1 & Yes & 3 & $\begin{array}{l}\text { European, } \\
\text { Samoan, } \\
\text { Māori }\end{array}$ \\
\hline Tongariro School & 1 & Yes & 1 & European \\
\hline $\begin{array}{l}\text { Tongariro } \\
\text { Kindergarten }\end{array}$ & 2 & No & 3 & $\begin{array}{l}\text { Māori, } \\
\text { Samoan, } \\
\text { European }\end{array}$ \\
\hline
\end{tabular}

Note: The decile ranking of a school in New Zealand relates to the socioeconomic status of the area in which the school is located with a ranking of 10 relating to the highest socioeconomic status and 1 the lowest. 
Table 5.6: Ethnic composition of kindergartens and new entrant classrooms in percentage terms

\begin{tabular}{|c|c|c|c|c|c|}
\hline $\begin{array}{l}\text { School or } \\
\text { kindergarten }\end{array}$ & Decile & $\begin{array}{c}\text { Pākehā } \\
(\%)\end{array}$ & $\begin{array}{c}\text { Māori } \\
(\%)\end{array}$ & $\begin{array}{c}\text { Samoan } \\
(\%)\end{array}$ & $\begin{array}{c}\text { Other } \\
(\%)\end{array}$ \\
\hline Aorangi School & 10 & 90 & 5 & & 5 \\
\hline Aorangi Kindergarten & 10 & 75 & 5 & 5 & 15 \\
\hline Cascade School & 1 & 10 & 40 & 50 & \\
\hline Cascade Kindergarten & 1 & 15 & 40 & 35 & 10 \\
\hline Dundass School & 10 & 85 & & 5 & 10 \\
\hline Dundass Kindergarten & 10 & 80 & & 5 & 15 \\
\hline Hikurangi School & 1 & & 20 & 80 & \\
\hline Hikurangi Kindergarten & 1 & 12 & 37 & 40 & 11 \\
\hline Tongariro School & 1 & 37 & 38 & 15 & 10 \\
\hline Tongariro Kindergarten & 2 & 20 & 65 & 10 & 5 \\
\hline
\end{tabular}

\subsection{Summary}

This chapter began by outlining the broad theoretical framework and research questions used in this study. A sociocultural framework and a case study approach formed the basis of this research. Descriptions were provided of the data collection methods and how these were used to build a rich description of the learning and teaching of mathematics in new entrant and kindergarten classrooms, alongside an exploration of teachers' beliefs relating to mathematics teaching and learning. Selected vignettes of mathematical events were analysed using a framework developed by Perry and Dockett $(2002,2005)$ to describe the nature of the mathematics that occurred within the two settings. Through information gathered from interviews and observation, a table was developed that begins to classify the levels of interaction between the schools and kindergartens. Brief descriptions of the environments were provided to more fully situate the research settings. 
In the following three chapters, I present the findings from the kindergartens and new entrant teachers. Chapters 6 and 7 discuss the mathematics teaching and learning in kindergartens and new entrant classrooms respectively. Chapter 8 discusses the beliefs and practices of teachers in both environments about the transition of children to school. 


\section{6: Findings: Kindergarten teachers' beliefs and practices in mathematics teaching and learning}

\subsection{Introduction}

This chapter focuses on the findings from the observations, questionnaires, and interviews about teachers' beliefs and practices in kindergartens in relation to mathematics teaching and learning. The information collected gives a consistent picture of mathematics education and teachers' beliefs and practices over the period before children make the transition to school.

Kindergarten teachers in this study said they held a holistic view of children's learning, and this was evident in both their beliefs and their practices in mathematics teaching. Their view of the holistic development of children was based on kotahitanga, the second principle of the early childhood curriculum, Te Whāriki (Ministry of Education, 1996, p. 41). This principle incorporates a view of learning based on a child's whole context, their surroundings, their emotions, their relationships, and their needs.

Kindergarten teachers in this study saw children's learning as a combination of experiences to build positive learning dispositions rather than as individual tasks or experiences in different learning areas. Teachers believed they were engaged in developing children's positive dispositions towards learning, and their teaching activities focused on identifying and supporting opportunities to achieve this aim. This became apparent through the analysis of teachers' responses to questionnaires, subsequent discussions with teachers, and observations of their practice. Detailed observations of mathematical events were selected to incorporate contextual factors when teachers supported and extended mathematical learning.

This chapter relates to kindergarten teachers. The observations reported relate to teachers as they interact with children in their final months of early education at kindergarten before going to school. Children were experienced in the ways and expectations of the kindergarten and familiar with their teachers and peers. Teachers worked with children in flexible groupings (one or more children) as incidents occurred. Teachers were able to extend and develop children's learning 
as they saw it evolving and take advantage of incidents as they arose in the environment.

The kindergarten teacher's role is not the same as that of a new entrant teacher. In a new entrant classroom, the teacher has a group of children, from a variety of early childhood settings (including the home), that are new to school. These children have to adjust to a new social context with different social requirements and the teacher's job is to support this adjustment in conjunction with continuing the child's education. The role of a new entrant teacher is not equivalent to that of a kindergarten teacher as they have different settings, groups of children at different stages, and varying organisational structures. These differences need to be kept in mind during the following discussion. Both groups of teachers are constrained by these differences. In terms of the activities provided, kindergarten teachers worked with variable groupings for differing periods. New entrant teachers were more restricted by their curriculum and developing the rules and norms of the school environment with a new group of children.

The mathematical activities reported here are in the form of vignettes about occurrences in the kindergarten. These vignettes resulted from opportunities that arose as the children interacted with their environment. In every instance but one, teachers were seen to enter into the activity and support children as they explored and developed their activities. There were no perceived time constraints or environmental constraints other than the end of the kindergarten day.

Wherever possible, the words of kindergarten teachers are used to illustrate their beliefs and practices. However, the interpretation of their words is mine. The evidence gathered focuses on the 14 kindergarten teachers who participated in this study. Teachers' observed practices are described in conjunction with descriptions of their beliefs obtained from questionnaires and informal discussions with teachers. The relationship between the beliefs and practices of kindergarten teachers relating to mathematics teaching and learning is examined and supplemented with descriptions and analysis of selected mathematical events recorded in kindergartens in the form of vignettes. 
6: Findings: Kindergarten teachers' beliefs and practices in mathematics teaching and learning

Each vignette contains an introduction to and explanation of the observed event, and is followed by a descriptive table that highlights the mathematisation of the event and provides commentary to support the event.

\subsection{Teachers' beliefs and practices about how children learn mathematics}

The way teachers organise their practice is based on their beliefs about mathematics teaching and learning in addition to curriculum and school constraints and requirements (Rivalland, 2007). Personal experiences combined with experiences as a teacher and a learner contribute to teachers' perceptions of how best to teach mathematics and what makes a good teacher of mathematics. This section examines some of these beliefs and their manifestation in practice from observations, questionnaires, and informal discussions with teachers.

Kindergarten teachers were found to have a close relationship between what they did (their practice) and what they believed about how children best learned mathematics (their beliefs). The observations gathered were analysed and compared with statements teachers had made about their beliefs. This is supported by a description from one kindergarten that illustrates the relationship observed between teachers' practice and beliefs.

The data from kindergarten observations show different events happening in kindergartens. Information relating to kindergarten teachers' practice was collated and categorised. Responses were aggregated from each kindergarten and reported as a single set of data under each category. The aggregation of data across all kindergartens in the study helped counter small variations in the time spent in each kindergarten and allowed for these discrepancies to be evened out over the kindergartens. Responses are reported under the headings (see the earlier discussion in section 5.3.7):

- teacher questioning: teachers asking open-ended questions of children

- teacher organising: teachers organising activities that contribute to the smooth organisation of the kindergarten

- teacher directing: teachers giving directions or using closed questions to direct learning 
- teacher supporting learning: teachers building on child-initiated learning

- teachers talking about mathematics with children: teachers responding to child-initiated mathematical activities.

Table 6.1 summarises these events. Just over half of all interactions involved organising and directing children's learning (categories 2 and 3). This was not unexpected given the age of the children and is consistent with findings from Hamre and Pianta (2007). The remainder of time involved teachers as they supported children in a variety of ways, by asking open ended questions, providing appropriate support to extend the children, and talking about mathematics with children.

Table 6.1: Summary of observed kindergarten events in each response category

\begin{tabular}{|l|c|c|c|c|c|c|}
\hline $\begin{array}{l}\text { Category of } \\
\text { response }\end{array}$ & Aorangi & Cascade & Dundass & Hikurangi & Tongariro & $\begin{array}{r}\text { Total } \\
\text { responses } \\
(\%)\end{array}$ \\
\hline $\begin{array}{l}\text { 1. Teacher } \\
\text { questioning }\end{array}$ & 15 & 11 & 39 & 14 & 10 & $\begin{array}{r}89 \\
(9 \%)\end{array}$ \\
\hline $\begin{array}{l}\text { 2. Teacher } \\
\text { organising }\end{array}$ & 46 & 128 & 77 & 90 & 72 & $\begin{array}{r}413 \\
(44 \%)\end{array}$ \\
\hline $\begin{array}{l}\text { 3. Teacher } \\
\text { directing }\end{array}$ & 28 & 16 & 20 & 20 & 14 & $\begin{array}{r}98 \\
(10 \%)\end{array}$ \\
\hline $\begin{array}{l}\text { 4. Teacher } \\
\text { supporting } \\
\text { learning }\end{array}$ & 41 & 48 & 58 & 50 & 84 & $\begin{array}{r}281 \\
(30 \%)\end{array}$ \\
\hline $\begin{array}{l}\text { 5. Teachers } \\
\text { talking about } \\
\text { mathematics }\end{array}$ & 5 & 17 & 10 & 12 & 22 & $\begin{array}{r}6 \% \\
(7 \%)\end{array}$ \\
\hline $\begin{array}{l}\text { 6. Total } \\
\text { interactions }\end{array}$ & 135 & 220 & 204 & 186 & 202 & 947 \\
\hline
\end{tabular}


The pedagogical categories (5, 1and 4) account for about 46\% (436 out of 947) of observed interactions. Seven percent (66 out of 947) of interactions directly related to teachers talking about mathematical matters with children (category 5). That leaves $54 \%$ of all interactions in the organisational categories which, when considering the age of the children and the number in the environment, is not unexpected.

From Table 6.1, it is evident that kindergarten teachers' practice had a twin focus: children's learning and managing and organising the kindergarten. The first focus is the extension and support of learning for children through teachers' interactions with different groups of children (categories 1, 4, and 5) of which talking about mathematics forms a part. The second focus, just over 50 percent (511 out of 947) of recorded interactions (categories 2 and 3), is on the organisation of the kindergarten environment, involving children, teachers, parents, and a variety of activities, which is consistent with other research (Hamre \& Pianta, 2007).

Observations of teachers' practice were compared with teachers' beliefs (gathered from questionnaires and informal discussions) about how children best learn mathematics. Without exception, these teachers followed the sociocultural framework espoused in Te Whāriki (Carr \& May, 1996). Kindergarten teachers said that before the introduction of Te Whāriki they believed they had followed a child-centred, developmental approach to children's learning. With the advent of Te Whāriki in 1996, they believed their approach had become more responsive to the needs of children or 'holistic' as described in Te Whāriki (Ministry of Education, 1993b). Kindergarten teachers said their holistic approach generally encompassed all the perceived needs of a child, not categorised into specific learning areas but incorporating the principles espoused in Te Whāriki and their own particular beliefs about children's learning and development. A holistic approach is one where " a new unity is more than the sum of the parts, and in which each element affects, and is affected by, each other element" (Ministry of Education, 1993b, p. 99). Children and teachers are building learning together and influencing and responding to each other. The head teacher at Dundass Kindergarten said: 
the introduction of Te Whāriki and its sociocultural framework has allowed us to give the children freedom to follow and develop their own interests, of course there is room for our interests as well, but this allows children opportunities to become creative and innovative learners.

(Questionnaire response, head teacher, Dundass kindergarten, 30/4/07).

Other kindergarten teachers in this study support this sentiment. Teachers in this study did not specifically plan mathematics experiences but capitalise on opportunities for learning as they arose from the children's play and explorations, as well as ensuring mathematically related activities (e.g., water play, number games, blocks, and puzzles) were available for use. As children were given the freedom to follow their own interests, many learning instances arose that teachers did not capitalise on. Sometimes, no teachers were present or teachers chose to observe without intervention, allowing children opportunities to develop their learning independently.

Table 6.2 compares kindergarten teachers' beliefs about their practices in mathematics with their actual practices as observed in kindergartens. Thirteen kindergarten teachers were observed. Teachers were found to have similar beliefs and practices across the five kindergartens, so the responses in Table 6.2 are common to the kindergartens in this study.

The observed practices were recorded alongside statements from the kindergarten teachers' questionnaires about their beliefs about their practice. Children were observed to be actively involved in learning and exploring the environment around them, with or without teacher participation or direction. The observations were evidence of teachers' beliefs about their practice. Teachers said they believed it was important to provide open-ended learning situations, follow the children's interests, and support children learning through play, and that children were the primary motivators of learning interests. These beliefs were evident in observed teacher practices.

The active involvement of children was determined through observations of children working on their chosen tasks and developing them through various ongoing interactions with their peers and teachers and independently. 
Kindergarten teachers' beliefs about how children best learn mathematics were seen in their practice. Kindergarten teachers believed children learn by doing, such as learning through play and having a variety of experiences. Tanya said, "I look at the child as a knowledgeable person and build on their knowledge and strengths" (questionnaire response, Tongariro Kindergarten, 5/6/06).

Kindergarten teachers stated that these beliefs came from their experiences, their professional development, and curriculum knowledge and were the basis of their observable practice. Teachers, believing that children learned more effectively from their own interests and motivation, followed this through in their practice by regularly observing, monitoring, and recording children's activities. From these observations, teachers used children's interests to extend learning and teaching opportunities.

In each kindergarten, a teacher was assigned a group of children to monitor and record their activities and behaviour. Each kindergarten allocated the children on a weekly or fortnightly basis, depending on numbers. Teachers, although able to work with other children, had a particular focus on their allocated children. The monitoring and recording consisted of photographing events of interest, recording conversations with children, and making general observations. These were then transcribed into learning stories and put into children's individual portfolios. Teachers used a dated checklist system to ensure children in their group were observed regularly. 
Table 6.2: Kindergarten teachers' beliefs and practices about the teaching of mathematics

\begin{tabular}{|c|c|c|c|}
\hline $\begin{array}{l}\text { Kinder- } \\
\text { garten }\end{array}$ & $\begin{array}{l}\text { Observed } \\
\text { practice }^{1}\end{array}$ & $\begin{array}{l}\text { Beliefs: Statements } \\
\text { about their practice }\end{array}$ & $\begin{array}{l}\text { Comparison of observed } \\
\text { practice and stated } \\
\text { beliefs }\end{array}$ \\
\hline \multirow[t]{5}{*}{$\begin{array}{l}\text { Aorangi } \\
\text { Cascade } \\
\text { Dundass } \\
\text { Hikurangi } \\
\text { Tongariro }\end{array}$} & $\begin{array}{l}\text { Teacher } \\
\text { questioning }\end{array}$ & $\begin{array}{l}\text { I provide opportunities for } \\
\text { children to have open- } \\
\text { ended tasks so I can } \\
\text { support them problem } \\
\text { solving and extending } \\
\text { their learning }\end{array}$ & $\begin{array}{l}\text { Teachers were observed } \\
\text { to ask very few closed } \\
\text { questions, most examples } \\
\text { provided opportunities for } \\
\text { children to explore } \\
\text { possibilities }\end{array}$ \\
\hline & $\begin{array}{l}\text { Teacher } \\
\text { organising }\end{array}$ & $\begin{array}{l}\text { I provide hands-on } \\
\text { meaningful experiences } \\
\text { for children }\end{array}$ & $\begin{array}{l}\text { The organisation of } \\
\text { kindergartens provided a } \\
\text { variety of activities for } \\
\text { children to explore as } \\
\text { they chose }\end{array}$ \\
\hline & $\begin{array}{l}\text { Teacher } \\
\text { supporting } \\
\text { learning }\end{array}$ & $\begin{array}{l}\text { I work from children's } \\
\text { interests } \\
\text { I record learning stories } \\
\text { that directly relate to } \\
\text { children's learning } \\
\text { Children learn through } \\
\text { play } \\
\text { I follow the sociocultural } \\
\text { framework of Te Whāriki }\end{array}$ & $\begin{array}{l}\text { Teachers were observed } \\
\text { supporting children's } \\
\text { learning in a variety of } \\
\text { ways that provided } \\
\text { opportunities for children } \\
\text { to develop and extend } \\
\text { their learning with and } \\
\text { without teacher } \\
\text { intervention }\end{array}$ \\
\hline & $\begin{array}{l}\text { Teacher } \\
\text { directing }\end{array}$ & $\begin{array}{l}\text { Children are the primary } \\
\text { motivators for learning }\end{array}$ & $\begin{array}{l}\text { Teachers intervened when } \\
\text { requested by children or } \\
\text { when they perceived a } \\
\text { specific need }\end{array}$ \\
\hline & $\begin{array}{l}\text { Teachers } \\
\text { talking } \\
\text { about } \\
\text { mathematics } \\
\text { with } \\
\text { children }\end{array}$ & $\begin{array}{l}\text { Mathematics is integrated } \\
\text { into all our programmes } \\
\text { I align my teaching with } \\
\text { the curriculum }\end{array}$ & $\begin{array}{l}\text { Teachers were able to } \\
\text { interact mathematically } \\
\text { with children } \\
\text { Children were seen to } \\
\text { work independently } \\
\text { without teacher } \\
\text { intervention on some } \\
\text { occasions }\end{array}$ \\
\hline
\end{tabular}

Note: 1 Categories are as for the observations in Table 6.1. 
6: Findings: Kindergarten teachers' beliefs and practices in mathematics teaching and learning

Teachers had regular meetings, at lunch time and after kindergarten, to meet and reflect on what was happening generally at the kindergarten and specifically with each group of children. Sometimes this reflection caused teachers to examine their own practice to effect a necessary change in children's behaviour.

For example, teachers had observed and recorded information about children that demonstrated they were not able to play well together. As a result of this reflection, teachers felt that they were spending too much time telling the children "no, you can't do that" and stopping children from exploring or doing things that the teachers did not approve of. In response to these observations and reflection on their own and children's practices, teachers discussed how to change their own behaviour to make more positive responses to children's explorations. In this particular case, children had been told not to run up the slide as teachers had decided this was inappropriate and unsafe behaviour. On reflection they decided that there was nothing intrinsically wrong with this behaviour, but it needed some guidelines to ensure children's safety. The following morning, guidelines were developed with the children during mat time, the children followed this up by having a great time running up the slide and teachers were able to focus on making positive comments which had the effect of improving overall behaviour. (Tongariro Kindergarten observation, 6/6/07)

The above example shows teachers who can develop and reflect on their beliefs and match these in their practice as recommended in the exploration (mana aoturoa) strand of Te Whāriki, "children experience an environment in which they learn strategies for active exploration, thinking, and reasoning" (Ministry of Education, 1996, p. 88) and "adults need to know how to support and extend children's play without interrupting or dominating the activity and should avoid unnecessary intervention" (Ministry of Education, 1996, p. 83). Teachers in these kindergartens said their practices were derived from the philosophy of Te Whāriki and this, as the case described above illustrates, was evident in their practice. 


\subsubsection{Kindergarten environment}

Without exception, these kindergartens were warm and inviting places. In this context, a warm and inviting classroom is one that is seen as "psychologically warm, friendly and responsive" and " marked by enthusiasm; ardent; kindly disposed and friendly" (Princeton University, 2009). It was evident through teachers' behaviour that they cared about children in their kindergarten and made sure children were aware of this. Teachers were friendly and their behaviour was indicative of high levels of interest in children and their activities.

Teachers appeared to have time to listen and engage with children and parents. In each study, kindergarten children and their parents were greeted in English, Māori, or Samoan as they came into the kindergarten. Established routines were evident as children and parents hung up bags and put food contributions into the kitchen. The friendly greetings and inter-change of conversation contributed towards the feeling of a welcoming environment. Children and parents were encouraged to have time together at an activity before the formal commencement of the day. Opportunities for mathematics arose out of children's play and spontaneous interests and from the environment around them, and teachers built on these. I observed examples of children developing and sustaining their own mathematical activities, individually or with other groups of children, without teacher input.

For example a group of three children were observed building in the block area of the kindergarten. They spent about ten minutes working together to build a tower with blocks with a hole through the middle while another child built a corresponding higher tower. Once these two structures were complete, the children joined forces and decided to link the towers via a shute, and putting an opening at the bottom of the lower tower. They proceeded to drop various objects into their shute and see how quickly they came out through the bottom of the lower tower. Their discussion focussed on the properties of the objects, their shape, size, and weight and which objects fell down faster. Their only contact with a teacher was a request for different sized marbles, the teacher made no enquiry as to why it was needed or viewed their tower until the group 
6: Findings: Kindergarten teachers' beliefs and practices in mathematics teaching and learning

collapsed it and the noise drew her attention. This self-sustained activity contained a number of mathematical skills that the children followed on their own, construction, size, weight, ratios, problem-solving, cooperation and comparison for example. The teacher was in the general vicinity of this activity working with another group of children.

(Observation at Dundass Kindergarten, 21/3/06)

Within this environment the children had the opportunity to develop their own challenges, further supporting the goals and strands of Te Whāriki (Ministry of Education, 1996, p. 16). In most cases, the amount of time parents could spend at the kindergarten was unlimited and there were no restrictions on the kind or location of an activity in all but Hikurangi Kindergarten. At Hikurangi, the first half hour of each session focused on literacy- and mathematics-related activities. The teachers at Hikurangi had noticed through their regular observations that some children rarely participated in these activities, so they imposed the restricted free choice to ensure every child had exposure to literacy- and mathematicsrelated activities.

Kindergarten environments encompassed the entire site as children, parents, and teachers moved freely through indoor and outdoor areas. A wide variety of resources and displays were evident in all kindergartens (see Appendix $\mathrm{M}$ for more detail).

Community involvement was an essential part of the kindergartens as parents and other community members were encouraged to share in the life of the kindergarten. Tongariro Kindergarten had parents bringing in carvings to share and discuss. At Dundass Kindergarten, one parent was a painter and she came in to share her skills with children. This was followed up with further extension by teachers. Aorangi Kindergarten children enjoyed seeing the rubbish truck coming up to their kindergarten. The children and the rubbish men had developed a casual relationship characterised by social talking around the rubbish collection and children's activities conducted by children on one side of the fence and the rubbish men on the other. Cascade Kindergarten had a landscape artist community member helping the children paint a mural on the fence, and Hikurangi Kindergarten children made regular visits to the road workers fixing the pavement 
outside their front gate to take photographs and discuss progress. The variety of challenging opportunities available for exploration, in indoor and outdoor settings, including the community, is an essential feature of the learning opportunities outlined in Te Whāriki (Ministry of Education, 1996, p. 55, 83).

All kindergartens in the study provided busy environments with a wide range of well-ordered mathematics equipment alongside other resources. A busy environment was deemed to be one in which all children were seen to be engaging in an activity or task, independently or in variable groupings, with or without adult support. I observed no instances of children wandering around doing nothing; it appeared children were always engaged in an activity of some kind, contributing to the busy atmosphere of kindergartens. The equipment in these kindergartens was easily accessible to children, and children were encouraged to finish one activity, for example a jigsaw, before embarking on another, putting things away in set places as they finished with them and contributing to orderliness.

Teachers were seen to encourage cultural diversity, with books, puzzles, equipment, and displays in more than one language. Children were encouraged, for example, to count in their home language, number puzzles were available in Māori and English, and picture books were in more than one language. Teachers supported the use of more than one language by using and practising these languages themselves in their day-to-day interactions with children and parents. Although most exchanges in languages other than English were restricted to singing, counting, and greeting, some teachers were attempting to broaden their range of language skills. Te Whāriki contains explicit references to supporting children's home language, and the use of the Māori language in particular was a feature of all kindergarten programmes observed (Ministry of Education, 1996, pp. 65,73$)$.

Teachers had the freedom and flexibility to follow children's directions and interests. The head teacher at Tongariro Kindergarten explains this further, we all (teachers and parent helpers) find time here to explore the children's ideas, listen to their thinking, and record and monitor what is happening. The children also are aware of our interest and actively seek 
6: Findings: Kindergarten teachers' beliefs and practices in mathematics teaching and learning

us out to share their ideas. (Personal communication, Tongariro

Kindergarten, 27/6/06)

This head teacher went on to describe a child who came to kindergarten with a small carving of a waka (canoe) and how their attention was focused on the child and his ensuing designs and recorded. The brief extract from his learning story below demonstrates this development.

We've noticed how you pay particular attention to the designs you add.

On your pencil plan your waka was totally covered with koru patterns, ${ }^{32}$ when it came to painting the waka, you created the koru patterns and then painted around them creating an amazing design no other child has done. We wonder where your originality will lead you? Keep up the good work. (Learning story, Tongariro Kindergarten, 27/6/06)

The kindergarten environment was one in which the adults provided "encouragement, warmth and acceptance. They also provide challenges for creative and complex learning and thinking, helping children to extend their ideas and actions through sensitive, informed, well-judged interventions and support" (Ministry of Education, 1996, p. 43). Teachers in the study kindergartens demonstrated how their practices matched their beliefs about how children best learned, consistent with the principles outlined in their curriculum.

Kindergarten teachers in this study said they did not specifically plan in detail for mathematics outcomes. At Hikurangi Kindergarten where children were restricted to literacy- and mathematics-related activities for the first half hour of each day, mathematics outcomes were not planned in detail either. Activities were set out for children to use and interact with but the outcomes were not planned. Teachers observed children's spontaneous free play, interacted, and capitalised on unfolding activities to support children's learning across learning areas. They planned general activities but waited until they saw the direction of children's interests.

Teacher observations of children and their activities preceded teacher documentation. These same teachers said that this retrospective and reflective

32 A koru pattern is a traditional Māori design based on an unfurling silver fern frond.. 
documentation was a significant shift in the way they thought about developing children's learning. According to the teachers, before Te Whāriki, they had planned set activities and routines for children around themes selected by teachers. While planning outlines of general activities were in place, the main documentation was put together after the events and contained detailed progressions of children's learning journeys, with photographic and anecdotal evidence to support these. Parents' voices, in the form of parents' stories relating to observations on their children, were included in this document. Once all the information about the previous term had been collated and annotated, it was bound in a single document and placed in the kindergarten library for all to share and reflect on the learning journeys undertaken.

Kindergarten teachers said that this shift in thinking about children's learning resulted from their increasing understanding and reflections on the underlying philosophy of Te Whāriki. As a result of their professional development and conversations with their peers about the implementation of Te Whāriki, teachers were able to change their beliefs about useful documentation for learning and teaching. A key feature of these kindergartens was that children were observed to be capable of prolonged, sustained activities with and without adult involvement, and in most instances they followed through activities until completion as determined by the child.

An example of the link between teachers' beliefs and practices in mathematics is provided by Hikurangi Kindergarten (Table 6.3). Hikurangi kindergarten was selected to use as an example as their views were similar to those of the other kindergarten teachers. A teacher at Hikurangi said she believed mathematics should be fun, children's thinking should be stimulated, and children should be able to work at activities independently and with a teacher. Her observed practices demonstrated that she was able to stand back and observe children working independently; she was able to hold conversations with children and follow their interests, and she monitored children's activities. Children were observed selecting their own activities and were seen to be capable of sustaining these independently from teacher intervention for varying periods of up to about 20 minutes. If the activities children were participating in were not perceived to be 
fun, it is unlikely that children would work on them independently for long periods without adult intervention or participation.

Table 6.3: Comparison of kindergarten teacher beliefs about how children learn mathematics with observed practices and student behaviour

\begin{tabular}{|l|l|l|l|}
\hline $\begin{array}{l}\text { Kinder- } \\
\text { garten }\end{array}$ & $\begin{array}{l}\text { Teacher beliefs } \\
\text { about how children } \\
\text { learn mathematics }\end{array}$ & $\begin{array}{l}\text { Observed teacher } \\
\text { practice }\end{array}$ & $\begin{array}{l}\text { Observed } \\
\text { responses from } \\
\text { children }\end{array}$ \\
\hline Hikurangi & $\begin{array}{l}\text { Mathematics is } \\
\text { integrated into all } \\
\text { areas } \\
\text { Making mathematics } \\
\text { fun } \\
\text { Provision of } \\
\text { resources to } \\
\text { stimulate thinking } \\
\text { Playing mathematics } \\
\text { games, both with } \\
\text { teacher and } \\
\text { independently }\end{array}$ & $\begin{array}{l}\text { Teachers } \\
\text { to work } \\
\text { independently } \\
\text { Teacher } \\
\text { conversations with } \\
\text { children developed } \\
\text { from the children's } \\
\text { interests } \\
\text { Teachers } \\
\text { systematically } \\
\text { observed and } \\
\text { recorded events and } \\
\text { behaviours }\end{array}$ & $\begin{array}{l}\text { Children } \\
\text { participated in } \\
\text { sustained activity } \\
\text { without teacher } \\
\text { direction for up to } \\
\text { 20 minutes } \\
\text { Children were able } \\
\text { to select activities } \\
\text { following own } \\
\text { interests }\end{array}$ \\
& & \\
\hline
\end{tabular}

Teacher-child interactions at kindergartens followed similar patterns in the study kindergartens. Children were free to choose their own activity with or without other children. In some instances, teachers would be working at an activity table (such as the puzzle table or collage table) or walking round in a particular area and the presence of a teacher appeared to encourage children to sit down at a table to work or choose an activity within the teacher's vicinity. Table 6.4 is an example of a commonly observed teacher-child interaction sequence at kindergarten. The task chosen relates to scoring a soccer game, and most tasks observed followed a similar format.

An example of the structure of typical interactions at kindergartens is included to support the vignettes and provide background to the variable nature of the interactions that occurred. The nature of the interactions with few perceived limitations provided opportunities for children to follow their interests and for 
teachers to support these without feeling constrained by planned sequences of activities and progressions.

\section{Table 6.4: Mathematical event structure at kindergarten}

\section{Sequence and structure of a typical mathematical event (variable time spans)}

- Teacher observing and recording children's activity.

- Teacher responding to children's activity by showing interest.

- Teacher invited to participate in activity by answering questions, recording, questioning, and interacting as required by children.

- Children choose to share task with teacher.

- Time span: variable.

The rest of the children at kindergarten were able to choose from a variety of activities for flexible amounts of time.

\subsubsection{Mathematics events observed}

Children had many opportunities for free play with the potential for play to be mathematically rich. The vignettes that follow provide observed examples with and without teacher involvement. The examples were chosen to illustrate particular mathematical events and the teaching and learning that was observed. Each example is outlined, and then followed by an analysis of the mathematical ideas in the event (Perry \& Dockett, 2002, 2005), incorporating the nine categories:

- mathematisation

- connections

- $\quad$ argumentation

- number sense and mental computation

- algebraic reasoning

- $\quad$ spatial and geometrical thinking

- data and probability sense

- expanding number knowledge 
6: Findings: Kindergarten teachers' beliefs and practices in mathematics teaching and learning

- $\quad$ assessing and recording.

These categories are explained in Chapter 5 .

Within each vignette, an example of a mathematics event is highlighted and colour-matched with the appropriate mathematical category that follows in the analysis. For example, in Vignette 6.1, a phrase is highlighted in yellow. This phrase matches the yellow highlighting of mathematisation in the table under the vignette, and is followed by a brief explanation of how the example fits within the category. After the description of the mathematical ideas, events are further discussed with an added commentary.

Vignette 6.1: Exploration of numbers within a social context-co-constructing rules

Vignette 6.1 tracks the development of rules for appropriate behaviour and expectations for anyone playing in the Galaxy Corner. This development began after a discussion about the creation of the Galaxy Corner and the need to set limits on its use.

At Aorangi Kindergarten both teachers were organising children to come to the mat for 'mat time' at the start of the day. It appeared to be a group activity that all enjoyed as the children left whatever they were engaged in and came to sit on the mat. The session began with the teacher and children discussing the events of the day, sharing news about what had happened at home, then moving on to the event for the day.

The previous night the teachers had established the Galaxy Corner, so the first task of the day was to develop a set of mutually agreed rules for participation and entry to the Galaxy Corner. The teachers had screened off a corner of the kindergarten with black cloth and paper and made a small entrance. Cut-out stars had been put up on the artificial ceiling and the rest of the details were for the children to complete. The Galaxy Corner arose from a child's interest the previous week, further illustrating progress in the child's education from their own interests.

The common expectations developed were applicable to both teachers and children and were evident from the initial discussion. The teacher led the 
discussion, but the children had an expectation of their equal right to participate and present their views, which in many instances took precedence over teacher views. The rules were recorded as they evolved.

The teacher is Anna (A) and each child (C) is differentiated numerically. 


\section{Vignette 6.1: Co-constructing rules}

A Okay that seems good, let's look at the first rule, any ideas?

C1 No food

C2 No we don't want food

C1 It spoils the floor

A That's a good rule to have but do we really need it?

C2 Maybe, but we keep our food on the kai (food) table,

C3 No not that rule

A How do you think we should behave in our galaxy then?

C3 Play nicely

C2 Play properly

C4 Don't run, you have to walk so as not to pull down the stuff

A What does that mean then? Shall I write up that we have to walk in there and be careful?

C1 Yeah we want it nice, quiet voices

A Okay then, how many people should we have in there?

C 4 [about 5 of them called this out]

A Are you sure?

C1 Yes 4, that's enough.

A Is that because you are all 4 too?

C4 Yes, it's nearly 5, that's our favourite number, not 100, not 3 but 4 is

better, only 4 allowed.

A writes up the rule that four children at a time are allowed in the Galaxy

Corner and the children all sit quietly watching as she scribes the words and

says them as she writes.

A What about if we want to have our mat time in there? Could we have more than four children then?

The children take time to discuss this amongst themselves and the consensus is still that only four children are allowed at any one time. A asks them if 
sometimes it could be all right if they all agreed to have a mat time in the corner but after some debate the children mostly agreed to stick to a maximum of four children. She moves on.

A What about the box of light sabres just outside the galaxy? Do you want to think about taking them in?

C1 Yes, they should stay out

A Okay then, shall I write that the light sabres have to go back into the box before you go in the galaxy?

The children nod.

A continued the discussion about rules with the children and it moved onto whether or not shoes were allowed in the galaxy area. This was followed by a discussion relating to the corner when it was finally finished and was really dark inside there might be a need to have a box of torches. The discussion focused on light and dark, how 'cool' it would be, and where the stars should be placed. They discussed an equitable way of allocating time in the galaxy so that everyone had a fair turn.

C4 You could have 5 minutes each with 4 people

C3 No let's have 500 minutes ... that's really long

C6 I think we should stay until 10.00 o'clock that's a long time

C1 I want 4 or 9 minutes, that's a long time, could have 3 minutes, that's after 2

C3 I think 3 hours we are at kindy for 3 hours so that's how long we should have

\section{C1 I think 4, 4 minutes is a good number}

All finally agreed on this and the discussion moved onto how to monitor this ... the timer was decided on and they practised to see how long this was.

C6 What about 100 minutes [all the children on the mat gasp and agree that that's a really long time] yes that would be a lot, it would take forever.

A led the discussion on how to choose who to go in, how to take turns and what to do if there were problems, the children contributed to this. 


\begin{tabular}{|l|l|}
\hline Category & Comment \\
\hline Mathematisation & $\begin{array}{l}\text { Exploration of number within a social context; children } \\
\text { are learning about time and number through a general } \\
\text { discussion }\end{array}$ \\
\hline Connections & $\begin{array}{l}\text { Using number and time in relation to the governance of } \\
\text { a social group; children deciding together how long a } \\
\text { period of time they can stay in the galaxy corner to } \\
\text { make it fair to everyone }\end{array}$ \\
\hline Argumentation & $\begin{array}{l}\text { Negotiating rules relating to number and time, } \\
\text { justification and reasoning relating to choices }\end{array}$ \\
\hline Number sense & $\begin{array}{l}\text { Exploration of size and relativity of number and time, } \\
\text { building concepts }\end{array}$ \\
\hline $\begin{array}{l}\text { Extending children's } \\
\text { number knowledge }\end{array}$ & $\begin{array}{l}\text { Children had the opportunity to discuss and explore } \\
\text { their ideas in relation to time and number relativities }\end{array}$ \\
\hline Recording and & $\begin{array}{l}\text { A recording children's ideas on display. } \\
\text { A recording the co-construction of social rules relating } \\
\text { to organisation }\end{array}$ \\
\hline Time taken & \begin{tabular}{l} 
25 minutes \\
\hline
\end{tabular}
\end{tabular}

Mat time lasted 25 minutes, but before finishing Anna suggested that some children might want to make some more things to go up in the Galaxy Corner. In response, half a dozen children moved to the collage table and began to cut and stick things together to hang in the Galaxy Corner.

From the discussion about the Galaxy Corner, it was evident that these children knew a lot about numbers and the relative size of numbers. Anna encouraged them to express their ideas and allowed time for children to discuss their choices. The children were able to clearly rationalise these choices and justify their decisions. The discussion was recorded and documented as a list of rules governing the use of the Galaxy Corner. This documentation was subsequently photographed for insertion into relevant learning stories for the children.

The children were able to sit still and focus on this discussion for at least 25 minutes, providing evidence that children before they go to school are capable of sitting on the mat and participating in sustained periods of interaction. 


\section{Vignette 6.1: Commentary}

Vignette 6.1 shows children who were developing mathematically. From the children's use of numbers in relation to time, they appeared to be developing number sense in terms of the relative size of a number and the length of time it might represent. This was evident from their discussions relating to 500 minutes being a long time, then 4 or 9 minutes being a long time, and their agreement that 100 minutes was a really long time and would take forever. Four appeared to be a favourite number among the children because it related to their age, and they were aware of numbers that come before and after four.

Anna supported the children as they developed and expressed their ideas about numbers and made links to social contexts. She encouraged children to think about the impact of having food in their special corner, the impact that inappropriate behaviour might have on others, and the importance of setting a time limit in the interests of equality of opportunities for all children to have a turn in this special area.

From the discussion focusing on negotiating rules for usage, children were encouraged to put forward their opinions and justify these in relation to operating within a social group. The teacher recorded the key features of the discussion, setting rules and time limits, and both children and teachers read these aloud together to reconfirm the limitations set on using the Galaxy Corner. The rules were put on a wall near the Galaxy Corner for future reference.

\section{Vignette 6.2: Proportions and ratios - mixing colours}

Vignette 6.2 follows the discussion of four children at Dundass Kindergarten as they explore mixing colours, building on from their prior experiences. The learning programme and progressions evolved through the children's interest. The programme was not teacher initiated but teacher supported. The teacher stopped at the request of the children and engaged the children in conversation about their activities. The teacher ensured the children maintained their momentum, but did not direct them. The children engaged in this learning initially without the teacher. The teacher is Donna (D) and each child (C) is differentiated numerically. 
The conversation continued with the children discussing and naming their colours even after Donna had moved away from the group. The fourth child observed and mixed and painted without making a contribution to the discussion but appeared to be listening closely. The teacher participated long enough to get the children thinking and talking about mixing colours as they had done before. They played and chatted about colours for another 10 minutes while continuing to paint the frame with combinations of colours.

The teacher mentioned later that they had done some work on mixing colours with the whole group and she was extending them by getting them to explain and discuss their thinking. From the children's comment that they could not make pink due to a lack of red paint, the children demonstrated an understanding of colour mixing.

This event was primarily a child-directed session with some interaction with the teacher.

\section{Vignette 6.2: Mixing colours}

Four children were outside painting a large wooden framework with a variety of colours. (From the portfolios it was evident that the children had already done a significant amount of work on colour mixing, with water, cellophane, and paint at various times during the first term.) D was passing by and $\mathrm{C} 1$ called her to attend to them.

C1 I just maked grey.

D Wow, how did you do that?

C1 A bit of this colour and a bit of that colour (indicating the black and white paint pots)

D You did too, I like that.

C2 This is army grey.

C3 Me to, I did to, with that green over there, a little bit of this and a little bit of that. 
D That's really interesting, it's good to mix a bit of this and a bit of that and see what you get.

C1 See look at me, a bit of this and a bit of that and I got yucky green [she had put some dirty blue and a bit less yellow together and got a muddy green]

D Can you make any other colours?

C2 Pink, only pink.

C1 Our favourite one.

D Show me how to do that.

C1,2,3 [together] Can't, can't, can't, we got no pink to show you.

D What happened to the pink?

C3 We used all the red on the fence over there, we need more in the pot.

\begin{tabular}{|l|l|}
\hline Category & Comment \\
\hline Mathematisation & $\begin{array}{l}\text { Children were exploring proportional ideas through } \\
\text { mixing differing amounts of paints to make new colours }\end{array}$ \\
\hline Argumentation & $\begin{array}{l}\text { Children are making statements about requisite amounts } \\
\text { of each colour and using these to describe their practical } \\
\text { actions }\end{array}$ \\
\hline Connections & To prior learning relating to mixing colours \\
\hline Number sense & $\begin{array}{l}\text { Informal beginning of ideas relating to proportions and } \\
\text { ratio }\end{array}$ \\
\hline $\begin{array}{l}\text { Data and probability } \\
\text { sense }\end{array}$ & $\begin{array}{l}\text { Using trial and error to explore assumptions about how } \\
\text { blended colours are made and how much of each colour } \\
\text { to use }\end{array}$ \\
\hline $\begin{array}{l}\text { Recording and } \\
\text { assessing }\end{array}$ & \begin{tabular}{l} 
Not evident \\
\hline Time taken
\end{tabular} \\
\hline
\end{tabular}




\section{Vignette 6.2: Commentary}

These children were developing an understanding of proportional relationships as they mixed bits of colours together to make new colours. They demonstrated that they were able to discuss how much of one colour they needed to create a new colour and could make connections to their prior learning. The children were able to work collaboratively and discuss their conclusions.

These open-ended exploration experiences support children as they work to build meaning to their environment (Ministry of Education, 1996). They were able to demonstrate their flexibility and creativity as they developed and extended their mathematical ideas in regard to proportional relationships.

Donna was involved by children as she passed by the group, and she asked questions to elicit explanations from children as they mixed various colours. She did not initiate the activity.

\section{Vignette 6.3: Recording numbers - scoring a game}

Dorothy at Dundass Kindergarten was observing a group of children as they played soccer (football). Vignette 6.3 details how Dorothy encouraged the children in their game and allowed children to freely express their ideas about scoring and recording without dominating.

Dorothy provided information about conventional recording when the children requested it, but the children generally recorded scores using their own numbering systems.

The children clearly invited the teacher to participate.

This activity provided a rich and meaningful context in which the children could develop their skills, not only in soccer but in scoring. Children learnt how to communicate their understanding of scoring in a meaningful and sequential way that supported the development of more abstract number relationships.

The conversations of the children involved have been summarised for clarity with only a few specific phrases recorded.

The teacher is Dorothy (D2) and each child (C) is differentiated numerically. 


\section{Vignette 6.3: Scoring a game}

D2 was outside with a group of six to eight (variable number groupings) children playing soccer on the deck. The children had been playing for about five minutes and kicking goals when one child decided they needed to score the game. D2 stood back while the children discussed what to do so they could easily see and record their goals. Finally, the children decided they wanted two big scoreboards outside.

One child went to get two large sheets of card, one got the hammer and nails for the teacher (who had not yet contributed to the discussion), and one got a pen. The children asked D2 to nail the sheets to the outside fence, and then the child with the pen asked her to write 'Team 1' on one sheet and 'Team 2' on the other.

The children discussed again and decided that the teacher needed to write up 'goals' so they knew what they were recording. The teacher then handed the pen to the children and they continued playing. The teacher watched and cheered but did not interfere.

\section{Each time a goal was scored, one of the children made a mark on the}

appropriate sheet along with a few squiggles. After 10 minutes of soccer, one of the children called out to the teacher and said they were up to 14, and asked how could she write this ... "a one and a four" responded the teacher, so the child recorded this and then proceeded to write 1 and 5 (reversed), 1 and 6, then more squiggles. The other team was using a marker system and marking off each set of five (four vertical lines with one horizontal line to mark the fifth point) and periodically counting up (nearly in the right order). Teams spent almost as much time playing soccer as they did sorting out and discussing the recording of the goals.

The teacher did not initiate learning but supported the children as they worked out what to do and she conformed to their requests. 


\begin{tabular}{|l|l|}
\hline Category & Comment \\
\hline Mathematisation & $\begin{array}{l}\text { Exploration of number system within a social context by } \\
\text { developing their own methods of recording and } \\
\text { numbering to represent an increasing number of goals }\end{array}$ \\
\hline Connections & $\begin{array}{l}\text { Using the number system to develop a scoring method } \\
\text { for soccer }\end{array}$ \\
\hline Argumentation & $\begin{array}{l}\text { Children discussed appropriate ways to record scores } \\
\text { and negotiated the recording of numbers and symbols }\end{array}$ \\
\hline Number sense & $\begin{array}{l}\text { Number sense and order by developing a sequential } \\
\text { method of scoring goals }\end{array}$ \\
\hline $\begin{array}{l}\text { Extending children's } \\
\text { number knowledge }\end{array}$ & $\begin{array}{l}\text { Teacher provided information on correct numbering } \\
\text { when requested }\end{array}$ \\
\hline Assessment and & $\begin{array}{l}\text { Children developed own recording and tallying systems } \\
\text { to score } \\
\text { The teacher's support was sometimes requested as an } \\
\text { information source }\end{array}$ \\
\hline Time taken & \begin{tabular}{l} 
20 minutes \\
\hline
\end{tabular}
\end{tabular}

\section{Vignette 6.3: Commentary}

The soccer game shows children who were able to explore how to use a number system in a social activity. The children were able to negotiate and discuss meaning and had developed their own methodology for scoring their game, which demonstrated their developing understanding of a number system. They were able to sequentially record the scores, and their discussion showed that, although not necessarily in a conventional manner, they were aware of the sequence and order of numbers and their use.

The teacher in this example did not take over scoring the game but conformed to children's requests and gave information on numbers as required. She was a participant in the event because the children asked for her expertise as necessary, but she did not otherwise contribute to the unfolding of the game. This fits most closely with the contribution (mana tangata) strand in Te Whāriki (Ministry of Education, 1996) - children develop mathematical problem-solving strategies in using numbers to communicate a common goal in scoring a game equitably. 
Vignette 6.4: Sequence and patterning - ordering bears

Sorting and ordering equipment, such as the plastic bears described in

Vignette 6.4 from Cascade Kindergarten, was a common feature in each

kindergarten observed. The same equipment was present in the new entrant classrooms, although it was not observed in use.

The teacher is Cathy (T) and the conversation she had is with just one child (C), although other children were present sorting bears at the table and talking with each other.

\section{Vignette 6.4: Sorting and ordering bears}

This activity was focused around plastic bears of different colours and shapes.

Children were sorting and organising the bears into various complicated

patterns that the teacher was trying to determine the reasons for.

T Why did you put that there?

C Cause it fits with the one next to it

$\mathrm{T} \quad$ How do you know it goes there?

C Cause it's the next bigger blue one and it needs to go next to the little one there.

$\mathrm{T} \quad$ I like the way you put them on this plate

C Yeah, cause it's a round one and the teddies all can walk round the plate

T That's good

C Now I want them in a row, one, two, three, and the big one at the end

$\mathrm{C}$ re-sorted her bears into sets of three while the teacher watched without comment. No reason was obvious for $\mathrm{C}$ to re-sort the bears into rows other than perhaps she liked the look of rows. The teacher did not ask for this information. Following the re-organisation of the bears, the child next to $\mathrm{C}$ then re-sorted her bears into lines of three before putting them back into the round bowl. The teacher observed this process then moved briefly to another group. 
6: Findings: Kindergarten teachers' beliefs and practices in mathematics teaching and learning

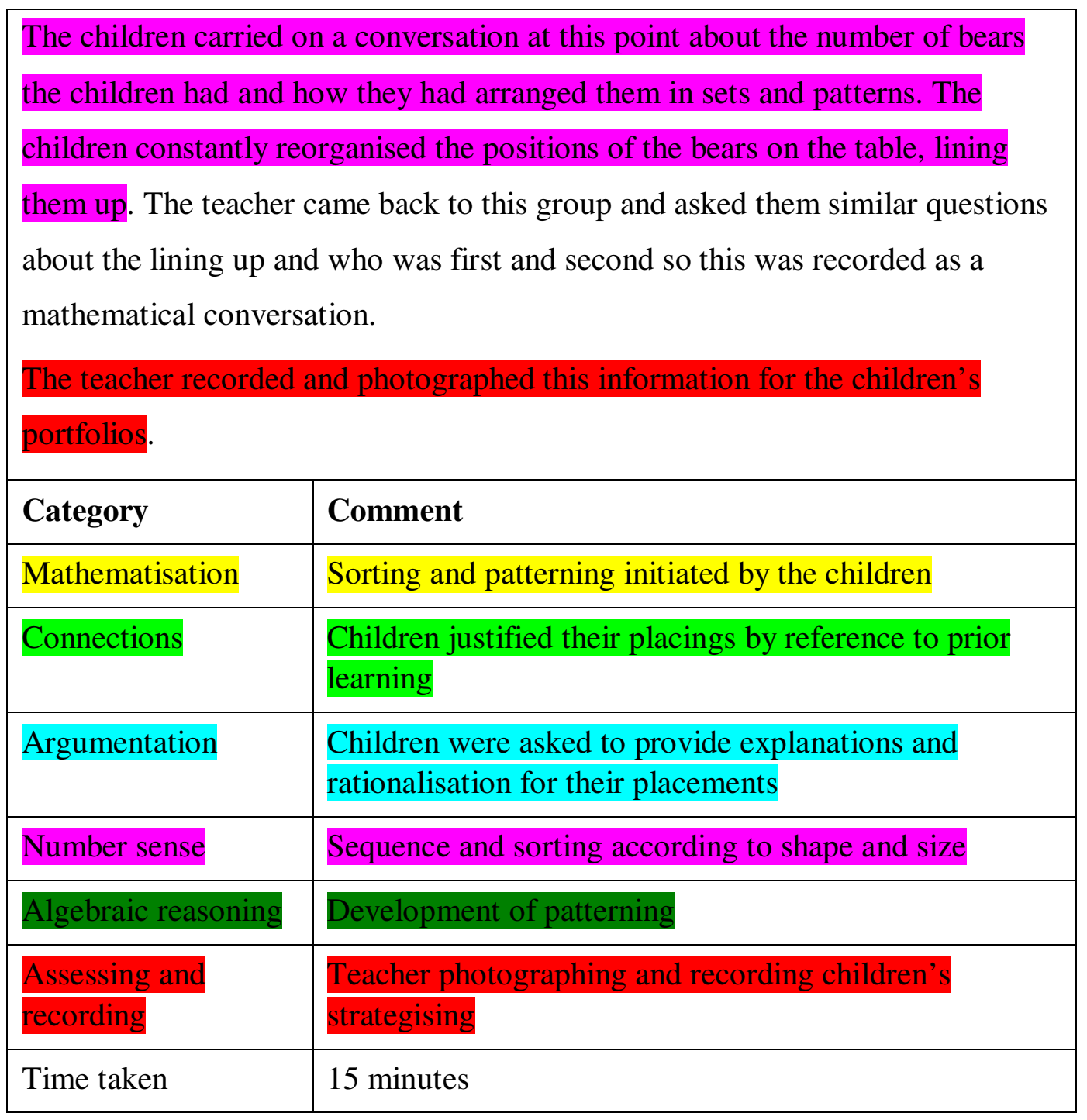

\section{Vignette 6.4: Commentary}

Vignette 6.4 provided an example of a teacher supporting and questioning the children, but not leading the discussion of ideas. The children were free to respond and define the issues in their own way without the teacher putting forward a predetermined, planned learning objective. Opportunities for mathematics learning were clearly present; the teacher observed, went away, and returned.

The child in this vignette could justify her reasons for placing the bears in particular places and had created her own story around her patterning. The teacher supported the children's learning by asking them to explain how they had determined their patterns and ordering. 
The patterning skills and sorting objects to shape and size are linked in Te Whāriki to the well-being (mana atua) and belonging (mana whenua) strands (Ministry of Education, 1996, pp. 94-95) as children begin to explore their environment by ordering patterns and relationships and develop mathematical concepts in their daily lives.

The teacher photographed and recorded the conversations, and the resulting learning story for these children had a clear mathematical focus on shapes, sizes, and patterning.

Vignette 6.5: Using positional language - constructing a jigsaw and building an adventure playground

Hikurangi Kindergarten had similar examples of teachers and children working together. Two examples illustrate learning where teachers and children created learning opportunities together: constructing jigsaws and building an adventure playground.

There were no observed occasions where a teacher directed the children's choice of activity or their interests.

These examples show the development of mathematical language and concepts. The teacher's use of language to describe the placing of puzzle pieces and parts of the adventure playground was copied and practised by the children as they placed their puzzle pieces in the jigsaw and positioned various items of equipment in their playground.

These children demonstrated their capacity for sustained interest in various activities. The teachers encouraged the children to learn through purposeful interactions with everyday activities.

At the jigsaw puzzle table, the teacher and children spent a considerable length of time discussing shapes, sizes, rotations, and which pieces belonged in which place. The children predominantly drove the discussion as they discussed what would and would not fit into the available spaces, while the teacher provided appropriate language to describe the children's choices. The children talked about putting that piece in that place, and the teacher followed this up and extended this by discussing the relative size, shape, and orientation of the piece and how to 
rotate it to fit in a particular space. Children followed this by modelling the teacher's language as they placed a puzzle piece.

This was an example of a teacher supporting children's learning and extending their language without dominating the conversation, ensuring the children continued discussing further amongst themselves. The children were encouraged to look under things, behind things, and next to things and match pieces for missing bits of puzzles.

The second example happened when a teacher was helping children to build their adventure playground at the back of the kindergarten.

Vignette 6.5 is a snapshot of the building of the adventure playground. The children repeated the positioning language supplied by the teacher as they placed their pieces and surveyed their playground.

\section{Vignette 6.5: Building an adventure playground}

The children were collecting bits and pieces and laying them down in an orderly pattern and the teacher provided the language for the positioning. The teacher said, "You've put that ladder next to the stepping stones. That looks great, where are you putting that bucket? Oh I see, underneath the branch ... what are you going to put after that?... [Child puts a truck down next to the bucket and indicates that you have to go round it to get to the ladder.] Okay, there you are, you have to go round the truck to climb up the ladder. [Child nods and her friend repeats round the bucket, round the truck, up the ladder a couple of times like a chant.] Now what are you going to put after the ladder?" [Children run off and get a mat that they place at the base of the tree. Children begin to tell the teacher that you have to jump on the mat but run off again to get the plastic hoop stand and a ball to finish off their course.]

After a brief interlude, the teacher collects the camera, then takes notes and

photos of the children, who are now taking turns to complete their course with much laughter and positioning conversations about the placement of obstacles. 


\begin{tabular}{|c|c|}
\hline Category & Comment \\
\hline Mathematisation & $\begin{array}{l}\text { Positional language such as next to, round, underneath, } \\
\text { planning for building }\end{array}$ \\
\hline Connections & $\begin{array}{l}\text { Social activity relating to every day problem solving in } \\
\text { building an adventure playground } \\
\text { Child initiated }\end{array}$ \\
\hline Spatial awareness & $\begin{array}{l}\text { The teacher was building the children's understanding } \\
\text { and use of positional language through modelling }\end{array}$ \\
\hline $\begin{array}{l}\text { Extending children's } \\
\text { number knowledge }\end{array}$ & Not evident \\
\hline $\begin{array}{l}\text { Assessing and } \\
\text { recording }\end{array}$ & $\begin{array}{l}\text { Teacher records and photographs as children use their } \\
\text { adventure playground }\end{array}$ \\
\hline Time taken & 30 minutes \\
\hline
\end{tabular}

\section{Vignette 6.5: Commentary}

The teacher did not suggest what items should be collected or where they should be placed, but waited and watched as the children constructed. She provided a model of language that described what the children were doing as they placed items in their adventure playground. This pattern was similar to that followed in the jigsaw puzzle example as the teacher provided language to describe the placement of pieces for the children to copy. Children repeated and practised this mathematical language as they worked both with the jigsaws and the playground. About four children were involved in the building project, with up to six more joining in intermittently. After the adventure playground was completed to the children's satisfaction, a group of about 12 children used it like an obstacle course and talked their way around it using much of the language that had been inserted and practised in the building process.

The teacher took the opportunity to record and photograph at this stage. This example fits with two strands of Te Whāriki: contribution (mana tangata) children have opportunities to develop their strengths and interests in organising and doing things with each other, and communication (mana reo) - children have 
6: Findings: Kindergarten teachers' beliefs and practices in mathematics teaching and learning

opportunities to develop early mathematical concepts and use them in their play (Ministry of Education, 1996, pp. 69, 79)

Children are building ideas relating to spatial awareness and positioning through the construction of an adventure playground with teacher support.

\section{Vignette 6.6: Counting and ordering - playing with water}

Vignette 6.6 from Hikurangi Kindergarten provides an example of a mathematical event in which the teacher, Hiria, did not participate, but observed and recorded. This vignette is an example of the number knowledge some children possess before they enter school.

Children were working independently on a sustained activity. They demonstrated an ability to count sequentially and generally match one to one. They had enough mathematical language to discuss the activity and describe what they were doing. These children demonstrated a considerable degree of knowledge about number order, sequencing, and one-to-one relationships.

Different children (C) are identified numerically.

\section{Vignette 6.6: Playing with water}

Four children were playing by three water tubs linked with open pipes. One child was repeatedly filling and emptying soap-powder scoops, one child was running her fingers through the water and playing with the equipment in the water, and the other two children were building a collection of small plastic containers. They filled a container with water, found the container's lid, and then lined up the bottles on one of the sloping pipes.

C1 Look we got lots of them

C2 I can count them $1,2,3, \ldots \ldots .20$

C1 That's lots, we doing heaps, all the way to 20

The two children continue filling the bottles and the other two at the water begin to watch the pipe filling with bottles although they continue with their own play. 


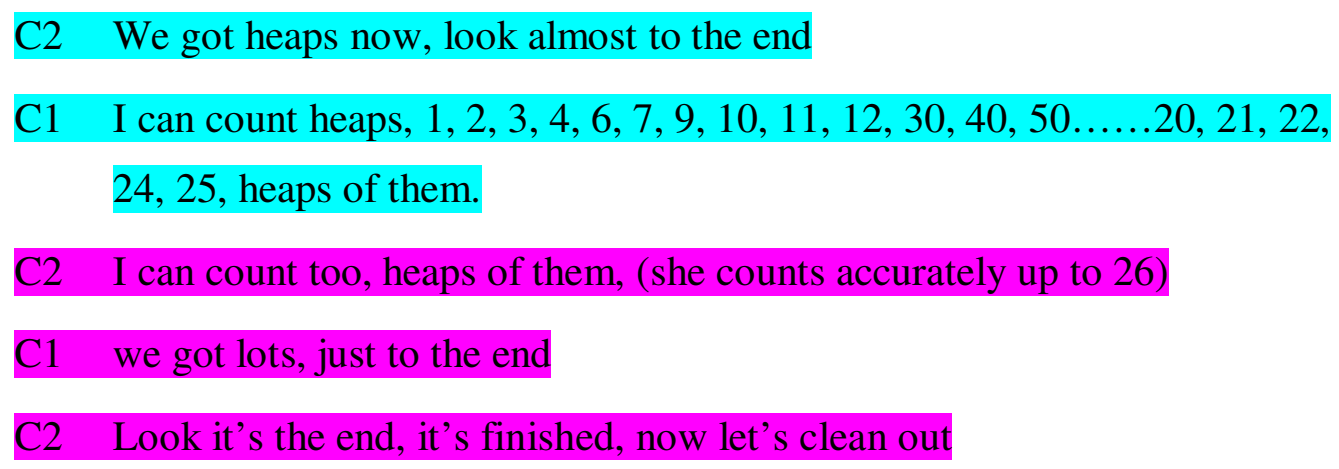

\begin{tabular}{|l|l|}
\hline Category & Comment \\
\hline Mathematisation & $\begin{array}{l}\text { Children are counting and linking the number they count } \\
\text { with the number of containers of water they fill, } \\
\text { developing one-to-one relationships and counting } \\
\text { sequences. }\end{array}$ \\
\hline Connections & $\begin{array}{l}\text { Using numbers to validate an important activity, filling } \\
\text { up and ordering containers }\end{array}$ \\
\hline Argumentation & $\begin{array}{l}\text { Children are making statements about requisite numbers } \\
\text { of filled containers and using these to describe their } \\
\text { practical actions }\end{array}$ \\
\hline Number sense & $\begin{array}{l}\text { Informal beginning of ideas relating to number } \\
\text { recognition, sharing an activity, and number sequence } \\
\text { Numbers are used to quantify an amount of objects }\end{array}$ \\
\hline Time taken & $\begin{array}{l}\text { Algebraic reasoning } \\
\text { A number word or symbol is used to represent a number } \\
\text { of objects (water containers) }\end{array}$ \\
\hline $\begin{array}{l}\text { Extending children's } \\
\text { number knowledge }\end{array}$ & $\begin{array}{l}\text { Children extending their own knowledge with their } \\
\text { peers }\end{array}$ \\
\hline Assessing and & \begin{tabular}{l} 
Teacher observing and recording, not participating \\
\hline
\end{tabular} \\
\hline recording
\end{tabular}




\section{Vignette 6.6: Commentary}

The teacher at Hikurangi was able to stand back, observe, and document evidence of children's knowledge about mathematics without needing to intervene (see Appendix O). The children were able to discuss and support each other with their number knowledge as they counted up the number of vials of water filled. Child $\mathrm{C} 1$ knew a lot about numbers and, although he could match one to one, he was not yet certain of the correct order for sequential counting. His partner, $\mathrm{C} 2$, modelled the correct sequence for counting, thus providing a model.

Wherever the children's number knowledge came from, the opportunity was present in the kindergarten for them to explore this through their own activities and interests.

Communication Goal 2 of Te Whāriki is supported in this example as children had the opportunity to play and have fun with words and sequenced activities, experiences, and problems (Ministry of Education, 1996, p. 77). Children were observed working and discussing ideas with their peers as they developed and consolidated their number sense and counting skills.

\section{Vignette 6.7: Patterning and design-documenting evolving art designs}

The following description is reported in the form of a vignette but is more a description of a sequence of events over a period. Tanya, one of the teachers at Tongariro Kindergarten displayed a child's, Tui's, ${ }^{33}$ portfolio. ${ }^{34}$ The planning and progression of learning was evident throughout this document.

33 Pseudonym.

34 A child's portfolio is a document available to parents, children, and teachers in which the teachers keep a photographic and written record of the child's learning journey. This leaves the kindergarten with the child when they move to school. 
Vignette 6.7: Documenting evolving art designs

Tui liked butterflies, so Tanya explained the documentation they completed together over two weeks that tracked her responses to Tui's interest and her development of skills over this period.

Tui's first picture of a butterfly, although recognisable, was lacking in significant detail. Tanya got her the book The Hungry Caterpillar and they read it together. The next butterfly picture was more complex.

They moved to finding out more about butterflies by conducting an internet search. A set of photos detailed her development again as her pictures contained finer and finer details and became more elaborate.

Tui was of Australian descent. Tanya recognised this and brought in examples of traditional art work for Tui to look at. Over the following two weeks, Tui incorporated these traditional designs into her art work in the shape of careful mathematical designs and patterns.

The learning journey documented here was sustained over a lengthy period (34 weeks) with photos and written documentation to track Tui's development and learning progressions.

\begin{tabular}{|l|l|}
\hline Category & Comment \\
\hline Mathematisation & $\begin{array}{l}\text { Increasing complexity of patterning developing through } \\
\text { symmetrical patterns and designs on butterfly wings }\end{array}$ \\
\hline Connections & $\begin{array}{l}\text { Patterning and design linked to child's interests and } \\
\text { connected with her background }\end{array}$ \\
\hline Argumentation & $\begin{array}{l}\text { Teacher and child working together to extend a learning } \\
\text { activity }\end{array}$ \\
\hline Algebraic reasoning & Mathematical designs and patterning, symmetry \\
\hline $\begin{array}{l}\text { Assessing and } \\
\text { recording }\end{array}$ & Written and photographic evidence collected \\
\hline Time taken & $3-4$ weeks \\
\hline
\end{tabular}




\section{Vignette 6.7: Commentary}

Vignette 6.7 explored how a teacher identified a child's interest and supported this interest by using a variety of techniques: the internet, the library, and conversations about art and design. The child was supported as she gradually extended and refined her existing skills through her artwork.

From an initial simple butterfly shape painting, the child's work developed into a symmetrical and complex representation of patterns on a butterfly's wings, incorporating her heritage with encouragement and support from the teacher.

The mathematical ideas surrounding the development of symmetrical patterns and shapes emerged from the child's initial interest in butterflies. The teacher was able to create links between the child's background and the kindergarten environment by recognising and developing the child's particular interest in line with the belonging (mana whenua) strand in Te Whāriki (Ministry of Education, 1996, p. 56) and use this interest to foster mathematical development.

\subsubsection{Levels of mathematical competency}

Using the mathematical frameworks developed by Carr et al. (1994) and Dunphy (2006) children's levels of mathematical competencies can be established. These researchers describe three level frameworks. Level one relates to the social and informal aspects of mathematics that children use as they interact with their environment. The vignettes described above demonstrate that children are showing interest in numbers and mathematics as they play and are clearly able to join and separate quantities. Level two on both frameworks describes children who have the necessary skills to solve problems with a mathematical orientation and understand the purpose of numbers. Vignette 6.1, 6.3, 6.5, and 6.6 would fit well into this level. The third level of these frameworks relates to children using numbers in a more formal way relating to awareness and use of numbers correctly and scoring the soccer game (vignette 6.3) and playing with water (vignette 6.6) demonstrate how children were beginning to use numbers in a purposeful way. Children from these kindergartens were capable of using mathematics in a variety of ways and demonstrated their ability to persist at tasks until completed. 


\subsection{Summary}

Teachers in the study kindergartens incorporated the principles and values espoused by Te Whāriki into their practice. They described having a holistic perception of children's learning as they supported the development of positive learning dispositions for each child.

Teachers were seen to capitalise on and extend children's learning as they observed it happening around them, making obvious links to Te Whāriki. They were able to support child-initiated activities in a variety of ways (e.g. providing extra resources, answering questions, using supporting language, and modelling).

Teachers were observed standing back and recording their observations of children's behaviour without needing to intervene. When teachers did set out equipment and activities for children to use, in all observed instances children were free to choose the activities they wanted to engage in. In many child-initiated activities teachers waited until the children asked them to participate or contribute.

Teachers were seen to analyse and modify their own behaviour in response to their observations of children's behaviour in order to support a more positive learning environment for children. Children were seen to be capable of working with one activity for lengthy periods (up to 30 minutes) without interruption. Mathematically related play activities such as water play, building, sorting, and playing and scoring a game provided children with rich contexts to support the learning of mathematical concepts.

By supporting children as they explore and develop their ideas, teachers are building an environment in which children learn to communicate their ideas, an essential skill in the development of mathematical thinking. Play is seen as a means of providing "rich learning contexts where children can reflect on previous experience and consolidate their current understanding" (Pound, 1999, p. 34).

Children in these vignettes show that they have a range of mathematical knowledge relating to proportions and ratios, number systems, patterning, and language that they could apply in a variety of different situations as they explored their surroundings. Teachers gave children opportunities to freely explore and interact with the environment, supporting the principle of empowerment. 
Children had opportunities to take responsibility for their learning and participate in a range of activities. Empowerment includes developing children as individuals and giving children opportunities to develop their sense of self-worth, evident through the attention given to strengthening bicultural and multicultural links. Teachers were seen to be involved with children as they learnt, and the principles from Te Whäriki were evident in their practice. The symbolism underlying Te Whāriki has been likened to weaving a mat where each early childhood centre uses the curriculum to develop a pathway suited to an individual and the particular needs of their setting. In the examples given, specific goals of Te Whāriki have been linked to the mathematical events observed in kindergartens. In some cases the goals could be seen to be similar, yet the activities that prompted these mathematical events were different in each kindergarten, suggesting the weaving of individual pathways according to the activities unfolding.

Evident in teachers' practice is their interpretation of the guidelines in Te Whāriki in the light of each particular kindergarten (or early childhood centre). Teachers encouraged community involvement in many aspects of kindergarten activities and were able to build on everyday interests of children.

Parents and community members' contributions were invited into kindergartens, valued, and developed, supporting the family and community (whānau tangata) principle of Te Whāriki. Parent voice was seen as a valuable aspect of the learning stories produced in kindergartens. These responsive and reciprocal relationships contribute to the richness of kindergarten environments, the fourth principle of $\mathrm{Te}$ Whāriki.

Children were observed on many occasions as capable of being involved in the same task for periods of up to 30 minutes. They were seen to be able to sit on the mat and participate in discussions with their teachers for long periods of time (1530 minutes) without appearing to lose their focus. They were observed completing tasks before moving to another task and on several occasions were seen to sustain interest in a particular task over a period of days. Children in these settings demonstrated their mathematical knowledge. They were able to talk about mathematics in context and make connections to their everyday lives. They demonstrated an ability to make choices, negotiate meanings, and work co- 
operatively. From the evidence gathered kindergarten age children were seen to be able to manage sustained learning interactions. They were able to problem solve and explore their environment mathematically. Children demonstrated that they have mathematical skills not solely relating to number. They were observed counting, comparing relative sizes of objects and numbers, developing language relating to positioning, patterning, and working with social contexts to further develop their mathematical knowledge and language skills.

Their teachers supported and extended opportunities for learning when children showed an interest. The teachers were able reflect on children's learning and work towards developing positive dispositions for learning in children. Close links were observed between teacher practice and beliefs and teachers demonstrated that they used their curriculum as a foundation for their practice. Teachers were observed recording and making observations relating to children's learning. Children were observed to be confident and capable, they were able to maintain various activities for sustained periods of time, and had knowledge relating to many aspects of mathematics. Teachers were observed interacting with children, observing their learning and retrospectively documenting evidence of children's learning through learning stories. The mathematical interactions outlined have been related to the curriculum that shapes teacher practices. These teachers showed that their beliefs about how children best learned mathematics were evident in their practice and these in turn can be related directly to Te Whāriki. 


\section{7: Findings: New entrant teachers' beliefs and practices in mathematics teaching and learning}

\subsection{Introduction}

This chapter examines the beliefs and practices of new entrant teachers in relation to mathematics teaching and learning. The chapter uses evidence from the observations, interviews, and documentation gathered from the teachers in the new entrant classrooms and school principals involved in this study. The information collected is used to develop a consistent picture of mathematics education and to examine teachers' beliefs and practices in mathematics teaching after children have made the transition to school.

New entrant teachers in this study said they believed children best learned mathematics through having 'hands-on' and real-life experiences. They believed that children learned by doing and it was important children were encouraged to take responsibility for their own learning. These teachers said it was important to provide many opportunities for problem solving in mathematics, but in some instances, they believed children came to school with very little mathematical knowledge. In these instances, they said children needed to be taught knowledgebased skills before they could successfully problem solve. In general, these teachers said they took a developmental approach to learning where children progressed through sequential stages in their learning. The examples of practices and beliefs detailed in the vignettes were chosen to illustrate typical mathematical events that occurred across classrooms in the study and to describe how teachers worked with children in mathematics. Classroom observations and individual teacher interviews, combined with informal discussions with teachers were used to build examples of mathematical practices in the five new entrant classrooms in this study. In most instances, the mathematical observations consisted of a teacher working with a group of up to eight children in a formal lesson on the mat. Some incidental mathematics events were observed and recorded, but instances where teachers directed children to practice or independent activities are not reported on because the focus of this study is on teacher practices and beliefs. In the new entrant classrooms, practice or independent activities were initiated by the teacher who monitored what children were doing at these from her position within her 
teaching group, in contrast to kindergarten teachers who had more apparent freedom to circulate around children and interact with events as they unfolded.

This chapter relates to the five new entrant teachers in this study. The observations and interviews relate to the teachers as they worked with a group of children who were new to the school system. In all instances, new entrant teachers were teaching a group of children experiencing new ways of doing things. The children had moved from being the oldest and most experienced children in an early childhood setting to being the youngest and newest in the school system. Children came to school with varying amounts of early education, including some children who may not have had any formal early education other than from home. Only some of the children had attended kindergarten. This diverse group of children with differing early experiences form the new entrant class. The task of socialising this group to school is part of the new entrant teacher's job.

Establishing routines and managing the variety of children influence how new entrant teachers begin to develop instructional routines within the class. While kindergarten teachers had the opportunity to work with flexible and variable groups of children on many child-initiated instances, this flexibility was not seen in new entrant classrooms as teachers developed the rules and norms of the school environment with their class alongside beginning their education in the generally more formal school setting. Children have to learn to operate within the school system, which readers should keep in mind throughout the discussion in this chapter.

Wherever possible I have used the words of the new entrant teachers to represent their beliefs about mathematics teaching and learning, but the interpretation of these words is mine. The findings presented in this chapter describe how teachers view their practice. Their beliefs about how children best learn mathematics are examined and compared with their observed teaching practice. Vignettes relating to mathematical events have been developed in a similar fashion to those in chapter 6 , and contain an introduction of the events followed by a descriptive table highlighting the mathematical ideas of the event and commentary. 


\subsection{Teacher beliefs and practices about how children learn mathematics}

How teachers view mathematics learning and teaching forms the basis of how they organise their classroom practice (Rivalland, 2007). Their personal experiences, experiences as teachers, and experiences as learners all contribute to their beliefs about what makes a good mathematics teacher and how best to teach children mathematics. A discrepancy between teacher beliefs and practices appears to be a common feature in research of this kind (Cobb, 1988; Frid, 2000; Jaworski, 1999). This section details the nature of the beliefs and practices in this study. Information about teachers' beliefs comes from their interviews. Their practice was observed. Vignettes describing particular mathematical events are used to describe and illustrate observed teacher practices in mathematics. Each of the five new entrant classrooms in this study comprised children who had recently made the transition to school. Teachers had to ensure children settled into school and were able to continue learning in the school system.

The data from the new entrant observations show different events happening in these classrooms. Information gathered from the five new entrant teachers was collated and is summarised in Table 7.1 using the same criteria for the information gathered from kindergarten teachers. Organising and directing learning in mathematics dominated the teaching practice observed in the new entrant classrooms. Although teachers interviewed said their beliefs about mathematics learning were largely developmental in origin and they believed children learned through play and by being challenged, these beliefs were not always evident in their observed practice. For example, Hiria at Hikurangi School said, "I don't really have a specific teaching style, I suppose it is more developmental, I need to provide information and skills until they [children] are ready to move, a progressive way" (interview, 29/3/06).

Notable is the final category, 'teachers talking about mathematics'. In the kindergarten, these events arose out of the children's spontaneous interactions, but mathematical events observed in new entrant classrooms arose from teacher planning and specific teaching of skills. In all observed instances mathematics teaching consisted of teachers giving directions, asking closed questions about 
mathematics, and telling children how to problem solve, so were not included in the 'talking about mathematics' category. From Mathematics in the New Zealand Curriculum (MiNZC), problem solving occurs when children are given opportunities to develop mathematical thinking "through applying concepts and skills in interesting and realistic contexts which are personally meaningful to them" (Ministry of Education, 1992, p. 11) and requires children to make connections and search for information. Most of the mathematics observed came under the teacher directing or organising category as in all instances in this study the teachers planned and executed the mathematics learning for children. These were not spontaneous interactions that arose from children's interests, but resulted from teachers' planning based on their beliefs about what children need to know. The observations are based on teacher interactions with the whole class, but the vignettes relate specifically to a teacher interacting with their teaching group while the rest of the class are directed to independent or practice activities.

Responses are reported in Table 7.1, using the headings explained in section 5.3.7.

- Teacher questioning - teachers ask open-ended questions of children.

- Teacher organising - activities that contribute to the smooth organisation of the kindergarten.

- Teacher directing - teachers giving directions or using closed questions to direct learning.

- Teacher supporting learning - teachers building on child-initiated learning.

- Teachers talking about mathematics with children - teachers responding to child-initiated mathematical activities.

Eight instances were recorded from 308 observations that related to the teachers supporting and extending children's learning. In only one observed instance did a teacher use questioning skills to extend and develop the children's ideas in mathematics. In other instances, questions were directed at gaining a response from the children (closed questioning). The expected response (ie, the correct answer) once given was not generally further explored by teachers or children. After a correct response was given, teachers occasionally asked a further question most commonly requiring another single response. The lessons consisted of closed question-and-answer sequences with little or no time spent on problem 
solving or extending and developing children's responses. Teacher practice in these classrooms was characterised by direction; teachers organised, managed, and directed children's learning in most observed instances. The teachers in the study said that the lack of perceived knowledge possessed by children in their classrooms meant they had to directly teach knowledge skills to children before teaching children how to problem solve at a later stage.

Table 7.1: New entrant teacher practices observed by response category

\begin{tabular}{|l|c|c|c|c|c|c|}
\hline $\begin{array}{l}\text { Category of } \\
\text { response }\end{array}$ & Aorangi & Cascade & Dundass & Hikurangi & Tongariro & $\begin{array}{c}\text { Total } \\
\text { responses } \\
(\%)\end{array}$ \\
\hline $\begin{array}{l}\text { 1. Teacher } \\
\text { questioning }\end{array}$ & 0 & 1 & 0 & 0 & 0 & $\begin{array}{r}1 \\
(.3 \%)\end{array}$ \\
\hline $\begin{array}{l}\text { 2. Teacher } \\
\text { organising }\end{array}$ & 33 & 12 & 33 & 30 & 25 & $\begin{array}{r}133 \\
(43 \%)\end{array}$ \\
\hline $\begin{array}{l}\text { 3. Teacher } \\
\text { directing }\end{array}$ & 30 & 35 & 18 & 45 & 38 & $\begin{array}{r}166 \\
(54 \%)\end{array}$ \\
\hline $\begin{array}{l}\text { 4. Teacher } \\
\text { supporting } \\
\text { learning }\end{array}$ & 0 & 1 & 5 & 2 & 0 & $(2.7 \%)$ \\
\hline $\begin{array}{l}\text { 5. Teachers } \\
\text { talking about } \\
\text { mathematics } \\
\text { with children }\end{array}$ & 0 & 0 & 0 & 0 & 0 & 0 \\
\hline $\begin{array}{l}\text { Total } \\
\text { interactions }\end{array}$ & 63 & 49 & 56 & 77 & 63 & 308 \\
\hline
\end{tabular}

The number of observations between study schools varied. This resulted from unexpected school events such as a fire drill, jump jam, ${ }^{35}$ and the presence of student teachers. Observations of teachers were characterised by organisationaland directional-type activities with few observed opportunities for supporting and extending learning. Teachers in the new entrant classrooms had a plan that outlined the progression of their mathematics lessons that, in turn, dictated the unfolding of events. Teachers were responsive to their strongly held beliefs

35 Jump jam is an organised group physical education dance programme incorporating synchronised movement with music. 
('sayings') relating to children's needs rather than responding to children's actual needs. The lessons were formed from teachers' plans ${ }^{36}$ that related to the mathematics they believed children needed to know. The style of teaching was organised and directed by the teacher with activities, questions, and instructions to children that conformed to the course of the lesson. Teachers followed their lesson plans with little apparent deviation.

New entrant teachers said they believed they held a developmental approach to learning. They said they believed that children learn mathematics through exposure to real-life contexts, problem-solving activities, and having fun. Teachers described children as not being ready for many aspects of mathematics learning at school. This lack of readiness for mathematics in the teachers' view meant they spent time teaching children basic mathematical knowledge in order to prepare them for further mathematical learning. Before children could learn to problem solve and explore mathematics in real-life contexts, teachers said they needed to be taught the necessary skills. Children were deemed not ready because teachers perceived them to lack knowledge in areas such as counting, grouping, and joining sets.

Table 7.2 summarises teachers' observed practices, which have been compared with information gained from semi-formal interviews. Information relating to how teachers believed they taught mathematics and what they considered important features of mathematics teaching are contrasted with classroom observations specifically related to mathematics teaching. The evidence collected from the observations suggests these teachers followed their lesson scripts (Cassidy\& Lawrence, 2000). Teachers said their lessons were based on their experiences and existing beliefs relating to their knowledge of what five-year-old children need to know in order to be successful at school. At Cascade School, the teacher said she had to "spend a lot of time teaching [the children] things they should know when they come, things that really ought to be taught at kindergarten" (interview, 1/8/06). These things included sitting still on the mat, finishing work, making patterns, writing their name, and counting. Teachers in the study schools said when children lacked these essential skills, it was difficult for them to be 
successful at school. Teachers were found to have similar beliefs and practices across the five schools, so the responses relate to each of the new entrant classrooms in this study.

Table 7.2: New entrant teacher practices and beliefs about the teaching of mathematics

\begin{tabular}{|c|c|c|c|}
\hline School & $\begin{array}{l}\text { Observed } \\
\text { practice }^{1}\end{array}$ & $\begin{array}{l}\text { Beliefs: Statements about } \\
\text { practice }\end{array}$ & $\begin{array}{l}\text { Comparison of stated } \\
\text { beliefs and observed } \\
\text { practices }\end{array}$ \\
\hline \multirow[t]{3}{*}{$\begin{array}{l}\text { Aorangi } \\
\text { Cascade } \\
\text { Dundass } \\
\text { Hikurangi } \\
\text { Tongariro }\end{array}$} & $\begin{array}{l}\text { Teacher } \\
\text { questioning }\end{array}$ & $\begin{array}{l}\text { Children need structure } \\
\text { Mostly knowledge based } \\
\text { lessons as children do not } \\
\text { yet have problem-solving } \\
\text { skills }\end{array}$ & $\begin{array}{l}\text { Teachers were observed } \\
\text { asking closed questions } \\
\text { supporting closed } \\
\text { problems, }{ }^{2} \text { providing } \\
\text { limited opportunities for } \\
\text { investigations }\end{array}$ \\
\hline & $\begin{array}{l}\text { Teacher } \\
\text { organising }\end{array}$ & $\begin{array}{l}\text { Real-life contexts } \\
\text { Understands the needs of } \\
\text { children } \\
\text { Knows what to teach based } \\
\text { on own experiences } \\
\text { Children learn by doing } \\
\text { Children should be given } \\
\text { responsibility for learning }\end{array}$ & $\begin{array}{l}\text { Teachers selected } \\
\text { mathematical activities for } \\
\text { children based on their } \\
\text { assumed knowledge of } \\
\text { children's competencies } \\
\text { Teachers directed children } \\
\text { to particular activities } \\
\text { Teachers selected a range of } \\
\text { independent activities for } \\
\text { children }\end{array}$ \\
\hline & $\begin{array}{l}\text { Teacher } \\
\text { supporting } \\
\text { learning }\end{array}$ & $\begin{array}{l}\text { Uses children's own } \\
\text { experiences } \\
\text { Integrates mathematics } \\
\text { across all areas of the } \\
\text { curriculum }\end{array}$ & $\begin{array}{l}\text { Some examples of teachers } \\
\text { basing mathematical events } \\
\text { on children's own } \\
\text { knowledge } \\
\text { Mathematics generally } \\
\text { taught at a specific time, } \\
\text { some evidence of } \\
\text { mathematics observed } \\
\text { during other periods of the } \\
\text { day (e.g., roll call and } \\
\text { physical education) }\end{array}$ \\
\hline
\end{tabular}




\begin{tabular}{|l|l|l|l|}
\hline School & $\begin{array}{l}\text { Observed } \\
\text { practice }\end{array}$ & $\begin{array}{l}\text { Beliefs: Statements about } \\
\text { practice }\end{array}$ & $\begin{array}{l}\text { Comparison of stated } \\
\text { beliefs and observed } \\
\text { practices }\end{array}$ \\
\hline $\begin{array}{l}\text { Teacher } \\
\text { directing }\end{array}$ & $\begin{array}{l}\text { Has high expectations } \\
\text { Developmental teaching } \\
\text { style } \\
\text { Need to provide information } \\
\text { and skills until children can } \\
\text { problem solve and move on } \\
\text { in the teacher's judgement }\end{array}$ & $\begin{array}{l}\text { Teachers organised children } \\
\text { into specific activities } \\
\text { Teachers followed their } \\
\text { work plans } \\
\text { Teachers specifically taught } \\
\text { knowledge based } \\
\text { mathematical skills to } \\
\text { children based on their } \\
\text { experience and beliefs as to } \\
\text { the necessary skills children } \\
\text { should possess on school } \\
\text { entry }\end{array}$ \\
\cline { 2 - 4 } & $\begin{array}{l}\text { Teachers } \\
\text { talking } \\
\text { about } \\
\text { mathematics } \\
\text { with } \\
\text { children }\end{array}$ & $\begin{array}{l}\text { Makes mathematics fun } \\
\text { Allows children autonomy } \\
\text { Many problem-solving } \\
\text { opportunities given } \\
\text { Provides a safe environment }\end{array}$ & $\begin{array}{l}\text { There were no observed } \\
\text { occasions where children } \\
\text { were given problem-solving } \\
\text { activities and the freedom to } \\
\text { explore independently of } \\
\text { teacher direction } \\
\text { Teachers provided a warm } \\
\text { environment for children } \\
\text { Children appeared to enjoy } \\
\text { mathematics lessons and } \\
\text { activities }\end{array}$ \\
\hline
\end{tabular}

Note

1 Categories are as for the observations in Table 7.1.

2 "Closed problems, which follow a well-known pattern of solution, develop only a limited range of skills" (Ministry of Education, 1992, p. 11).

Table 7.2 presents what teachers said about how children learn mathematics (teachers' beliefs) and their practices as observed within the classroom. Teachers believed they provided a hands-on approach, giving children opportunities to problem solve and advance their learning. Teachers held these beliefs in conjunction with the belief that they knew from their personal experiences what five-year-old children needed to know in mathematics in order to be successful at school. Teachers said they had a responsibility to fill these perceived knowledge gaps before they could teach children to problem solve. Most statements about teacher beliefs contrasted with observed practice. Teachers may believe they are 
providing problem-solving experiences within real-life contexts, yet they were observed to be managing learning for children. Hiria from Hikurangi School said:

At this school the kids come often without too much knowledge ... I think that children from kindergarten don't come with skills I would expect them to have. It is my feeling that the children from the aoga amata $^{37}$ are more able to do some of these skill-based things to a greater degree than children from kindergarten, they are taught specific skills, they are able to sit down, say the alphabet, they can listen and count. (Interview, 29/3/06)

Hiria felt her school's long-term plan $^{38}$ for mathematics was not useful for her because new entrant children "have different needs and many of the things on the long-term plan can't be done because you need to fill the gaps first" (interview, 29/3/06). Hiria's belief about "filling the gaps first" is a common feature of the beliefs of the new entrant teachers in this study. This belief guided the content of the lesson plans. In each class, the teacher directed the learning of mathematics in knowledge-building skills. The socialisation aspect of the classroom, having obedient and compliant children, and having a planned and well-managed programme was a further feature of classroom practice. Evidence of careful management and following the plan is evident from Table 7.1 where most of the observed interactions related to teachers directing and organising lessons, learning, and activities.

New entrant teachers in this study selected activities for children to complete that in most instances reinforced the lesson taught by the teacher. Mathematics occurred at a set time in the day, and children were organised into groups based on their ability in mathematics as determined by the diagnostic interview (Ministry of Education, 2005a) and teachers' professional judgement. Teachers had to spend time managing and organising up to three separate groups and ensuring the class operated smoothly. While the content of lessons was important, of similar importance was making sure children knew how to behave and manage school ways of doing things.

37 Name for a Samoan language early childhood centre.

38 See Appendix $\mathrm{Q}$ for an example of a school's long-term plan. 
New entrant teachers worked alone in independent, self-contained classrooms, teacher aides were observed only at Dundass and Aorangi Schools for a small part of the school day, in contrast to kindergarten teachers who worked as a team in the same space. New entrant teachers belonged to the junior school syndicate in each school. The role of the syndicate was to overview the term's work programmes and support for teachers. Some co-operative planning occurred but new entrant teachers said they did not benefit from this because the needs of new entrant children were different from the other children in the syndicate. Some syndicate discussion centred on specific children if a teacher had specific concerns but, in general, reflection on practice was not a feature of syndicate meetings. New entrant teachers were not observed taking written notes as a way to monitor progress, but Hiria from Hikurangi School showed me some of the informal jottings she used to monitor children's progress. Donna from Dundass School said:

The needs of the children are recorded but are often mentally noted and that gap is filled for a group of children when the need arises. This means the teaching groups can be quite variable and changing. My assessment is continuous and ongoing and may not always be written down. (Interview at Dundass School, 2/3/06)

The assessment of children's progress was not done on a regular basis; teachers said they reported on mathematical progress once a term as outlined in their longterm plans, and this information supported their classroom groupings. The numeracy diagnostic assessment was completed at the beginning of the year in these new entrant classrooms and teachers said this guided their initial groupings of the children.

\subsubsection{New entrant classroom environment}

Each new entrant classroom in this study was a self-contained room with the teacher operating independently of other teachers, unlike in the kindergartens. New entrant teachers said they saw their role as a special one in the school environment because they were often the first point of contact parents had with the school and they had the task of ensuring: 
in the first few weeks children learn the class routines, school rules, begin to participate in activities, make friends and build up their confidence and self-esteem. They need to learn that they are part of a class and settle into being a happy child at school. School has got to be fun and enjoyable otherwise children just switch off. (Interview at Dundass School, 2/3/06)

This section explores some of the features of new entrant classrooms observed as teachers worked to ensure children made a successful transition to school. Without exception, these classrooms were warm $^{39}$ and inviting places. The teachers showed they cared about the children in their charge and worked hard to ensure children were aware of this by listening and talking with them. The mathematics opportunities in the new entrant classrooms in this study were contained within the physical space of the classroom. No community involvement was observed. Children engaged in mathematics at the direction of their teacher. New entrant teachers followed their plan, and children operated within teacherorganised groupings and spaces. The emphasis was on routine and structure, which was evident in the way children moved around the classroom and used the equipment. Children knew where to go and what to do, and good behaviour was reinforced.

The first impression in each room was that it was a pleasant place to be. Teachers were in the classrooms before school preparing the day's work. The teacher greeted the children in English. Children and parents were welcomed into the classroom. Once maintenance activities (such as hanging up bags, and putting reading books away) were completed, the children were free to engage in a quiet, inside activity sanctioned by the teacher or to go outside and play until school started. Parents did not usually stay in the classroom after the start of the school day. Sometimes parents stayed in the classroom before the beginning of school to communicate with the teacher about their child.

Before school started (at 9 am) children could use, with the teacher's consent, some of the classroom equipment (e.g. books, pens and paper, and some quiet

39 Warm environments are as described by Docket and Perry (1999) and further detailed in section 6.2.1. 
games) but most commonly children used equipment as directed by the teacher to support aspects of her teaching and learning programme.

The classrooms were busy environments with a wide range of well-ordered mathematics equipment. The busyness of classrooms was determined by the fact children were engaged on the mat or in an activity during most observation sessions. There were very few examples observed of children doing nothing. A variety of wall displays related to mathematics, but were not solely numeracy oriented.

There were no examples of mathematics in any language other than English despite the multicultural nature of the schools. There were no observed instances of counting in any other language; English language dominated the classrooms. Angela from Aorangi School summed up this perception when she said, "Why would I teach [the children] to count in another language, if they can't count in English they won't be able to do the maths" (interview, 25/10/06).

In these classrooms, teachers spoke of caring for the children and trying to make sure they gave the children everything they needed to ensure future success and had the skills necessary for learning progressions. This caring environment was evident, yet a personal communication from a literacy adviser indicated that this caring might not be enough, because children needed to be challenged and extended (personal communication, literacy adviser, Wellington, 25/5/06). The literacy adviser said:

I think we are holding the children back in literacy. The teachers are really good and presenting good material to the children to read but you know, it's hard to put a finger on it but they seem to be holding the children back and consolidating them too much. So in many instances the children aren't really being challenged. I think in a way we are all too nice, we don't challenge the children to make that next step, just that little bit harder, more difficult because we don't want them to fail. I think it is a fine line but I am seeing teachers that are just too nice and because of this we are spending too long going over material that is just at the right level. They are not doing the children any favours by not challenging, pushing them, we're all just too nice. 
Further evidence of a belief that new entrant children are not being sufficiently challenged in some lessons is given below (personal communication, numeracy adviser 1, Wellington, 25/5/06):

You know that I was observing in the junior classes at X school and I was left with the feeling that something was not quite right. The classes were lovely, full of resources and activities, the planning was all there but there was something missing. It took me a while to figure it out, it was the teachers, they were all in charge of the class, there were no opportunities for the children to problem solve, they were filling the kids up with knowledge and not giving them any chances to operate with this knowledge to problem solve. I think the implication was that these teachers didn't think that children this young were able to problem solve until they had some knowledge so they didn't give them any problems to do. It seemed to be the case in all the junior classes at the school but it took me a while to figure out what exactly was not quite right about these classes because you know they were lovely rooms with some really nice activities going on.

(Note that the school referred to above was in a different geographic location to the schools in this study.)

Another numeracy adviser indicated the same lack of challenge (personal communication at a numeracy workshop, numeracy adviser 2, Auckland, 30/11/07). The adviser was running a workshop when a teacher of a year 2 class told her that children in her class could read six-digit numbers competently:

[B]efore I could even jump in and say that's wonderful, she asked me very tentatively if it was really okay to take children that far at that age. You know that appeared to be a common view in the group, they seemed to feel that children at this age shouldn't be able to read numbers that big. Teachers said they wanted to ensure children could succeed at school. Teachers set up activities for children to do, they ensured children could follow routines, and made sure children possessed the necessary knowledge skills to later learn to problem solve. Evidence from the personal communications with the literacy adviser (2006), numeracy adviser 1 (2006), and numeracy adviser 2 (2007), 
described above, suggests that in some cases this may not be enough; children need to be presented with challenges at early stages in their learning as they may be more competent than teachers realise.

In the new entrant classrooms in this study a variety of mathematical events occurred. Examples were chosen from the schools to describe the nature of the mathematics events and illustrate common teacher practices. Each chosen event was part of a planned mathematics lesson. In these events, teachers were supportive of children, ensuring children could give the correct response for each planned learning step. This was evident in how teachers made explicit links for children and ensured they taught the children what they had planned to teach. For example, in a lesson where children were having difficulty identifying the number before and the number after a given number, the teacher, rather than allowing children time to discuss how to solve this problem, immediately offered support. She demonstrated how to count up to the given number to obtain the number before or count on past the given number in order to get to the number after. The next time a child had difficulty with this, she made the same link to this particular counting strategy and demonstrated it again, before the child had time to think, get stuck, discuss strategies with classmates, or try the strategy.

Despite some teachers believing the tasks they gave children were extending their mathematics by providing opportunities for problem solving, no instances were observed of these. In general, the lessons were directed by the teacher who managed the learning and made connections for the children.

Table 7.3 outlines the beliefs of Hiria from Hikurangi School as she relates how children best learn mathematics. These beliefs are in the form of statements about her practice from her interview and they are matched with her observed practices in the classroom. Children's responses are described as the teacher works with them. Similar information from the other four schools in the study is in Appendix R. 
Table 7.3: Comparison of new entrant teacher beliefs about how children learn mathematics, teacher practices, and student behaviour

\begin{tabular}{|l|l|l|l|}
\hline School & Hiria believed: & Observed practice & $\begin{array}{l}\text { Observed response } \\
\text { from children }\end{array}$ \\
\hline Hikurangi & $\begin{array}{l}\text { She brings numbers } \\
\text { to the attention of } \\
\text { the children } \\
\text { She has clear } \\
\text { expectations of } \\
\text { children } \\
\text { Children have fun } \\
\text { learning } \\
\text { Children are active } \\
\text { problem solvers }\end{array}$ & $\begin{array}{l}\text { Makes links to prior } \\
\text { learning } \\
\text { Structures lessons } \\
\text { Adheres to lesson } \\
\text { plans }\end{array}$ & $\begin{array}{l}\text { Being quiet } \\
\text { Sitting still } \\
\text { Responding when } \\
\text { asked }\end{array}$ \\
\hline
\end{tabular}

Hiria at Hikurangi School said she believed children were capable problem solvers and that she made sure children had fun learning mathematics. In her classroom practice, she followed a structured lesson plan when she made links to children's prior learning. Her focus in the mathematics instructional time was primarily on the group she was teaching. From time to time, she had to attend to the other children in the class to maintain their focus on their particular activity. Hiria's lessons consisted of her asking closed questions to named children and children answering as requested.

Children in Hiria's teaching groups were observed sitting in a circle around her, responding to her directions, and waiting to be told what to do. When the teacher's attention was diverted from the teaching group, children began to talk among themselves about the mathematics lesson and explore strategies. Once the teacher's attention returned to the group, children returned to their previous quiet behaviour. Children did not talk to each other while the teacher was with the group. The other children in the class worked on activities selected by the teacher to reinforce prior learning or chose an activity from a selection of activities set out by the teacher. This behaviour was common across these new entrant classrooms. Teachers were not observed responding to children's interests, other than reinforcing correct responses, during the mathematics lesson time. 
Table 7.4 outlines the format of a typical lesson observed. Most lessons observed in the new entrant classrooms in this study followed this basic format.

Table 7.4: Typical lesson structure in a new entrant classroom

\section{Sequence and structure of a typical mathematics lesson (15-20 minutes)}

- Teacher with a group of 6-10 children.

- Task clarification by teacher (e.g., numeral identification).

- Children asked to make a set of objects (up to 10).

- Children show numbers on a number fan according to teacher direction.

- Children identify numbers as teacher displays them.

- Children make sets of objects to match numeral cards distributed by teacher.

- Children are given an independent task to complete.

The remainder of the class works on independent activities organised by the teacher until it is their turn for a group lesson with the teacher.

In the new entrant classrooms few instances of spontaneous mathematical events were observed by either teachers or children.

Teachers were observed making explicit links to children's prior learning, rather than supporting children to make links. Each lesson started with teachers telling children what to do, introducing the materials, and directing their usage. Teachers questioned children, modified tasks as necessary, corrected misunderstandings, and provided strategies. The task modification presupposes that some assessment is taking place as a result of teachers monitoring children's mastery of the given tasks. The teachers' classroom discourse guided the organisation of the lesson through reminders about rules, routines, and the use of materials more than supporting the development of children's mathematical problem-solving strategies. In some cases the lack of attention paid to children's prior knowledge and experiences lead to the teacher underestimating the knowledge and abilities of their students. In some instances, children spent time completing activities they appeared to have already mastered, a similar finding to that of Young-Loveridge (1989a). 


\subsubsection{Mathematics lessons observed}

Children were seen to have few opportunities for free play during the observed lessons. ${ }^{40}$ The vignettes that follow provide examples of structured lessons aimed at providing knowledge for children. The vignettes centre on the teacher with a group of children on the mat. The focus of this study is on teachers' beliefs and practices, so the focus for the observations was predominantly on the teacher and the group of children she was working with. The remainder of the children in the classroom were involved in practice or independent activities as chosen by the teacher. The lessons are discrete examples and follow objectives that the teachers have determined. Each example of a mathematics lesson is outlined and followed with an analysis of the mathematical ideas in the event (Perry \& Dockett, 2002, 2005). A full explanation of the mathematical ideas categories is in chapter 5. Within each vignette, examples are highlighted in the same fashion as in the vignettes in chapter 6 . Each example was chosen to illustrate some aspect of mathematics observed. Following the analysis of the mathematical ideas in the lesson, is a brief explanation and commentary on the lesson.

In instructional group settings, teachers were in control of the interactions and followed their lesson plans. These teachers had strong beliefs about what children needed to know in order to be successful at school, so that is what they taught children. In general, there appeared to be a discrepancy between what teachers said they did and what was observed in the classroom. For example, Donna from Dundass School said she believed in "modelling for and guiding the children and nurturing them so they are more engaged in learning. I like to guide the children's learning and teach them how to make choices for themselves" (interview at Dundass School, 12/3/06). Her practice suggested she made choices for children. However, the general assumption by teachers seemed to be that children actually knew very little when they came to school. Although the teachers believed children should be "problem solving", they also believed children were unable to do this because they believed children did not have the necessary skills on their

40 In kindergartens these 'lessons' were referred to as events because they usually occurred spontaneously, but in new entrant classrooms they were usually planned lessons. 
entry to school. Comments from new entrant teachers at Cascade (decile 1) and Aorangi (decile 10) Schools reinforce this perception:

I want them to be able to problem solve but they are unable to as they don't have the language. Mostly the children who come here don't know any of this [basic number concepts] so there is a lot to teach them.

(Caroline, Cascade School, 27/6/06)

Children come to school with no number knowledge, especially children who are second language learners. (Angela, Aorangi School, 15/4/06)

\section{Vignette 7.1: Number identification - locating and identifying numbers}

At Hikurangi School, a group of children was being instructed in numbers as if they knew very little about numbers, and yet when the teacher, Hiria, was called away from the group it was evident from the ensuing discussion that the children knew quite a lot about numbers.

Children were sitting on the mat in a semi-circle facing their teacher and the whiteboard. The rest of the class was working on activities within sight of Hiria, enabling her to monitor their attention to the tasks given. When the noise level of children not working with the teacher reached an unacceptable level for Hiria, she got up from her instructional group and moved to the other children to monitor their behaviour. This prompted the children in the instructional group to have a conversation with each other about how to identify numbers if they were not sure. Once Hiria returned to her instructional group, children reverted to the more passive role of waiting to be asked a closed question. Vignette 7.1 illustrates this lesson. The teacher is Hiria $(\mathrm{H})$, and each child $(\mathrm{C})$ is differentiated numerically. 
Vignette 7.1: Number identification - locating and identifying numbers

A group of five children are on the mat with their teacher, $\mathrm{H}$.

The lesson relates to identifying numbers on the number fan.

$\mathrm{H} \quad$ Can you show me 5?

C (All find 5 and display it for $\mathrm{H}$.)

H Show me 4. Good now can you find 9?

( $\mathrm{H}$ is distracted by another group, so the children have a discussion together.)

C1 Where is that number?

C2 Look, you got to start here (0) and then you count.

$\mathrm{C} 1, \mathrm{C} 2, \quad 0,1,2 \ldots 8,9$.

Children shared with each other ideas about how to find numbers and how to count up to find it, if they were not sure where the number came.

Teacher returned to the mat and children displayed 9 for her.

H Show 9, oh good you have it. Now show me 8.

( $\mathrm{H}$ did not ask the children how they got to 9.)

\begin{tabular}{|l|l|}
\hline Category & Comment \\
\hline Mathematisation & Number identification to 10 \\
\hline Connections & Numbers in isolation, no obvious connections \\
\hline Argumentation & $\begin{array}{l}\text { No opportunities for discussion with teacher present } \\
\text { Children discussed strategies for problem solving when } \\
\text { the teacher was distracted }\end{array}$ \\
\hline $\begin{array}{l}\text { Number sense } \\
\text { number knowledge }\end{array}$ & None, children repeating number names only \\
\hline $\begin{array}{l}\text { Recording and } \\
\text { assessing }\end{array}$ & No recording or assessing observed \\
\hline Time taken & 15 minutes \\
\hline
\end{tabular}


The children located numbers on the number fan on the teacher's instruction and engaged in discussion with each other when the teacher left the group. Once the teacher had left, children demonstrated their ability to both strategise to locate an unknown number and support their peers.

\section{Vignette 7.1: Commentary}

Children were able to discuss how to 'drop back' to count up to identify an unknown number. The art of dropping back is defined as (Ministry of Education, 2005, p. 11):

For the forwards and backwards number word sequences, dropping back means that the student says or mentally counts several numbers up to the given number. He/she then says the number before or after that number. For example, the student finds the number after 5 by saying one, two, three, four, five, six. A student finds the number before 14 by saying 10 , $11,12,13,14$, then says 13 .

Hiria did not explore how the children identified the number nine when she returned to the group. Her focus was on the correct identification of numbers. There were no observed opportunities given to the children to extend and develop their ideas about numbers when the teacher was present, and she appeared to be underestimating or unaware of the children's abilities. There was no evidence in this lesson of Hiria monitoring or recording the children's learning. The purpose of the lesson was the identification of numbers, which, from the children's independent discussion, was well within their abilities and did not present a challenge.

\section{Vignette 7.2: Reproducing shapes - geometry in action}

Vignette 7.2 from Aorangi School follows the progress of a geometry lesson where the teacher had a clear plan of the direction to follow. The focus of this lesson was for children to reproduce geometric shapes independently. When a challenge was presented to the children, they were not encouraged to work together to solve the problem or discuss possible ways to solve it. 
In this vignette, the teacher is Angela (A), and each child (C) is differentiated numerically. Child C2 was of particular interest because of the discussion that followed at morning tea after this lesson. Children were on the mat facing Angela.

\section{Vignette 7.2: Reproducing shapes - geometry in action}

A group of eight children is on the mat with the teacher (A). A gives out geoboards with rubber bands and instructions on how to behave with them. A directs the task.

A Choose one of the picture shapes to make that shape.

Children focus individually on their task and make comments such as, "it's easy", it's hardest", "I made it", but do not discuss the features they were trying to reproduce from the model chosen.

A Now let's see what everybody has made.

A $\mathrm{C} 1$, what have you made?

C1 Triangle.

A How do you know?

C1 Three sides.

A Good, you can choose another shape to make.

The children were working independently of each other. The teacher asked each child to retell the basic attributes of their shapes. No attempt was made to assess or develop understanding; it was an exchange of facts.

A Has everybody got a second shape I can see? Hold it up so I can see. Now without a triangle next to you, turn your rubber band into a triangle.

The children hold up their new shapes, A reinforces correct shapes without discussing the features of a triangle and further reinforces the importance of children doing their own thinking.

A gives children a challenge; she holds up a hexagon shape and challenges the children to make the shape. A counts down from 30, only one child (C2) can complete the task and he is told to hide his shape so the others can not see it. 
A makes positive comments to those who are still trying individually, but children are not encouraged to share their ideas or ways of making shapes. Six of the eight children are still struggling at play time and they are told to try to work it out over morning tea time.

A You must be able to make it yourself.

\begin{tabular}{|c|c|}
\hline Category & Comment \\
\hline Mathematisation & Recognising and making geometric shapes \\
\hline Connections & None \\
\hline Argumentation & No opportunities for discussion between children \\
\hline Number sense & Children count number of sides for some shapes \\
\hline $\begin{array}{l}\text { Spatial and } \\
\text { geometric thinking }\end{array}$ & $\begin{array}{l}\text { Basic shape geometric attributes } \\
\text { Reproducing geometric models }\end{array}$ \\
\hline $\begin{array}{l}\text { Extending children's } \\
\text { number knowledge }\end{array}$ & Possible \\
\hline $\begin{array}{l}\text { Recording and } \\
\text { assessing }\end{array}$ & No recording or assessing observed \\
\hline Time taken & 12 minutes \\
\hline
\end{tabular}

This was a lesson where children were encouraged to repeat back to the teacher what they had learned. Limited opportunities were given for children to explore and discuss what they were doing and to talk to each other. Children had individual sets of equipment to work with (geoboards and rubber bands) while Angela held the set of different shapes for children to choose from.

\section{Vignette 7.2: Commentary}

In this vignette, children were given a problem to solve (making a hexagon) and they were expected to solve it independently and without discussion after initial practice in making three- and four-sided shapes. The children were challenged to make a hexagonal shape, but the teacher offered no support. When it became evident that this task was too difficult for most of the children in the group, Angela told the children that they had to be able to make it themselves. This 
vignette shows children who are doing as they are told; they are not encouraged to make links to prior learning or to discuss various aspects of their shapes. Angela believes that children are able to actively problem solve (Appendix $\mathrm{S}$ ) as well as believing that she knows what five-year-old children need (see Table 7.2). Her practice shows evidence of a more traditional style of teaching.

C2 was the only child to make the hexagon shape. His first language was not English. Angela commented at morning tea:

I've got some extra help for him [C2] this term; his English is still not good. I told his parents that they should really be speaking English at the dinner table because it's such a social time for developing language but I really don't think they do. He just has so many confusions.

However, despite the teacher's perception of C2's alleged confusions, he was the only child in the group who was easily able to create the correct shape and understand what was required of him, but this was neither recognised nor acknowledged by the teacher. Angela's beliefs about second language learning combined with her assertion that she knows what to teach five-year-olds allowed her to overlook evidence that suggests $\mathrm{C} 2$ is more capable than she realises. The other children in this group were able to independently copy simple shapes and identify them but were unable to complete the challenge independently. The children were also not encouraged to work together.

\section{Vignette 7.3: Counting to 10 - forwards and backwards}

Vignette 7.3 from Cascade School follows the progression of a counting lesson in which the teacher, Caroline, tells children how to strategise by dropping back, yet she does not give the children opportunities to practise this independently.

Children are sitting on the mat in a semi-circle with Caroline in front of the whiteboard. Caroline tells the children the learning intention for the lesson, "We are learning to count numbers to 20 in order and match one-to-one" (Observation at Cascade School, 12/3/07). 
Vignette 7.3: Counting to 20 - forwards and backwards

Caroline gives the five children in the group a pile of counting sticks each. She organises the children in turn to put one stick at a time into the centre and count as they go. Caroline is in control, supporting the children as they count round the group when they put a stick into the centre. If a child is stuck, as happened on several occasions, the teacher demonstrated how to drop back, for example, the next number was seven so the teacher said "four, five, six" and articulated the initial sound of the number seven. The child then said seven.

In the next activity, the children put the sticks into a bucket in the centre. Caroline dropped back on three occasions to help a child get to the next number.

$10,11,12,13, \ldots 14$

$13,14,15, \ldots 16$

$16,17,18,19, \ldots 20$

The activity was repeated twice with Caroline dropping back on every occasion that a child did not get their number as they counted round.

The children were encouraged to count up to 10 in unison using their fingers and then count back from 10 .

The activity moved on to making finger patterns, the teacher held up a number fan and the children modelled the number with their fingers. She demonstrated how to check their response. She modelled counting on from five to check numbers greater than five but on all occasions the children started from one. 


\begin{tabular}{|c|c|}
\hline Category & Comment \\
\hline Mathematisation & $\begin{array}{l}\text { Children modelling numbers less than } 10 \text { on their } \\
\text { fingers }\end{array}$ \\
\hline Connections & None, the teacher made connections for the children \\
\hline Argumentation & $\begin{array}{l}\text { No opportunities for discussion or strategising for the } \\
\text { children }\end{array}$ \\
\hline Number sense & $\begin{array}{l}\text { Counting: establishing one-to-one counting with } \\
\text { numbers to } 10 \text {, extending to } 20 \text { with the teacher } \\
\text { demonstrating how to drop back in order to get the next } \\
\text { counting number }\end{array}$ \\
\hline $\begin{array}{l}\text { Expanding } \\
\text { children's number } \\
\text { knowledge }\end{array}$ & Possible not obviously evident \\
\hline $\begin{array}{l}\text { Recording and } \\
\text { assessing }\end{array}$ & $\begin{array}{l}\text { No recording or assessing observed during the lesson, } \\
\text { one occasion of monitoring emerged after the lesson }\end{array}$ \\
\hline Time taken & 20 minutes \\
\hline
\end{tabular}

\section{Vignette 7.3: Commentary}

There was evidence of monitoring in this lesson. One child was found to know number names when shown the number on a number fan, and Caroline commented that she had not known the child had mastered this successfully. She may have been holding information relating to the child's achievement in her head as there was no evidence shown of written recording.

Caroline demonstrated to children how to drop back if they could not get to a number, but in this lesson the children were not given an opportunity to discuss their own strategies or practice the strategy demonstrated. Each time a difficulty arose, Caroline provided the necessary information and strategy, so there were no spaces in the lesson for the children to discuss the strategy. Caroline said she believed that children should be given responsibility for their own learning (see Table 7.2) yet in practice she supported children by making connections and linking strategies, taking opportunities to do this from the children. 
There was no evidence to suggest this lesson was too hard or too easy for the children, because on this occasion, they were given no opportunities to demonstrate mastery, the teacher did all the work.

Likewise at Dundass School, children had limited opportunities to initiate learning independently from the teacher. ${ }^{41}$ In most cases, children were observed responding to the teacher, Donna, as she gave directions and instructions. When children were given a task, Donna circulated, encouraging and supporting children to complete the task. The primary focus appeared to be on task completion as opposed to supporting children to make the next learning step themselves. Time was spent organising children and reinforcing good behaviour and routines. Donna focused on developing the language of mathematics and modelling mathematical vocabulary. She spent time encouraging children to image ${ }^{42}$ and create pictures in their minds. However, Donna was the initiator of the learning and developed the ideas and links. Donna ensured she covered all the work she had planned to do. She had a wide range of numeracy-based activities available for the children to explore, and she gave clear directions on what to do with each activity and when to rotate to the next one. She did no observed written monitoring of activities or children's completion of these. She focused on keeping children on task and busy as she circulated around the groups. Donna believed she used the children's own interests and integrated mathematics across all areas of learning. She believed children could problem solve, yet she made the links for children in mathematics. She said, "I believe that it is important for children to become risk-takers in a non-threatening environment" (interview, Dundass School, 2/3/06).

The environment Donna provided was non-threatening but opportunities for risk taking were minimised as she directed and controlled each activity. The activities observed seemed to present few challenges for children as they completed each activity easily and with minimal discussion. Donna believed she followed "a more Vygotskian approach to teaching and learning", and said she thought that this

41 A detailed description of this vignette is not included because it resulted in no new insights being very similar to vignette 7.3 .

42 Imaging occurs when a child can visualise the mathematics they are doing in their head. 
matched up to the developmental programme ${ }^{43}$ she used to run in her classroom (personal communication with Donna, 7/10/06). In the observations in Donna's classroom, her method of teaching primarily followed a transmission approach.

\section{Vignette 7.4: Incidental mathematics - roll call}

Several opportunities were observed for incidental mathematics learning and teaching. On most occasions, the teacher did not capitalise on these opportunities and appeared to have another agenda. Vignette 7.4 from Hikurangi School occurs at the beginning of the day. The children are busy counting and exploring numbers and the teacher, Hiria, is busy ensuring routines are established.

\section{Vignette 7.4: Incidental mathematics - roll call}

At Hikurangi School the day began with roll call. The teacher ensured children had hung up their bags and gathered their book bags before coming to sit on the mat at the beginning of the school day.

As the children came to sit on the mat, they counted each other and each additional child as they sat down. Counting each other appeared to be a wellestablished pattern. It was the source of much amusement and discussion amongst the children as they added children and discussed who was and was not present for the day. Children talked about how many children were in the class and how many had been present the day before. The teacher appeared to be unaware of this discussion as she focused on establishing an efficient routine for hanging up bags and coming to the mat.

\begin{tabular}{|l|l|}
\hline Strategy & Comment \\
\hline Mathematisation & $\begin{array}{l}\text { Children were counting, adding and subtracting } \\
\text { numbers of children coming to sit on the mat at the } \\
\text { beginning of the school day }\end{array}$ \\
\hline Connections & Relating counting to members of a social group \\
\hline Argumentation & $\begin{array}{l}\text { Children discussing who was and was not present and } \\
\text { relating this to total number of children }\end{array}$ \\
\hline Time taken & 8 minutes \\
\hline
\end{tabular}

${ }^{43}$ A developmental programme features a variety of activities in which children can engage freely to extend their learning. The teacher's role is to support, extend, and scaffold learning. 


\section{Vignette 7.4: Commentary}

On this occasion, Hiria's focus was on establishing a well-ordered routine rather than listening to the children. Hiria appeared unaware of the discussions on the mat about how many children were present and how many were missing from school that day. Hiria's focus was on getting the bags hung up quickly and having all the children sitting on the mat to start the roll call.

The establishment of routines is important because these children were new to the school environment and need to know school ways of doing things, yet taking the roll and counting up who is and is not present was a good opportunity for the teacher to develop mathematics in a real context that was initiated and sustained by children.

Hiria said she felt it important to establish these basic routines because she believed children from kindergarten were allowed to do what they liked when they liked. She felt that when children came to school, she had to teach them how to conform to the school system and provide structure to their day (interview at Hikurangi school, 29/3/06). Structure was a key feature of this observation. Hiria said children from the local aoga amata ${ }^{44}$ came to school with more structure than kindergarten children because they had been taught to sit down, listen, and count. Despite Hiria's perception of differences between children with different early childhood experiences, her focus in the observation above provided the same structure for all children in her class - they all had to fit into the school system.

\section{Vignette 7.5: One-to-one counting - matching caterpillar legs to numbers}

Hiria followed the roll call (in Vignette 7.4) with her mathematics lesson. Hiria reminded a group of children how to play a previously taught game called Hungry Caterpillars. ${ }^{45}$ The game involved the children reading the number of legs the caterpillar had, then collecting the correct number of pegs to peg onto a picture of the caterpillar as its legs. The teacher had the equipment organised. Vignette 7.5 follows the lesson. The teacher is Hiria $(\mathrm{H})$ and the children $(\mathrm{C})$ are differentiated numerically.

44 A Samoan language early childhood centre.

45 A game from the numeracy project material relating to counting the number of legs on a caterpillar. 
Vignette 7.5: One-to-one counting - matching caterpillar legs to numbers

The children were organised into playing a game called Hungry Caterpillars. $\mathrm{H}$ reminded the children how to play. She checked that the children had the caterpillars from 5 to 9 and asked them one at a time for the number on their caterpillar.

For the caterpillar with a label showing 9:

$\mathrm{H} \quad$ How did you know it was 9?

C1 I counted to 9.

$\mathrm{H}$ made no comment and moved on to the next child.

$\mathrm{H} \quad$ What number have you got? (She pointed to the child with caterpillar 6.)

C2 (The child shrugged.)

\section{H told her the similarities and differences between 6 and 9 .}

Each time children put the requisite number of legs on the caterpillar they looked to the teacher for confirmation; they did not check or discuss the number with their group mates. The child with number 7 had not put enough pegs on and had not realised this until the teacher pointed out that there were not enough legs on the caterpillar.

$\mathrm{H} \quad$ What do you need to do?

\section{C3 Put more on.}

$\mathrm{H}$ confirmed this and gave $\mathrm{C} 3$ the right number of extra pegs to put on.

$\mathrm{H} \quad$ Are you right now?

C3 Nods.

On another occasion, a child had too many legs. H pointed this out and counted the number of legs with the child. When they counted past the required number, the teacher took off the extra legs and counted again with the child correctly.

The teacher reinforced the correct number. 


\begin{tabular}{|c|c|}
\hline Category & Comment \\
\hline Mathematisation & $\begin{array}{l}\text { Children had the opportunity to recognise a number and } \\
\text { count up to that number as they placed the appropriate } \\
\text { number of legs }\end{array}$ \\
\hline Connections & Teacher made connections \\
\hline Argumentation & Teacher corrected children's responses \\
\hline Number sense & $\begin{array}{l}\text { One-to-one number knowledge, children counting and } \\
\text { confirming number of legs on the caterpillar }\end{array}$ \\
\hline $\begin{array}{l}\text { Expanding } \\
\text { children's number } \\
\text { knowledge }\end{array}$ & Not evident \\
\hline $\begin{array}{l}\text { Recording and } \\
\text { assessing }\end{array}$ & $\begin{array}{l}\text { No observed recording. Monitoring consisted of the } \\
\text { teacher correcting children if they made an error. }\end{array}$ \\
\hline Time taken & 20 minutes \\
\hline
\end{tabular}

\section{Vignette 7.5: Commentary}

The children did the activity one at a time and waited in between for their turn for the teacher to monitor and correct their work. No occasions were observed when the children had the opportunity to take time to think about or process problems. The teacher filled all gaps. If a child put an incorrect number of caterpillar legs on, it was the teacher who noticed this, told the child, and then directed the correction to make certain the correct number were then placed on the caterpillar. Opportunities were present in this lesson for children to develop their one-to-one skills, work together, and be supported to learn how to monitor and self-correct their work, but these were not fully developed.

The follow-up practice activity involved an A3 piece of paper with the number five (5) on it. The children were shown and reminded how to use scissors and glue. The children had to cut out examples of the number five from magazines and glue them on their large five chart. The teacher demonstrated the task to the children. While on their own, the children chatted quietly about the numbers that they were finding and discussed their placement on the chart. This follow-up activity after the Hungry Caterpillar game did not appear to challenge the 
children. This was an example of a teacher reinforcing what children already knew and giving children more practice. The teacher did not give the children problem-solving activities. The lesson was organised and structured, and it was only when the teacher's attention was diverted from the group that the children discussed how they solved the problem or worked out answers.

\section{Vignette 7.6: Geometry - naming geometric shapes}

Vignette 7.6 is an example of a teacher-directed lesson in which the children are guided through a knowledge-based lesson focusing on geometry at Hikurangi School. The teacher is Hiria $(\mathrm{H})$ and children $(\mathrm{C})$ are differentiated numerically.

\section{Vignette 7.6: Geometry - naming geometric shapes}

A group of eight children is sitting in a circle facing the teacher, $\mathrm{H}$.

$\mathrm{H} \quad$ What can you see? (H focuses on child opposite.)

C1 It's a triangle

$\mathrm{H} \quad$ How many sides does it have?

C1 3

$\mathrm{H} \quad$ Count them and see, show me.

Child counts three corners.

$\mathrm{H} \quad$ What are sides?

Child runs a finger along the sides.

H What can you see? (Question asked of the whole group.)

C Square, circle, triangle (Children say shape names without pointing to any of the shapes in front of them)

$\mathrm{H} \quad$ Tell me about our shapes?

Children mumble things like four sides, three sides, four corners.

$\mathrm{H} \quad$ Choose a shape to put in front of you.

Children select a shape.

$\mathrm{H} \quad$ Tell me the name of your shape.

In turn, children name the shape they selected.

$\mathrm{H} \quad$ Now get me a shape that is round. 
Chat time: a little one, a big one, look at my small one.

$\mathrm{H} \quad$ Now put the shape in front of you, check the person next to you has a round shape. What's it called again?

Now I want you to get something with three sides, count to five then sit on your bottoms. Check the person next to you has a three-sided shape, if they don't, help them find the right one. You're not next to him, who are you next to?

H Now tell me the name of your shape.

\section{C2 A triangle}

$\mathrm{H} \quad$ How many sides does it have?

C2 Three

$\mathrm{H} \quad$ How many corners does it have?

C2 Three

$\mathrm{H} \quad$ Which bit is the corner?

C2 The pointy bit.

\begin{tabular}{|c|c|}
\hline Category & Comment \\
\hline Mathematisation & $\begin{array}{l}\text { Geometry: recognition of simple shapes and description } \\
\text { of some attributes, round, small, big. }\end{array}$ \\
\hline Connections & Teacher made connections for children \\
\hline Argumentation & $\begin{array}{l}\text { Teacher initiated question and answer session with } \\
\text { children being asked about attributes of their shape, } \\
\text { name, number of sides and corners }\end{array}$ \\
\hline Number sense & Repeating the number of sides \\
\hline $\begin{array}{l}\text { Spatial and } \\
\text { geometrical thinking }\end{array}$ & $\begin{array}{l}\text { Shape identification for simple shapes, triangle, circle, } \\
\text { rectangle, square }\end{array}$ \\
\hline $\begin{array}{l}\text { Expanding } \\
\text { children's number } \\
\text { knowledge }\end{array}$ & Not evident \\
\hline $\begin{array}{l}\text { Recording and } \\
\text { assessing }\end{array}$ & No recording or assessing evident \\
\hline Time taken & 14 minutes \\
\hline
\end{tabular}




\section{Vignette 7.6: Commentary}

This discussion continued in a similar way to Vignette 7.3 with teacher-directed activities and few opportunities observed for children to explore their ideas. The children repeated back to the teacher what they had already been taught or already knew. There were no observed attempts to develop any strategies for working out geometric shapes or putting them in context at this stage; the lesson focus was on ensuring children had the requisite knowledge in geometry as determined by the teacher's beliefs. There was no evidence to suggest that the teacher assessed or recorded the knowledge that she was developing through this lesson. Children were able to locate and name simple shapes and describe some attributes.

Hiria commented, “well you know you can't teach these kids anything much until they have some knowledge. They come with very few skills so you have to make sure that they know all this stuff before you can really teach them anything" (personal communication, Hikurangi School, 12/6/06). This comment supports the perception that these teachers clearly believed that children were unable to problem solve until their teachers were assured the children had the requisite knowledge as determined by the teacher.

\section{Vignette 7.7: Numeracy - number identification and using the 10s frame}

At Tongariro School directions, observations, and instructions came from the teacher, Tanya. Children had limited opportunities to interact with each other and problem solve. The teacher reinforced good behaviour on the mat and in the classroom. When children sat quietly, when they did as they were told without questioning, the teacher said they were good children. The following example follows a whole class lesson when the teacher is focusing on number identification to 20 , making numbers to 10 on children's fingers, and introducing the 10 s frame. ${ }^{46}$

46 The 10s frame is a piece of equipment consisting of a frame of 10 equal squares in a five by two pattern. 
Vignette 7.7: Numeracy - number identification and using the 10s frame

The teacher, Tanya, held up numbers to 20 . One at a time, she asked children to identify the number shown. No child called out, and only one child answered at a time. Tanya used finger patterns and 10s frames to reinforce the identification of the numbers.

Children had to count on their fingers (numbers were 10 and less) to identify a number and check this with a friend. Tanya did not confirm their accuracy. She called out a number and children called out the number before or after according to direction. There was no discussion. Tanya held up a number card, the children made the number on their fingers. There was no discussion between the children and no opportunities for discussion. Tanya introduced the 10 s frame and explained how it worked.

Children were asked to think about how they knew what was left when some spaces were filled in on the 10s frame (e.g., Tanya put seven counters in the $10 \mathrm{~s}$ frame in a five and two pattern). Only one child got chosen to verbalise a response. Tanya formed the children into a circle. She put two 10s frames in the middle of the circle, then chose one child at a time to make the number on the frame that she held up. The rest of the group were encouraged to check. They were told how to check rather than being encouraged to work this out and share. There were no opportunities during observations of children exploring and discussing how they identified or made numbers on their fingers or on the 10 s frames. 


\begin{tabular}{|l|l|}
\hline Category & Comment \\
\hline Mathematisation & Children were asked to identify numbers to 20 \\
\hline Connections & $\begin{array}{l}\text { Children were asked to make numbers with their fingers } \\
\text { in response to teacher holding up a number card, no } \\
\text { opportunities given for discussion }\end{array}$ \\
\hline Argumentation & $\begin{array}{l}\text { One child was chosen to respond and explain how she } \\
\text { knew how many spaces were left when some counters } \\
\text { were put on a 10s frame, the other children were asked } \\
\text { to think about it but no check was made }\end{array}$ \\
\hline $\begin{array}{l}\text { Number sense } \\
\text { Children made appropriate number representations on } \\
\text { their fingers }\end{array}$ \\
\hline $\begin{array}{l}\text { Expanding } \\
\text { children's number } \\
\text { knowledge }\end{array}$ & \begin{tabular}{l} 
Not evident \\
\hline $\begin{array}{l}\text { Recording and } \\
\text { assessing }\end{array}$
\end{tabular} \\
\hline $\begin{array}{l}\text { Time taken } \\
\text { No recording or assessing evident }\end{array}$ \\
\hline
\end{tabular}

\section{Vignette 7.7: Commentary}

Tanya viewed herself as an inclusive teacher with the children involved in problem solving. All instructions, all directions, and all questions came from her and she elicited and expanded on children's responses. Tanya believed she extended children's learning (see Appendix S) and allowed children some autonomy (Table 7.2), yet this was not evident during the observation.

Children had the opportunity to make numbers on their fingers in response to Tanya holding up a number, but when she was demonstrating how to make numbers on the 10 s frame, only one child was chosen to make the number, the rest of the class observed. Tanya said this was the children's introduction to the 10 s frames. In this introduction, children were given few opportunities to explore the nature of the equipment for themselves and discuss its usage. 


\subsection{Summary}

New entrant teachers in this study generally worked alone in single classroom with a group of children new to the school setting who had had a variety of early childhood experiences. This contrasts with the kindergarten teachers in this study who were observed working in conjunction with one or two other kindergarten teachers in the same location. The children they worked with were, in general, in their last few months before transitioning to school, and were familiar with kindergarten expectations and their teachers. New entrant teachers were primarily observed working with specific groups of children. The teacher determined the groupings of children, and most commonly grouped children with similar abilities together. In kindergartens, groupings of children were variable in number and usually circumstantial.

The above examples from the primary schools show teachers who are concerned with children having the requisite skills in order to succeed in mathematics. This concern and care appears to over-ride their beliefs relating to problem solving and learning mathematics through fun activities. Children were engaged in learning at the teachers' direction. In these classrooms, there were no observed examples of the teachers encouraging and supporting children to initiate, explore, or develop their own strategies for problem solving. The primary concern in most instances was to ensure children had the requisite knowledge for later success in mathematics as determined by their teachers, the required tasks were completed, and children learned about fitting into school and class routines. The new entrant teachers specifically planned learning according to their beliefs about what they thought children needed to know. The lessons were structured in such a way as to ensure success, presenting few challenges for children.

Teachers had the expectation that children in their class would conform to directions and instructions given to them. Teachers spent time developing school routines so children knew how to behave in class and in school. These examples of mathematics teaching and learning show teachers to be in control of and structuring children's learning. Children in these new entrant classrooms needed to understand ways of operating within the school system, teachers provided this for them. These teachers did care about the children in their classes and from their 
beliefs it is clear they wanted the best for the children as they moved through the school. This is evident through comments made by teachers in informal discussions:

My role is to educate, guide children through learning experiences, taking into account their own interests and levels of understanding. (Donna at Dundass School, 14/8/07)

It is my responsibility to ensure that they recognise and understand numbers as it is a part of life, a life skill for everything. I always put problems in context for the children, children learn from their experiences over time. (Angela at Aorangi School, 14/4/06)

The new entrant teachers interviewed believed in providing children with opportunities to problem solve and develop responsibility for their own learning. They believed children should have hands-on experiences situated in realistic contexts. Most commonly, teachers in this study provided examples of strategies for children to use. When children experienced difficulties, teachers intervened by supplying the strategy, thus reducing opportunities for children to practise, explore, and consolidate the strategy. Limited opportunities were provided for children to engage with each other and develop the use of a particular strategy. Opportunities were provided for children to practise and consolidate existing knowledge. Responsibility remained with the teacher on most occasions because they made links for children and stepped in to provide solutions for children without allowing time for children to develop and discuss ideas and strategies. Teachers were observed managing children's learning and behaviour. Fitting into the school system and conforming to the ways of the classroom were seen as important parts of the routines in a new entrant classroom. For the new entrant teacher, this extra role of socialising children to school appears to over-ride teachers' beliefs about developing independent and capable learners. Teachers had developed warm and inviting classrooms. Their programmes were planned and orderly. Mathematics was taught in a structured fashion according to the beliefs of teachers and their perceptions about the knowledge new entrant children needed to have to be successful at school. In some instances, this knowledge presented few challenges for children and limited opportunities to explore mathematical strategies. 


\section{8: Making the transition to school: Differences between kindergartens and new entrant classrooms}

\subsection{Introduction}

As children progress from kindergarten to new entrant classrooms, differences exist between the two settings. Kindergarten teachers discussed their beliefs and practices in relation to children who had had at least one year of kindergarten education before starting school. These children were familiar with their environment and their teachers. They were the oldest in the group of children at kindergarten, knew how to operate socially within the kindergarten, and, according to their teachers, were developing positive dispositions towards learning. As described in chapter 6, children were capable of sustained activity, demonstrated mathematical skills, and had opportunities for mathematisation and argumentation and to make connections. ${ }^{47}$ In contrast to this, when these children went to school they became the youngest learners in school, they had to learn a new set of social skills and expectations, get to know their teacher, and conform to school ways of doing things. Teachers in new entrant classrooms described children who knew very little about mathematics on school entry, were unable to sit on the mat for more than five minutes, were unable to complete tasks, and needed to be taught basic skills to be successful at school. Due to this perceived lack of skills (including social skills), new entrant teachers gave few opportunities for children to engage in mathematisation or argumentation, or to make connections as they focused on ensuring children could fit into school.

This chapter explores some of the beliefs held by new entrant and kindergarten teachers about children's readiness for school at the point of transition. Transition to school can be viewed in terms of a 'rite of passage' (Clark \& Lovric, 2008), so there is usually an expectation that there will be at least some differences to mark this change of circumstances. It is said that "children need to learn to make sense of school" (Peters, 1998a), but differences between early childhood settings and new entrant classrooms may make the transition difficult for some children. These differences may impact on children's learning (Niesel \& Griebel, 2007). The

47 The terms 'mathematisation', 'argumentation', and 'connections' are explained in section 5.4.1 and are used to describe the mathematical events in chapters 6 and 7. 
differences observed relate to the nature of the environment and the need for children to fit with the school system. From the interviews and questionnaires differences emerged between teachers' beliefs about the knowledge they believed children should have on school entry and the specific skills they should have mastered. The four sections in this chapter describe these differences between the schools and kindergartens in this research. Section 8.2 explores the differences between kindergarten and new entrant teachers as they talk about their beliefs about their expectations of children before they begin school and on entry to school. Section 8.3 examines the differences between teachers in both settings regarding the use of their curriculum documents particularly in relation to mathematics teaching and learning. This sections is followed by a comparison of the physical environment of both settings (section 8.4) and section 8.5 on the levels of communication that were observed and recorded from interviews and questionnaires between kindergartens and new entrant classes.

\subsection{Expectations of children at age five}

Teachers' beliefs relating to their expectations of children at particular ages shape their practice, and these beliefs are in turn influenced by the social values of the time and the current school culture (Spodek, 1988). Early childhood teachers' beliefs about teaching and learning provide opportunities for children to have a variety of experiences and opportunities to develop positive dispositions for learning (Carr, 1998; Meade, 1999; Peters, 1999) to become life-long learners. In contrast to this, in many cases new entrant teachers are preoccupied with the socialisation of children into the school system, teaching children to listen to their teacher, to share and follow directions (Burgon \& Thompson, 1997). While new entrant teachers may share many similar beliefs with kindergarten teachers, their differing expectations of children on school entry may create some difficulties for children as they transition to school. In some instances, new entrant teachers held beliefs about children's knowledge and skills that were inconsistent with evidence they had gathered from assessments of children's actual achievement. This section examines the beliefs held by both groups of teachers separately and is followed by a discussion of the differences observed. 


\subsubsection{Kindergarten teachers' beliefs about their expectations of children on school entry}

While early childhood teachers do not generally regard early childhood education as preparing children for school, early childhood teachers along with their counterparts in schools, do share a key role in ensuring the transition is as smooth as possible (Peters, 1998b). Kindergarten teachers in this study had high expectations for children when they started school, but these expectations were not related to specific knowledge domains. There was a discrepancy between their expectations of children and what they believed the expectations of new entrant teachers to be. Their expectations of children at five years old were consistent with their expectations of the early childhood curriculum, Te Whāriki (Ministry of Education, 1996). The high expectations kindergarten teachers held of children and their belief that schools do not have the same high expectations are summed up in this statement:

Schools actually expect very little of the kindergarten, they don't expect the children to aim high e.g. 'if they could sit on the mat that would be good', but we have high expectations of the children which we meet. Children are not empty vessels that we can fill up; they come to us and to the school with amazing knowledge from their families/whānau ${ }^{48} /$ cultural experiences and of course from the kindergarten. (Head teacher at

Cascade Kindergarten, questionnaire response, 31/5/06)

The aim is to have children leaving early childhood centres, including kindergartens, with well-established dispositions that focus on skills to do with "being a learner" (Ministry of Education, 1996, p. 3), not specific mastery of learning intentions but learning dispositions. From discussions with kindergarten teachers, this philosophy was consistent with their beliefs about readiness for school and fits with the New Zealand Curriculum Framework (NZCF) (Ministry of Education, 1993a) ${ }^{49}$ and Mathematics in the New Zealand Curriculum

48 Māori language term for family groupings.

49 The New Zealand Curriculum also states that, "The transition from early childhood education to school is supported when the school: builds on the learning experiences that the child brings with them" ((Ministry of Education, 2007, p. 41). 
(MiNZC) (Ministry of Education, 1992), which specify the importance of teachers building on children's existing knowledge and skills.

Statements that relate to kindergarten teachers' expectations of children are detailed in Table 8.1. These statements came from questionnaire responses and subsequent informal comments. Individual teachers are not identified, because the statements made were similar in each kindergarten in this study.

Table 8.1: Kindergarten teachers' beliefs about expectations of children before school entry

Statements from kindergarten teachers about their expectations of children on school entry.

We expect children to experience learning and learn through their experiences. We don't 'formally' teach literacy and numeracy but we provide a wide range of experiences.

Children learn through play.

We value the knowledge and experiences the children have when they come to us.

In summary, these teachers expressed no formal academic expectations of children's knowledge on school entry but said they held a holistic ${ }^{50}$ view of children's learning. They said they had the expectation that children would possess positive dispositions to learning when they transitioned to school.

Kindergarten teachers in this study said they believed they were teaching children to be life-long learners with positive dispositions towards learning. Kindergarten teachers described following children's interests, reflective practice, and retrospective recording of events, and the need to make careful observations to meet the needs of the child rather than planning to meet specific outcomes. Children were free to engage in learning independently from teacher input if they chose to do so. Children were regarded as capable learners who were able to make their own choices and follow their own pathways with support from their teachers and peers.

50 Kindergarten teachers used the term a 'holistic approach' as it is used in Te Whāriki and defined in section 2.2 . 
Assessments in kindergarten predominantly took the form of learning stories (Carr, 2001). These learning stories or narrative assessments, contained detailed observations of individual children or groups of children that clearly stated the links those children made to various aspects of Te Whāriki and were stored in individual portfolios accessible to children, parents, and teachers and formed part of the official records for each kindergarten. The written observations contained accounts of the challenges faced by children and how they mastered these, and were complemented with photographic evidence. Donna at Dundass Kindergarten (23/3/06) said she:

carried out detailed assessments (including photographs) on 2 or 3 children each day, and these were observations of individuals or groups of children. At the end of each day I write these up and make links between children's activities and Te Whāriki, outlining the challenges faced by the children and how they dealt with them. ${ }^{51}$

Children were free to view their portfolio, and parents were able to contribute if they wished. In each kindergarten, children were observed reading, reflecting on, and discussing their portfolios with teachers and friends. The assessment practices outlined above are consistent with the goals of Te Whāriki. The purpose of assessment in Te Whāriki is “to give useful information about children's learning and development" and "involve intelligent observation of the children by experienced and knowledgeable adults" (Ministry of Education, 1996, p. 29). Assessment is about individual children's learning and development, and the needs of children determine the pathway of the curriculum implemented by kindergarten teachers.

Similarly, the beliefs held by teachers in this study relating to their expectations of children at age five are consistent with the goals and aims for children outlined in Te Whāriki (Ministry of Education, 1996). Te Whāriki (p. 20) acknowledges the diversity of learners and the range of abilities among children, which in turn determine the focus of learning as it applies to each child. Teachers in kindergartens were seen to observe children and use these observations to build on their perceived needs and abilities. "There is no developmental cut-off at school 
entry age" (Ministry of Education, 1996, p. 21), and kindergarten teachers provide opportunities for children to experience new challenges and experiences that "help to meet their expanding capabilities and provide a smooth transition to school" (Ministry of Education, 1996, p. 26). The view of each child and their learning needs held by these kindergarten teachers fits well with the goals outlined in Te Whāriki in relation to children going to school.

Kindergarten teachers in this study held similar views relating to the expectations new entrant teachers held of children on school entry (see section 8.2.2). In general, they felt schools, and new entrant teachers in particular, expected children to come to school able to concentrate, able to communicate, and to have some good self-help skills. The kindergarten teachers thought these were good expectations to have, in addition to their other expectations. Alongside these expectations was the belief that new entrant teachers had unrealistic expectations in terms of specific bits of academic knowledge. For example, at Aorangi Kindergarten, one teacher commented that new entrant teachers "want the children to focus for ridiculous periods of time and work to a set curriculum" (questionnaire response, 16/5/06). At both Hikurangi and Tongariro Kindergartens, teachers said schools had very high expectations of children, particularly in mathematics, and they thought these expectations were unrealistic. In addition, kindergarten teachers said they believed schools paid little attention to the learning environment that children came from - learning through play - and schools generally had more formal expectations of children's learning. Overall, the view held by kindergarten teachers was that most children from kindergartens exceeded the expectations of their new entrant teachers.

\subsubsection{New entrant teacher beliefs about their expectations of children on school entry}

According to the Ministry of Education, children should leave early childhood centres (including kindergartens) with well-established learning dispositions that focus on skills to do with "being a learner" (Ministry of Education, 1996, p. 3), not specific mastery of learning intentions but learning dispositions. This belief is consistent with the beliefs of kindergarten teachers. Both the NZCF and MiNZC specify the importance of teachers building on children's existing knowledge and 
skills. This long-held belief is further reinforced in the New Zealand Curriculum (Ministry of Education, 2007b), which states that "the transition from early childhood education to school is supported when the school: builds on the learning experiences that the child brings with them" (p. 41). In this study, the new entrant teachers held specific beliefs about their expectations for children's social and academic skills on school entry.

Table 8.2 contains quotations from the new entrant teachers' interviews. The quotations are reported separately for each of the five teachers because of their variability, and in contrast to the kindergarten teachers who held similar beliefs about their expectations of children about to go to school.

Table 8.2: Teacher expectations of children on school entry

\begin{tabular}{|l|l|}
\hline School & $\begin{array}{l}\text { Statements from new entrant teachers about beliefs relating to } \\
\text { five-year-old children on school entry }\end{array}$ \\
\hline Aorangi & Children should know their letters and know how to count. \\
\hline Cascade & $\begin{array}{l}\text { I want them to know their basic number concepts and how to } \\
\text { make small sets of things. } \\
\text { They need to know how to sit still for longer than five minutes. } \\
\text { They need to be more focused. } \\
\text { They come to school with limited knowledge of basic skills for } \\
\text { maths, for example counting objects and recognising numbers. } \\
\text { They can't count and don't know their colours and stuff. }\end{array}$ \\
\hline Dundass & $\begin{array}{l}\text { Children need some early academic skills when they start school, } \\
\text { one to one, the ability to write their name, hold a pencil, recognise } \\
\text { some of the letters of the alphabet, know their numbers and have } \\
\text { some early writing skills. }\end{array}$ \\
\hline Hikurangi & $\begin{array}{l}\text { Children come to school with very few skills. } \\
\text { Children are unable to draw a picture, count to 10 and know some } \\
\text { sounds and letters, colours and shapes. } \\
\text { There should be more direction at kindergarten to ensure that they } \\
\text { are taught these skills. }\end{array}$ \\
\hline Tongariro & $\begin{array}{l}\text { I expect that children should come to school able to write their } \\
\text { names and know some letters of the alphabet and be able to } \\
\text { interact nicely. }\end{array}$ \\
\hline
\end{tabular}


These expectations reflect the belief of new entrant teachers in this study that children should have some social and academic skills on school entry. They expect five-year-old children to know how to write their name, have some letter knowledge, be able to count, and have some social skills. They made no mention of children having the positive dispositions for learning that are encouraged through Te Whāriki and are linked to the objectives of the school curricula. These expectations were held despite there being no benchmarks for the skills and knowledge of children on school entry in New Zealand. These views or sayings appear to commonly be accepted among the wider community as well: The Dominion Post newspaper has reported on the lack of basic skills held by children on school entry (Blundel \& Palmer, 2009).

\subsubsection{Differing beliefs of new entrant and kindergarten teachers}

This section compares the different beliefs held by new entrant and kindergarten teachers as they describe their expectations of children. New entrant teachers in this study focused on the skills they believed children should have when they arrived at school. These skills related to measurable outcomes, such as the ability to write their name and count to 10 , with a few related to social skills, children should be able to take turns, hang up their bags, and manage their own social interactions. These in turn reflected the expectations new entrant teachers had for the kindergarten teachers in this study. New entrant teachers said there should be specific teaching of these skills at kindergarten, so children were ready to enter school. Donna at Dundass School said, "The kindergarten is very good on developing social skills but they need a bit more structure to what they do rather than sitting back and waiting until the children are ready" (teacher interview, 2/3/06). Donna thought kindergarten teachers should specifically plan to teach these perceived missing skills. Hiria at Hikurangi School held a similar perception of what happened at kindergarten. She said, "I wonder if it is just free play or whether it would be better if it was more directive" (teacher interview, 29/3/06). Both new entrant teachers expressed views common to those of other new entrant teachers in the study, indicating they appeared to know little about what happened in kindergarten and the philosophy on which kindergarten programmes were 
based. The focus of new entrant teachers related to the skills (both social and academic) they believed children should have on school entry.

New entrant teachers described their beliefs and practices in relation to events that happened within the classroom. The classroom was the place where learning occurred and was managed by teachers. The management of learning and the organisation of this learning appeared to take priority over the learning needs of children. New entrant teachers spent most of the observed time directing and organising children for learning (see Table 7.1). They planned lessons in mathematics to meet the perceived needs of children and controlled the outcomes of lessons by using closed questions that required correct answers. In kindergartens, teachers described following the children's interests, reflective planning, and close observations to meet observed needs of children rather than planning to meet specific outcomes for learning. The learning pathways of the children in kindergarten were less constrained by specific curriculum objectives or teachers' beliefs about the acquisition of particular skills.

Assessment in each classroom was described in similar terms by new entrant teachers. They used the Numeracy Project diagnostic interview (Ministry of Education, 2005a) as the primary means of establishing the knowledge and strategies held by the children in conjunction with school-based checklists. From the diagnostic interview, teachers established the knowledge and skills held by children. Teachers spoke of informal assessments of children during teaching time and using student profiles to record information gathered. However, from the vignettes described in chapter 7 , it is evident that some teachers were clearly teaching children what they already knew, a finding consistent with YoungLoveridge's work (1998). Hiria at Hikurangi School (29/3/06) said:

I use the diagnostic interview, I use student profiles, and I have regular informal assessments that I just scribble down on bits of paper to help me assess where the children are at, we have assessment folders and portfolios and Classroom Manager [a school-wide database], which we don't really use.

Despite this collection of information about children's knowledge and skills in mathematics, observations of Hiria's teaching practice showed that she spent time 
teaching children what they already knew (see Vignette 7.1). Her belief, possibly unsubstantiated, that children come to school with very few skills seemed to override information gathered through more formal assessments of children on school entry, not an uncommon feature of new entrant teacher practice in this study. Kindergarten teachers said they had no fixed beliefs about the knowledge and skills children should possess on school entry. In some instances, kindergarten teachers said they believed it would be good if children had certain social skills when they went to school (such as being able to help themselves by being able to open their lunch box, change their clothes, and communicate their needs).

However, a lack of these skills did not preclude a child going to school and kindergarten teachers taught these skills as the need arose rather than planning to teach them.

Assessment at kindergarten was most commonly based on narrative learning stories that focused on observations relating to what children were observed doing. Kindergarten teachers said they used this information to guide their programmes to follow children's interests and support the development of positive dispositions to learning as outlined in Te Whāriki.

New entrant teachers described what they thought should be taught at kindergarten. None of these teachers mentioned having any knowledge of the curriculum for early childhood, Te Whāriki, although several indicated that this would be useful. On some occasions when they made regular contact with their local kindergarten, new entrant teachers felt kindergarten teachers were clearly not teaching the skills and knowledge that new entrant teachers believed were essential for a child's success at school. For example, Donna at Dundass School reported on regular visits to the kindergarten. She had noticed that some children lacked fine motor skills, so she told the kindergarten teachers that they should be teaching children how to hold a pencil correctly:

[She] gave the kindy ${ }^{52}$ some laminated alphabet sheets which they could put out at an activity table with a teacher to support the learning. They only had them out a couple of weeks but if a kindy teacher had stayed

52 Colloquial abbreviation for kindergarten. 
and supported the learning the children would have been interested.

(Dundass teacher interview, 25/5/06)

Donna believed this kindergarten was very good at developing social skills in children but the kindergarten teachers needed a bit more structure to what they do so rather than "sitting back and waiting, ${ }^{, 53}$ until the children were ready, a common view among these new entrant teachers. Another commonly held perception was that kindergarten children in particular were allowed to "flit round and don't have to finish things off" (Cascade School interview, 21/5/06), an observation that is not substantiated by evidence presented in chapter 6. On the other hand, kindergarten teachers believed new entrant teachers held unrealistic expectations about children on school entry. However, only one kindergarten said it had links with its neighbouring primary school, and teachers from both these settings spent time learning about each other's programmes and expectations.

This apparent lack of understanding of the curriculum and culture may lead to tension between new entrant teachers and kindergarten teachers. The new entrant teachers in this study appeared to hold the view that the kindergarten teacher's role was to prepare the children for school entry. From chapter 6 it is clear the kindergarten teachers in this study held a broader perception of learning than new entrant teachers held. Kindergarten teachers said they saw themselves as setting up children by developing positive dispositions to learning for life-long learning. New entrant teachers said they wanted children to be successful at school but to do this they had to make sure children had the necessary knowledge. Despite establishing these knowledge levels, new entrant teachers did not necessarily use this information in their observed teaching. Most of the teacher practice observed in new entrant classrooms focused on managing children rather than developing their learning. As children make the transition to school, they are moving from an environment where they are regarded as confident and capable learners to one in which they are perceived as lacking essential skills for school success, which may create difficulties.

53 From Donna at Dundass School, interview, 25/6/06. 


\subsection{Use of the curriculum}

Teachers need to know what children already know, what they need to learn, and how to provide experiences that will challenge and support children in their learning (Ministry of Education, 2007). Curriculum documents provide guidelines to support and promote effective teacher practice and student achievement. Te Whāriki is "an early childhood curriculum specifically designed for children from the time of birth to school entry, and it provides links to learning in school settings." (Ministry of Education, 1996, p. 9). The curriculum in schools provides guidelines to support effective teacher practice and student achievement. The curriculum underpinning the teaching of mathematics in new entrant classrooms provides guidance and direction for teaching and learning. Links between Te Whāriki and primary schools are reflected in the NZCF (Ministry of Education, 1993b) and in the New Zealand Curriculum (Ministry of Education, 2007b) as programmes for learning are required to build on children's prior learning and experiences. This section examines how kindergarten and new entrant teachers use and value their curriculum to support these aims in mathematics and explore commonalities and differences between the two sectors that may affect children as they make the transition to school.

Without exception, teachers in the kindergartens said they valued their curriculum and used it as the foundation for their teaching and planning. Error! Reference source not found. is indicative of the extent of their commitment to the curriculum. Their beliefs, practices, and the curriculum are interwoven and form the basis of their teaching and learning. The beliefs of head teachers about the curriculum have not been separated out because of the consistency of their beliefs with those of teachers in their kindergarten. The table contains quotations from the questionnaires that relate to teacher beliefs about their curriculum and how they regard it in their practice. 
Table 8.3: Kindergarten teachers' views on the use of the curriculum

\begin{tabular}{|l|l|}
\hline Kindergarten & Teacher views on the use of Te Whāriki \\
\hline Aorangi & $\begin{array}{l}\text { Well, it makes links to our programmes. We have a good } \\
\text { knowledge of the curriculum and we apply the main principles } \\
\text { to our programmes. }\end{array}$ \\
\hline Cascade & It underpins everything we teach, the underlying framework. \\
\hline Dundass & $\begin{array}{l}\text { I always use it, it is our national curriculum. I interweave it } \\
\text { into all my practice by making it a living document; it is part of } \\
\text { my whole teaching practice. }\end{array}$ \\
\hline Hikurangi & $\begin{array}{l}\text { Te Whāriki, our New Zealand early childhood curriculum } \\
\text { document is used always in my practice. It looks at the holistic } \\
\text { way the children learn and is used as part of assessing, } \\
\text { planning, and evaluating children's learning. }\end{array}$ \\
\hline Tongariro & $\begin{array}{l}\text { Our whole philosophy is based on the principles of Te } \\
\text { Whāriki, and consequently this becomes how we approach our } \\
\text { programming. }\end{array}$ \\
\hline
\end{tabular}

In addition to these beliefs, the kindergartens in this study had wall displays that linked the principles of Te Whāriki to the children's learning. Labels on children's work related displays to objectives outlined in Te Whāriki. Kindergartens had information areas for parents to inform them about aspects of learning and to share ways of working with children.

Te Whāriki was not just a curriculum document for these teachers but formed a central component of teaching and learning. Teachers used Te Whāriki as the foundation of their practice and their beliefs.

It is the New Zealand early childhood curriculum, I use it all the time, it looks at the holistic way the children learn and is used as part of assessing, planning, and evaluating children's learning, our goals and outcomes are linked to Te Whāriki. (Questionnaire response, Hiria at Hikurangi Kindergarten, 5/4/06). 
In schools, the function of the curriculum is similar to that of the curriculum in kindergartens, aiming to support effective teacher practice and enhance student achievement. These documents should form the basis of teaching and learning.

The key outcome of mathematics education is the development of the ability to apply certain of the essential skills described in The New Zealand Curriculum Framework - communication skills; numeracy skills; information skills; problem-solving skills; socials and co-operative skills; and work and study skills. The mathematical processes identified in this curriculum statement are the expression of these essential skills in mathematical contexts. This curriculum statement suggests approaches to teaching, learning, and assessment which will give students the maximum possible opportunity to develop the essential skills. (Ministry of Education, 1992, p. 10)

Both MiNZC and Te Whāriki provide guidelines for learning to help ensure a continuity of practice and goals between school and kindergarten. The expectation is that these documents are seen as a focus for good practice. MiNZC contains the official guidelines for teaching mathematics that teachers must observe.

Table 8. describes new entrant teachers' views on the usefulness of the curriculum guidelines for their practice in the classroom. With one exception (at Tongariro School), the teachers felt they already knew what five-year-olds needed to know about mathematics, so that is what they planned to teach them. The information came from their prior experience and knowledge about five-year-olds combined with information from Numeracy Project materials and guidance from school long-term plans. At Tongariro School, although Tanya said she planned from the curriculum objectives for level 1, it appeared from the lessons observed that children's learning needs, based on diagnostic information, were not fully taken into consideration (see Vignette 7.7). 
Table 8.4: New entrant teacher views on the New Zealand Curriculum Framework and Mathematics in the New Zealand Curriculum

\begin{tabular}{|c|c|}
\hline School & New entrant teacher views on the use of the curriculum \\
\hline & $\begin{array}{l}\text { I know what children of this age needed so that is what I teach } \\
\text { them. } \\
\text { I haven't opened the curriculum in a long time. } \\
\text { There is a school policy for mathematics but I don't use it as I use } \\
\text { Numeracy Project books instead. }\end{array}$ \\
\hline Cascade & $\begin{array}{l}\text { I do not need the curriculum as I use the Numeracy Project books } \\
\text { instead. } \\
\text { I do not know where my copy of the New Zealand Curriculum } \\
\text { Framework (NZCF) is. } \\
\text { I follow the school long-term plan given out by the principal. }\end{array}$ \\
\hline Dundass & $\begin{array}{l}\text { I do not find either Mathematics in the New Zealand Curriculum } \\
\text { (MiNZC) or the NZCF useful or practical. } \\
\text { I use the school long-term plan and the Numeracy Project material. }\end{array}$ \\
\hline Hikurangi & $\begin{array}{l}\text { I don't specifically refer to MiNZC or NZCF as I do not need to. } \\
\text { I use the Numeracy Project books to help me decide what to teach. } \\
\text { The school has long-term plans but I can't fit these with the specific } \\
\text { needs of the children as they don't know enough. }\end{array}$ \\
\hline Tongariro & $\begin{array}{l}\text { We [a syndicate] pull out specific objectives from level } 1 \text { of the } \\
\text { curriculum document and plan and extend from these. }\end{array}$ \\
\hline
\end{tabular}

The comments from these teachers suggest that based on their knowledge and prior experiences they knew what children needed on school entry in mathematics to set them up for future success. These views suggest the curriculum for mathematics was neither believed to be useful for experienced teachers nor used by all but one of these teachers. These teachers said they used Numeracy Project books if they needed to, but otherwise their vision of the mathematics needed by five-year-old children guided their practice. While school long-term plans for mathematics were based on the curriculum achievement objectives, it is apparent from the above comments that teachers did not acknowledge this influence on mathematics planning. 
Primary school principals in this study believed it was important for teachers to have an understanding of the curriculum (MiNZC and NZCF) and use this understanding when they planned programmes to meet the needs of the children. They believed the curriculum documents provided a vision for mathematics teaching and learning.

\section{Principals were unanimous in their belief that not only were the curriculum} documents used, their teachers understood how to assess the children's needs and use the data gathered to meet these specific needs. Teachers' opinions of the curriculum from

Table 8. suggest this is not the case, because, in general, teachers believed the curriculum documents were neither useful nor relevant to them in meeting the specific needs of the children in their classrooms.

Learning stories and the development of positive dispositions to learning are thought to provide a means of linking early childhood education to primary school education (Avery \& Thomson, 2003). Both Te Whāriki and the NZCF refer to the commonalities that support the transition of children to school, but Avery and Thomson (2003) suggest the understanding of each sector, between the sectors, needs further development to enhance and develop these links and commonalities. If new entrant teachers are not using their curriculum, it may contribute to differences between kindergarten and school and the links intended to contribute to a seamless curriculum. New entrant teachers appeared to have limited knowledge of Te Whāriki and its overall aims for children. It is not clear from the information collected whether kindergarten teachers had knowledge of the curriculum governing school programmes as their focus was on following their own curriculum. Primary school principals' views on the use of the curriculum clearly differed from those of their new entrant teachers. These differences in curriculum usage and a perceived lack of knowledge about each other's curriculum may affect children as they make the transition to school. 


\subsection{Differences in cultural environments}

The kindergarten environments in this study reflected the cultural diversity of the children within. Teachers used more than one language when meeting and greeting children and parents. Wall displays were in more than one language, despite Aorangi and Dundass Kindergartens having small proportions of children from Māori and Samoan backgrounds. Kindergarten teachers clearly linked the cultural expectations of their curriculum to their programmes, acknowledging the multicultural composition of the kindergarten by using prominent wall displays for both parents and children (see Table 5.6 for details about the ethnic composition of schools and kindergartens). Māori, Samoan, and English language labels were used in displays, alongside artefacts from each culture. Where children came from other cultural backgrounds, kindergarten teachers had some form of display to acknowledge that diversity.

Table 8. outlines the evidence from kindergartens that support this commitment to fulfilling the "bicultural issues in relation to empowerment" where teachers are expected to "actively seek Māori contributions to decision making, and ensure that Māori children develop a strong sense of self-worth" (Ministry of Education, 1996, p. 40). This commitment is then extended to the needs of the wider community. 
Table 8.5: Acknowledging the bicultural and multicultural nature of the kindergarten

\begin{tabular}{|c|c|c|}
\hline $\begin{array}{l}\text { Kinder- } \\
\text { garten }\end{array}$ & Reflecting the ethnic composition of kindergartens & $\begin{array}{l}\text { Decile } \\
\text { ranking }\end{array}$ \\
\hline Aorangi & $\begin{array}{l}\text { Wall display dedicated to recognising and promoting } \\
\text { the value of the dual cultural heritage of New Zealand. } \\
\text { Māori language and artefacts were prominent. } \\
\text { Programme planning and children's portfolios were } \\
\text { also easily accessible. Some Samoan language displays } \\
\text { alongside artefacts from Asia. }\end{array}$ & 10 \\
\hline Cascade & $\begin{array}{l}\text { Large variety of multicultural artefacts. Displays in } \\
\text { English, Māori, and Samoan. Some evidence of Māori } \\
\text { language spoken. }\end{array}$ & 1 \\
\hline Dundass & $\begin{array}{l}\text { A wide range of artefacts from a variety of cultures } \\
\text { clearly displayed, predominantly Māori with Pacific } \\
\text { input. } \\
\text { A copy of the Treaty of Waitangi displayed in an } \\
\text { obvious position with Māori artefacts displayed around } \\
\text { it. } \\
\text { English was the dominant language. }\end{array}$ & 10 \\
\hline Hikurangi & $\begin{array}{l}\text { Multicultural displays evident, English was the } \\
\text { dominant language, although there were displays and } \\
\text { greetings in other languages, Māori, Samoan, Cook } \\
\text { Islands Māori, and Tongan. }\end{array}$ & 1 \\
\hline Tongariro & $\begin{array}{l}\text { Children's learning journeys well detailed. } \\
\text { Treaty of Waitangi issues: the kindergarten had done a } \\
\text { project linking its place with the culture of its setting } \\
\text { and environment. The kindergarten planned and built a } \\
\text { whare (house) out the back where carvings of Rangi } \\
\text { and Papa }{ }^{1} \text { were erected. The display included the } \\
\text { progression of the project and detailed the members of } \\
\text { the local community who were intimately involved } \\
\text { with the project. The teachers were consciously talking } \\
\text { about and actively promoting the use of more Māori } \\
\text { language in the kindergarten. } \\
\text { Some displays in Samoan. }\end{array}$ & 2 \\
\hline
\end{tabular}

Note

1 Rangi and Papa are the personal names of the Sky Father and Earth Mother respectively, held by Māori to have been the originators of all living things. 
At Tongariro Kindergarten, the teacher's planning and documentation related to the expressed needs and interests of the children. Teacher observations of children as they talked and played together formed the basis of the kindergarten programmes as teachers worked towards supporting the expressed interests of children. There was evidence from both the teachers' questionnaire responses and practice of their increasing commitment to the Treaty of Waitangi and to their curriculum. At the beginning of the year (2006) and for the years past, the head teacher, Tanya, commented that the kindergarten's commitment to the Treaty of Waitangi and Māori language was just tokenism.

The teachers had a few Māori words like "kia ora", and could count but that was it. With the gathering interest in the whare building project and the extension to planning and building the waka and the burgeoning interest from the local community and the iwi the teachers have made a real shift in their commitment to the Māori language. Now we teach the kids' songs and poi [swinging ball] games, we know about our local community and we are really trying. It has made us much more comfortable, and it's made a difference to our parents as well, they are much more involved in our kindy, ${ }^{54}$ they bring things in to show us as well as the children. We all find time here to explore the children's ideas, listen to their thinking and record and monitor what is happening. The children also are aware of our interest and actively seek us out to share their ideas. (Head teacher, Tongariro Kindergarten, informal discussion, $25 / 6 / 06)^{55}$

A feature of the NZCF and mathematics curriculum documents relates to the cultural climate of schools. Table 8. explores some of the signs of attention observed in the classroom environment relating to the bicultural and multicultural composition of classes. This attention was seen to be minimal in these classrooms; English was the only observed medium for learning and teaching.

54 Colloquial abbreviation for kindergarten.

$55 \mathrm{Kia}$ ora, whare, waka, iwi, and poi are Māori words for greeting, building, canoe, tribal affiliation, and dance apparatus respectively. 
Table 8.6: Acknowledging the bicultural and multicultural nature of new entrant classrooms

\begin{tabular}{|l|l|l|}
\hline School & $\begin{array}{l}\text { Reflecting the ethnic composition of new entrant } \\
\text { classes }\end{array}$ & $\begin{array}{l}\text { Decile } \\
\text { ranking }\end{array}$ \\
\hline Aorangi & $\begin{array}{l}\text { No evidence of displays other than in English, one } \\
\text { small display of kowhaiwhai }{ }^{1} \text { patterns made by the } \\
\text { student teacher in the previous week. "Thank goodness } \\
\text { my student teacher did this as I am not very good at } \\
\text { that stuff" (Angela, 23/8/06). }\end{array}$ & 10 \\
\hline Cascade & $\begin{array}{l}\text { Door with a kowhaiwhai pattern and some Māori } \\
\text { artefacts. No other evidence of bicultural or } \\
\text { multicultural displays or events. All teaching and } \\
\text { counting observed in English. }\end{array}$ & 1 \\
\hline Dundass & $\begin{array}{l}\text { No language used other than English, several displays } \\
\text { in Māori. }\end{array}$ & 10 \\
\hline Hikurangi & $\begin{array}{l}\text { No language evident other than English, no evidence of } \\
\text { 95 percent Polynesian composition of the class and } \\
\text { school. }\end{array}$ & $\begin{array}{l}\text { No visual evidence of any language other than English. } \\
\text { One display relating to biculturalism in English. }\end{array}$ \\
\hline Tongariro & 2 \\
\hline
\end{tabular}

Note

1 A kowhaiwhai pattern is a term given to Māori patterns predominantly used in traditional buildings.

Table 8.6 suggests that despite the large proportions of Māori and Samoan children in Cascade, Hikurangi, and Tongariro new entrant classrooms, few attempts were made to acknowledge this diversity. The dominant medium appeared to be English.

Aorangi and Dundass new entrant classrooms had very small proportions of children from backgrounds other than English and had little evidence displayed to reflect the diversity of New Zealand (see Table 5.6 for ethnic composition).

A clear discrepancy exists between the cultural environment of the kindergarten and the new entrant classroom. At kindergarten, the languages and cultural heritage of children were seen to be valued. In new entrant classrooms, the focus was seen to be primarily on English with no evidence of mathematics or learning 
in other languages. One teacher suggested that if children were unable to operate in English they might not be successful in mathematics (Angela at Aorangi school, 15/4/06). The attention to the cultural environment forms part of the requirements of each guiding curriculum document. Kindergartens have incorporated this into their daily routines whereas in the new entrant classrooms, these considerations were not observed, creating a further possible difference between the two settings.

\subsection{Communication levels between kindergarten and new entrant teachers}

The questionnaires and discussions with kindergarten and new entrant teachers were analysed to look for signs of communication between the kindergartens and the schools. Kindergarten teachers' responses to questions 10-15 on their questionnaire were analysed to examine how they perceived the level of communication they had with schools. New entrant teachers' interview responses were similarly examined to determine how they viewed their levels of communication with kindergartens.

Visible signs of communication were determined by asking teachers in both settings about the number of exchange visits between the two settings and whether teachers met each other to explore common issues or concerns. Indicators of levels of communication centred on establishing whether there was an exchange of information through newsletters, by telephone, by email, or in person, sharing information about aims and goals for children, and building connections between the settings through common understandings of each others' curriculum guidelines. If kindergarten teachers and the corresponding new entrant teacher independently spoke about sharing information about children, having regular visits, and working together to benefit children, they were deemed to share a high level of communication. If they appeared to operate independently of each other, they were deemed to have a low level of communication. This is described further in section 5.4.2. 
Two kindergartens had a high level of interaction with schools. Tongariro kindergarten teachers spoke of having regular communication with the Tongariro new entrant teacher. They described how Tanya from Tongariro School made regular visits (about once a term) and participated in the daily kindergarten programme on those occasions. Tanya discussed how she attempted to become more familiar with the kindergarten programme to develop her understanding of the philosophy of the kindergarten and to better understand where children had come from when they entered school. The principal at Tongariro School said his school wanted a "true relationship with the kindergarten, not something that made them all feel good" (Tongariro principal interview, 30/6/06). To support this the principal facilitated his new entrant teacher making regular kindergarten visits. Tongariro kindergarten teachers also reported on developing meaningful relationships with the school. They were the only school-kindergarten pair in this study that was developing this level of contact and communication. This was a recent development and a result of a local initiative between the school and kindergarten. Both groups of teachers said they had worked hard to increase the links between school and kindergarten, including sharing some teaching time to gain insights into each other's curriculum and environment.

The Hikurangi Kindergarten teachers had developed a high level of communication with a neighbouring school, but not Hikurangi School. The kindergarten teachers described communicating with a neighbouring school and valuing the visits they had, and wanting more visits. With Hikurangi School, kindergarten teachers said they had no communication or collaborative visits and said, "I think it is very beneficial for the children's teachers to become more familiar with each other, but due to time and staff constraints we are unable to extend our visiting to more than one school" (Questionnaire response, 5/4/06). The levels of communication in relation to Hikurangi School were in the middle level of communication. Kindergarten teachers had informal discussions where they passed on oral information regarding children about to make the transition to school. Hikurangi Kindergarten's teachers (Questionnaire response, 5/4/06) said they wished their local schools would visit more to see what they did, and they expressed a wish for more open communications between the schools and kindergarten. 
Teachers at the other three kindergartens in the study, although they wanted increased levels of involvement with schools, believed they were undervalued by schools, and low levels of communication did nothing to change this perception. In the words of Anna from Aorangi Kindergarten:

my role is to encourage, to support children, to give them confidence and a love of learning, to support children's theories, their social skills and help them to have the ability to articulate their thoughts. I feel that we work from their interests and strengths, schools are more interested in what they can't yet do. (Questionnaire response, 24/6/06)

These kindergarten teachers said they thought primary teachers had little or no understanding of the early childhood curriculum and saw this as a barrier to increasing levels of interaction between kindergartens and schools. Kindergarten teachers did not comment on their understanding of the school curriculum. "We expect our children to set their own agenda and learning paths and to follow these at their own pace whereas the school has a more formal curriculum which they follow" (questionnaire response, Donna at Dundass Kindergarten, 23/6/06). Kindergarten teachers said a further barrier to developing understanding between school and kindergartens was that in many instances they were unable to make school visits as it left the rest of the kindergarten understaffed (there is a mandated ratio of children to teachers).

As mentioned, Tongariro School was the only school in this study that seemed to have a high level of communication with its neighbouring kindergarten. New entrant teachers at the other four schools appeared to have lower levels of communication with kindergartens. Of these four, the new entrant teacher at Dundass School was the only one who mentioned making regular kindergarten visits, and she said she discussed children who were about to make the transition to school with the kindergarten teacher and visited regularly. Donna said these were quite informal occasions where "the teachers and I chat about the children starting school and if I have any difficulties with a specific child, I would go down and seek more information" (interview with Donna at Dundass school, 1/10/06). Dundass Kindergarten did not really give Donna specific information about what each child was able to do in relation to early academic skills. She believed 
kindergartens should do more to prepare children for school, and said she did not know much about Te Whāriki. Her school was classified as having a medium level of interaction with kindergartens.

Aorangi, Hikurangi, and Cascade Schools new entrant teachers said they had no communication with their local kindergartens. Hiria at Hikurangi School said:

I think it would be great if I could have more contact with the pre-schools that feed into our school (including Hikurangi Kindergarten) because I don't really know what happens in a kindergarten or how they work. (Interview with Hiria at Hikurangi school, 29/3/06)

Hiria commented that she should really go and see for herself, but she could not spare the time. Caroline from Cascade School held similar beliefs. She said kindergartens should focus children through more structured sessions, making patterns and developing children's language skills (interview with Caroline at Cascade School, 1/8/06). Angela at Aorangi School reflected these beliefs. She believed she should:

have a regular time to visit the kindergarten so I could meet the children coming to my room. I like children to come to my class four times before they start [school], two visits with a parent and two alone. The kindergarten teachers never bring the children up, they make excuses like they don't have enough adults. (Interview with Angela at Aorangi school, 25/10/06)

These three schools are described as having low levels of communication with kindergartens.

Overall, kindergartens were dissatisfied with the level of interaction they had with schools. Kindergarten teachers felt undervalued by new entrant teachers and believed their curriculum was not fully understood by new entrant teachers, which may lead to children's abilities being underestimated on their entry to school. It did not appear that kindergartens (other than Tongariro Kindergarten) initiated increased levels of communication with schools. Kindergarten teachers had a variety of reasons for this: child-to-staff ratios, perceived undervaluing of them by schools, and new entrant teachers' lack of understanding of the early childhood curriculum. New entrant teachers in general would like more contact with 
kindergartens and gave similar reasons such as a lack of available time to explain low levels of communication with kindergartens.

\subsection{Concluding comments}

Kindergarten teachers in this study identified with the underlying principles of Te Whāriki. These principles are empowerment, holistic development, family and community, and relationships that contribute to the major aim of Te Whāriki - for children to grow up as confident learners and communicators, healthy in mind and body, who can contribute in a meaningful way to society (Ministry of Education, 1996). These principles form the basis of teachers' beliefs about how children best learn, and teachers' practice derives from these.

First, children are given opportunities to explore their environment, and build connections to and with their existing knowledge and skills. In this environment teachers have the freedom to follow on and extend learning based on children's interests and explorations. Many opportunities arise and there appear to be no boundaries for learning and no preconceived ideas about what children need to know at particular ages and stages. There was a remarkable degree of consistency between kindergarten teachers both within and between kindergartens in relation to their strongly held beliefs about how children learned most effectively and how kindergarten teachers demonstrated this within their practice. All teachers attached value to the development of positive dispositions towards learning and saw themselves as giving children "the best possible start to education through encouragement, support and building self-esteem" (questionnaire response from Dundass Kindergarten, 1/8/06).

Secondly, kindergarten teachers held a holistic approach to children's learning and believed in linking many aspects of learning. While mathematics is not specifically identified and taught, the building of mathematical knowledge is supported through many of the kindergarten activities, both those initiated by children and those provided by teachers. Teachers could recognise the mathematical potential of many activities and then supported these activities as the children explored and created activities following their interests. Teachers in these kindergartens had a clear understanding of cultural concepts relating to the 
bicultural and multicultural nature of New Zealand society and incorporated these into the environment they developed for children.

Kindergartens are places where teachers and children build learning together and independently. The environments are not constrained by the four walls of a classroom. Children have the freedom to develop and examine their interests in a variety of spaces (for example, inside, outside, on the internet, in the library, with the teacher, and with the outside community). Teachers follow the beliefs outlined in their curriculum, and these beliefs are evident in their practice. Kindergarten head teachers are closely aligned with their teachers and are fully involved in all aspects of the teaching and learning that occurs within the kindergarten. Assessment in kindergartens, based on learning stories and dispositions for learning, are built on understandings and observations of what children can do across a broad range of competencies. Teachers see themselves as being in partnership with the learning of children rather than as the originators or directors of learning.

Within these kindergartens and their respective local schools, there were few established mechanisms and procedures to support the transition of children to school. The kindergarten teachers acknowledged this lack. In several instances, kindergartens and schools worked together to enhance the readiness of the school for the child (Tongariro School and Kindergarten are a good example of this) and built connections between the two environments. The overall perception was that kindergarten teachers would like to have more contact with schools but "we have connected with the schools and given them information but we get very little back" (personal communication at Cascade Kindergarten, 5/5/06). This opinion is reflected by the other kindergartens with the exception of Tongariro.

Kindergarten teachers in this study believed children come to kindergarten with a wealth of knowledge, which they as teachers build on and develop with children. A tension exists between this belief and the belief that schools focus on what the children are unable to do and have low expectations of children. These teachers saw the lack of attention paid by the school to the kindergarten environment and curriculum as a possible factor in a child's inability to successfully make the transition to school. 
This chapter explored the beliefs and practices of five new entrant teachers through observations and interviews. In this study, teachers had similar beliefs about how children best learned mathematics, yet their classroom practices did not support these beliefs. In most instances, these teachers felt that because of their knowledge about the low entry-level skills of five-year-old children in mathematics, teachers had an obligation to ensure these skills were secure before starting children on more cognitively challenging tasks.

Children's perceived lack of number knowledge on school entry is not supported by research (Aubrey, 1997; Young-Loveridge et al., 1995). Teacher beliefs centred on children having fun in mathematics and being given opportunities to problem solve and explore their own interests. However, in most instances these beliefs were over-ridden by the perception that new entrant children came to school with very little knowledge about mathematics, so teachers had a responsibility to fill these perceived knowledge gaps.

Because of this, new entrant children had limited opportunities to problem solve, explore their own interests, and learn to work co-operatively. Opportunities to negotiate, discuss, and communicate the results of investigation were not observed in these classrooms. These teachers taught children skills, based on their own beliefs about significant knowledge gaps in children on school entry and not on children's existing knowledge and skills. New entrant teachers paid limited attention to the bicultural or multicultural composition of many of their classrooms and instructed predominantly in English.

While kindergarten teachers had freedom within Te Whāriki to follow the learning pathways and directions of the children's interests, it seems these new entrant teachers were guided in their teaching by their firmly held beliefs about the necessary mathematical skills for five-year-old children to be successful at school. Observed mathematics took place in the classroom, following the directions and order determined by the teacher. The curriculum was not held to be of immediate value with teachers more likely to use the resources from the Numeracy Project to support their teaching and learning progressions. In general, they followed an ordered pathway for learning. It appeared that this pathway was primarily determined by teachers' existing beliefs about the mathematics they deemed 
necessary on a child's entry to school. Mathematics was a subject independent from other learning for the new entrant teachers in contrast to kindergarten teachers who held a more holistic view of mathematics.

New entrant teachers in this study said children on school entry were often unable to conform to the routines of the classroom. They saw this socialisation into school as a necessary part of ensuring children made a successful transition to school. It is important children know school ways of doing things, yet mathematics learning (and other learning) should not be overshadowed by the need to have obedient, compliant children. Kindergarten children on the point of transition to school are already well versed in the routines of the kindergarten, which enables their teachers greater freedom to focus on learning and teaching. New entrant teachers, working alone in their classroom, have new children entering their room on a regular basis throughout the school year. This continual influx of children new to the school system and needing to be settled at school would seem to have had a negative impact on their practice with managing and socialising children taking priority over teaching and learning. 


\section{9: Discussion: Similarities and differences in teacher practices and beliefs as children make the transition from school to kindergarten}

\subsection{Introduction}

I expect children to be able to tidy up and put things away in a responsible way. (Tanya at Tongariro School, 7/9/06)

Tanya said she believed children should be able to operate socially within the school system before she expected them to engage in more formal aspects of learning. Kindergarten teachers said they believed children could set the pace for their own learning and saw children as confident and capable learners. The focus of this study was based on examining the practices and beliefs of kindergarten and new entrant teachers in mathematics teaching and learning. Teacher practices and beliefs in kindergartens and new entrant classrooms in mathematics were explored to look for similarities and differences between the two sectors as children make the transition to school.

Overall, this study found that new entrant teachers said they believed children were coming to school with a less than adequate knowledge in mathematics (and in other areas relating to the curriculum and socialisation skills). On the other hand, kindergarten teachers believed when children left kindergarten to start school they possessed positive dispositions towards learning, which included unspecified skills in mathematics. New entrant and kindergarten teachers shared similar beliefs about how children best learned mathematics, but the manifestation of these beliefs differed between the two settings. There appeared to be few mechanisms between kindergartens and new entrant classrooms to support the smooth transition of children to school, despite the intention of curriculum documents. New entrant teachers in this study had a tendency to focus on managing children for learning and socialising them into school expectations before more formal learning took place. Kindergarten teachers, using their curriculum as the foundation of their practice, supported children as they interacted with the environment around them in order to build positive dispositions towards learning. 
In this study, kindergarten and new entrant teachers said they believed children learn through doing, which included learning through play and being exposed to a variety of experiences. In general, kindergarten teachers carried this belief, derived from their experiences, their professional development, and curriculum knowledge, into their practice. New entrant teachers had similar beliefs, derived predominantly from their experiences as well as from curriculum knowledge and professional development, but these beliefs were not always evident in their practice. An additional belief held by new entrant teachers was that many children on school entry had little or no mathematical knowledge, which teachers said they had to remedy before embarking on more formal schooling.

Further differences existed between the two environments in relation to the organisation for learning. In general, kindergartens were more flexible spaces, allowing for a clear indoor-outdoor flow of children moving around their environment. Kindergarten teachers had similar freedom to circulate, observing children and engaging with them as they explored various learning activities in their environment. This flexibility of movement provided opportunities for kindergarten teachers to extend learning for children as they observed them developing within the environment. New entrant teachers, in this study, were observed mainly operating within their classroom space according to a planned timetable. These teachers followed their script for learning (Cassidy \& Lawrence, 2000), which may limit opportunities for mathematics learning to those included in teachers' plans.

Not only were there differences in practices relating to mathematics teaching and learning, but differences existed in how each group of teachers regarded the curriculum documents that govern their practices. New entrant teachers in this study said they did not attach a great deal of importance to the curriculum as it related to mathematics because they believed they already had a good understanding of what children needed to know in mathematics when they started school. They also believed that in some cases the curriculum did not meet the needs of children. Kindergarten teachers, with a curriculum that encourages them to weave their own pathway, said they worked within their curriculum guidelines and followed its philosophy in their teaching and learning programmes. 
Kindergarten teachers attempted to provide inclusive environments that built on their knowledge of children and attempted to meet their specific needs. In these new entrant classrooms, teaching and learning primarily occurred in English, and teachers planned programmes of learning to meet the needs of five-year-old children. These planned programmes in mathematics initially appeared to be based, in most cases, on teachers' beliefs about the mathematical knowledge deemed essential for success on school entry rather than on children's actual needs. Contributing to these differences were few observed meaningful communication instances between the two settings, which may influence the level of knowledge teachers had of the other setting.

During the early years, it is important children develop a secure mathematical foundation to help ensure their future success. Young children are constructing their beliefs about what it is to do mathematics and be a mathematician. These beliefs impact on their later thinking, performance, and attitudes towards mathematics (Aubrey, 1997; Perry \& Dockett, 2002; Peters, 2004). Children need to have mathematics experiences that build on their existing knowledge and understandings. In general, young children are active learners and their teachers have a responsibility to recognise and develop this. To ensure continuity between kindergarten and new entrant classrooms, teachers have to identify and develop children's existing knowledge and establish the learning needs of each child. This should enable teachers to support the development of new mathematical competencies rather than teaching from their predetermined beliefs about what children at a particular age need to know.

Young children have access to a range of mathematical ideas that are developed and strengthened through their interactions with their peers, teachers, and families. Teachers have a role to play in supporting children as they explore, recognise, and engage with the mathematical ideas around them.

This chapter discusses the findings from this study in relation to the four questions posited. Section 9.2 examines the similarities and differences in kindergarten and new entrant teacher practices and beliefs in mathematics and how these may affect the mathematics experiences and programmes offered to children. Section 9.3 examines how teachers use the curriculum documents that guide their practice in 
mathematics teaching and learning. Section 9.4 explores the similarities and differences that were found in the two settings that may have an impact on children as they make the transition to school. This section also discusses teachers' beliefs about children's readiness for school, focusing on the mathematical and social competencies teachers believe should be mastered by school entry. Section 9.5 examines the communication levels that were observed between the two settings to see how these may impact on the transition of children to school. This section also discusses the differences observed between the two environments. Section 9.6 explores some of the limitations of this study and the final section examines some possible implications of the New Zealand curriculum (2007b) and the re-introduction of national standards for schools.

\subsection{Similarities and differences in teacher beliefs and practices in mathematics teaching and learning}

Children enter school knowing a great deal about numbers and mathematical concepts with considerable degrees of variation in the levels of their knowledge (Perry et al., 2007; Peters, 2001; Young-Loveridge, 1989a). In this study, there was strong consistency between what kindergarten and new entrant teachers said they believed about how children best learn mathematics. However, kindergarten teachers' observed practice was found to be more consistent with their beliefs while new entrant teachers' observed practice appeared to be based on an additional belief held about the necessary knowledge and skills five-year-old children needed to know in mathematics. New entrant teachers had a common tendency to underestimate or be unaware of the mathematical competencies of children on school entry despite their belief that they catered for the needs of children.

This underestimation of children's abilities in mathematics was evident through classroom observations, ${ }^{56}$ although research has demonstrated that new entrant teachers have the ability to accurately assess children's mathematical knowledge on school entry (Cassidy, 2005; Young-Loveridge, 1989b). Teachers initially perceived new entrant children as lacking essential mathematical knowledge that

56 See Vignette 7.1 for an example of this. 
would enable them to make connections and operate mathematically. In contrast to this belief, kindergarten teachers, by observing the children, could build on and extend children's experiences. Not every opportunity was taken, as there were observed instances when teachers were unaware of children's explorations. Kindergarten teachers perceived children as having individual learning needs and interests that provided starting points for learning.

Teachers' implicit theories of teaching arise out of their own experiences (Spodek, 1988). In general, teachers do not usually quote a theoretical position relating to their practice, they act the way they do because of their own experiences and observations (Cassidy \& Lawrence, 2000). This was evident in the practices observed in new entrant classrooms in this study. The teachers' set of beliefs focused primarily on the acquisition of early mathematical knowledge, counting strategies, basic geometry and measurement, statistics, and simple addition and subtraction. Teachers felt no apparent obligation to deal with more complex mathematics such as developing place value understanding and problem-solving strategies. Early mathematical knowledge was perceived as a necessary acquisition so children could successfully move into the next class level. New entrant teachers did assess children's mathematical abilities when they came to school but this information appeared to be overlooked in many of the lessons observed as children demonstrated mastery of skills being taught. Kindergarten teachers' beliefs relating to mathematics teaching and learning were more focused on developing positive dispositions towards learning rather than on the acquisition of specific skills in mathematics.

Studies relating to socialisation and compliance at school suggest teachers' classroom decisions are more likely to be based on teachers' strongly held personal beliefs consistent with new entrant teachers' beliefs in this study (For examples see Bell,1990; Doyle, 1983; Farquhar, 1991; McCaslin \& Good, 1992; Spodek, 1988). Good behaviour and socialisation into school feature in classroom practice, reflecting many of our own early educational experiences. Doyle (1983) claimed that many of these practices focus on the necessity of 'getting the work done' and ensuring children are well behaved and orderly. This consistent orientation towards the acquisition of skills in mathematics allows teachers to 
focus on order and management, which teachers hold to be an important part of socialisation to school and setting children up for successful learning as they move through the school system, despite their beliefs about the acquisition of early mathematical knowledge. A consistent feature of the new entrant lessons observed was a focus on order and responding to the teacher with a correct answer. Lessons observed were structured and children were well managed. Kindergarten teachers held similar beliefs to each other about how children best learn mathematics. The teachers in this study said their beliefs came from their experiences and they had moderated these beliefs as a result of their training, their curriculum, and professional discussions with their colleagues. Kindergarten teachers had a strong focus on the socialisation of children. This was described in terms consistent with the principles of their curriculum (empowerment, holistic development, family and community, and relationships) rather than in terms consistent with order and the acquisition of skills. Kindergarten teachers said they regarded children as active participants in their environment who were capable and confident learners. They saw their role as working with children, building on and extending children's learning, and following their interests. From the models of mathematics learning outlined in chapter 3 , these teachers fit more closely with a connectionist approach to learning and teaching (Askew et al., 1997; Ernest, 1989; Nisbet \& Warren, 2000).

Kindergarten teachers in this study were able to reflect on how their beliefs about children's learning and their teaching changed with the introduction of Te Whāriki. Consistent across these kindergartens was evidence of reflective practice (from conversations with teachers) resulting in changing and evolving practices.

New entrant teachers appeared to be less likely than kindergarten teachers to reflect on their practice as they claimed to already know what was required for five-year-old children to master learning in mathematics. Kindergarten teachers said they held the expectation that children could follow their own pathways and agendas. When children went to school, the new entrant teachers took over this responsibility. New entrant teachers said they expected on school entry that children had some formal academic skills, such as the ability to write their name, 
count, and recognise the letters of the alphabet. They believed kindergartens were good at developing social skills in children, a belief that is not consistent with their observed practices in some instances, and they would like kindergarten teachers to more actively teach children the knowledge they believed children should have on school entry.

Evidence for this difference in practice comes from the observations carried out in kindergarten and new entrant classrooms. A degree of managing and directional behaviour is to be expected in both kindergarten and new entrant classrooms due to the age of the children and the necessity of running an educational institution involving several participants. In kindergartens in this study, approximately half the teachers' time was involved with organising and directing children. In the rest of the time teachers questioned children, supported their learning, observed interactions, and engaged in and recorded various interactions. In the new entrant classrooms, teachers spent more than 95 percent of their time on organising and directing activities with only a very small percentage of time spent supporting children's learning. There were no instances observed of teachers engaging in specific mathematical interactions outlined in this study. All the mathematics observed was teacher controlled and directed. While it cannot be claimed that this discrepancy in organisational and directional activities is a typical difference between kindergartens and new entrant classrooms, it may be indicative of a tendency for new entrant teachers to focus on socialisation to school in preference to extending children's opportunities for learning, while kindergarten teachers focus more on developing positive dispositions for learning.

This difference in teacher practices may reflect the nature of the two settings. Kindergarten children just before school entry are familiar with the environment, know their teachers, and understand the general routines of the kindergarten, which in turn may allow teachers to focus more on developing positive dispositions for learning. Children are comfortable with the kindergarten community, and in this situation teachers were seen to spend less time managing and more time developing learning dispositions. New entrant teachers are managing a larger number of children from a variety of early childhood experiences to accommodate to school ways of doing things. This difference in 
circumstances may account for the time new entrant teachers spent managing and organising children in order to get them ready for learning.

\subsubsection{Differences in mathematical practices}

Examples were chosen from kindergartens and new entrant classroom observations to illustrate typical mathematical events. These examples were analysed using Perry and Dockett's $(2002,2005)$ mathematisation of events in chapters 6 and 7.

Not every opportunity for mathematics was recognised or observed in kindergartens, but the ones that were show evidence of teachers supporting rich mathematical contexts for learning. Teachers supported and extended children's learning as they explored their environment in their own ways. Children demonstrated that they were capable of managing sustained interactions (up to 30 minutes on some occasions) and possessed a range of competences associated with mathematical learning. For example, children were seen to be able to record, explore spatial concepts, develop sets of procedures, count in sequence, and pattern. Teachers gave children opportunities to work things out for themselves and to make connections to other events. Teachers did not necessarily intervene when they observed children having difficulties and frequently waited until children requested their support for specific issues. Not every opportunity for mathematics learning was observed or supported by teachers.

In the new entrant classrooms, teachers supported children's learning by making explicit links for children, possibly reducing situations that might result in children having opportunities to explore and construct their own interpretations of the task. The mathematics that was observed was structured and consisted of knowledge-based lessons that followed teachers' plans. There were limited opportunities for child-initiated learning and, in some instances, opportunities for working mathematically were denied to children as teachers intervened before children encountered a situation that could cause difficulties. Teachers managed and directed children's mathematical learning and, on some occasions, children's prior knowledge was unacknowledged. 
When these classroom practices are examined in the relation to Perry's (2000) elements of best practice and New Zealand work on effective pedagogy in mathematics (Anthony \& Walshaw, 2007), it seems evident that more targeted professional development for new entrant teachers involved in mathematics teaching and learning would be beneficial. Likewise for kindergarten teachers as Young-Loveridge, Carr, and Peters study (1995) demonstrated that by increasing the content knowledge of early childhood teachers, children's achievement in mathematics was increased.

\subsection{Using the curriculum}

This research was undertaken when the early childhood curriculum, Te Whāriki (Ministry of Education, 1996), Mathematics in the New Zealand Curriculum (MiNZC) (Ministry of Education, 1992), and the New Zealand Curriculum Framework (NZCF) (Ministry of Education, 1993a) were the current documents supporting teacher practice in schools. MiNZC and the NZCF have now been superseded by the New Zealand Curriculum 2007 (Ministry of Education, 2007b). The discussion in this chapter relates to the earlier documents.

The New Zealand curriculum documents were intended to support and guide teacher practice. "The early childhood curriculum provides a foundation for children to become confident and competent and, during the school year, to be able to build on their previous learning" (Ministry of Education, 1996, p. 93). The NZCF was designed to give direction to the development of the national curriculum statements, of which MiNZC is one, and describes the outcomes that are expected. The mathematics curriculum document gives clear guidelines for teachers in the teaching and learning of mathematics to help ensure children are given every opportunity for success. It states, "It is important that students are given explicit opportunities to relate their new learning to knowledge and skills which they have developed in the past" (Ministry of Education, 1992, p. 12) and "It is not expected that all students of the same age will be achieving at the same level at the same time" (Ministry of Education, 1992, p. 17).

New entrant teachers in this study said they did not use the curriculum documents to guide their practice in mathematics because they knew what children needed to 
know. This knowledge guided their classroom practice. Lessons were observed to be structured and directed to fill apparent gaps in children's mathematical knowledge. Teachers said that once they believed these deficits in children's knowledge were remedied, they could then move on to teaching mathematics from the curriculum. There appeared to be few opportunities for children to relate their new learning in mathematics to learning and skills they already possessed on school entry.

Kindergarten teachers used their curriculum as the basis of their practice. They said they had adapted their practices to fit with Te Whāriki. Each kindergarten had the opportunity to shape its practice, based on Te Whāriki, according to its specific needs. Each kindergarten believed its own reflective practices and professional development enabled it to develop programmes that followed individual children's needs and interests more closely than had occurred before the introduction of Te Whāriki. By making detailed observations and recording interactions that occurred as children engaged with their learning environment, teachers were encouraged to use their curriculum to build on the needs of children. Te Whāriki was perceived by these teachers as the foundation of their practice, so it formed the basis of their teaching.

New entrant teachers in this study said they did not see value in using the curriculum because they felt it did not adequately cater for the specific needs of five-year-old children. Teachers said they knew what children of this age required, and this was not covered in the curriculum. In general, these new entrant teachers appeared to hold a deficit view of children's mathematical skills on school entry. The curriculum document for mathematics with its lack of prescriptive requirements for children on school entry did not meet children's needs in their opinion. The perspective generally held was that children should be better prepared for school at kindergarten and this specifically meant teaching children certain skills so they would be ready to start learning at school. While new entrant teachers said they used their school's long-term plans as the basis for their planning, it appeared that in some cases these were over-ridden by their firm beliefs about the needs of the children. 
The new curriculum, introduced into New Zealand primary and secondary schools in 2007 , has some changes that may have a profound effect on the continuity of the curriculum from early childhood through to secondary school. The essential learning areas that dominate the NZCF have been replaced with five key competencies more closely aligned with the key competencies of Te Whāriki (Carr, 2006). When these competencies are fully implemented in schools, they may result in increased continuity between early childhood centres and primary schools.

The Curriculum Stocktake Report (Ministry of Education, 2002) included a recommendation that the essential learning areas (57 of them in eight groupings) be reorganised to be more consistent with the five groups of essential skills and attitudes outlined in Te Whāriki. The essential learning areas have been renamed as key competencies and, similar to learning dispositions, they are about active learning. As with the NZCF, the New Zealand Curriculum 2007 specifically makes links from early childhood to primary school and identifies the factors that contribute towards a smooth transition to school.

The transition from early childhood education to school is supported when the school:

- Fosters a child's relationships with teachers and other children and affirms their identity:

- Builds on the learning experiences that the child brings with them:

- Considers the child's whole experience of school:

- Is welcoming of family and whānau. (Ministry of Education, 2007b, p. 41)

\subsubsection{Principals' expectations of the use of the curriculum}

Kindergarten head teachers and primary school principals said they believed their teachers used the relevant curriculum documents as the basis for their classroom programmes. Kindergarten teachers said their curriculum formed the basis of everything they did; it underpinned their practice and guided their beliefs, supporting their head teachers' beliefs. They reported on how their understandings about children's learning had been influenced by the more sociocultural 
perspectives espoused by Te Whāriki. In contrast to this, new entrant teachers placed little emphasis on the use of the curriculum documents, and in some instances were unsure where to find the documents. Their principals believed that at the very least teachers had an understanding of the documents, as this was the basis of teaching and learning. In only one school was this belief of the principal supported by the actions of the teacher as her team used the achievement objectives for level 1 in mathematics for their planning. The other four principals assumed their teachers based their planning on the curriculum documents, which was not what the teachers concerned did.

Differences between how kindergarten teachers and new entrant teachers use their curriculum may create discrepancies for children when they go to school. Kindergarten teachers use the curriculum to support their teaching, and they describe children's learning in terms that reflect this usage. New entrant teachers' beliefs about the need to fill perceived gaps in children's knowledge of mathematics drive their teaching programmes. They believed they could not use the requisite curriculum as it did not meet the perceived needs of children at this level. Children have to adjust from being perceived as competent and confident learners at kindergarten to being viewed as lacking in essential mathematical knowledge (and other skills deemed necessary) when they go to school.

\subsection{Readiness for school: Teacher expectations}

I agree with the free play and things like that but I really feel that by $4 \frac{1}{2}$ or so, the teachers at kindergarten should really focus more on preparing the children for school. (Angela at Aorangi School, 24/10/06)

Angela commented further that it was her belief children from kindergarten spent their day 'flitting from activity to activity' and never completed anything because they were unable to focus for prolonged periods. This statement is not corroborated by examples of mathematics events recorded in chapter 6 for kindergarten children. Angela, along with the other new entrant teachers in this study, believed it was the kindergarten's role to prepare children for school. They expected children to be taught some basic literacy and numeracy skills alongside social skills such as being able to sit on the mat and complete their work. Angela's beliefs about children's lack of readiness for school ignore the changing 
international perception that readiness for school is not solely related to the child, but involves the school's readiness, the early childhood education facility, the family, and the community (Dockett \& Perry, 2007). Angela's statement, with its focus on preparation for school, suggests the content of the early childhood curriculum, Te Whāriki, does not feature in her perceptions of the aims of early childhood education and is contrary to the beliefs early childhood teachers have of their role in educating children. Her lack of knowledge of the environment, the philosophy, and the curriculum underlying early childhood may be seen as a barrier to children's effective transition to school. Her perception, along with those of the other teachers in this study, of early childhood education is one of preparation for school - getting children ready for school. Readiness for school for these teachers implies children should possess certain skills before they go to school despite there being no such requirements in the curriculum for five-yearold children.

Early childhood teachers saw their role as developing children with positive dispositions to learning for life, a different perception from that of new entrant teachers.

My aim is to encourage and support confidence in the children, to develop a love of learning and foster children's theories, social skills and their ability to articulate and reflect on their thoughts. We work from their [the children's] strengths and interests; schools are interested in what they can't yet do. (Aorangi Kindergarten, 25/8/06)

Early childhood teachers did not see their role as one of preparing children for school by ensuring children had mastered certain skill sets. Kindergarten teachers said they focused on their curriculum and its requirements because they believed the development of positive dispositions was the central issue. They did not plan to meet the specific needs of new entrant teachers and the outcomes of the school curriculum documents.

The disparity of beliefs about the role of the teacher and the top-down view held by new entrant teachers is captured in a statement from Dundass Kindergarten's head teacher (21/3/06), which illustrates the differing perspectives: 
We see the child leaving here and we may say they are a happy sociable child who is capable of persevering until a task is finished and she [the new entrant teacher] comes down and says that the child is incapable of finishing a task and doesn't have many social skills. You know sometimes she has a completely different view of the child.

This apparent lack of value attached to what happens at the level below (in this case kindergarten) is not uncommon at other educational transition points in New Zealand (Averill, 2001). New entrant teachers believed their role as teachers was similar to that of the role of a kindergarten teacher, but at "a higher level at school" (Angela at Aorangi School, 25/10/06), a further sign of a top-down model. Kindergarten teachers felt their role as a teacher was the same as that of a new entrant teacher with the added proviso, "we work from their [children's] interests and strengths, schools are interested in what they [children] can't yet do" (Hikurangi Kindergarten, 19/7/07). Teachers may believe the curriculum content expectations are higher when children go to school, but there is no evidence of this in their practice. New entrant teachers believed mathematics at primary school was at a higher level than in kindergartens, but their expectations of the children and their mathematics practice in the classroom do not necessarily support this view.

"School is a different world from kindergarten and I have frequently heard parents saying 'it will get sorted once they are at school"' (Donna at Dundass School, $2 / 3 / 06$ ), an attitude that seemed to pervade her teaching. Donna, along with the other new entrant teachers, focused initially on teaching children knowledge skills so they might then have the ability to work mathematically. New entrant teachers in this study focused on the product of mathematics rather than the process of developing mathematical understandings and learning dispositions, which is favoured by the kindergartens and supported by the relevant curriculum documents.

This difference in perception of the role of the teacher and the belief that kindergartens should do more in relation to preparing children for school was present in the beliefs of school principals. The principals of the five study schools believed children should enter school with "a basic set of core knowledge, 
recognise numbers to five, know their colours and shapes, count in sequence to 10 at least and be able to work in small groups" (Principal, Aorangi School, 12/6/06). A commonly voiced opinion amongst the principals was that "children need to learn to fit with the school routines and have the expectation that learning will be harder here" (Principal, Tongario School, 18/7/07). Whether these principals were influenced by their new entrant teachers is difficult to determine, but it is evident that both groups felt children should be better prepared by kindergartens for the more formal, academic nature of school. New entrant teachers and principals in the study schools had expectations for children on school entry in mathematics that were not based on the curriculum, which has no requirements for children to have mastered specific skills before school entry. When children did not meet teacher expectations on school entry, children were perceived as lacking in essential knowledge for school success. This perceived lack of skills may get in the way of teachers exploring the skills and knowledge that children actually possess on school entry.

Teachers and principals in schools believed children were not properly prepared for school in terms of academic skills. Children, in their opinion, were welldeveloped socially but lacked the basic academic skills believed to be necessary at school. Teachers' classroom practices did not support the perception that children are well prepared with social skills on school entry. New entrant teachers built the children's knowledge and focused on task completion and following directions. Children were given few opportunities to take responsibility for their own learning as teachers directed them to pre-selected activities unlike in kindergartens where children had more freedom to select their own activities. It is expected that new entrant teachers spend time ensuring children are familiar with the routines and expectations of school when children make the transition to school, yet the vignettes described in chapter 7 suggest that this took precedence over curriculum expectations.

Overall, this study found that teachers in both settings held different expectations of children on school entry in terms of both mathematical competencies and social expectations. When children move from kindergarten, where they have been regarded as capable learners and can function in a familiar environment, to a new 
entrant classroom, where they may be viewed as not possessing the requisite social and mathematical skills expected by their teacher, some children may experience some discontinuities in their learning. The head teacher at Dundass Kindergarten (15/3/06) summed this up when she said:

I think a major difference in expectations is that we expect our children to set their own agendas and learning paths and to follow these at their own pace whereas the school sets the agenda for learning and pace.

\subsection{Communication between kindergarten and new entrant teachers}

Going to school is an important step for children. Described as a "rite of passage" (Clark \& Lovric, 2008), the success or failure of this passage has the potential to affect how children perceive themselves. Where schools and early childhood institutions make connections with each other and children have a sense of belonging as they move from one setting to another they are more likely to make a successful transition to school (Dockett \& Perry, 2005; Margetts, 2007). Some continuity of practice is recommended between the two settings to support children as they make links from an early childhood setting to school (Dockett \& Perry, 2001). This section discusses the communication observed between kindergartens and new entrant classrooms, then examines the differences observed between the two environments.

The level of two-way communication between institutions can be seen as an indication of the relationship between them (Hopps, 2004). Several schools reported having informal communications with the kindergarten nearest them, but the main focus of these communications was the gathering of information about children (predominantly in relation to those children who might pose a challenge at school). The teachers who gained this information did not record it in any formal way. In general, new entrant teachers felt kindergarten teachers did not give them any useful information about children's achievement. New entrant teachers did not see learning stories as a primary source of information about children, although they often contained information about children's achievements and dispositions to learning in accordance with Te Whāriki. Teachers did not usually ask children or parents for individual learning stories on the child's arrival at school and if they did it was treated as a news item for the child rather than an 
informative document about the child's learning progressions and dispositions for learning.

Kindergarten teachers said that before the introduction of Te Whāriki they used to use checklists to gather information about children relating to various skills. These checklists were sometimes passed on to the school, but now kindergarten teachers complete learning stories, which they believe were neither understood nor valued by the schools. The learning stories, containing carefully documented, observable aspects of children's learning progressions, could serve as a useful bridge between the home, the school, and the kindergarten. In most cases kindergarten teachers felt that even when they had communication channels open with the new entrant teachers, communication was superficial. A common theme was that kindergartens would like to engage in "meaningful dialogue with the junior department at school" (Aorangi Kindergarten, 12/8/06). Kindergarten teachers commented on the lack of understanding of their curriculum by new entrant teachers and felt this was a factor in the level of communication that existed and the lack of realistic expectations of children held by new entrant teachers.

New entrant teachers had a similar view in that they would like to have more dialogue with kindergartens, but said they lacked time for this. They said they wanted more specific information from kindergartens about children's learning skills. On some occasions, new entrant teachers did visit the kindergarten to obtain details about particular children. The overall belief held by new entrant teachers was that they wanted more detailed information from kindergartens, but it was not provided. Learning stories were not deemed to be useful as new entrant teachers viewed them as a general portfolio of activities children had engaged in rather than an informative document detailing children's learning in accordance with Te Whāriki, and, in many cases, they did not have access to the learning story unless a child brought it to school to share.

It appeared that both groups of teachers held a limited understanding about the other. The lack of meaningful communications between the two settings contributes to this limited understanding. Kindergarten and new entrant teachers said they wanted increased communication with each other, but there appeared to be few mechanisms to support this. 


\subsubsection{Environmental differences}

There were differences observed in the kindergarten and new entrant classrooms in this study. The kindergarten environments had open indoor-outdoor flow that is not present in the new entrant classrooms. New entrant classroom environments came with the expectation of conformity to a set of established routines and procedures in the classroom. In most instances, the day in a new entrant classroom was timetabled and controlled by bells that signalled breaks, including morning tea, lunch time, and the end of the school day. This structure was not evident in kindergartens. Kindergartens did have break times but they were not clearly defined, taking place over a period when children were free to wash their hands and sit down in a designated area and have something to eat.

At kindergarten a variety of activities were evident. Children had, in all but one case, free access to choose from activities around the whole area. These broad parameters enabled children to move freely and interact with both their environment and interests and a variable range of participants. Activities were available for children to select and develop their own interests. A good example of this was when a child's interest in a waka (canoe) lead to the whole kindergarten working on drafting, planning, building waka, building a marae, and developing a more involved partnership with parents and the local community through this initial interest. The teachers used these events retrospectively to build on from the children's initiatives and record their progressions. Open boundaries, flexible planning, and interactions enabled the teachers to more closely follow and develop children's interests and extend opportunities for learning.

In contrast to kindergartens, new entrant classrooms were more constrained in terms of space and management. Children were expected to complete work designated by teachers. Mathematics and reading occurred at fixed times of the day in contrast to the more general freedom of the kindergarten. As in kindergartens, a range of resources was evident, but children used these resources at specific times regulated by teachers. Activities within the classroom were directed and managed by teachers, and the focus of learning appeared to be on socialising children and ensuring they gained sufficient knowledge to progress through the school system. Kindergarten children had the opportunity to follow 
their interests and develop multiple ways of making connections, but at school teachers usually endorsed one particular method and children had to learn to conform quickly to the ways of the classroom.

The way in which teachers organised for learning differed between the two settings. Kindergartens supported flexible groupings, interactive and responsive learning occasions, combined with careful observations of developing learning through children's interactions with teachers, other children, and the environment. These beliefs about organisation and learning may also be held by new entrant teachers, but in practice new entrant classrooms portrayed a more formal approach to learning, with structured groups according to teachers' beliefs about children's needs, and formal, planned learning occasions designed to meet specific outcomes, in some cases irrespective of children's actual needs. Kindergarten teachers used their observations of children's interests to guide the directions for learning. New entrant teachers used their beliefs about what children should know to plan lessons to meet these perceived needs.

The differences in the organisation for learning in both settings may have influenced the nature of the mathematical learning that was observed. Young children in kindergarten had the opportunity to pursue their own interests with or without their teachers and peers. On occasions, a teacher picked up on children's interests and provided information and support for them to develop this learning interest further. A result of this was evident in mathematical events outlined in chapter 6 where children had access to a range of mathematical ideas through their activities, both supported and unsupported by their teachers. Within new entrant classrooms, teachers' adherence to their planning might restrict opportunities to extend the mathematisation of events. Examples of the mathematical events in chapter 7 show lessons where children were taught within a lesson plan with little or no room for deviation. A consequence of this structure was the apparent lack of attention paid to the individual learning needs of children.

There is no expectation that kindergarten and school environments should be the same, but to facilitate ease of transition to school it would be reasonable to suggest the two environments have some similarities. Adaptation to a new environment and the process of adapting to discontinuities are important in the 
growth and development of individuals (Clark \& Lovric, 2008; Niesel \& Griebel, 2007; Perry \& Dockett, 2005). Children expect that going to school will involve change (Dockett \& Perry, 2007), yet the presence of some familiar events may ease the process of going to school and support children as they transition to school. Within the two environments in this study, there are many areas of discontinuity that may affect the ease a child's transition to school. These areas relate to management, compliance, order, and teachers' perceptions about the capabilities of young children in mathematics.

\subsubsection{Acknowledging diversity}

New Zealand is a diverse society and the curriculum documents that guide teacher practice acknowledge this. It is the responsibility of teachers to support this aim through their practice. The kindergartens and schools involved in this study were from both the highest and lowest decile schools in New Zealand with a range of children from diverse backgrounds in their populations. The expectation from the curriculum documents is that each environment should reflect the composition of children in the educational setting and the bicultural heritage of New Zealand.

Within the kindergartens, teachers made an effort to use languages other than English as appropriate, using simple phrases and greetings in a variety of languages (depending on the cultural backgrounds of children). Teachers at Tongariro Kindergarten provided an example of teachers making a commitment to increase their usage of te reo Māori (the Māori language). This had the unexpected (for the teachers) effect of increasing the level of community involvement in the everyday life of the kindergarten. These teachers had moved from a 'token' ${ }^{57}$ attempt at fulfilling their bicultural expectations to a committed attempt at enhancing these (head teacher, Tongariro Kindergarten, 25/6/06). Teachers at this kindergarten were learning more songs in Māori, and said they were able to use more Māori phrases, including counting language, when they worked with children. Displays in more than one language in kindergartens reflected teachers' recognition of a diverse society and curriculum requirements.

57 Teacher's word from Tongariro kindergarten. 
In the new entrant classrooms, all the teaching that was observed occurred in English, and there were no observed instances of children being greeted in any language other than English. In some instances, a teacher saw a lack of proficiency in English as an impediment to mathematical learning despite evidence to the contrary (e.g., Vignette 7.2 and following discussion). Displays in classrooms were primarily in English with only a few concessions to the bicultural commitment of the curriculum. These consisted of signs in Māori relating to greetings and simple commands. Angela at Aorangi School (23/8/06) commented that the display in Māori was only in her classroom as a result of having a teacher trainee in her class as she herself was "no good at that sort of thing".

A sense of belonging to kindergarten and then to school is seen by Dockett and Perry (2005) as a factor that supports children to make a successful transition to school. While some differences between school and kindergarten are expected, the ease of transition for children can be supported by some similarities to enable children to make connections to the new settings (Margetts, 2007). In the kindergarten and new entrant classrooms in this study, differences existed between the two environments. The perceived lack of communication between the two settings may not support children as they go to school.

\subsection{Going to school}

Going to school is an important event for children. Some differences are expected between the two environments to mark the transition (Niesel \& Griebel, 2007). But the transition process may be enhanced when there are also similarities between the two environments (Dockett \& Perry, 2001; Margetts, 2007). This chapter examined differences and similarities in teachers' practices and beliefs in mathematics teaching and learning and how teachers in kindergartens and new entrant teachers used their curriculum documents. Teachers' beliefs about children's readiness for school and differences between the two environments were also discussed. The differences found between the two settings may affect the ease of transition to school. As children move to school, they move from a more open, less bounded environment to one that is more structured in terms of both space and time. 
Kindergarten teachers looked at children and used their existing skills, interests, and knowledge to further stimulate learning. New entrant teachers looked at children coming into their classroom and thought about what children were unable to do. Consequently, children were taught the essential knowledge believed to be necessary for success at school as determined by their teachers, which may or may not meet their learning needs.

\subsection{Limitations of this study}

There are several possible limitations to this study. Firstly, it is possible that had this study been carried out in both urban and rural areas or over a wider geographical area than this one, the results may have been different.

Secondly, a different person in the same settings as me may possibly have selected different vignettes to illustrate the mathematical events occurring in the kindergartens and classrooms. For example, some may contest that vignette 6.2 relating to mixing paint colours does not reflect the beginnings of proportionality. As a primary trained teacher I was observing in both kindergarten and new entrant classrooms and my particular lens may well have influenced some of the interpretations of information that I have made. Tobin and Kincheloe (2006) claim that the difficulty of cross-checking information and the possibility of researcher bias present a further limitation on this kind of case study.

Thirdly, both kindergartens and new entrant classrooms have different curricula which may lead to differences in pedagogy. While teachers' stated beliefs about teaching and learning appeared to be similar they demonstrated through their practice different interpretations of their role as a teacher.

In spite of these limitations the information contained in this study reveals a picture of teacher practices and beliefs in mathematics teaching that will be available for comparisons with any subsequent studies relating to mathematics teaching. 


\subsection{Concluding comments}

Over the past 20 years there have been some major curriculum developments in both early childhood and primary school education across the whole curriculum, not just in mathematics education. In the last few years early childhood educators have participated in professional development about their curriculum. This initiative, Kua Tei o te Pai, has, according to early childhood teachers had a major impact on their practice and the way they teach and work with children. A major report concluded that kindergarten teachers had shifted their practice and increased reflection on their pedagogies (Stuart et. al., 2008). The curriculum and its underlying philosophy have been incorporated into their everyday practice and become an essential element of their beliefs relating to teaching and to how children best learn mathematics (Stuart et. al., 2008). Te Whāriki gave early childhood teachers the freedom and responsibility to "weave" their own pathways according to the best interests of children.

The new curriculum (Ministry of Education, 2007b) bridges the gap between Te Whāriki, (Ministry of Education, 1996) and the NZCF (Ministry of Education, 1993a) by bringing a closer alignment between the underlying philosophy of educational practices in New Zealand. The new curriculum document parallels the five strands in Te Whāriki, with a set five competencies which align with the strands making a more seamless transition possible. The learning dispositions in both curriculum documents focus on the needs of the learner and the role of the teacher as a facilitator of learning. Teachers are expected to develop communities of learning within their classrooms. The reduction in the number of achievement objectives outlined in the 1990s for schools to a more manageable set in the New Zealand curriculum (2007b) can only support primary teachers as they move towards developing learning competencies in their students.

Primary teachers, including new entrant teachers, were exposed to new curriculum documents across all subject areas in the 1990s. They participated in professional development relating to mathematics teaching and learning in the early years of the twenty first century and had their curriculum revised, up-dated and re-written in response to the curriculum stock-take of the beginning of this century (Ministry of Education, 2002). The curricula at the time of this study was organised in 
essential learning areas, levels and achievement objectives. This lead to the development of assessment practices that demonstrated coverage of the curriculum and achievement objectives (May, in press). In order to manage the demands imposed on them teachers teach lessons to meet pre-determined goals in order to ensure coverage of achievement objectives and to make sure that children had all the necessary knowledge and skills to ensure success. These demands, compounded when new entrant teachers held the belief that children knew very little on school entry, have impacted on practice in the classroom (Carr et. al., 2010; May, in press).

There is a noticeable difference between the two teaching environments, not all of which can be accounted for by the differing expectations of their curricula. Kindergarten teachers, with a flexible and progressive early childhood curriculum have the freedom to work alongside children and allow for divergent pathways and individual interests all of which contributes to the development of positive dispositions for learning. The broad strands in Te Whāriki supported multiple learning pathways to meet individual and collective learning needs.

New entrant teachers believed that children learned by doing and having fun, in a very similar way to kindergarten teachers. This was overridden by their beliefs about children's knowledge and skill levels on school entry, combined with perceived constraints on their practice from the curriculum. Though new entrant teachers in this study claimed that the curriculum was neither used nor useful, I would suggest that the style of teaching practiced in these classrooms was focused on the achievement of very specific objectives relating to perceived, deficit knowledge in children on school entry. Downward pressure from the next year level up could also be a factor in their directive practice. No new entrant teacher would want to move children up to the next year level feeling that children did not have the necessary skills in order to move towards the next level of the curriculum. Parents, while not a feature of this study, also carry expectations that at school learning begins (Interview at Dundass school, 2/3/06) placing additional pressures on new entrant teachers to ensure visible signs of learning in the form of mastery of clear learning objects, such as being able to say the number before and after a given number. 
A further constraint felt by new entrant teachers is their role as the first point of contact at school for five-year-olds and their parents. It is their perceived role to ensure that the child makes a successful transition to school. In most cases in this study new entrant teachers took the responsibility of ensuring that children settled well into school, learnt the school routines and began to read, write and do mathematics. This pressure may well have contributed to the formalised teaching practices observed in the new entrant classrooms which are so very different from those in the kindergartens.

The introduction of National Standards in educational achievement by the Government of 2007 in New Zealand could have a major impact on teachers', changing their practice to one more driven by achievement objectives and measureable standards. Standards based assessment is not new to New Zealand. It ceased for the first time in New Zealand in 1936 (May, in press). The then Department of Education celebrated the uniformity of instruction and results across the country (Thrupp, 2008). Evidence from the time shows examples of teaching to the test (Crooks et. al., 2009; May, in press: Thrupp, 2008.) The reintroduction of national standards may well send out a clear message about what is valued in teaching and lead to a return to the over-emphasis on testing as opposed to a focus on students. As to the effect on teachers, particularly new entrant teachers as seen in this study, the impact could further constrain their teaching practice. An opportunity existed with the introduction of the $2007 \mathrm{New}$ Zealand Curriculum for teachers to move away from the constraints of ensuring children reached each achievement objective towards a greater focus on developing lifelong competencies for learning. Introducing national standards now may mitigate this effect and anecdotal evidence already exists suggesting some teachers have been encouraged to focus on teaching towards explicit national standards (May, in press) rather than meeting the needs of the children. The concluding comments in the following chapter aim to make links between the findings of this study and existing research in order to make recommendations that may impact on teachers' beliefs and practices in mathematics learning and teaching over the period of transition to school. 


\section{0: Conclusion: Compatibility of teacher practices and beliefs in mathematics between early childhood and new entrant school settings}

\subsection{Introduction}

This study examined similarities and differences in teachers' beliefs and practices in mathematics teaching and learning as children make the transition from kindergarten to new entrant classrooms in New Zealand. The study found that teachers in both settings shared similar beliefs about how children best learned mathematics.

Kindergarten teachers said they believed that children should have fun, have opportunities to explore and interact with their environment, and be provided with stimulating equipment. These beliefs were evident through observations in kindergartens where children were seen to be involved in a wide variety of activities with the freedom to follow their own directions with or without teacher support.

New entrant teachers said they believed children best learned mathematics through hands-on activities, by having fun, and by engaging with mathematics. New entrant teachers shared a further similar belief to each other about the knowledge they believed children should possess on school entry. In classroom observations, this specified knowledge was explicitly taught to children because teachers believed that without this essential mathematical knowledge, children would be unable to work mathematically.

Differences in practice between the two settings may affect a child's ability to make a successful transition to school. In all instances, teachers said they cared about the outcomes of education and believed they were doing the best they could for the children they were working with. In kindergartens, teachers ensured children were provided with a rich variety of experiences and opportunities and teachers were present to support, guide, and extend opportunities for children's learning. In the new entrant classrooms, teachers ensured children were taught skills intended to provide a foundation for further school experiences through explicit and directed learning experiences, in some observed instances with 
limited regard for children's actual learning needs and existing knowledge and skills. In practice, this meant teachers gave children few opportunities for making mathematical connections.

There are differences between kindergartens and new entrant classrooms and teachers that qualify any conclusions drawn. Kindergarten teachers, when discussing children before school entry, talked about children who were accustomed to kindergarten and familiar with their teachers. Kindergarten teachers saw their role as one of supporting and developing children's positive dispositions towards learning through their participation in activities. New entrant teachers discussed children who had come from a variety of early childhood settings and were new to the school environment. New entrant teachers said an important part of their role was to ensure children were socialised into school ways of doing things and were able to operate within the school system, which was not a feature of kindergarten teacher practice. When new entrant teachers judged that children did not have the knowledge and skills necessary for school success they believed their primary task was to develop these. The findings from this study should be considered bearing in mind these differences.

This chapter examines the findings of this study and offers suggestions for future development and exploration of teacher practices and beliefs in mathematics education that may impact on the successful transition of children to school. The four main sections of this chapter discuss the four questions posed in this study. Section 10.2 examines whether kindergarten and new entrant teachers share common beliefs about how children best learn mathematics. Section 10.3 examines similarities and differences in the observed practices of teachers as children make the transition to school. Section 10.4 explores the links between teacher practices and beliefs in mathematics learning and teaching that may influence how children make the transition to school. This is followed by a brief section (section 10.5) that examines the curricula and how teachers use these to make links from kindergarten to school. Section 10.6 discusses making connections with education. Section 10.7 concludes this chapter. 


\subsection{Teacher beliefs in mathematics teaching and learning}

In this study, kindergarten teachers used Te Whāriki as the basis for their teaching and learning programmes. They incorporated the key competencies of Te Whāriki in their beliefs and practices and supported children as they engaged in learning. Teachers focused on developing positive dispositions for learning alongside developing appropriate learning experiences for children in all areas. A fundamental belief of these teachers is that all children are capable of successful learning, a finding similar to that reported by Anthony and Walshaw (2007) in their report on effective pedagogy. Kindergarten teachers saw their role as one of guiding, supporting, and extending learning for children. These teachers acknowledged the changing focus of their role, moving from a more developmental, readiness approach towards extending children's learning interests.

Kindergarten teachers made decisions about children's learning based on their observations of children's interests. In practice, this meant that although kindergartens had a variety of equipment and activities available, specific learning directions were taken to follow children's expressed interests as in the case of building the waka at Tongariro Kindergarten (section 6.2.1). Kindergartens did not operate with long-term plans as these arose retrospectively as a result of children's interests. When teachers initiated a theme, as in the case of the Galaxy Corner (Vignette 6.1), they provided the basic idea (the Galaxy Corner) and children had opportunities to further explore the subject by creating objects for display and developing a set of social understandings for using the corner appropriately.

New entrant teachers made decisions about children's learning based on their own preconceived beliefs about what children needed to know. These beliefs were not necessarily based on evidence from children's existing knowledge, and were more likely to be based on commonly held expectations surrounding the knowledge in mathematics new entrant teachers thought necessary for five-year-olds. In addition to this, new entrant teachers had a necessary focus on the order and management of children, as this supported the smooth running of the classroom. 
Teachers planned mathematics lessons based around this 'necessary' knowledge for school entry as opposed to building on from children's needs.

While achievement objectives from the mathematics curriculum were a part of schools' long-term plans, it appeared in practice that teachers did not necessarily adhere to these or to the underpinning philosophy of the curriculum. The outcomes-based curriculum, perceived by the teachers not to be useful or valued, may have contributed to the predominantly skill-based lessons observed in classrooms.

This apparent disparity between the curriculum as interpreted and practised in kindergartens and the curriculum that apparently was neither used nor valued in new entrant classrooms may be addressed by increasing the level of communication between the sectors or by placing more emphasis on the use of the curriculum in the lower primary school. The new curriculum (Ministry of Education, 2007b) may address these issues by specifically linking the competencies in Te Whāriki with the school curriculum, but the knowledge held by teachers of each curriculum needs to be increased.

Teachers in both settings perceived their roles as being similar. There was a contradiction in that new entrant teachers believed their teaching was more indepth and at a higher level, a finding not supported by practice observed in this study. Carr et. al. (2010) found similar evidence confirming the different roles enacted by teachers. They found that early childhood teachers were engaged with children in jointly developing a 'script for learning' (Cullen \& St. George, 1996, p.196). Children had opportunities to initiate learning with teachers supporting them as they made connections across curriculum boundaries. In primary schools teachers developed and enacted the script for learning and children had limited opportunities to make connections between different curriculum areas as the focus was primarily on routines and procedures. It seems that little has changed in new entrant classrooms in the last thirteen years. In this study teachers had not found a balance between creating learning opportunities and a necessary focus on routines and procedures.

An aspect of teaching seemingly overlooked by both kindergarten and new entrant teachers is the necessity of having knowledge of both where the learner is going 
and where they have come from. This understanding of a learning continuum and children's placement on it is overlooked in the new entrant classrooms as the teachers continue to focus on a perceived lack of skills. Teachers in new entrant classrooms did not appear to have up-to-date knowledge of the early childhood curriculum and how it was manifested in action. Kindergarten teachers claimed the new entrant teachers did not recognise or value the competencies children possessed on school arrival, yet they did little to address this lack of knowledge, believing new entrant teachers did not value their input. This lack of knowledge carries the risk that when children go to school their dispositions towards learning may be shut down as they adjust to the new environment (Carr et. al., 2010).

With the exception of one school and its contributing kindergarten, low levels of interaction were present between schools and kindergartens. This was evident in the lack of meaningful communications reported on and the limited number of interactions evident as well as the negative perceptions kindergarten teachers believe new entrant teachers held about kindergarten programmes. This low regard held by primary teachers for early childhood teachers is not particular to this study and is similarly reported by Hopps (2004). Any increase in the level of positive interactions between schools and kindergartens would be an improvement and may lead to developing increasing understanding of the philosophy underlying each other's curriculum. By increasing the communication levels it may be possible for teachers to get over 'talking past each other' (Metge \& Kinloch, 1978) and start listening to each other.

\subsection{Similarities and differences in teacher practice}

A personal communication with a numeracy adviser (Smith, 2/6/06) related an observation of teachers in a school who took control of mathematics learning, allowing children no opportunities to make connections, explain, and explore the mathematics examples presented. Teachers in that school did not provide mathematical examples that enabled children to work mathematically as they believed children lacked the necessary knowledge. The schools in this study were in a different location but teacher practice was similar. The message conveyed here is that new entrant teachers believe children when they come to school do not possess enough knowledge in mathematics to enable them to successfully work 
mathematically. Kindergarten teachers observed children making connections in mathematics on a daily basis, building, playing, constructing, or generating a series of operational rules. Both groups of teachers held similar beliefs about how children best learn mathematics, but these were not evident in new entrant teachers' practice because they had a common observed practice of presenting lessons for children based primarily on the acquisition of skill-based knowledge. Changing beliefs and practice is not an easy task and Anderson et al. (2005, p. 11) state that "no consistent patterns have been identified in facilitating teacher change". Raymond (1997) believed teachers must be encouraged to unpack their own beliefs and develop a coherent philosophy of teaching for themselves before engaging in practice. Teachers need to be supported as they are encouraged to challenge and reflect on their beliefs. Teacher education programmes are paying increasing attention to the development of reflective practice leading to change. However, it may not be enough to influence a wide-spread change in beliefs through the development of reflective practice. Raths (2001) believes a change in beliefs and practice is more likely through the development of positive dispositions towards teaching and learning; others claim that beliefs and practices will change when teachers are shown evidence of student improvement resulting from changes in practice (Guskey, 1986; Muir, 2008; Timperley, 2003).

In this study, kindergarten teachers reported on their changing practice resulting from the introduction of Te Whāriki, the professional development that accompanied it, alongside increased professional discussions and reflecting with their colleagues. This perception of a change of practice was evident in other early childhood settings in New Zealand (Carr et. al., 2010; Stuart et. al., 2008; Ministry of Education, 2004b). New entrant teachers had been given professional development in relation to improving mathematics teaching pedagogy through the Numeracy Project's professional development. This did not yet appear to have had an impact on their beliefs about the learning needs of five-year-old children despite new entrant teachers in this study reporting on their adherence to the Numeracy Project and use of the diagnostic interview for assessment purposes. It may be that professional discussions and reflections with colleagues have not continued past the professional development cycle, as they appear to have in the 
kindergartens. As mentioned in the previous section, increasing levels of communication between the two settings may serve to strengthen understandings of each other and influence teachers' beliefs about children on school entry.

\subsection{Making the transition}

This section explores the differences between teacher practices and beliefs in mathematics learning and teaching in kindergarten and new entrant classrooms that may influence how children make the transition to school. Kindergarten teachers supported children as they explored their environment by following children's individual and collective interests and extending these as they found necessary. Teachers focused on developing positive dispositions towards learning and believed that children left kindergarten with knowledge relating to being successful learners. New entrant teachers in this study held strong beliefs about the knowledge and skills possessed by children on school entry. These beliefs in some cases led to teachers underestimating children's abilities in mathematics. These differing beliefs about children's capabilities may influence how children make the transition to school and whether they are able to make connections from their kindergarten environment to the school environment.

Kindergartens did not, in general, provide information about children to the new entrant teachers unless it was requested. Most information transmitted to the school was anecdotal and was usually transmitted only when the new entrant teacher held concerns about a child. Learning stories were not used as an information source about the dispositions and skills of children. Although new entrant teachers in the study said they assessed children's skill levels in mathematics using the diagnostic interview (Ministry of Education, 2005), it did not appear that this information guided their planning as many instances were observed when children already knew the information the teacher was teaching. Increasing the level of communication between kindergarten and new entrant teachers may help to alleviate this lack of transference of information and perceived lack of knowledge of children. There appeared to be a top-down alignment between kindergartens and new entrant classrooms. New entrant teachers described children moving up to school, a perception not shared by 
kindergarten teachers. At the time of this study, new entrant teachers failed to acknowledge the learning possessed by children on school entry. With the new curriculum (Ministry of Education, 2007b) promoting closer links between the key competencies and learning dispositions from Te Whāriki, it is possible increasing levels of meaningful communications could develop between schools and kindergartens. Specific recognition of early childhood programmes that promote the development of positive dispositions to learning may improve the connections between kindergarten and new entrant teachers with each group developing understanding of what the other does. 'Talking past each other' may become less of an issue as they increase their levels of knowledge about where the children have come from and where they are going to.

New entrant teachers in this study are constrained by the perceived lack of knowledge possessed by children on school entry. This perception appears to over-ride their other beliefs about how children best learn mathematics and lends itself to teachers following a more transmission approach to teaching as they attempt to remedy perceived gaps in children's knowledge. Teachers' beliefs that are embedded within their personal experiences and existing knowledge may not always lead to best practices. Cassidy and Lawrence (2000) suggest that more professional development and discussion that leads to reflection in action may support changes in practice. Increasing professional development may not always be effective as teachers have a tendency to adopt only the 'bits' that suit their existing approaches (Muir, 2008; Mutch, 2003). It is not until increasing levels of student achievement result from the implementation of new practices in the classroom that teachers start to change their beliefs (Guskey, 1986; Muir, 2008). Raths (2001) suggests that changing teacher dispositions to teaching through modelling and reflection may reduce teachers' reliance on specific beliefs.

This study shows kindergarten teachers who said they had been able to change their practices and beliefs with the introduction of Te Whāriki. Through their professional development and continuing reflective practice with their colleagues they said they had changed the way they taught in accordance with the principles underlying their curriculum. These teachers said they had many opportunities to 
discuss their beliefs and practices as they worked in a team during the day, monitoring and observing children in accordance with their curriculum.

New entrant teachers in this study had had at least two years of professional development in teaching mathematics through the Numeracy Project. This professional development aimed to strengthen children's achievement levels by developing teacher practice. While this may be successful in some aspects, it appears from the new entrant teachers in this study that many of their initial practices in mathematics teaching and learning continue to focus on what they believe children do not know. Teachers in new entrant classrooms generally worked alone with opportunities for team or syndicate meetings after school. These meetings did not in general focus on reflective practice, but more on the smooth running and management of the syndicate, children, and teachers.

Building closer relationships and increasing levels of communication between the two environments could lead to increasing dialogue and discussion relating to differing practices. As teachers communicate more, opportunities may arise that build understandings of each other's practices and beliefs. Kindergarten and new entrant teachers may develop joint practices that contribute positively towards supporting children as they make the transition to school. New entrant teachers by developing their knowledge of the kindergarten (and any early childhood setting) may increase their understanding of the knowledge and skills possessed by children on school entry and accordingly adjust their teaching to meet these needs. By increasing their knowledge of school-related practices kindergarten teachers may be able to incorporate some of these practices in their curriculum philosophy to better support children as they go to school.

At the time of this study, differences in the beliefs and practices of the teachers in kindergartens and new entrant classrooms that participated may influence how children make the transition to school. Low levels of communication between schools and kindergartens combined with little knowledge about each other's beliefs and practices may make it challenging for children to make links between the two environments to support them. Lack of information about the learning that occurs in each setting may make it difficult for teachers to understand the 
environment that children have come from and the environment they are going to and may contribute to children experiencing discontinuities in their learning.

\subsection{Connecting the curricula}

This study examined the curriculum documents relating to kindergarten and new entrant teaching and learning. Specific connections are made from Te Whāriki (Ministry of Education, 1996) to the NZCF (Ministry of Education, 1993b) and MiNZC (Ministry of Education, 1992). These documents have clearly stated links to support children as they make the transition to school. These links continue to be made in the New Zealand Curriculum (Ministry of Education, 2007) and are aimed at ensuring children's learning in one environment is supported and built on in the next environment. It is clearly stated that teachers have a responsibility to use children's prior learning and knowledge to build new learning and knowledge. The continuity of learning experiences is an essential part of building successful transitions to school.

The links between Te Whāriki and the school curriculum did not appear to be acknowledged by teachers in this study and both settings operated mostly independently of each other. While kindergarten teachers said they based their teaching on the principles outlined in Te Whāriki, new entrant teachers said their curriculum was not useful or relevant to the perceived needs of the children they taught. This discrepancy between how teachers in each setting perceived their curriculum may be a contributing factor in the differences in teacher practices in mathematics teaching in each setting. Kindergarten teachers were seen to base their practices on Te Whāriki. New entrant teachers said they based their practices on their beliefs about the perceived needs of children and found their curriculum unhelpful when children first came to school.

More links need to be made between kindergartens and new entrant classrooms to strengthen the connections between the two settings and increase the understanding both groups of teachers have of each other. Using the levels of mathematics continuity as developed by Carr et. al (1994) and Dunphy (2006) may provide a way forward for both primary and kindergarten teachers to position children's mathematical competencies along a continuum to support teachers, 
particularly in new entrant classrooms, more accurately teach to meet the actual needs of their students. Likewise the work done by Perry (2000) and Anthony and Walshaw (2007) provide a good framework for teachers to focus on elements of best practice in mathematics teaching and learning to develop positive dispositions towards learning in children leading to increasing student achievement.

\subsection{Recognising the continuity of learning}

Kindergarten teachers provided opportunities for children to develop positive dispositions towards learning and explore and construct their environment in line with the early childhood curriculum. On moving to school children were faced with teachers who were constrained by the aims and objectives of a number of curriculum documents, including mathematics, and who had a focus on management and compliance. A child's identity as a learner also shifts, from being seen by kindergarten teachers as competent and capable to one where they are seen as lacking in knowledge and skills by their new entrant teacher. This may lead to situations where children are under extended, or re-learning existing knowledge as teachers may be unaware of their skills (Aubrey et. al., 2000; Carr et. al., 2010; Young-Loveridge et. al., 1995).

Teacher subject knowledge in mathematics was found to be low in many instances (Aubrey et. al., 2000; Young-Loveridge, 1995) and this study is no exception with most teachers having mathematics up to the high school level only (Appendix U, Section 5.5.2). Evidence shows that increasing teachers' subject knowledge in mathematics has an impact on student achievement and consequently teacher practice and beliefs (Farquhar, 2003; Hedges, 2002). Improving subject content knowledge should be a key focus of teacher professional development programmes in both sectors along with an acknowledgement of the special role of the new entrant teacher.

New entrant teachers need to have the time to get to know children as they come to school, to recognise and make links to their prior learning (Peters, 2010). The underlying curriculum documents support these connections but it is evident from 
this study that there is still a mismatch between teacher practices and beliefs in kindergarten and new entrant classes.

\subsection{Concluding comments}

In general, both groups of teachers expressed dissatisfaction with the process of transition to school and held differing expectations of children and each other. These differing expectations of children lead to differences in teacher practice in new entrant and kindergarten classrooms. While the curriculum documents in use at the time of this study supported close links between education at early childhood institutions and primary schools, this was not evident in the practices observed here.

A closer relationship between schools and early childhood settings may be fostered through the alignment of key competencies and learning dispositions (Carr, 2006; Carr et. al., 2010; Peters, 2010). There is no expectation that the two environments should be the same, but having some similarities and increasing levels of meaningful communication, should contribute towards supporting children, kindergartens, and schools over the transition period. Recognition of the value of learning stories (which contain varying degrees of detail relating to children's achievement) and increasing their usage in new entrant classrooms could further support continuity over the transition period (Peters, 2002). Again it is important to remember that kindergarten teachers and new entrant teachers are working with children over the period of transition to school. Kindergarten teachers work with a group of children who are familiar with their environment, their teachers and their routines prior to school entry. New entrant teachers are working with a group of children from diverse early childhood educational settings who are new to the school system and need to develop familiarity with school ways of doing things. This difference between the two groups of children and the roles of the teachers need to be acknowledged in the interpretation of the information in this study.

The period of transition to school is important for children. Recognition of this through professional development aimed at supporting early childhood teachers 
and new entrant teachers together may support teachers to work more closely. By developing closer relationships between schools and kindergartens, teachers should be better able to explore the commonalities and differences between them. This will support teachers as they develop their understandings of the experiences children have had in order to build on these to support children's future learning. This understanding may contribute towards changing new entrant teachers' beliefs relating to the knowledge possessed by children on school entry and developing kindergarten teachers knowledge about the environment children are going to.

The mathematics examples shown in this study illustrate the difference between teacher practice in kindergartens and in new entrant classrooms. Kindergarten teachers favour an approach that builds on children's existing knowledge and interests. Teachers have the freedom to follow the observed interests of children. New entrant teachers use their beliefs about the knowledge they think children should have on school entry to plan their mathematics programmes. This leads to lessons that focus on building knowledge with little apparent attention paid to children's existing skills and knowledge. If new entrant teachers had the opportunity to work more closely with their colleagues in early childhood settings and see what children are capable of before school entry, it is possible new entrant teachers' perceptions of children's knowledge might change. The differing styles of learning observed in kindergartens and new entrant classrooms pose a challenge for children as they make the transition to school with a potential impact on children's learning (Carr et. al., 2010; Fabian, 2007; Peters, 2010).

Schools and kindergartens have a responsibility to reduce potential disruptions to learning over the transition period. Common links between the two environments would support children as they move from a usually more informal setting to the usually more formal setting of school. It is generally held that some discontinuities over the transition period can be beneficial (Clark \& Lovric, 2008) and the process of developing strategies to deal with transition is important (Fabian, 2007), but it is important there are shared understandings and approaches to learning across both settings (Carr et. al., 2010; McNaughton, 1998). If teachers are seen to value experiences from both settings, children are more likely to find commonalities as they make the transition to school. 
Overall there are differences in the mathematics teaching and learning that occurs in the kindergartens and new entrant classrooms which may effect how children develop mathematically at school. Kindergarten teachers allow children freedom to explore and develop their ideas and support them on some occasions as this occurs. Teaching is characterised by teachers working to support children as they explore the environment around them supported with the philosophy underpinned by Te Whāriki. New entrant teachers, although having many similar beliefs to kindergarten teachers, focus on skills they perceive to be lacking in children on school entry. This focus influenced the nature of the teaching programmes observed in new entrant classrooms where teachers were observed to be concerned with filling gaps in children's knowledge and ensuring good classroom routines. In many instances this overriding focus for new entrant teachers resulted in children being taught mathematical understandings that they had already mastered.

The curriculum documents in New Zealand, including the New Zealand Curriculum (Ministry of Education, 2007b) clearly outline the continuity of education from early childhood through to secondary school and explicitly link Te Whāriki with the school curriculum. Teachers have a responsibility to develop these links to support the transition of children to school. The New Zealand Curriculum (2007b) has the potential for a greater degree of freedom and flexibility for teachers to determine the detail of learning. This may give teachers opportunities to explore and make connections to children's prior knowledge and skills provided that the re-introduction of National Standards (Ministry of Education, 2008) does not constrain teachers' abilities to do this. National Standards have only been in force for a limited period at the time of writing this but anecdotal evidence already indicates an impact on teacher practices that is not positive (May, in press).

Further research on developing a framework for early mathematics development in kindergartens and new entrant classrooms and positioning this alongside Te Whāriki and the New Zealand Curriculum (2007b) may serve as a means of increasing teachers' understandings of children's mathematical development and competencies. Making these links between kindergarten and new entrant 
10: Conclusion: Compatibility of early childhood and new entrant teacher practices and beliefs

classrooms more explicit could lead to an increase in the communication levels as teachers become more aware of the commonalities between their curricula and the common outcomes sought. 


\section{Appendix A: Information for principals and new entrant teachers regarding study}

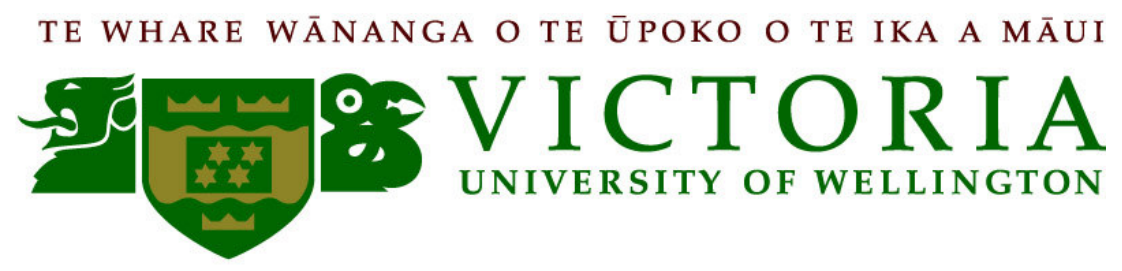

Dear

My name is Brenda Sherley and I am working as a Numeracy Adviser at Victoria University of Wellington. I am undertaking research directed at the transition of children from Kindergarten to Primary Schools in the area specifically relating to mathematics education. My Master's thesis looked at quality issues in early childhood education and now I am looking at the documentation that underpins Kindergarten Education and the beliefs and practices of teachers as they translate this document into practice in their programmes.

The research will involve two interviews with each teacher exploring their beliefs about early childhood mathematics education and how children learn best alongside two observation sessions to observe teacher beliefs in action. The interviews will be semi-structured and will take up to one hour and the observations will cover the morning sessions at school. All the data that is gathered and all interview transcripts will be written up and presented to each relevant participant for their input before it is used in any way in this study. The children will not be specifically observed as I am more interested in teacher practice.

Every effort will be made to ensure that the information gathered will remain confidential to the researcher and the participant. No participant will able to be directly identified once this study is complete and neither will the schools or the kindergartens. Information gathered in this research will be used to complete a doctoral study and in relevant follow-up work (publications and conference presentations). I hope that from this study a comprehensive picture will be built of the compatibility of teacher practice and beliefs in mathematics in kindergartens 
and primary schools and some recommendations will arise relating to the teaching of mathematics and the transition to school.

Should you wish for a summary of the final report please let me know and I will send this out on completion of the thesis.

Thank you for your time.

Yours sincerely

Brenda Sherley

\section{Contacts}

brenda.sherley@vuw.ac.nz

School of Primary and Secondary Teacher Education

Victoria University of Wellington

Phone: 044639611

Supervisors:

Associate Professor Megan Clark

School of Mathematics, Statistics and Computer Science

Victoria University of Wellington

Phone: 044636738

megan.clark@vuw.ac.nz

Dr. Joanna Higgins

School of Primary and Secondary Teacher Education

Victoria University of Wellington

Phone: 044639576

joanna.higgins@vuw.ac.nz 


\section{Appendix B: Consent form for teachers and principals.}

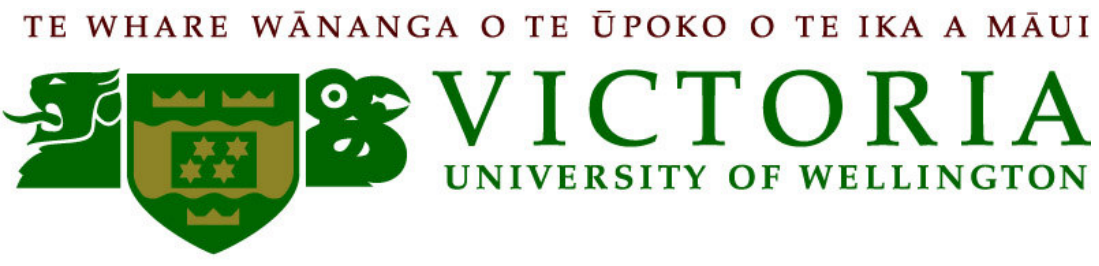

I consent to taking part in this study and I am willing to take part in interviews and classroom observation.

I understand that the information gathered will be given back to me for moderation before it is used in any way.

I understand that I can withdraw from this study at any time.

I understand that I can request an overview of the study on completion.

I understand that I will not be identified in any way in the study.

Name

Date. 


\section{Appendix C: Information letter for kindergartens participating in this study}

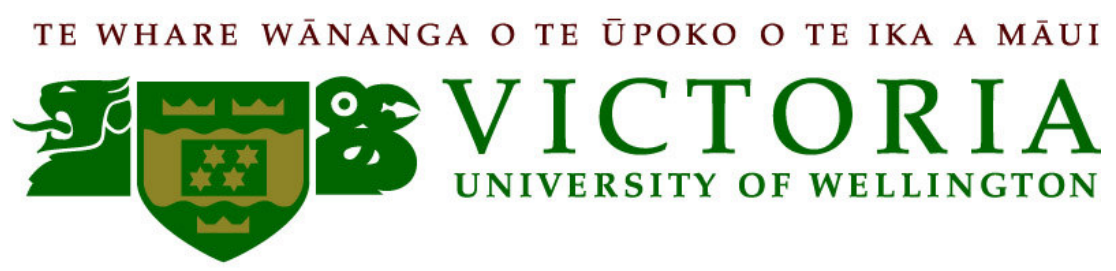

School of Primary and Secondary Education

Victoria University of Wellington

P.O. Box 17310

Karori

Wellington

To the Principal and Teachers at Kindergarten

My name is Brenda Sherley and I am working as a Numeracy Adviser at Victoria University of Wellington. I am undertaking research directed at the transition of children from Kindergarten to Primary Schools in the ------------- area specifically relating to mathematics education. My Master's thesis looked at quality issues in early childhood education and now I am looking at the documentation that underpins Kindergarten Education and the beliefs and practices of teachers as they translate this document into practice in their programmes.

The research will involve two interviews with each teacher exploring their beliefs about early childhood mathematics education and how children learn best alongside two observation sessions to observe teacher beliefs in action. The interviews will be semi-structured and will take up to one hour and the observations will cover a full session at kindergarten. All the data that is gathered and all interview transcripts will be written up and presented to each relevant participant for their input before it is used in any way in this study. The children will not be specifically observed as I am more interested in teacher practice. 
Every effort will be made to ensure that the information gathered will remain confidential to the researcher and the participant. No participant will able to be directly identified once this study is complete and neither will the schools or the kindergartens. Information gathered in this research will be used to complete a doctoral study and in relevant follow-up work (publications and conference presentations). I hope that from this study a comprehensive picture will be built of the compatibility of teacher practice and beliefs in mathematics in kindergartens and primary schools and some recommendations will arise relating to mathematics teaching and the transition to school.

Should you wish for a summary of the final report please let me know and I will send this out on completion of the thesis.

Thank you for your time.

Brenda Sherley

\section{Contact Details}

Brenda Sherley

School of Primary and Secondary Teacher Education

Victoria University of Wellington

Phone: 044639611

Email: Brenda.Sherley@vuw.ac.nz

Supervisors:

Associate Professor Megan Clark

School of Mathematics, Statistics and Computer Science

Victoria University of Wellington

Phone: 044636738

megan.clark@vuw.ac.nz

Dr. Joanna Higgins

School of Primary and Secondary Teacher Education

Victoria University of Wellington

Phone: 044639576

joanna.higgins@vuw.ac.nz 


\section{Appendix D: Consent form for kindergarten teachers}

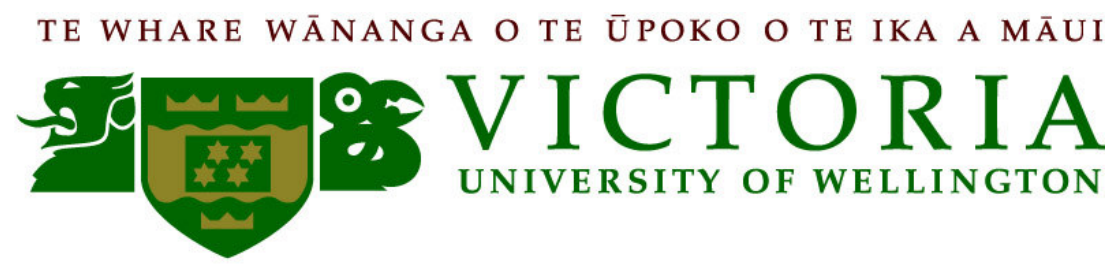

I consent to taking part in this study and I am willing to take part in interviews and kindergarten observation.

I understand that the information gathered will be given back to me for moderation before it is used in any way.

I understand that I can withdraw from this study at any time.

I understand that I can request an overview of the study on completion.

I understand that I will not be identified in any way in the study.

Name.

Date 


\section{Appendix E: Semi-structured interview questions for new entrant teachers}

Interview Schedule: Semi structured

1 Demographic questions: Qualifications, experiences, training and setting

2 How do you think children best learn mathematics? (Kinds of experiences provided, teacher role, range of activities, kinds of interactions sought)

3 How do you decide what is important for you to teach in mathematics?

a Curriculum Documents (influence of MiNZC, Te Whariki, NZCF) Do they impact or are they just there?

b School Policy (who developed it, how many documents, kind of guidance provided, perceived value)

c Long term plans, planning requirements, daily/weekly/ unit plans, own input into direction of learning etc

d Constraints upon practice: Parental influences etc

4 To what extent do you think your practices and beliefs are driven by external factors? Do you believe that you are setting the foundations for future learning or something more than this ie real teaching? What do you believe your role is?

5 What expectations do parents have of you regarding their child's mathematical development? How do you meet these expectations?

6 What do you believe is important for you to develop in your mathematics programme? (General beliefs about how children learn/develop mathematical skills) Where do you think your beliefs about how children learn mathematics come from?

7 How do you encourage learning in young children? (any evidence of systematic progressions, basis for deciding what is important, impact of daily school life)

8 What provision do you make in your programme for mathematical learning? (any fixed events, timetabled maths, maths corner etc.) What expectations do you have regarding the mathematical development of young children? 
9 How do you record your knowledge of children's mathematical development and what happens to this information? Assessment information. (look for evidence of passing information on to primary school, or gathering knowledge from children's parents etc)

10 What is your own background in mathematics, i.e. highest level achieved?

11 Influence of Kindergarten/Year one teachers, what perception do they have of each other's practice and constraints, any suggestions for transition ease, any conflicting beliefs or perceptions. Do you believe your role is the same as that of a kindergarten teacher? What information comes to you from the preschool?

12 Is there anything else you would like to share with me about your mathematical practices? (parental expectations of the teacher?) What is your view of the ideal parent? Do you think that parents at decile one schools are any different from parents at higher decile schools?

Describe experiences based on current practices, reflect on the methods used to familiarise themselves with their new intake of children and describe issues and concerns (Cassidy, 2005)

Questions for the second interview will arise from the results of the first interview and observation sessions and seek further clarification of ideas. 


\section{Appendix F: Questionnaires for kindergartens: modified as a result of teacher preferences}

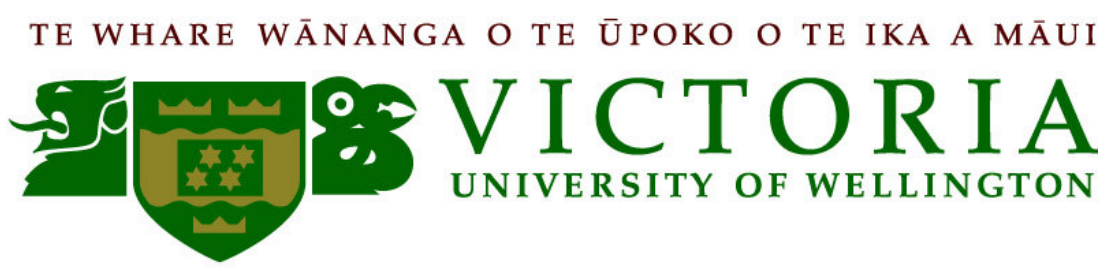

Questionnaire: Kindergarten

1 Demographic information:

Male/Female

Highest qualification

Years of experience

Additional training

Highest personal level of mathematics

2 How do you think children best learn mathematics?

3 How do you decide what is important for you to teach in mathematics at this level? (Official documents, personal views, policies etc.)

4 How do you encourage learning in young children? What provisions do you make in your Kindergarten programmes to develop mathematical learning?

5 What are your personal beliefs about how children learn? Where do you think your beliefs about how children learn best in mathematics come from?

6 To what extent do parents influence what you teach? How do you inform the parents about their child's progress in mathematics? Do parental expectations of their children influence your programme?

7 How do you use Te Whariki to guide your teaching?

8 To what extent do you believe your practices and beliefs are driven by external factors?

9 How do you record your knowledge of the children's mathematical development and what happens to this information? 
10 What information do you collect in order to pass on to the primary school? How do you record this information? Do schools ask for information from you?

11 What do you think the primary school expects of the children who come from Kindergarten? Do you agree with their expectations?

12 What is your role as a Kindergarten teacher in the child's education? Is there a difference between your role and that of the primary teacher?

13 What do you do to ensure a smooth transition to school? What do you think could be done better?

14 Do you think that there are any significant differences between your expectations of the children and the expectations of the Primary School?

15 What would be the ideal relationship between school and Kindergarten in terms of ensuring a smooth transition?

16 Are there any further issues that you believe are important when looking at children's mathematical development and the smooth transition to school?

Thank you for your time. It is very much appreciated.

Brenda Sherley

Brenda.sherley@vuw.ac.nz

044639611 


\section{Appendix G: Semi-structured interview questions for principals}

1 What expectations do you have of your staff in teaching mathematics? How do you know your expectations are met?

2 Do you expect your staff to have a degree of knowledge regarding the curriculum documents, ie NZCF and MiNZ? What do they use to inform their planning in mathematics? Do they use the curriculum documents?

3 What expectations do your parents have at this school of the children and the teachers?

4 What expectations do you have of your teachers regarding assessment in Numeracy?

5 What expectations do you have of children who come here from kindergarten?

6 Have you noticed any changes over time in your new entrant children's mathematical ability or the skills they enter school with?

7 Do you think that your new entrant children are challenged in their learning? 


\section{Appendix H: Interview dates with principals and comments}

\begin{tabular}{|c|c|c|}
\hline School or kindergarten & Date & Comment \\
\hline Aorangi & June 2006 & $\begin{array}{l}\text { New principal recently } \\
\text { from a new entrant } \\
\text { classroom }\end{array}$ \\
\hline Cascade & June 2006 & $\begin{array}{l}\text { Experienced principal, } \\
\text { more than five years in } \\
\text { the school }\end{array}$ \\
\hline Dundass & March 2006 & $\begin{array}{l}\text { Experienced principal, } \\
\text { more than } 10 \text { years in } \\
\text { the school }\end{array}$ \\
\hline Hikurangi & May 2006 & $\begin{array}{l}\text { Last year before } \\
\text { principal's retirement }\end{array}$ \\
\hline Tongariro & August 2006 & $\begin{array}{l}\text { Experienced principal, } \\
\text { more than } 15 \text { years in } \\
\text { the school }\end{array}$ \\
\hline $\begin{array}{l}\text { All kindergarten head } \\
\text { teachers }\end{array}$ & $\begin{array}{l}\text { Included in the teacher } \\
\text { dates for kindergartens }\end{array}$ & $\begin{array}{l}\text { Kindergarten head } \\
\text { teachers' information } \\
\text { gathered with general } \\
\text { questionnaires. }\end{array}$ \\
\hline
\end{tabular}




\section{Appendix I: Amendments to interview questions resulting from trials}

\section{Demographic questions.}

\section{How do you think children best learn mathematics?}

The new entrant teacher had firm views about the kinds of strategies and knowledge children needed to learn mathematics but these were not related to any research evidence. For example, in her view, children learned mathematics by doing it, by being given experiences, by being ready to learn and practicing and so on. This question was in fact too broad and as an initial question it didn't elicit the kind of information that was expected. The kindergarten teacher described what she wanted the children to learn and what she wanted to teach the children but not a methodology for teaching. Neither teacher described a theory of learning.

\section{How do you decide what is important for you to teach in mathematics?}

The classroom teacher detailed the process of how they (all junior teachers in her school) decided what to teach, firstly from the year plan and the Numeracy project material followed by "other stuff" as they deem it to be important.

The kindergarten teacher said that her kindergarten followed Te Whariki and the activities were planned in advance to meet the children's needs. The teachers collectively determined the children's needs based on their (teachers) views and then planned to meet them although there was scope to capitalise on specific children's interests.

4 To what extent do you think your practices and beliefs are driven by external factors?

The response to this question "time, never enough" indicated that further elaboration was required in order to determine what drove teacher practice; curriculum documents, research, their prior experiences and other factors.

5 What expectations do parents have of you regarding their child's mathematical development? How do you meet these expectations?

6 What do you believe is important for you to develop in your mathematics programme? 
The important thing for this teacher was developing the appropriate language and background for the children in order to create an environment in which they could succeed. Part of her own personal response to this question was in terms of her own attitude towards mathematics and overcoming her own inhibitions regarding mathematical ability and knowledge.

The kindergarten teacher believed that the children needed a chance to explore and develop their ideas in their own way.

It was clear that I needed to ensure that the teachers elaborated further in this area to get past their own feelings to their specific beliefs about what was important in teaching mathematics.

\section{How do you encourage learning in young children?}

This question worked very well and elicited a lot of valuable and useful information without extra probing. The gist of the response from both teachers was that they had to ensure that learning was fun.

\section{What provision do you make in your programme for mathematical} learning?

9 How do you record your knowledge of children's mathematical development and what happens to this information? (Look for evidence of passing information on to primary school, or gathering knowledge from children's parents etc)

This question needed further development in that the responses dealt primarily with recording the information gathered on the child from observations, anecdotal evidence and recording planning. Questions regarding prior information gathered and used or passed on information about the children's abilities still had to be asked as this information was not forthcoming.

10 What is your own background in mathematics?

11 Influence of kindergarten/year one teachers, what perception do they have of each other's practice and constraints, any suggestions for transition, and conflicting beliefs or perceptions. Do you believe your role is the same as that of a kindergarten teacher? What information comes to you from the pre-school? 
Kindergarten \& New Entrant Teachers' Beliefs \& Practices in Mathematics Teaching \& Learning

\section{Is there anything else you would like to share with me about your mathematical practices?}

This open-ended question worked well.

Questions 5, 8, 10, and 11 did not need further elaboration as both teachers in the pilot study responded in full to the intent of each question. 


\section{Appendix J: Observations and observation schedule}

\section{Observations}

\section{Two pronged}

7. Anecdotal evidence of mathematics teaching and learning segments, recording of discussions as they occur. The aim of these is to capture the oneoff sessions and interactions that arise during the course of the day that are related to mathematics.

8. Interval recording of what is happening in the classroom in relationship to the teacher. (Include some snapshots of teacher behaviour and interaction

Information will be collated and categorised after the event.

Narrative Checklist of mathematical events to be developed.

The second observation session will follow a similar format and seek to fill in gaps from first session and look for more incidental mathematics events.

\begin{tabular}{|l|l|l|l|}
\hline School: & \multicolumn{2}{|l|}{} & $\begin{array}{l}\text { Comments/ Observation Details/ } \\
\text { Date: }\end{array}$ \\
Time: & \multicolumn{2}{|l|}{} & \\
Present: & \multicolumn{2}{|l|}{} & \\
\hline Time & $\begin{array}{l}\text { Teacher } \\
\text { Activity }\end{array}$ & Description & \\
\hline & & & \\
& & & \\
\hline
\end{tabular}

Page spread of observation schedule. 


\section{Appendix K: Table for classification of major themes relating to teacher beliefs}

Teachers' beliefs about curriculum, learning and teaching of mathematics in New Zealand kindergartens and new entrant classrooms

\begin{tabular}{|l|l|l|}
\hline Area of belief & $\begin{array}{l}\text { Major themes from } \\
\text { new entrant teachers }\end{array}$ & $\begin{array}{l}\text { Major themes from } \\
\text { kindergarten teachers }\end{array}$ \\
\hline $\begin{array}{l}\text { Place of Overall } \\
\text { curriculum } \\
\text { Te Whariki } \\
\text { MiNZC }\end{array}$ & & \\
\hline $\begin{array}{l}\text { Place of Mathematics in } \\
\text { the curriculum }\end{array}$ & & \\
\hline $\begin{array}{l}\text { How children learn } \\
\text { Role of teacher in } \\
\text { children's learning }\end{array}$ & & \\
\hline
\end{tabular}

Source: Adapted from (McLachlan-Smith \& St George, 2000). 


\section{Appendix L: Analysis of 'typical' events in mathematics}

The following table was used to support analysis of 'typical' mathematical events within both kindergarten and primary school settings.

\begin{tabular}{|l|l|l|l|l|l|l|}
\hline $\begin{array}{l}\text { Group } \\
\text { structure }\end{array}$ & Discourse & Math & $\begin{array}{l}\text { Materials } \\
\text { used }\end{array}$ & $\begin{array}{l}\text { Teacher } \\
\text { activity }\end{array}$ & $\begin{array}{l}\text { Pupil } \\
\text { activity }\end{array}$ & Comments \\
\hline & & & & & & \\
\hline
\end{tabular}




\section{Appendix M: Kindergarten environment}

\begin{tabular}{|c|c|c|}
\hline Kindergarten & $\begin{array}{l}\text { Mathematical displays } \\
\text { (multilingual in every } \\
\text { kindergarten) }\end{array}$ & $\begin{array}{l}\text { Mathematical equipment (in } \\
\text { Māori as well as English) }\end{array}$ \\
\hline Aorangi & $\begin{array}{l}\text { Good range including: } \\
\text { - } \quad \text { Number charts } \\
\text { - } \quad \text { Number puzzles } \\
\text { - } \quad \text { Shape pictures } \\
\text { - } \quad \begin{array}{l}\text { Portfolios available for } \\
\text { everyone }\end{array} \\
\text { - } \quad \begin{array}{l}\text { Explanation of learning } \\
\text { goals for mathematics }\end{array}\end{array}$ & $\begin{array}{l}\text { Wide variety of indoor and } \\
\text { outdoor mathematical equipment, } \\
\text { blocks, puzzles books etc. }\end{array}$ \\
\hline Cascade & 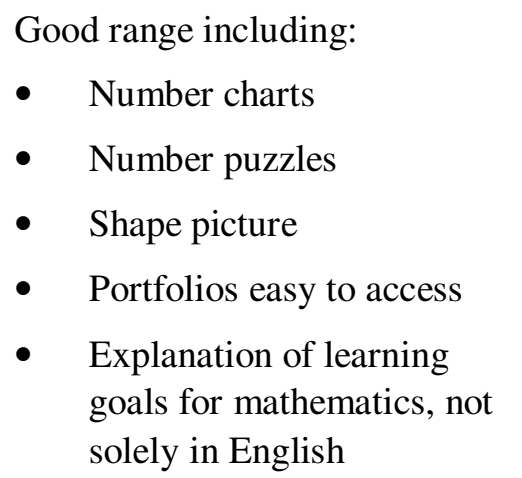 & $\begin{array}{l}\text { Wide variety of indoor and } \\
\text { outdoor equipment. } \\
\text { Books related to mathematics }\end{array}$ \\
\hline Dundass & $\begin{array}{l}\text { Good range including: } \\
\text { - } \quad \text { Number charts } \\
\text { - } \quad \text { Number puzzles } \\
\text { - } \quad \text { Shape pictures } \\
\text { - } \quad \begin{array}{l}\text { Examples of group learning } \\
\text { stories for mathematics }\end{array} \\
\text { - } \quad \text { Easily accessible portfolios } \\
\text { - } \quad \begin{array}{l}\text { Explanation of learning } \\
\text { goals for mathematics }\end{array}\end{array}$ & $\begin{array}{l}\text { Books, puzzles, blocks, collage, } \\
\text { outdoor play equipment. } \\
\text { Books related to mathematics }\end{array}$ \\
\hline Hikurangi & $\begin{array}{l}\text { Good range including: } \\
\text { - } \quad \text { Number charts } \\
\text { - } \quad \text { Number puzzles } \\
\text { - } \quad \text { Shape picture } \\
\text { - } \quad \text { Portfolios easily accessible } \\
\text { - } \quad \text { Explanation of learning } \\
\quad \text { goals for mathematics }\end{array}$ & $\begin{array}{l}\text { Wide variety of equipment, } \\
\text { blocks, puzzles, games, paint, } \\
\text { outdoor equipment and books. }\end{array}$ \\
\hline
\end{tabular}




\begin{tabular}{|c|c|c|}
\hline Kindergarten & $\begin{array}{l}\text { Mathematical displays } \\
\text { (multilingual in every } \\
\text { kindergarten) }\end{array}$ & $\begin{array}{l}\text { Mathematical equipment (in } \\
\text { Māori as well as English) }\end{array}$ \\
\hline Tongariro & 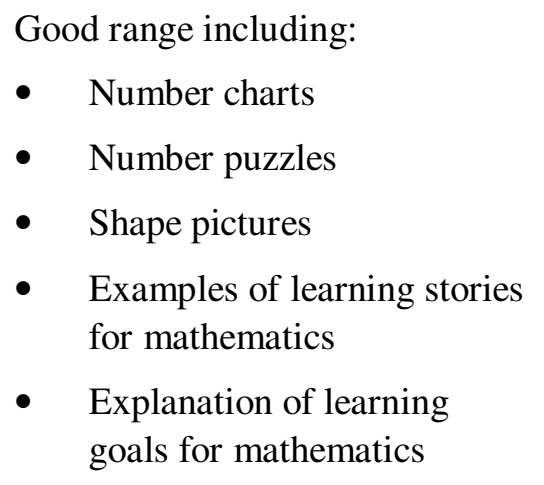 & $\begin{array}{l}\text { Good variety of equipment as for } \\
\text { Hikurangi kindergarten. }\end{array}$ \\
\hline $\begin{array}{l}\text { General } \\
\text { environment }\end{array}$ & \multicolumn{2}{|c|}{$\begin{array}{l}\text { Indoor outdoor flow } \\
\text { Literacy and numeracy areas } \\
\text { Areas for blocks, puzzles, art activities, collage } \\
\text { Home corner, including play kitchen, dolls, etc } \\
\text { Central mat area } \\
\text { Music space } \\
\text { Large outdoor play equipment including bars, bikes, slides, sand, and } \\
\text { large toys } \\
\text { Wide variety of displays for both children and parents } \\
\text { Well-labelled storage areas } \\
\text { Curriculum statements displayed } \\
\text { Use English and other languages (mainly Māori and Samoan) for } \\
\text { signage } \\
\text { Water play, dough and wood work activities were evident }\end{array}$} \\
\hline
\end{tabular}


Appendix N: Comparison of kindergarten teacher beliefs, observed practices, and student activity

\begin{tabular}{|c|c|c|c|}
\hline Kindergarten & $\begin{array}{l}\text { Teacher beliefs } \\
\text { about how } \\
\text { children learn } \\
\text { mathematics. }\end{array}$ & $\begin{array}{l}\text { Observed teacher } \\
\text { practice }\end{array}$ & $\begin{array}{l}\text { Observed } \\
\text { responses from } \\
\text { children }\end{array}$ \\
\hline Aorangi & $\begin{array}{l}\text { Informally } \\
\text { Real-life contexts } \\
\text { Encourage and } \\
\text { support peer } \\
\text { learning } \\
\text { Providing } \\
\text { stimulating } \\
\text { resources }\end{array}$ & $\begin{array}{l}\text { Teachers interacted } \\
\text { with the children to } \\
\text { further develop } \\
\text { children's learning } \\
\text { Teachers spent } \\
\text { time talking with } \\
\text { children to } \\
\text { establish interests } \\
\text { Teachers } \\
\text { systematically } \\
\text { observed and } \\
\text { recorded events } \\
\text { and behaviours }\end{array}$ & $\begin{array}{l}\text { Children engaged } \\
\text { in activities } \\
\text { Children able to } \\
\text { select activities } \\
\text { following own } \\
\text { interests } \\
\text { Children } \\
\text { persevered at tasks } \\
\text { for up to } \\
30 \text { minutes }\end{array}$ \\
\hline Cascade & $\begin{array}{l}\text { Children learn } \\
\text { through play } \\
\text { Incorporating } \\
\text { mathematics into } \\
\text { games and } \\
\text { language } \\
\text { Children make own } \\
\text { choices } \\
\text { Provision of wide } \\
\text { range of equipment } \\
\text { Mathematics arises } \\
\text { naturally from } \\
\text { experiences }\end{array}$ & $\begin{array}{l}\text { Teachers involved } \\
\text { in following the } \\
\text { children's interests } \\
\text { Teachers did } \\
\text { nothing for } \\
\text { children that they } \\
\text { were capable of } \\
\text { achieving for } \\
\text { themselves } \\
\text { Teachers } \\
\text { systematically } \\
\text { observed and } \\
\text { recorded events } \\
\text { and behaviours }\end{array}$ & $\begin{array}{l}\text { Children spent } \\
\text { time reflecting on } \\
\text { their own learning } \\
\text { (using portfolios) } \\
\text { Children } \\
\text { persevered at tasks } \\
\text { for up to } 30 \\
\text { minutes } \\
\text { Children able to } \\
\text { select activities } \\
\text { following own } \\
\text { interests }\end{array}$ \\
\hline
\end{tabular}




\begin{tabular}{|c|c|c|c|}
\hline Kindergarten & $\begin{array}{l}\text { Teacher beliefs } \\
\text { about how } \\
\text { children learn } \\
\text { mathematics. }\end{array}$ & $\begin{array}{l}\text { Observed teacher } \\
\text { practice }\end{array}$ & $\begin{array}{l}\text { Observed } \\
\text { responses from } \\
\text { children }\end{array}$ \\
\hline Dundass & $\begin{array}{l}\text { Hands on } \\
\text { experiences } \\
\text { Trial and error } \\
\text { Meaningful context } \\
\text { Teacher supports } \\
\text { and extends } \\
\text { learning } \\
\text { Teacher scaffolds } \\
\text { learning } \\
\text { Encourage active } \\
\text { explorations } \\
\text { Use of open ended } \\
\text { activities } \\
\text { Teachers work } \\
\text { alongside children }\end{array}$ & $\begin{array}{l}\text { Teachers did } \\
\text { nothing for } \\
\text { children that they } \\
\text { were capable of } \\
\text { achieving for } \\
\text { themselves } \\
\text { Teacher } \\
\text { conversations with } \\
\text { children develop } \\
\text { from the children's } \\
\text { interests } \\
\text { Teachers } \\
\text { systematically } \\
\text { observed and } \\
\text { recorded events } \\
\text { and behaviours }\end{array}$ & $\begin{array}{l}\text { Children engaged } \\
\text { in sustained } \\
\text { activity without } \\
\text { teacher direction } \\
\text { Children use } \\
\text { teachers to } \\
\text { progress, support } \\
\text { or extend their } \\
\text { activities but not to } \\
\text { initiate } \\
\text { Children able to } \\
\text { select activities } \\
\text { following own } \\
\text { interests }\end{array}$ \\
\hline Tongariro & $\begin{array}{l}\text { Through play and } \\
\text { meaningful, } \\
\text { relevant } \\
\text { experiences } \\
\text { Wide range of } \\
\text { exciting resources } \\
\text { provided } \\
\text { Working alongside } \\
\text { children } \\
\text { Allowing children } \\
\text { to make their own } \\
\text { choices and } \\
\text { building from these }\end{array}$ & $\begin{array}{l}\text { Teacher } \\
\text { conversations with } \\
\text { children develop } \\
\text { from the children's } \\
\text { interests } \\
\text { Teachers building } \\
\text { own knowledge in } \\
\text { response to } \\
\text { children's interests, } \\
\text { for example in their } \\
\text { increasing } \\
\text { commitment to the } \\
\text { Māori language }\end{array}$ & $\begin{array}{l}\text { The children } \\
\text { actively seek out } \\
\text { teachers to discuss } \\
\text { their ideas } \\
\text { Children engaged } \\
\text { in sustained } \\
\text { activity without } \\
\text { teacher direction } \\
\text { for up to } 20 \\
\text { minutes } \\
\text { Children spent } \\
\text { time reflecting on } \\
\text { their own learning } \\
\text { (using portfolios) }\end{array}$ \\
\hline
\end{tabular}




\section{Appendix O: Transcript of teacher documentation of water play at Hikurangi kindergarten}

Note: This is a typed copy of the original notes before they were typed up as a learning story and inserted into the participating children's portfolios.

Date: 16 May 2007

Ben, Carly, Joshua and Susan [non-identifying pseudonyms assigned by researcher]

Children playing with water trough and two plastic tubs. Ben and Carly have linked the tubs with open pipes so water can flow from one to the other. Joshua and Susan are playing with the containers in the main trough, soap scoops and buckets, and tipping water from one container to another.

Ben starts filling up film canisters with water, putting the lids on and lining them up along one of the plastic pipes. Carly counts them 1, 2,3, 4, 5 pointing to each one and then joins in helping him fill the canisters.

Joshua and Susan stop what they are doing to watch as the line of canisters grows but don't join the activity. Carly counts the new number to 20 pointing to each one as she goes, Ben joins in the counting modelling her by pointing to each one, he is able to count accurately to 4 , and knows number names to 25 but not the teen numbers.

Carly and Ben are working together and sharing ideas and equipment, Joshua and Susan are interested in watching but don't join in the counting. As Carly and Ben begin to empty our their containers the other two go back to their individual explorations with water.

Communication: talking to each other about what they are doing and co-operating Sharing: working together

Mathematics: Counting and ordering, number names, one to one Language: supporting each other

Contribution: co-operative play

(Six photographs taken by teacher to be used when she wrote the learning story.) 


\section{Appendix P: Lesson plan}

\begin{tabular}{|c|c|c|c|c|c|}
\hline & Number Plan & $\checkmark$ Entrance & Week 5 & Term 1 & \\
\hline Hot Spot Focus: Ro & e counting to $5 / 10 / 2$ & $0 \quad$ Counting backw & rds from 15 & & \\
\hline Lily pad/jump on nos & to 10 before and af & er to 10 & & & . \\
\hline $\begin{array}{l}\text { Knowledge Learning } \\
\text { Outcome }\end{array}$ & Lesson one & Lesson two & Lesson three & Lesson four & Maths Unit Focus \\
\hline $\begin{array}{l}\text { Identify the nos } 0-20 \\
\text { Count to and from } 15 \\
\text { Before and after to } 10 \\
\text { Order 0-10 } \\
\text { Recognise parterns to } 10 \\
\text { Count / form set of objects } \\
\text { to } 10 / 20 \\
\text { Whole class }\end{array}$ & $\begin{array}{l}\text { Clapping counting to } 20 \\
\text { and backwards from } 15 \text {. } \\
\text { Make me } 0-10 \text { with your } \\
\text { fingers (in pairs) } \\
\text { Making sets to } 10 \\
\text { Standing in no order } 0 \text { - } \\
10\end{array}$ & $\begin{array}{l}\text { Clapping counting to } 20 \\
\text { and backwards from } 15 \\
\text { Make me 0-10 with your } \\
\text { fingers (in pairs) } \\
\text { Making sets to } 10 \\
\text { Standing in no order 0- } \\
10\end{array}$ & $\begin{array}{l}\text { Clapping counting to } 20 \\
\text { and backwards from } 15 \\
\text { Make me } 0-10 \text { with your } \\
\text { fingers (in pairs) Making } \\
\text { sets to } 10 \text { Standing in no } \\
\text { order } 0-10\end{array}$ & $\begin{array}{l}\text { Clapping counting to } 20 \\
\text { and backwards from } 15 \\
\text { Make me } 0-10 \text { with your } \\
\text { fingers (in pairs) Making } \\
\text { sets to } 10 \text { Standing in no } \\
\text { order 0-10 }\end{array}$ & $\begin{array}{l}\text { MEASUREMENT } \\
\text { LENGTH } \\
\text { Jaspers Beanstalk } \\
\text { length height } \\
\text { Long longer longest } \\
\text { what happened next/ } \\
\text { before }\end{array}$ \\
\hline GROUP $11-10$ & $\begin{array}{l}\text { Focus on number } 3 \\
\text { Make from play dough } \\
\text { copy cut paste match } \\
3 \text { objects } 1-1 \text { counting }\end{array}$ & $\begin{array}{l}\text { Lily pad } \\
\text { Jump on } \\
0,1,2,3 \\
3 \text { objects 1-1 counting }\end{array}$ & $\begin{array}{l}\text { Repeat lily pad } \\
\text { Find numbers on } \\
\text { number fans } 0,1,2,3 \\
\text { Cut paste three from } \\
\text { magazines }\end{array}$ & $\begin{array}{l}\text { Play dough numbers } \\
\text { make number then roll } \\
\text { balls to represent the } \\
\text { number } \\
1,2,3\end{array}$ & $\begin{array}{l}\text { WEDNESDAY } \\
\text { MATHSS ACTIVITIES } \\
\text { Threading beads- } \\
\text { repeating patterns } 1-1 \\
\text { matching } \\
\text { Connecti-geo shanes }\end{array}$ \\
\hline GROUP $20-20$ & $\begin{array}{l}\text { Number lines } \\
0 \text {-20 finding numbers } \\
\text { out of sequence } \\
\text { Make number in pairs } \\
\text { on fingers } 10 \text { and } \\
\text { makes }\end{array}$ & $\begin{array}{l}\text { Lily pad } \\
\text { Sets to twenty / ten } \\
\text { and make teen nos }\end{array}$ & $\begin{array}{l}\text { Use number fans to } \\
\text { make teen numbers as } \\
\text { a group and in pairs }\end{array}$ & $\begin{array}{l}\text { Abacus } \\
\text { Make teen numbers in } \\
\text { pairs check each } \\
\text { others. } \\
\text { Make number before }\end{array}$ & $\begin{array}{l}\text { Play dough numers- } \\
\text { identifying/making nos } \\
\text { representing amounts } \\
\text { Zoo animals-geo shpes } \\
\text { cages-1-1 matching }\end{array}$ \\
\hline AI T wark in & roup sharing my id & id the maths equif & & & \\
\hline & 10 & - & & & \\
\hline & & & & & \\
\hline
\end{tabular}




\section{Appendix Q: Long-term plan}

\begin{tabular}{|c|c|c|c|c|c|c|c|c|c|c|c|}
\hline & WEEK 1 & WEEK 2 & WEEK 3 & WEEK 4 & WEEK 5 & WEEK 6 & WEEK 7 & WEEK 8 & WEEK 9 & WEEK 10 \\
\hline & & \begin{tabular}{l|l|}
$7-10$ \\
February
\end{tabular} & $\begin{array}{l}13-17 \\
\text { February }\end{array}$ & \begin{tabular}{|l|}
$20-24$ \\
February
\end{tabular} & $\begin{array}{l}27 \text { February } \\
-3 \text { March }\end{array}$ & $\begin{array}{l}6-10 \\
\text { March }\end{array}$ & $\begin{array}{l}13-17 \\
\text { March }\end{array}$ & $\begin{array}{l}20-24 \\
\text { March }\end{array}$ & $\begin{array}{l}27-31 \\
\text { March }\end{array}$ & 3- 7 April & $\begin{array}{l}10-13 \\
\text { April }\end{array}$ \\
\hline \multirow{2}{*}{\multicolumn{2}{|c|}{ MATHS }} & \multicolumn{10}{|c|}{$\begin{array}{l}\text { Number: teachers to develop number teaching based on class and group needs. To be a component of the programme on a planned and regular basis } \\
\text { Include AO's from algebra etc that can be covered with number. }\end{array}$} \\
\hline & & \multicolumn{5}{|c|}{ Measurement: Length and Capacity Link to theme } & \multicolumn{2}{|c|}{ Statistics: } & \multicolumn{3}{|c|}{ Geometry: } \\
\hline \multicolumn{2}{|c|}{$\begin{array}{l}\text { PHYS } \\
\text { EDUCATION } \\
\text { \& HEALTH }\end{array}$} & \multicolumn{3}{|c|}{ Co-operative Games A.O. B1,2,3,4 } & \multicolumn{5}{|c|}{$\begin{array}{l}\text { Athletics Rotation: Run Jump Throw A.O. B1, 2, 3, } 4 \\
\text { Developing skills for school athletics sports. } \\
\text { Date to be finalised. }\end{array}$} & \multicolumn{2}{|c|}{$\begin{array}{l}\text { Swimming (6 lessons @3 } \\
\text { per week for } 2 \text { weeks?) } \\
\text { A.O. A3, B4 }\end{array}$} \\
\hline $\begin{array}{l}T \\
H \\
E\end{array}$ & DRAMA & \multicolumn{5}{|c|}{$\begin{array}{l}\text { Select a prop or costume and work with it to take on a role it suggests. } \\
\text { View others' roles and comment on their use of props and costumes. (PK, } \\
\text { DI, CI) }\end{array}$} & & & & & \\
\hline \multirow{3}{*}{\multicolumn{2}{|c|}{$\begin{array}{l}A \\
R \\
T \\
S\end{array}$}} & & & & & & & & & & \\
\hline & & \multicolumn{10}{|c|}{$\begin{array}{l}\text { Listening, music games, \& singing can happen throughout the year as part of the classroom programme. } \\
\text { Singing and Listening Learn and perform songs from a variety of cultures }\end{array}$} \\
\hline & & & & & & & \multicolumn{5}{|c|}{$\begin{array}{l}\text { Strands: PK, DI } \\
\text { Creating and Playing } \\
\text { Use suitable playing techniques when playing untuned percussion } \\
\text { instruments. } \\
\text { - Explore sounds and improvise with them to create an effect } \\
\text { - } \quad \text { Play and improvise simple rhythmic patterns }\end{array}$} \\
\hline & $\begin{array}{l}\text { VISUAL } \\
\text { ARTS }\end{array}$ & \multicolumn{10}{|c|}{$\begin{array}{l}\text { Colour - "Me" } \\
\text { Use Paint mixing, Paint, crayon and dye, different techniques } \\
\text { Practical Knowledge } \\
\text { Communicating Ideas }\end{array}$} \\
\hline & & \multicolumn{10}{|c|}{ Drawing } \\
\hline \multicolumn{2}{|c|}{$\begin{array}{l}\text { SCHOOL } \\
\text { EVENTS }\end{array}$} & \multicolumn{10}{|c|}{ See school calendar produced by Connad for the up to date events dates } \\
\hline
\end{tabular}




\section{Appendix R: New entrant classroom environments}

\begin{tabular}{|c|c|c|c|}
\hline School & $\begin{array}{l}\text { Classroom } \\
\text { environment }\end{array}$ & $\begin{array}{l}\text { Mathematics } \\
\text { environment }\end{array}$ & Equipment \\
\hline Aorangi & $\begin{array}{l}\text { Warm }{ }^{1} \text { classroom } \\
\text { environment } \\
\text { Emphasis on } \\
\text { management }\end{array}$ & $\begin{array}{l}\text { Large number displays } \\
\text { Large sequence chart } \\
\text { Shape posters } \\
\text { Repeating patterns } \\
\text { Evidence of children's } \\
\text { work in displays } \\
\text { English only displays }\end{array}$ & $\begin{array}{l}\text { Designated } \\
\text { mathematics table } \\
\text { Sets of sorting } \\
\text { equipment } \\
\text { Puzzles } \\
\text { Clocks } \\
\text { No obvious } \\
\text { mathematics-related } \\
\text { books }\end{array}$ \\
\hline Cascade & $\begin{array}{l}\text { Well-ordered, warm } \\
\text { and safe } \\
\text { Well established } \\
\text { routines } \\
\text { Emphasis on good } \\
\text { classroom behaviour }\end{array}$ & $\begin{array}{l}\text { Large number sets on } \\
\text { display } \\
\text { Three statistical } \\
\text { displays } \\
\text { Three geometric } \\
\text { displays } \\
\text { Three symmetrical } \\
\text { displays } \\
\text { Clear labelling of all } \\
\text { displays } \\
\text { English only displays }\end{array}$ & $\begin{array}{l}\text { Wide range of } \\
\text { equipment } \\
\text { Literacy materials } \\
\text { related to mathematics }\end{array}$ \\
\hline Dundass & $\begin{array}{l}\text { Warm and welcoming } \\
\text { Environment } \\
\text { Good routines } \\
\text { Well structured }\end{array}$ & $\begin{array}{l}\text { Six different number } \\
\text { displays } \\
\text { Timetables, days of the } \\
\text { week, months of the } \\
\text { year, birthday lists } \\
\text { English only displays }\end{array}$ & $\begin{array}{l}\text { Well organised, easily } \\
\text { accessible range of } \\
\text { resources } \\
\text { Mathematics related } \\
\text { books and poems } \\
\text { present }\end{array}$ \\
\hline
\end{tabular}




\begin{tabular}{|l|l|l|l|}
\hline School & $\begin{array}{l}\text { Classroom } \\
\text { environment }\end{array}$ & $\begin{array}{l}\text { Mathematics } \\
\text { environment }\end{array}$ & Equipment \\
\hline Hikurangi & $\begin{array}{l}\text { A safe place } \\
\text { Busy and well } \\
\text { organised }\end{array}$ & $\begin{array}{l}\text { Three different number } \\
\text { lines } \\
\text { Colour ladder } \\
\text { Count the teddies } \\
\text { display } \\
\text { Days of the week chart } \\
\text { Regular rotation of } \\
\text { displays, evident from } \\
\text { different visits } \\
\text { English only displays }\end{array}$ & $\begin{array}{l}\text { Mathematics big books } \\
\text { Numeracy project } \\
\text { equipment } \\
\text { Jigsaws, blocks, games } \\
\text { Poetry charts related to } \\
\text { mathematics }\end{array}$ \\
\hline Tongariro & $\begin{array}{l}\text { Warm and supportive } \\
\text { environment } \\
\text { Close relationships } \\
\text { with teacher } \\
\text { Busy and exciting } \\
\text { environment }\end{array}$ & $\begin{array}{l}\text { Variety of well } \\
\text { displayed number } \\
\text { charts } \\
\text { Clear learning } \\
\text { intentions visible in } \\
\text { English } \\
\text { Range of mathematics } \\
\text { charts displayed }\end{array}$ & $\begin{array}{l}\text { Range of equipment } \\
\text { consistently available } \\
\text { Jigsaws, number mats, } \\
\text { books related to } \\
\text { mathematics }\end{array}$ \\
\hline
\end{tabular}

Note

1 Dockett and Perry (1999) use the term 'warm' to describe the nature of the classroom environment. 


\section{Appendix S: Comparison of new entrant teacher beliefs}

about how children learn mathematics, teacher practices, and student behaviour

\begin{tabular}{|c|c|c|c|}
\hline School & Teacher believed that: & Observed practice & $\begin{array}{l}\text { Observed response } \\
\text { from children }\end{array}$ \\
\hline Aorangi & $\begin{array}{l}\text { She made sure children } \\
\text { have necessary skills } \\
\text { before they move on } \\
\text { Children are able to } \\
\text { actively problem solve } \\
\text { but they need the skills } \\
\text { before they can } \\
\text { Children come to } \\
\text { school with very few } \\
\text { skills }\end{array}$ & $\begin{array}{l}\text { Teacher made links } \\
\text { Teacher directed } \\
\text { learning } \\
\text { Adherence to lesson } \\
\text { plan }\end{array}$ & $\begin{array}{l}\text { Quiet behaviour } \\
\text { Good discussions } \\
\text { when teacher not } \\
\text { present related to } \\
\text { mathematics } \\
\text { Follow teacher } \\
\text { directions }\end{array}$ \\
\hline Cascade & $\begin{array}{l}\text { Children can problem } \\
\text { solve } \\
\text { Children are active } \\
\text { learners } \\
\text { Children should be } \\
\text { engaged in learning } \\
\text { She supports children } \\
\text { to attain beginning } \\
\text { skills }\end{array}$ & $\begin{array}{l}\text { Supportive teacher } \\
\text { Teacher in control and } \\
\text { directing learning } \\
\text { No observed problem } \\
\text { solving } \\
\text { Adherence to lesson } \\
\text { plan }\end{array}$ & $\begin{array}{l}\text { Passive behaviour } \\
\text { Follow directions } \\
\text { Respond to teacher } \\
\text { questioning } \\
\text { Children do not } \\
\text { usually initiate } \\
\text { responses }\end{array}$ \\
\hline Dundass & $\begin{array}{l}\text { Children have fun } \\
\text { She engages children } \\
\text { in learning } \\
\text { She plans well for } \\
\text { teaching } \\
\text { Children are able to } \\
\text { problem solve }\end{array}$ & $\begin{array}{l}\text { Methodical and } \\
\text { directive teaching } \\
\text { Teacher made links } \\
\text { Teacher organised } \\
\text { learning } \\
\text { Knowledge based } \\
\text { lessons } \\
\text { Adherence to lesson } \\
\text { plan }\end{array}$ & $\begin{array}{l}\text { No observed problem } \\
\text { solving by children } \\
\text { Children have fun as } \\
\text { teacher directs } \\
\text { No observed child } \\
\text { initiated activities }\end{array}$ \\
\hline Tongariro & $\begin{array}{l}\text { She demonstrates } \\
\text { inclusive teaching } \\
\text { She extends children's } \\
\text { learning } \\
\text { Children are engaged } \\
\text { in learning but follow } \\
\text { her direction }\end{array}$ & $\begin{array}{l}\text { Teacher directed } \\
\text { learning } \\
\text { Teacher made links } \\
\text { Teacher initiated } \\
\text { discussions }\end{array}$ & $\begin{array}{l}\text { No observed } \\
\text { opportunities for } \\
\text { children to initiate } \\
\text { learning } \\
\text { Quiet behaviour }\end{array}$ \\
\hline
\end{tabular}




\section{Appendix T: The learning story}

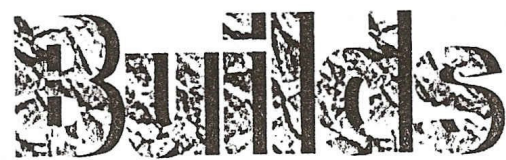

October 05

you were working so hard building! Every time your building fell down you laughed and laughed. Then you persevered and built it up again and again. You watched carefully how the others were building and were very interested watching them try and balance blocks on the round blocks.

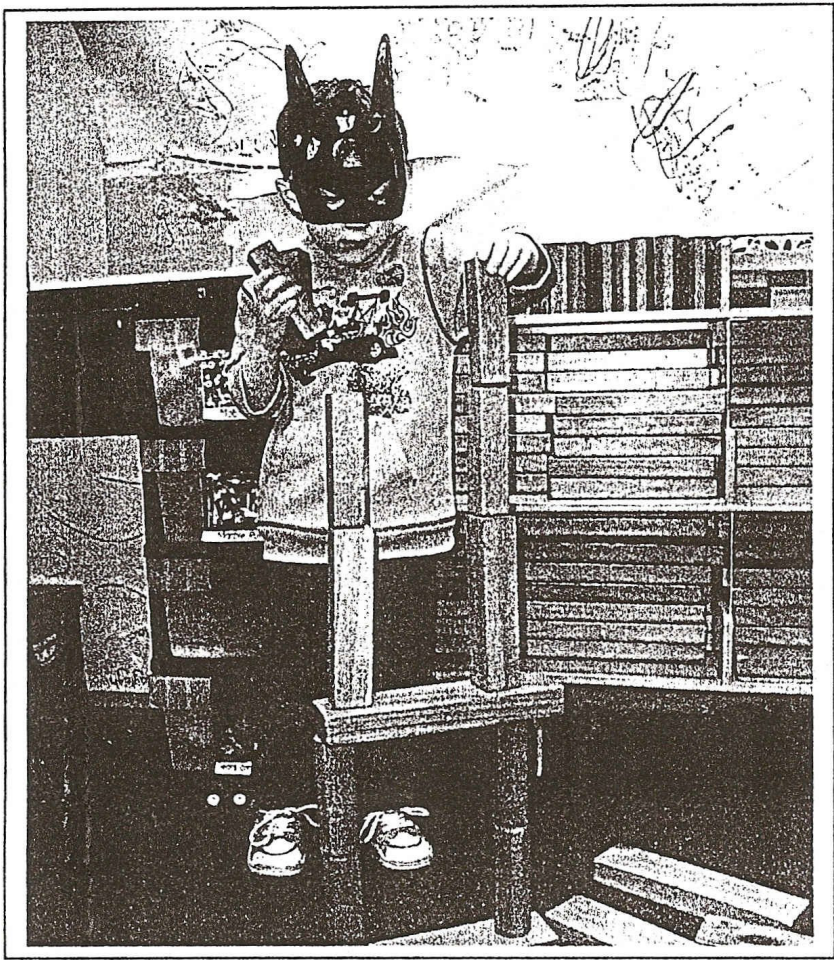

you were practicing lots of maths skills as you built your buildings - balancing, measuring/comparing, matching, counting and estimating.

You concentrated for a long time carefully choosing your blocks and playing really constructively with your friends.

Keep up the good work? _...2 I'm looking forward to see you building more buildings. 


\section{Appendix U: Kindergarten teacher demographic information}

\begin{tabular}{|c|c|c|c|c|c|}
\hline $\begin{array}{l}\text { Kindergarten } \\
\text { name } \\
\text { (teacher } \\
\text { number) }\end{array}$ & Sex & $\begin{array}{l}\text { Years of } \\
\text { experience }\end{array}$ & Ethnicity & $\begin{array}{l}\text { Highest } \\
\text { qualification }\end{array}$ & $\begin{array}{l}\text { Highest level of } \\
\text { mathematics }\end{array}$ \\
\hline Aorangi 1 & $\mathrm{~F}$ & 15 & European & Dip ECE & $\begin{array}{l}\text { School certificate } \\
(\text { Year } 11)\end{array}$ \\
\hline Aorangi 2 & $\mathrm{~F}$ & 11 & European & Dip ECE & $\begin{array}{l}\text { University } \\
\text { entrance (Year 12) }\end{array}$ \\
\hline Cascade 1 & $\mathrm{~F}$ & 9 & European & $\begin{array}{l}\text { BA/Dip } \\
\text { ECE }\end{array}$ & $\begin{array}{l}\text { University } \\
\text { entrance (Year 12) }\end{array}$ \\
\hline Cascade 2 & $\mathrm{~F}$ & 8 & Maori & Dip ECE & $\begin{array}{l}\text { University } \\
\text { entrance (Year 12) }\end{array}$ \\
\hline Cascade 3 & $\mathrm{~F}$ & 8 & Maori & $\begin{array}{l}\text { BA/Dip } \\
\text { ECE }\end{array}$ & $\begin{array}{l}\text { University } \\
\text { entrance (Year 12) }\end{array}$ \\
\hline Dundass 1 & $\mathrm{~F}$ & 15 & European & BEd & Not specified \\
\hline Dundass 2 & $\mathrm{~F}$ & 19 & European & Dip ECE & $\begin{array}{l}\text { University } \\
\text { entrance (Year 12) }\end{array}$ \\
\hline Dundass 3 & $\mathrm{~F}$ & 5 & European & BEd (ECE) & $\begin{array}{l}\text { Bursary level } \\
\text { (Year 13) }\end{array}$ \\
\hline Hikurangi 1 & $\mathrm{~F}$ & 13 & European & Dip ECE & $\begin{array}{l}\text { PD courses in } \\
\text { mathematics }\end{array}$ \\
\hline Hikurangi 2 & $\mathrm{~F}$ & 7 & Maori & BEd (ECE) & $\begin{array}{l}5^{\text {th }} \text { form certificate } \\
\text { (Year } 11)\end{array}$ \\
\hline Hikurangi 3 & $\mathrm{~F}$ & 8 & Samoan & $\mathrm{BEd}$ & $\begin{array}{l}\text { School certificate } \\
\text { (Year 11) }\end{array}$ \\
\hline Tongariro 1 & $\mathrm{~F}$ & 9 & Maori & Dip ECE & $\begin{array}{l}\text { University } \\
\text { entrance (Year 12) }\end{array}$ \\
\hline Tongariro 2 & $\mathrm{~F}$ & 6 & European & Dip ECE & $\begin{array}{l}\text { School certificate } \\
(\text { Year } 11)\end{array}$ \\
\hline Tongariro 3 & $\mathrm{~F}$ & 3 & Maori & Dip ECE & $\begin{array}{l}\text { School certificate } \\
(\text { Year } 11)\end{array}$ \\
\hline
\end{tabular}


Kindergarten \& New Entrant Teachers' Beliefs \& Practices in Mathematics Teaching \& Learning

Note: At each kindergarten the head teacher is designated with the numeral 1. 


\section{References}

Anderson, J., White, P., \& Sullivan, P. (2005). Using a schematic model to represent influences on, and relationships between, teachers' problem-solving beliefs and practices. Mathematics Education Research Journal, 17(2), 9-38.

Angrosino, M. V. (2008). Reconceptualizing observation: Ethnography, pedagogy, and the prospects for a progressive political agenda. In N. K. Denzin \& Y. S. Lincoln (Eds.), Collecting and interpreting qualitative materials (3rd ed., pp. 161-184). Los Angeles: Sage Publications.

Anning, A., Cullen, J., \& Fleer, M. (2004). Research contexts across cultures. In A. Anning, J. Cullen \& M. Fleer (Eds.), Early childhood education: Society and culture (pp. 1-18). London: Sage Publications.

Anthony, G., \& Walshaw, M. (2007). Effective pedagogy in mathematics/pāngarau: Best evidence synthesis iteration. Wellington: Ministry of Education.

Askew, M. (2001). Policy, practices and principles in teaching numeracy. In P. Gates (Ed.), Issues in mathematics teaching (pp. 105-119). London: Routledge Falmer.

Askew, M., Brown, M., Rhodes, V., Wiliam, D., \& Johnson, D. (1997). Effective teachers of numeracy in primary schools: Teachers beliefs, practices and pupils' learning. Paper presented at the British Educational Research Association.

Atkin, J. (1996). From values and beliefs about learning to principles and practice. Seminar series 52. Jollimont: Incorporated Association of Registered Teachers of Victoria.

Aubrey, C. (1997). Mathematics teaching in the early years: An investigation of teachers' subject knowledge. London: Falmer Press.

Aubrey, C., David, T., Godfrey, R., \& Thompson, L. (2000). Early childhood education research. London: RoutledgeFalmer.

Averill, R. (2001). "Just by aiming at the middle": A study of year 9 mathematics schemes. Unpublished MEd thesis. Victoria University of Wellington. 
Avery, J., \& Thomson, K. (2003). On the mat with Te Whāriki and the New Zealand Curriculum Framework (NZCF): Ways to enhance continuity of learning between early childhood education and school. Paper presented at the 8th Early Childhood Convention, Palmerston North, New Zealand.

Barkatsas, A., \& Malone, J. (2005). A typology of mathematics teachers' beliefs about teaching and learning mathematics and instructional practices. Mathematics Education Research Journal, 17(2), 69-90.

Baroody, A. J., \& Ginsberg, H. P. (1990). Children's mathematical learning: A cognitive view. In R. B. Davis, C. A. Maher \& N. Noddings (Eds.), Constructivist views on the teaching and learning of mathematics. Journal for Research in Mathematics Education, Monograph Number 4 (pp. 51-64). Virginia: National Council of Teachers of Mathematics.

Bath, C. (2009). Learning to belong: Exploring young children's participation at the start of school. Oxon: Routledge.

Beeby, C. E. (1974). The present position of educational planning. In W. L. Renwick \& L. J. Ingham (Eds.), Educational planning in New Zealand. Wellington: Government Printer.

Bell, N. (1990). Theorising practice in early childhood education. Unpublished thesis presented in partial fulfilment of the requirements the degree of master in arts in education, Massey University, Palmerston North.

Berry, K. (2006). Research as bricolage: Embracing relationality, multiplicity and complexity. In K. Tobin \& J. Kincheloe (Eds.), Doing educational research: A handbook (pp. 87-116). Rotterdam/Taipei: Sense Publishers.

Beswick, K. (2005). The beliefs/practice connection in broadly defined contexts. Mathematics Education Research Journal, 17(2), 49-67.

Beswick, K. (2007). Teachers' beliefs that matter in secondary mathematics classrooms. Educational Studies in Mathematics, 65 (1), 95-120.

Beswick, K., Swabey, K. \& Andrew, R. (2008). Looking for attributes of powerful teaching for numeracy in Tasmanian K-7 classrooms. Mathematics Education Research Journal, 20 (1), 3-31. 
Biber, B. (1988). The challenge of professionalism: Integrating theory and practice. In B. Spodek, D. N. Saracho \& D. L. Peters (Eds.), Professionalism and the early childhood practitioners (pp. 29-47). New York: Teachers College, Columbia University.

Blaiklock, A. J., Kiro, C. A., Belgrave, M., Low, W., Davenport, E., \& Hassell, I. B. (2002). When the invisible hand rocks the cradle: New Zealand children in a time of change. Florence: UNICEF Innocenti Research Center.

Blundel, K., \& Palmer, R. (2009). New entrants 'lack basics'. The Dominion Post, 26 March, p. 1.

Bobis, J. (2002). Is school ready for my child? Australian Primary Mathematics Classroom, 7(4), 4-8.

Bronfenbrenner, U. (1979). The ecology of human development: Experiments by nature and design. Massachusetts: Harvard University Press.

Brooker, L. (2008). Supporting transitions in the early years. Maidenhead, England: Open University Press.

Brostrom, S. (2005). Transition problems and play as transitory activity. Australian Journal of Early Childhood, 30(3), 17-25.

Burgon, J., \& Thompson, G. B. (1997). Dimensions of social behaviour: Fiveyear-olds at school. SET, 13, 1-4.

Cannella, G. (2005). Reconceptualising the field. In N. Yelland (Ed.), Critical issues in early childhood education. Berkshire, England: Open University Press.

Carr, M. (1998). Taking dispositions to school. Childrenz Issues, 2(1), 21-24.

Carr, M. (2001). Assessment in early childhood settings. London: Paul Chapman.

Carr, M. (2002). Keeping it connected: A keynote address. Paper presented at the Te Tari Puna Ora o Aotearoa/ New Zealand childcare Association annual Conference, Christchurch.

Carr, M. (2006). Learning dispositions and key competencies: A new curriculum continuity across the sectors? SET, 2, 23-27.

Carr, M. (2008). Spotlight on learning: An interview with Margaret Carr. SET: Research information for teachers. Wellington: New Zealand Council for Educational Research. 
Carr, M., \& May, H. (1996). The politics and processes of the implementation of Te Whariki, the New Zealand national early childhood curriculum. In H. May \& M. Carr (Eds.), Implementing Te Whāriki: Te Whāriki papers two (pp. 113). Wellington: Institute for Early Childhood Studies, Victoria University of Wellington.

Carr, M., May, H., Podmore, V., Cubey, P., Hatherly, A., \& Macartney, B. (2000). Learning and teaching stories: Action research on evaluation in early childhood research. Wellington: New Zealand Council for Educational Research.

Carr, M., Peters, S., \& Young-Loveridge, J. M. (1994). Early childhood mathematics: A framework. In J. Neyland (Ed.), Mathematics education: A handbook for teachers, Volume 1 (pp. 262-270). Wellington: Wellington College of Education, New Zealand.

Carr, M., Smith, A.B., Duncan, J., Jones, C., Lee, W. \& Marshall, K. (2010) Learning in the making: Disposition and design in early education. Rotterdam: Sense Publishers.

Carr, W., \& Kemmis, S. (1986). Becoming critical: Education, knowledge and action research. London: Falmer Press.

Cassidy, D. J., \& Lawrence, J. M. (2000). Teachers' beliefs: The "whys" behind the "how tos" in child care classrooms. Journal of Research in Childhood Education, 14(2), 193-204.

Cassidy, M. (2005). 'They do it anyway': A study of primary 1 teachers' perceptions of children's transition into primary education. Early Years, 25(2), 143-154.

Clark, M., \& Lovric, M. (2008). Suggestion for a theoretical model for secondarytertiary transition in mathematics. Mathematics Education Research Journal, 20(2).

Clarke, B., Clarke, D., \& Cheeseman, J. (2006). The mathematical knowledge and understanding young children bring to school. Mathematics Education Research Journal, 18(1), 78-103.

Clay, M. (1991). Becoming literate: The construction of inner control. Auckland: Heinemann. 
Cobb, P. (1988). The tension between theories of learning and instruction in mathematics education. Educational Psychologist, 23(2), 87-103.

Cobb, P., \& Yackel, E. (1996). Constructivist, emergent, and sociocultural perspectives in the context of developmental research. Educational Psychologist, 31(3/4), 175-190.

Cobb, P., Wood, T., \& Yackel, E. (1990). Classrooms as learning environments for teachers and researchers. In R. B. Davis, C. A. Maher \& N. Noddings (Eds.), Constructivist views on the teaching and learning of mathematics (pp. 125-146). Reston, VA: National Council of Teachers of Mathematics.

Cohen, L., Manion, L., \& Morrison, K. (2000). Research methods in education (5th ed.). London: Routledge Falmer.

Confrey, J. (1999). Voice, perspective, bias and stance: Applying and modifying Piagetian theory in mathematics education. In L. Burton (Ed.), Learning mathematics: From hierarchies to networks (pp. 3-21). Studies in Mathematics Education Series 13. London: Falmer Press.

Corsaro, W. A., Molinari, L., \& Rosier, K. B. (2002). Zena and Carlotta: Transition narratives and early education in the United States and Italy. Human Development, 45(5), 323-349.

Crooks, T., Darr, C., Gilmore, A., Hall, C., Hattie, J., Smith, J., \& Smith, L. (2009). Towards defining, assessing and reporting against national standards for literacy and numeracy in New Zealand. Wellington: The New Zealand Assessment Academy.

Cullen, J. (1998). Emergent learners: Making the transition to school learning. Childrenz Issues, 2(1), 30-33.

Cullen, J. (1999). Children's knowledge, teacher's knowledge: Implications for early childhood teacher education. Australian Journal of Teacher Education, $24(2), 15-25$.

Cullen, J., Foote, L., Jordan, B., \& Marsich, A. (2002). Teacher education for the early years: Why birth to eight? NZ Principal, 18(2), 10-13.

Cullen, J., \& St. George, A. (1996). Scripts for learning: Reflecting dynamics of classroom life. Journal for Australian Research in Early Childhood, 1, 1019. 
Cuskelly, M., \& Detering, N. (2003). Teacher and student perspectives of school readiness. Australian Journal of Early Childhood, 28(2), 39-46.

Dahlberg, G., Moss, P., \& Pence, A. (1999). Beyond quality in early childhood education and care: Postmodern perspectives. London: Falmer Press.

Dalli, C. (2003). Knowing/questioning/developing our theoretical basis/bases in the postmodern age: Challenges for the early years teachers. Paper presented at the Collaborative Approaches in the Early Years: A primary and early childhood education conference $0-8$ years, Victoria University of Wellington.

Denscombe, M. (2001). The good research guide for small-scale social research projects. Buckingham: Open University Press.

Denscombe, M. (2003). The good research guide for small-scale social research projects (2nd ed.). Berkshire, England: Open University Press.

Denscombe, M. (2007). The good research guide for small-scale social research projects (3rd ed.). Maidenhead, Berkshire: Open University Press.

Denzin, N. K., \& Lincoln, Y. S. (2008a). Introduction: The discipline and practice of qualitative research. In N. K. Denzin \& Y. S. Lincoln (Eds.), Collecting and interpreting qualitative materials (3rd ed., pp. 1-44). Los Angeles: Sage Publications.

Denzin, N. K., \& Lincoln, Y. S. (Eds.). (2008b). Collecting and interpreting qualitative materials (3rd ed.). Los Angeles: Sage Publications.

Department of Education. (2005). How should mathematics be taught in early childhood [Electronic Version]. Retrieved 4/5/06 from www.education.tas.gov.au/ocll/publications/curriculum/4/hsmb.htm.

Dickie, J. (1998). Emerging literacy at home and at school. Childrenz Issues, 2 (1), 42-46.

Dockett, S., \& Perry, B. (1999). Starting school. Watson, ACT: Australian Early Childhood Association.

Dockett, S., \& Perry, B. (2001). Starting school: Effective transitions. Early Childhood Research and Practice, 3(2), 1-20.

Dockett, S., \& Perry, B. (2005). Starting school in Australia is "a bit safer, a lot easier and more relaxing": Issues for families and children from culturally and linguistically diverse backgrounds. Early Years, 25(3), 271-281. 
Dockett, S., \& Perry, B. (2007). Transitions to school: Perceptions, expectations, experiences. Sydney: University of New South Wales Press.

Doyle, W. (1983). Academic work. Review of Educational Research, 53(2), 159199.

Dunlop, A. (2003). Bridging children's early education transitions through teacher collaboration. Paper presented at the New Zealand Association of Research in Education.

Dunlop, A., \& Fabian, H. (Eds.). (2007). Informing transitions in the early years: Research, policy and practice. Berkshire: Open University Press.

Dunphy, E. (2006). An exploration of young children's number sense as they enter primary school in Ireland. Open University, Dublin.

Education Review Office. (1998). The use of Te Whàriki. Wellington: Education Review Office.

Education Review Office. (2000). Early literacy and numeracy: The use of assessment to improve programmes for four to six year olds. Education evaluation reports 3. Wellington: Education Review Office

Einarsdottir, J. (2007). Children's voices on the transition from pre-school to primary school. In A. Dunlop \& H. Fabian (Eds.), Informing transition in the early years: Research, policy and practice (pp. 75-91). Maidenhead, Berkshire: Open University Press.

Ernest, P. (1989). The knowledge, beliefs and attitudes of the mathematics teacher: A model. Journal of Education for Teaching, 15(1), 13-33.

Ethell, R. (1998). A critical first step in learning to teach: Confronting the power and tenacity of student teachers' beliefs and preconceptions. Paper presented at the New Zealand Association for Research in Education Conference, Christchurch.

Fabian, H. (2007). Informing transitions. In A. Dunlop \& H. Fabian (Eds.), Informing transitions in the early years: Research, policy and practice (pp. 3-17). Maidenhead, Berkshire: Open University Press.

Fabian, H., \& Dunlop, A.-W. (2002). Introduction. In H. Fabian \& A.-W. Dunlop (Eds.), Transitions in the early years: Debating continuity and progression for young children in early education (pp. 1-7). London: RoutledgeFalmer 
Fang, Z. (1996). A review of research on teacher beliefs and practices.

Educational Research Journal, 38(1), 47-65.

Farquhar, S. E. (1991). Quality is in the eye of the beholder: The nature of early childhood centre quality. Dunedin: University of Otago, Education Department.

Farquhar, S. E. (2003). Quality teaching early foundations: Best evidence synthesis. Wellington: Ministry of Education.

Fontana, A., \& Frey, J. H. (2008). The interview: From neutral stance to political involvement. In N. K. Denzin \& Y. S. Lincoln (Eds.), Collecting and interpreting qualitative materials (3rd ed., pp. 115-160). Los Angeles: Sage Publications.

Foote, L., Smith, J., \& Ellis, F. (2004). The impact of teachers' beliefs on the literacy experiences of young children: A New Zealand perspective. Early Years, 24(2), 135-147.

Forman, E. A. (2003). A sociocultural approach to mathematics reform: Speaking, inscribing, and doing mathematics within communities of practice. In J. Kilpatrick, W. G. Martin \& D. Schifter (Eds.), A research companion to principles and standards for school mathematics (pp. 333-352). Reston, VA: National Council of Teachers of Mathematics.

Frid, S. (2000). Constructivism and reflective practice in practice: Challenges and dilemmas of a mathematics teacher educator. Mathematics Teacher Education and Development, 2, 17-33.

Frid, S., Goos, M. \& Sparow, L. (2009). What knowledge is needed for effective teaching of mathematics? Mathematics Teacher Education and Development, 10, 1-3.

Gallagher, G. (2005). “They didn't stretch my brain” Challenged by chance: factors influencing transition to school for gifted children. Unpublished Masters in Gifted Education thesis: Flinders University, Adelaide.

Genishi, C. (Ed.). (1992). Ways of assessing children and curriculum: Stories of early childhood practice. New York: Teachers College Press.

Gerring, J. (2007). Case study research: Principles and practices. New York: Cambridge University Press. 
Goos, M., Galbraith, P., \& Renshaw, P. (1999). Establishing a community of practice in a secondary mathematics classroom. In L. Burton (Ed.), Learning mathematics: From Hierarchies to Networks (Vol. 13, pp. 36-61). London: Falmer Press.

Graue, M. E., \& Marsh, M. M. (1996). Genre and practice: Shaping possibilities for children. Early Childhood Research Quarterly, 11, 219-242.

Grossman, P. L. (1995). Teacher's knowledge. In P. L. Anderson (Ed.), International encyclopaedia of teaching and teacher education (2nd ed., pp. 20-24). New York: Pergamon.

Guskey, T. R. (1986). Staff development and the process of teacher change. Educational Researcher, 15(5), 5-12.

Haggerty, M. (2003). Reconceptualising notions of curriculum: The case of Te Whāriki. New Zealand Research in Early Childhood Education, 6, 35-49.

Hamre, B. K., \& Pianta, R. C. (2007). Learning opportunities in pre-school and early elementary classrooms. In R. C. Pianta, M. J. Cox \& K. L. Snow (Eds.), School readiness and the transition to kindergarten in the era of accountability (pp. 49-84). Baltimore: Paul H. Brookes Publishing Co.

Handal, B., \& Herrington, A. (2003). Mathematics teachers' beliefs and curriculum reform. Mathematics Education Research Journal, 15(1), 59-69.

Hartley, C., Rogers, P., Smith, J., Peters, S., \& Carr, M. (2009). Across the border: a community negotiates the transition from early childhood to primary school. Centres of Innovation final report to the Ministry of Education.

Hawk, K., \& Hill, J. (2000). Bridging educational islands: Making the Aotearoa/ New Zealand system a seamless experience for students. New Zealand Association for Research in Education.

Haynes, M. (2000). Mathematics education for early childhood: A partnership of two curriculums. Mathematics Teacher Education and Development, 2, 93104.

Hedges, H. (2001). Knock, knock! Who's there? A researcher! Early Education, 25.

Hedges, H. (2002). Subject content knowledge in early childhood curriculum and pedagogy. Massey University, Palmerston North. 
Hedges, H., \& Cullen, J. (2005). Meaningful teaching and learning: Children's and teachers' content knowledge. ACE Papers (16), 11-24.

Hodgen, E. (2007). Competent learners @ 16: Competency levels and development over time - Technical report. Wellington: New Zealand Council for Educational Research.

Holmes, T. (1998). Transition to school. Childrenz Issues: Journal of the Children's Issues Centre, 2(1), 50-51.

Hopps, K. (2004). Teacher communication across the preschool-school boundary. Australian Journal of Early Childhood, 29(1), 8-23.

Horne, J. (1999). A family milestone: Stress and transition to school. Unpublished Master in Education Thesis, Auckland University: Auckland.

Howard, P., Perry, B., \& Lindsay, M. (1997). Secondary mathematics teachers' beliefs about the learning and teaching of mathematics. In F. Biddulph \& K. Carr (Eds.), People in mathematics education (Proceedings of the 20th annual conference of the Mathematics Education Group of Australasia) (pp. 231-238). Rotorua: Mathematics Education Research Group of Australasia.

Jackson, M. (1987). Making sense of school. In A. Pollard (Ed.), Children and their primary schools: A new perspective (pp. 74-87). New York: The Falmer Press.

Jaworski, B. (1993). Constructivism and teaching: The socio-cultural context [Electronic Version]. Retrieved 29/10/09 From www.grout.demon.co.uk/Barbara/chreods.htm.

Jaworski, B. (1999). Tensions in teachers' conceptions of mathematics and teaching In L. Burton (Ed.), Learning mathematics: from hierarchies to networks (Vol. 13, pp. 153-172). London: Falmer Press.

Jones, C. (2006). Continuity of learning: Adding funds of knowledge from the home environment. SET Research Information for Teachers, No. 2,2006, 28 31.

Kagan, S. L. (1994). Early care and education: Beyond the fishbowl. Phi Delta Kappa, 16(3), 184-187.

Katz, L., \& Raths, J. (1985). Dispositions as goals for teacher education. Teaching and Teacher Education, 1(4), 301-307. 
Kirova, A., \& Bhargava, A. (2002). Learning to guide preschool children's mathematical understanding: A teacher's professional growth. Early Childhood Research and Practice, 4(1).

Kuijpers, J. M., Houtveen, A. A. M. \& Wubbels, T. H. (2010). An integrated professional development model for effective teaching. Teaching and Teacher Education, 26, 1687-1697.

Lambert, E. B. (2000). Problem solving in the first years of school. Australian Journal of Early Childhood, 25(3), 32-38.

Lave, J. (1990). The culture of acquisition and the practice of understanding. In J. Stigler, A. Schweder, \& G. Herdt (Eds.), Cultural psychology: Essays in comparative human development (pp. 61-75). Cambridge: Cambridge University Press.

Lave, J., \& Wenger, E. (1991). Situated learning: Legitimate peripheral participation. New York: Cambridge University Press.

Ledger, E., Smith, A., \& Rich, P. (1998). 'Do I go to school to get a brain?' The transition from kindergarten to school from the child's perspective. Childrenz Issues, 2(1), 7-11.

Lee, J. S., \& Ginsberg, H. P. (2007). What is appropriate mathematics education for four-year-olds? Pre-kindergarten teachers' beliefs. Journal of Early Childhood Research, 5(2).

Mallard, T. (2002). Minister of Education's speech. Paper presented at the Collaborative Approaches in the Early Years: A primary and early childhood education conference, $0-8$ years.

Mangere Bridge Kindergarten. (2008). Transition Research, Centres of Innovation. Auckland Kindergarten Association.

Margetts, K. (1999). Transition to school: Looking forward. Paper presented at the Australian Early Childhood Association national conference.

Margetts, K. (2002). Transition to school: Complexity and diversity. European Early Childhood Education Research Journal, 10(2), 103-114.

Margetts, K. (2007). Understanding and supporting children: Shaping transition practices. In A. Dunlop \& H. Fabian (Eds.), Informing transitions in the early years: Research, policy and practice (pp. 107-118). Maidenhead, Berkshire: Open University Press. 
May, H. (in press). I am five and I go to school. Wellington: New Zealand Council for Educational Research.

May, H. (2005). School beginnings: A $19^{\text {th }}$ century colonial story. Wellington: New Zealand Council for Educational Research.

May, H. (2002). Aotearoa-New Zealand: An overview of history, policy and curriculum. McGill Journal of Education, 37(1), 19-36.

May, H. (1997). The discovery of early childhood. Wellington: New Zealand Council for Educational Research.

McCaslin, M., \& Good, T. L. (1992). Compliant cognition: The misalliance of management and instructional goals in current school reform. Educational Researcher, 21(3), 4-17.

McGee, C., \& Penlington, C. (2001). Research on learning and teachers' roles: Report 4: Teacher knowledge, Beliefs and thinking. Hamilton: University of Waikato.

McLachlan-Smith, C., \& St George, A. M. (2000). "Children learn by doing": Teachers' beliefs about learning, teaching and literacy in New Zealand kindergartens. New Zealand Journal of Educational Studies, 35(1), 37-47.

McMurchy-Pilkington, C. (2004). Pangarau: Māori medium mathematics curriculum - Empowerment or a new hegemonic accord?, University of Auckland.

McNaughton, S. (1998). Activating developmental processes over the transition to school. Childrenz Issues, 2(1), 34-38.

Meade, A. (1999). Not only child-centred, it must be children-centred. Keynote address. Paper presented at the Northern Ireland Pre-school Playgroup Association Millennium, Belfast.

Merriam, S. B. (2001). Qualitative research and case study applications in education (2nd ed.). San Francisco: Jossey-Bass.

Merriam, S. B. (2002a). Assessing and evaluating qualitative research. In S. B. Merriam \& Associates (Eds.), Qualitative research in practice: Examples for discussion and analysis (pp. 18-33). San Francisco: JosseyBass. 
Merriam, S. B. (2002b). Introduction to qualitative research. In S. B. Merriam \& Associates (Eds.), Qualitative research in practice: Examples for discussion and analysis (pp. 3-17). San Francisco: Jossey-Bass.

Metge, J., \& Kinloch, P. (1978). “Talking past each other?” Problems of crosscultural communication. Wellington: Victoria University Press.

Middleton, S. \& May, H. (1997). Teachers talk teaching, 1915-1995: Early childhood schools and teachers' colleges. Palmerston North: Dunmore Press.

Miller, L., \& Smith, A. P. (2004). Practitioners' beliefs and children's experiences of literacy in four early years settings. Early Years, 24(2), 121-134.

Ministry of Education. (1992). Mathematics in the New Zealand Curriculum. Wellington: Learning Media.

Ministry of Education. (1992b). School entry assessment. Wellington: Learning Media.

Ministry of Education. (1993a). New Zealand Curriculum Framework: Te Anga Marautanga o Aotearoa. Wellington: Learning Media.

Ministry of Education. (1993b). Te Whāriki: He whariki matauranga mō ngā mokopuna o Aotearoa - Draft guidelines for developmentally appropriate programmes in Māori early childhood services. Wellington: Learning Media.

Ministry of Education. (1996). Te Whāriki: He whaariki mātauranga mō ngā mokopuna o Aotearoa - Early childhood curriculum. Wellington: Learning Media.

Ministry of Education. (1999). Report of the Literacy Taskforce. Wellington: Ministry of Education.

Ministry of Education. (2002). Curriculum stocktake report. Wellington: Learning Media.

Ministry of Education. (2002b). Curriculum stocktake report. Wellington: Ministry of Education.

Ministry of Education. (2004). Book 4. Teaching number knowledge. Wellington: Ministry of Education.

Ministry of Education (2004b). An introduction to Kei Tua o te Pae (Book 1). Kei Tua o te Pae Assessment for Learning: Early childhood exemplars. Wellington: Learning Media Ltd. 
Ministry of Education. (2005a). Book 2: The diagnostic interview (Vol. 2). Wellington: Ministry of Education.

Ministry of Education. (2005b). Changes for the early days. New Zealand Education Gazette, 84(20), 2.

Ministry of Education. (2006). Early childhood education given prominence. New Zealand Education Gazette, 80(19).

Ministry of Education. (2007a). Easing the transition to school. New Zealand Education Gazette, 86(2), 10-13.

Ministry of Education. (2007b). The New Zealand curriculum for English-medium teaching and learning in years 1-13. Wellington: Learning Media.

Ministry of Education. (2008). Ka Hikitia-Managing for success: The Maori Education Strategy 2008-2012. Wellington: Ministry of Education.

Mitchell, L. (2002). Border crossing: Early childhood and primary teachers constructing an education for citizenship. Paper presented at the Collaborative Approaches in the Early Years: A primary and early childhood education conference, Victoria University of Wellington.

Mitchell, L., \& Cubey, P. (2003). Characteristics of professional development linked to enhanced pedagogy and children's learning in early childhood settings: Best evidence synthesis. Wellington: Ministry of Education.

Mitchell, L., Wylie, C., \& Carr, M. (2008). Outcomes of early childhood education: Literature review. Wellington: Ministry of Education.

Muir, T. (2008). Principles of practice and teacher actions: Influences on effective teaching of numeracy. Mathematics Education Research Journal, 20(3), 78101.

Mutch, C. (2003). One context, two outcomes: Comparison of Te Whariki and the New Zealand curriculum framework. In J. Nuttall (Ed.), Weaving Te Whāriki: Aotearoa New Zealand's early childhood curriculum document in theory and practice (pp. 111-129). Wellington: New Zealand Council for Educational Research.

Neyland, J. (2004). An ethical critique of the paradigm case: The mathematics curriculum. In A.-M. O’Neill, J. Clark, \& R. Openshaw (Eds.), Reshaping culture, knowledge and learning: Policy and content in the New Zealand Curriculum Framework (pp. 143-160). Palmerston North: Dunmore Press. 
Niesel, R., \& Griebel, W. (2007). Enhancing the competence of transition systems through co-construction. In A. Dunlop \& H. Fabian (Eds.), Informing transitions in the early years: Research, policy and practice (pp. 21-32). Berkshire: Open University Press.

Nisbet, S., \& Warren, E. (2000). Primary school teachers' beliefs relating to mathematics, teaching and assessing mathematics and factors that influence these beliefs. Mathematics Teacher Education and Development, 2, 34-48.

O’Neill, A.-M. (2004). Mapping the field: An introduction to curriculum politics in Aotearoa/New Zealand. In A.-M. O’Neill, J. Clark, \& R. Openshaw (Eds.), Reshaping culture, knowledge and learning: Policy and content in the New Zealand curriculum framework (pp. 25-46). Palmerston North: Dunmore Press.

Pajares, M. F. (1992). Teachers' beliefs and educational research: Cleaning up a messy construct. Review of Educational Research, 62(3), 307-332.

Pascal, C., \& Bertram, T. (1999). Accounting early for lifelong learning. In L. Abbott \& H. Moylett (Eds.), Early education transformed (pp. 93-104). London: Falmer Press.

Perry, B. (2000). Early childhood numeracy (Publication no. ED462286). Retrieved 15/5/07, from Australian Association of Mathematics Teachers, Adelaide: www.eric.ed.gov/ERICWebPortal/search/detailmini.jsp?_nfpb=true\&_\&ERI CExtSearch_SearchValue_0=ED462286\&ERICExtSearch_SearchType_0=no $\&$ accno $=\mathrm{ED} 462286$

Perry, B., \& Dockett, S. (2002). Young children's access to powerful mathematical ideas. . In L. English (Ed.), Handbook of international research in mathematics education (pp. 81-111). Mahwah, NJ: Lawrence Erlbaum Associates.

Perry, B., \& Dockett, S. (2005). What did you do in maths today? Australian Journal of Early Childhood, 30(3), 32-37.

Perry, B., Dockett, S., \& Harley, E. (2007). Learning stories and children's powerful mathematics. Early Childhood Research and Practice, 9(2). http://ecrp.uiuc.edu/v9n2/perry.html. 
Perry, B., Dockett, S., \& Howard, P. (2000). Starting school: Issues for children, parents and teachers. Journal of Australian Research in Early Childhood Education, 7, 41-55.

Perry, B., Dockett, S., \& Tracey, D. (1998). "At preschool they read to you, at school you learn to read": Perspectives on starting school. Australian Journal of Early Childhood, 23, 6-11.

Perry, B., Howard, P., \& Conroy, J. (1996). K-6 teachers' beliefs about the learning and teaching of mathematics. In P. C. Clarkson (Ed.), Technology in mathematics education (Vol. 1, pp. 453-460). Melbourne: Mathematics Education Research Group of Australasia.

Perry, B., Howard, P., \& Tracey, D. (1999). Head mathematics teachers' beliefs about the learning and teaching of mathematics. Mathematics Education Research Journal, 11(1), 39-53.

Peters, S. (1998a). Assessment and reporting within the context of the transition to school. Paper presented at the New Zealand Association for Research in Education Conference, Dunedin, March 1998.

Peters, S. (1998b). Gathering and sharing information on young children within the context of the transition to school. Science and Mathematics Education Papers, 107-122.

Peters, S. (1999). Planning for transition: Early childhood teachers' roles in enhancing children's transition to school. Paper presented at the Seventh Early Childhood Convention, Weaving threads for life - Te raranga i te oranga tangata, Nelson, 27-30 September 1999.

Peters, S. (2000). Multiple perspectives on continuity in early learning and the transition to school. Paper presented at the European Early Childhood Research Conference.

Peters, S. (2001). Early numeracy. Early Childhood Folio, 5, 10-14.

Peters, S. (2002). Talking about transition: Exploring different perspectives in order to foster a collaborative approach. Paper presented at the Collaborative Approaches in the Early Years: A primary and early childhood education conference $0-8$ years, Victoria University of Wellington. 
Peters, S. (2002). Teachers' perspectives of transitions. In H. Fabian \& A.W. Dunlop (Eds.), Transitions in the early years: Debating continuity and progression for young children in early education (pp. 87-97). London: RoutledgeFalmer.

Peters, S. (2003). Theoretical approaches to transition. SET, 3, 15-20.

Peters, S. (2004). "Crossing the border": An interpretive study of children making the transition to school. Unpublished $\mathrm{PhD}$ thesis, University of Waikato, Hamilton.

Peters, S. (2010). Literature review: Transition from early childhood education to school. Report to the Ministry of Education. New Zealand: Ministry of Education.

Peters, S., Hartley, C., Rogers, P., Smith, J. \& Carr, M. (2009). Supporting the transition from early childhood education to school: Insights from one centre of innovation project. SET, 4-10.

Pianta, R. C. (2004). Going to kindergarten: Transition models and practices. In D. Whitton, B. Perry \& S. Dockett (Eds.), Proceedings of the International Conference, Continuity and change: Transitions in education (CD Rom). Sydney: University of Western Sydney.

Podmore, V., May, H., \& Carr, M. (2001). “The child's questions”. Programme evaluation with Te Whāriki using “Teaching Stories”. Wellington: Victoria University of Wellington.

Pound, L. (1999). Supporting mathematical development in the early years. Buckingham, Philadelphia: Open University Press.

Priestman, B. (1952). Froebel education today. London: University of London Press.

Princeton University. (2009). Wordnetweb. Retrieved 1/9/09, from http/wordnetweb.princeton.edu/perl/webwn.

Ragin, C. C., \& Becker, H. S. (Eds.). (1992). What is a case? Exploring the foundations of social enquiry. New York: Cambridge University Press.

Raths, J. (2001). Teachers' beliefs and teaching beliefs [Electronic Version]. Early Childhood Research and Practice, 3, 1-11. Retrieved 1/5/06 from http://ecrp.uiuc.edu/v3n1/raths.html. 
Raymond, A. (1997). Inconsistency between a beginning elementary school teacher's mathematics beliefs and teaching practice. Journal for Research in Mathematics Education, 28(5), 550-576.

Renwick, M. (1984). To school at five. Wellington: New Zealand Council for Educational Research.

Renwick, M. (1987). Transition to school: The children's experience. The Best of SET, 2, 2-6.

Rivalland, C. M. P. (2007). When are beliefs just the 'tip of the iceberg'? Exploring early childhood professionals' beliefs and practices about teaching and learning. Australian Journal of Early Childhood, 32(1), 30-37.

Robinson, V., Timperley, H., \& Bullard, T. (2000). Strengthening education in Mangere and Otara evaluation: Second evaluation report. Auckland: The University of Auckland.

Rogoff, B. (1990). Apprenticeship in thinking. New York: Oxford University Press.

Schorr, R. Y. (2000). Impact at the student level: A study of the effects of a teacher development intervention on students' mathematical thinking. Journal of Mathematical Behaviour, 19, 209-231.

Sherley, B. M. (2003). Perceptions of quality in a Samoan pre-school. Unpublished Master of Education thesis. Massey University, Palmerston North.

Shulman, L. S. (1987). Knowledge and teaching: Foundations of the new reform. Harvard Educational Review, 57 (1), 1-22.

Smith, A. B. (1998). Editorial. Childrenz Issues, 2(1), 3-4.

Smith, L. (1999). Decolonising methodologies: Research and indigenous peoples. Dunedin: University of Otago Press.

Spodek, B. (1988). Implicit theories of early childhood teachers: foundations for professional behaviour. In B. Spodek, D. N. Saracho, \& D. L. Peters (Eds.), Professionalism and the early childhood practitioner (pp. 161-172). New York: Teachers College Press.

Stake, R. E. (1995). The art of case study research. California: Sage Publications. Stake, R. E. (2006). Multiple case study analysis. New York: The Guilford Press. 
Steinberg, S. R. (2006). Critical cultural studies research: Bricolage in action. In K. Tobin \& J. Kincheloe (Eds.), Doing educational research: A handbook (pp. 117-138). Rotterdam/Taipei: Sense Publishers.

Stipek, P., \& Byler, P. (1997). Early Childhood education teachers: do they practice what they preach? Early Childhood Research Quarterly, 123(3), $305-327$.

Stuart, D., Aitken, H., Gould, K., \& Meade, A. (2008). Evaluation of the implementation of Kei Tua o te Pae Assessment for learning: Impact evaluation of the Kei Tua o te Pae 2006 Professional development. A report prepared for the Ministry of Education, Wellington.

Tamarua, L. (2006). Pathways to literacy and transition to school: Enabling incorporation and developing awareness of literacy. Unpublished $\mathrm{PhD}$ thesis, University of Auckland, New Zealand.

Te Tahuhu o te Mātauranga. (1994). Pangarau te tauaki marautanga: He tauira. Wanganui a Tara. New Zealand: Te Pou Taki Korero.

Thackeray, Syme, K. \& Hendry, D. (1992). A survey of school entry practices: How schools gather information on new entrants. Wellington: Learning Media.

Thompson, A. G. (1992). Teachers' beliefs and conceptions: A synthesis of the research. In D. A. Grouws (Ed.), Handbook of research on mathematics teaching and learning (pp. 127-146). New York: McMillan Publishing Company.

Thompson, P., \& Hall, C. (2008). Opportunities missed and/or thwarted? 'Funds of knowledge' meet the English national curriculum. Curriculum Journal, 19 (2), 87-103.

Thrupp, M. (2008). National standards for New Zealand's primary and intermediate schools. New Zealand Annual Review of Education, 17, 199218.

Timperley, H. (2003). Shifting the focus: Achievement information for professional learning. Wellington: Ministry of Education.

Timperley, H., McNaughton, S., Howie, L., \& Robinson, V. (2003). Transitioning children from early childhood education to school: Teacher beliefs and transition practices. Australian Journal of Early Childhood, 28(2), 32-38. 
Timperley, H., \& Robinson, V. (2001). Achieving school improvement through challenging and changing teachers' schema. Journal of Educational Change, $22,281-300$.

Tobin, K. (2006). Qualitative research in classrooms: Pushing the boundaries of theory and methodology. In K. Tobin \& J. Kincheloe (Eds.), Doing educational research: A handbook (pp. 15-58). Rotterdam: Sense Publishers.

Tobin, K., \& Kincheloe, J. (Eds.). (2006). Doing educational research: A handbook. Rotterdam: Sense Publishers.

Torner, G. (2002). Mathematical beliefs: A search for a common ground - Some theoretical considerations on structuring beliefs, some research questions, and some phenomenological observations. In G. C. Leder, E. Pehkonen \& G. Torner (Eds.), Beliefs: A hidden variable in mathematics education? (pp. 73-94). Dordrecht: Kluwer Academic Publishers.

Tringham, K. (2006). Transition to school. New Zealand Education Gazette, 85(5), 11.

Usher, L., Usher, M., \& Usher, D. (2003). Nurturing five dispositions of effective teachers. second national symposium of educator dispositions. Retrieved 15/10/08 from www.educatordispositions.org/dispositions/symposium\%25202003/papers/Di spositionsproceedingssession_P.doc.

van Huizen, P., van Oers, B., \& Wubbles, T. (2005). A Vygotskian perspective on teacher education. Journal of Curriculum Studies, 37(3), 267-290.

Wagemaker, H. (1998). Guest editorial. Childrenz Issues, 2(1), 5-6.

Walsh, D. J. (2005). Developmental theory and early childhood education: necessary but not sufficient. In N. Yelland (Ed.), Critical issues in early childhood education (pp. 40-48). Maidenhead: Berkshire: Open University Press.

Walton, J. (1992). Making the theoretical case. In C. C. Ragin \& H. S. Becker (Eds.), What is a case? Exploring the foundations of social enquiry (pp. 121137). New York: Cambridge University Press.

Warren, E. (2009). Early childhood teachers' professional learning in early algebraic thinking: A model that supports new knowledge and pedagogy. Mathematics Teacher Education and Development. 10, 30-45. 
Wartman, S. (1997). Building blocks and barriers: The transition from kindergarten to school for children with special needs. Christchurch: Education Department, University of Canterbury.

Wasik, B. K., Bond, M. A., \& Hindman, A. (2002). Effective early childhood curriculum for children at risk. In D. N. Saracho \& B. Spodek (Eds.), Contemporary perspectives on early childhood curriculum (pp. 63-90). Greenwich, Connecticut: Information Age Publishing.

Webber, E. (1984). Ideas influencing early childhood education: A theoretical analysis. New York: Teachers College Press.

Wood, S. (2007). Personal communication at numeracy workshop. Auckland, $30 / 11 / 07$.

Wood, T. (1995). An emerging practice of teaching. In P. Cobb \& H. Bauersfeld (Eds.), The emergence of mathematical meaning: Interaction in classroom cultures (pp. 203-228). New Jersey: Lawrence Erlbaum Associates.

Woodhead, M., \& Brooker, L. (2008). A sense of belonging. Early Childhood Matters, 111, 3-6.

Wylie, C., \& Thompson, J. (1988). Competent children at 6: Families, early education, and schools. Wellington: New Zealand Council for Educational Research.

Yelland, N. (Ed.). (2005). Critical issues in early childhood education. Maidenhead, Berkshire: Open University Press.

Yelland, N., \& Kilderry, A. (2005). Against the tide: New ways in early childhood education. In N. Yelland (Ed.), Critical issues in early childhood education (pp. 1-14). Maidenhead: Berkshire: Open University Press.

Young-Loveridge, J. M. (1989a). The development of children's number concepts: the first year of school. New Zealand Journal of Educational Studies, 24(1), 47-64.

Young-Loveridge, J. M. (1989b). The development of number knowledge in five to eight-year-olds. Delta, 42, 25-37.

Young-Loveridge, J. M. (1991). The development of children's number concepts from ages five to nine: Early mathematics learning project: Phase II, Volume 1. Report of findings. Hamilton: Education Department, University of Hamilton. 
Young-Loveridge, J. M. (1993). The effects of early mathematics intervention: The EMI-5's study. Volume 1: Report of findings. Hamilton: Department of Education Studies, University of Waikato.

Young-Loveridge, J. M. (1998). Number skills in junior classrooms. SET, 2(1998), Item 16.

Young-Loveridge, J. M., Carr, M., \& Peters, S. (1995). Enhancing the mathematics of four-year-olds: The EMI-4s Study. Volume 1: Report of findings. Hamilton: School of Education, University of Waikato. 